\title{
Behavioural Models for \\ Common Mode EMI Filters
}

by

Anne Roc'h 


\section{Samenstelling van de promotiecommissie:}

Voorzitter \& secretaris:

prof.dr.ir. A.J. Mouthaan

\section{Promotor:}

prof.dr.ir. F.B.J. Leferink

\section{Co-Promotor:}

prof.dr.eng. J.A. Ferreira

\section{Leden:}

prof.dr. F. Canavero

prof.dr. A.J. Tijhuis

prof.ir. M. Antal

prof.dr.ir. C.H. Slump

dr. F. Marliani

dr.ir. M.J. Mark Bentum
University of Twente, The Netherlands

University of Twente, The Netherlands

\author{
Politecnico di Torino, Italy \\ Technical University of Eindhoven, The Netherlands \\ Technical University of Eindhoven, The Netherlands \\ University of Twente, The Netherlands \\ ESA, The Netherlands \\ University of Twente, The Netherlands
}

The work described in this thesis is supported by the Dutch Ministry of Economic Affairs, under the IOP EMVT programme.

The research presented in this thesis was carried out at the Telecommunication Engineering group, Faculty of Electrical Engineering, Mathematics and Computer Science, University of Twente, P.O. Box 217, 7500 AE Enschede, The Netherlands.

The front cover depicts a behavioural model of an EMI filter in Simulink (inspiration from the painting Victory Boogie-Woogie (1944), Piet Mondriaan).

Copyright (C) 2012 by Anne Roc'h

All Rights reserved. No part of this publication may be reproduced, stored in a retrieval system, or transmitted, in any form or by any means, electronic, mechanical, photocopying, recording, or otherwise without the prior written consent of the copyright owner.

ISBN: 978-94-6191-429-3

Printed by Ipskamp Drukkers B.V., Enschede, The Netherlands 


\title{
BEHAVIOURAL MODELS FoR COMMON MODE EMI FILTERS
}

\author{
PROEFSCHRIFT
}

ter verkrijging van

de graad van doctor aan de Universiteit Twente, op gezag van de rector magnificus, prof.dr. H. Brinksma, volgens besluit van het College voor Promoties in het openbaar te verdedigen op vrijdag 12 oktober 2012 om 14:45 uur

door

Anne Roc'h

geboren op 5 januari 1981

te Straatsburg, Frankrijk 
Dit proefschrift is goedgekeurd door:

De promotor: prof.dr.ir. F.B.J. Leferink

De co-promotor: prof.dr.eng. J.A. Ferreira 


\section{Summary}

\section{Behavioural Models of Common Mode EMI filters}

EMC is defined as the "ability of an equipment or system to function satisfactorily in its electromagnetic environment without producing intolerable electromagnetic disturbances to anything in that environment". EMC means that equipment shall be designed and manufactured, in such way that:

- The electromagnetic disturbance generated does not exceed the level above which radio and telecommunication equipment or other equipment cannot operate as intended.

- It has a level of immunity to the electromagnetic disturbance to be expected in its environment which allows it to operate without unacceptable degradation of its indented use.

Electric motors convert electrical power into mechanical power within a motor-driven system. Electric motors and the systems they drive are the single largest electrical energy consumer, more than twice as much as lighting, the next largest energy consumer, and represent close to $70 \%$ of the electrical energy consumption in the industrial sector worldwide [1]. One of the major problems faced by motor drives is Electromagnetic Interference (EMI) which produces unwanted effects on surrounding electronic devices. A traditional way to control EMI in motor drives is the introduction of EMI filters. However a successful and first-time-right design is a 'done thing' only to a few experienced designers. The filter though is often not optimized in terms of weight, cost and EMI reduction abilities. Enhancing these performance criteria and supporting a first-time-design at the early stages of development, are the objectives of the work presented in this thesis.

Behavioural models have been chosen as the modelling technique because they relates the designable parameters of the EMI filter to its final performance placed in the motor drive and respect the underlying physics involved. 
The thesis starts with a description of the generation mechanisms of EMI in motor drives when no precautionary action is taken to reduce them. A focus is made on common mode current as they are the main cause of conducted and radiated electromagnetic emission.

Behavioural models of the common mode EMI filter involve the complete motor drive. It has been modelled step by step, starting from a component point of view towards a global approach. It combines functional parameters together with the EMI ones.

The constitutive components of the filter are the Y-capacitors and the Common Mode Choke (CMC). A new equivalent circuit of this latter component has been developed. The choice of the proper material is a trade off between cost, size and performance. Their properties have therefore also been described and compared.

The common mode choke is first placed alone at the output of the motor drive and a first level of an in-situ behavioural model is developed. Initial common mode current flowing in the drive are used along with the common mode impedance of the rest of the circuit. Deviation and sensitivity studies are also used to link designable parameters with the final performances of the component placed in the drive. The overall concept of a behavioural model for a CMC representing its actual performance is new.

All common mode EMI filter topologies have been considered afterwards. For each structure a new equivalent circuit is proposed and validated. Traditional design rules are described and complemented with their corresponding behavioural model.

The proper description of the common mode current flowing in the cable towards the motor is essential for the prediction of level of radiated emission around the motor drive system. This current is the main contributor to the level of radiated electromagnetic emission. A quick evaluation method is proposed to evaluate the worst case scenario in term of radiated emission. It has been extracted from existing models of the common mode input impedance of thin wire antennas. The link between the lowest values of the common mode input impedance, highest values of current and the highest levels of electromagnetic field is validated using measurements performed on a complete motor drive.

This thesis is providing a global behavioural model of the motor drive linking the designable parameters to the in-situ performances of the filter to be inserted in the system. Objectives regarding the performance are reduction in EMI, reduction in volume and reduction in weight. 


\section{Samenvatting}

\section{Gedragsmodellen van Common Mode EMI filters}

EMC is gedefinieerd als het "vermogen van een device, apparaat of systeem om in zijn elektromagnetisch milieu bevredigend te kunnen functioneren, zonder zelf ontoelaatbare stoorsignalen voor iets in dat milieu toe te voegen”. EMC betekent dat apparatuur op een zodanige manier ontworpen en gebouwd moet worden dat:

- De opgewekte elektromagnetische storing het niveau waarop radio en telecommunicatie apparatuur of andere apparatuur niet meer naar behoren kan functioneren, niet overschrijdt.

- Deze een immuniteitsniveau ten opzichte van de te verwachten elektromagnetische storing in zijn omgeving heeft die het in staat stellen zonder ontoelaatbaar prestatieverlies zijn bedoelde functie te vervullen.

Elektrische motoren zetten elektrisch vermogen om naar mechanisch vermogen in een motor-aangedreven systeem. Elektrische motoren en de systemen die zij aansturen zijn de grootste elektrische energie verbruikers, meer dan het dubbele van het verbruik van eerstvolgende categorie, elektrische verlichting. $\mathrm{Ze}$ vertegenwoordigen daarmee bijna $70 \%$ van het elektrische verbruik in de industriële sector wereldwijd [1]. Eén van de grote problemen in de elektronica die deze motoren aanstuurt, is Elektromagnetische Interferentie (EMI) die ongewenste effecten teweegbrengt in andere elektronica in de buurt. De traditionele manier om EMI door motor besturingen te beheersen is de toevoeging van EMI filters. Echter, een succesvol, eerste-keer-goed ontwerp is slechts weinige, ervaren ontwerpers gegund. Het filter is vaak niet optimaal in termen van gewicht, kosten en EMI reductie. Verbetering van deze prestatie criteria en ondersteuning van een nieuw ontwerp in de eerste stadia van ontwikkeling zijn de doelstellingen van het werk dat in dit proefschrift gepresenteerd wordt.

Gedragsmodellen zijn gekozen als beschrijvingstechniek omdat deze de door de ontwerper te beïnvloeden parameters van het EMI filter koppelen aan de uiteindelijke prestaties daarvan nadat het in de motor besturing is ingebouwd, rekening houdend met de onderliggende natuurkundige principes. 
Het proefschrift begint met een beschrijving van de mechanismes die EMI in motor besturingen opwekken, wanneer geen maatregelen zijn genomen om deze te verminderen. De nadruk ligt daarbij op common mode stromen omdat deze de belangrijkste oorzaak zijn van geleide emissie en de opwekking van elektromagnetische velden.

Gedragsmodellen van de common mode EMI filters omvatten de gehele motor besturing. Ze worden stap voor stap opgebouwd vanuit het perspectief van de componenten tot aan een allesomvattende systeem beschrijving. Deze aanpak combineert de functionele parameters met die aangaande EMI.

De componenten waaruit het filter wordt opgebouwd zijn de Y-condensatoren en de Common Mode Spoel (CMC). Voor deze laatste component is een nieuw vervangend schema ontwikkeld. De keuze van de juiste materialen is een afweging tussen kosten, afmetingen en prestaties. Hun samenstellingen worden daarom ook beschreven en vergeleken.

De common-mode spoel wordt eerst alleen op de uitgang van de motorbesturing geplaatst en er wordt een eerste niveau van een in-situ gedragsmodel ontwikkeld. De initiële common mode stroom die in de motorsturing loopt wordt gebruikt in combinatie met de common mode impedantie van de rest van de schakeling. Ook wordt een sensitiviteiten onderzoek voor verstoringen gedaan om de ontwerpbare parameters te koppelen aan de uiteindelijke prestaties van de component als deze in de besturing is ingebouwd. Het gehele concept van een gedragsmodel voor een CMC dat zijn feitelijke prestaties in het uiteindelijke systeem representeert, is nieuw.

Alle EMI common mode filter topologieën zijn uiteindelijk in de beschouwing betrokken. Elke structuur is onderzocht en een nieuw en gelijkwaardig circuit wordt voorgesteld en gevalideerd. Traditionele ontwerpregels zijn beschreven en aangevuld met het corresponderende gedragsmodel.

De correcte beschrijving van de common mode stroom die over de kabel naar de motor vloeit, is essentieel voor de juiste voorspelling van de door het motor besturingssysteem uitgestraalde elektromagnetische velden. De bijdrage van deze stroom is daarin dominant. Een snelle evaluatie methode wordt voorgesteld om het meest ongunstige scenario te schetsen in termen van deze uitgestraalde velden. Deze is afgeleid van bestaande modellen voor de common mode ingangsimpedantie van dunne draad antennes. De relatie tussen de laagste waarden van deze common mode ingangsimpedantie, de hoogste waarden van de stroom en de hoogste waarden van het elektromagnetische veld is gevalideerd met metingen op een complete motor besturing. 
Dit proefschrift biedt een allesomvattend gedragsmodel van de motorbesturing dat de door de ontwerper te beïnvloeden parameters koppelt aan het in-situ gedrag van het filter dat in het systeem moet worden opgenomen. De doelstellingen aangaande de prestaties zijn de vermindering van EMI, vermindering van volume en vermindering van het gewicht. 


\section{Contents}

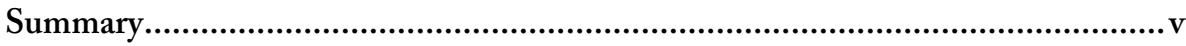

Samenvatting ................................................................................................vii

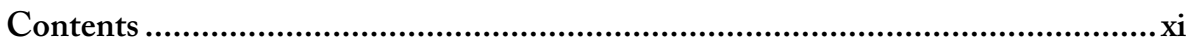

Chapter 1. Introduction ..................................................................................... 1

1.1. The Research Project.........................................................................2

1.2. Outline of the thesis ............................................................................... 4

Chapter 2. Motor drive and noise generation ......................................................

2.1. Main definitions..............................................................................

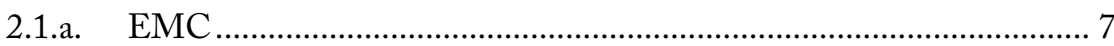

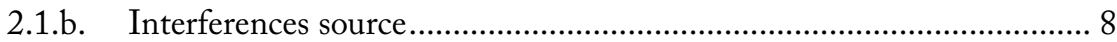

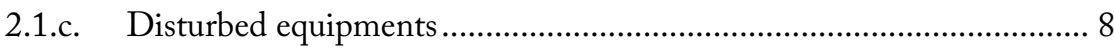

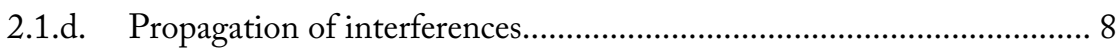

2.1.e. Definition of Common mode (CM)/ Differential Mode (DM) ......... 8

2.2. Switch Mode Power Supply (SMPS) introduction ................................. 9

2.2.a. General introduction.................................................................... 9

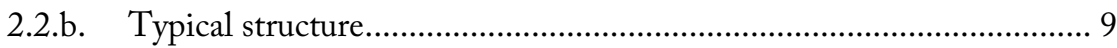

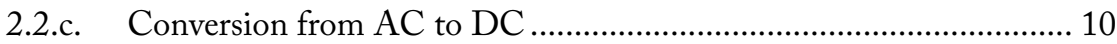

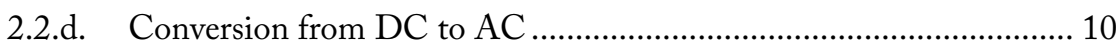

2.3. Conducted interference overview ....................................................11

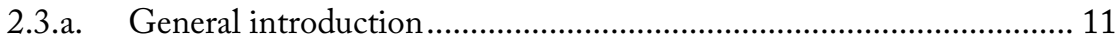

2.3.b. Common mode current generation in a motor drive ......................... 12

2.3.c. Differential mode current generation in a motor drive ........................ 14

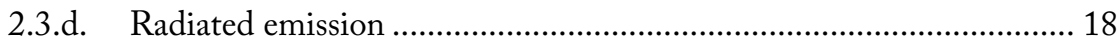

2.4. Bearing currents............................................................................20

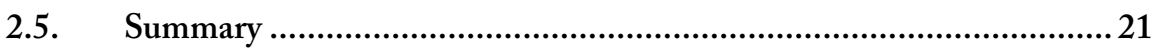

Chapter 3. Passive EMI Filter .....................................................................23

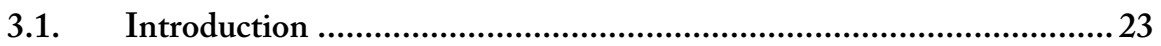


3.2. Capacitors to ground: presentation and design limitations ................26

3.2.a. Structure of a feedthrough capacitor ................................................ 26

3.2.b. Usage limitations and need for an additional component................. 26

3.3. Common mode choke: presentation of the ferromagnetic materials..... 27

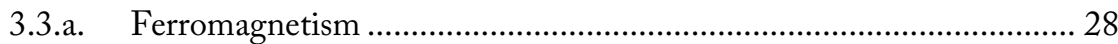

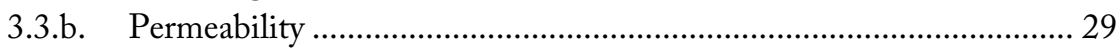

3.3.c. Hysteresis loop and saturation level ............................................... 29

3.4. General material properties overview .......................................... 33

3.5. Common mode chokes: existing models and limitations .....................36

3.5.a. Models of the common mode choke as a single inductance, with or without parallel capacitance ........................................................................ 37

3.5.b. Model of the common mode choke as an extracted equivalent circuit37

3.5.c. Model of the common mode impedance using the complex permeability of the core material.................................................................. 37

3.6. Common mode chokes, impedances and designable parameters.......... 38

3.6.a. Impedances and designable parameters identification ....................... 38

3.6.b. Related Impedance modelling....................................................... 39

3.6.c. Measurements and equivalent circuit validation ............................. 43

3.7. Towards a new behavioural model for the common mode choke.......... 49

3.7.a. A behavioural model of the common mode choke............................ 49

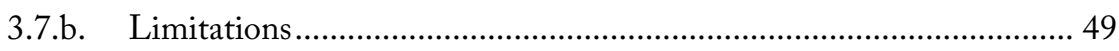

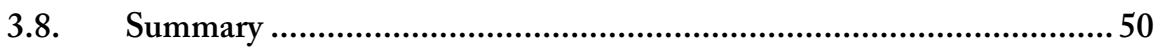

Chapter 4. Behavioural model for common mode chokes.............................51

4.1. Criteria of a behavioural model of a common mode choke..................51

4.1.a. Major criteria for behavioural modelling of common mode chokes .. 51

4.1.b. General way of working of the behavioural model........................... 53

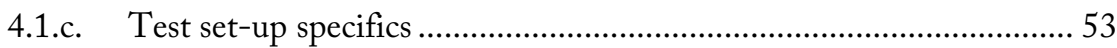

4.2. Modification factors calculations ............................................55

4.2.a. Electrical equivalent common mode circuit of the motor drive ......... 54

4.2.b. Discussion on the stability of the noise voltage................................. 55

4.2.c. Expression of the modification factor for the common mode current 55

4.3. Modification factors evaluation.................................................55

4.3.a. Measured impedances as inputs of the model.................................... 56

4.3.b. Common mode chokes used in this thesis ........................................ 57

4.3.c. Common mode modification factor................................................... 57 


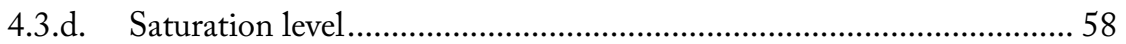

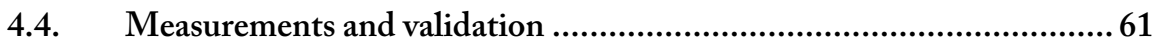

4.4.a. Impedance measurements .............................................................. 61

4.4.b. Measurement results and model validation via impedance

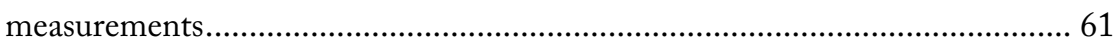

4.4.c. Validation of the common mode current attenuation ....................... 62

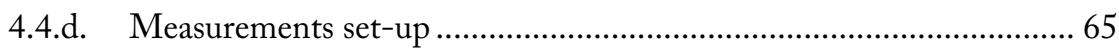

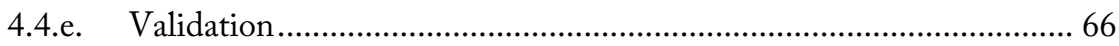

4.5. Sensitivity, deviation and designable parameters...........................70

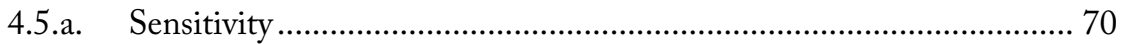

4.5.b. Local sensitivity and the common mode current attenuation ............. 70

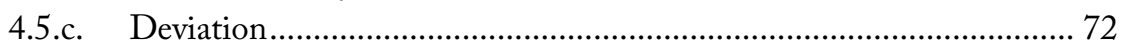

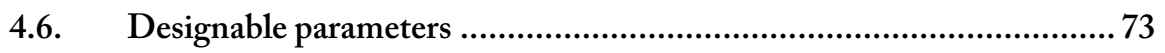

4.6.a. Designable parameters: effect of the material ................................. 73

4.6.b. Designable parameters: effect of the size of the choke....................... 75

4.6.c. Designable parameters: effect of number of turns.............................. 76

4.6.d. Designable parameters: effect of the wiring system ......................... 77

4.6.e. Modification of the common mode current for very low impedance to

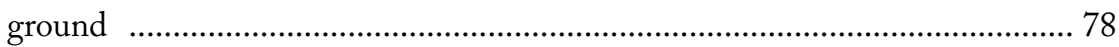

4.6.f. Designable parameters: effect of the wire dimension........................ 78

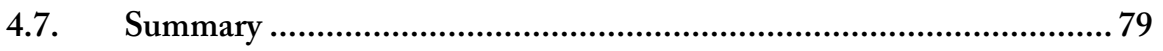

Chapter 5. Behavioural model for EMI filters ....................................... 81

5.1. Strategies of filter designs in the literature ................................... 82

5.2. Designable parameters of the filter and its environment ....................83 83

5.3. Study of the different structures of common mode filters ...................83 83

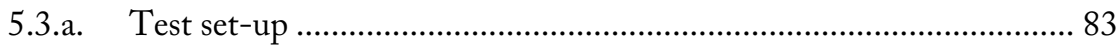

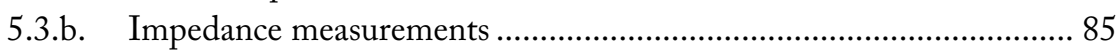

5.3.c. Current and impedance measurements .......................................... 85

5.3.d. Common mode chokes used in the experiment ............................... 85

5.3.e. Noise source characterization........................................................ 89

5.3.f. EMI filter structures considered .................................................... 94

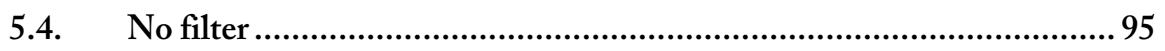

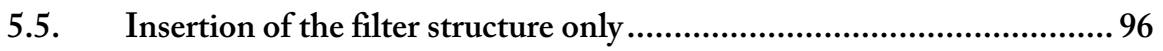

5.5.a. Impedance overview .................................................................... 97

5.6. Insertion of the filter structure and the $\mathrm{Y}$-capacitors ...................... 101 
5.7. Insertion of the filter structure and the common mode choke 105

5.7.a. Discussion on the parasitic capacitance of the choke with respect to

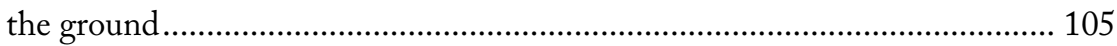

5.7.b. Insertion of the common mode choke ............................................ 106

5.7.c. Insertion of the common mode choke and the filter structure......... 109

5.8. Insertion of the common mode choke and the Y capacitor ............... 114

5.9. Insertion of the $\mathrm{Y}$ capacitor and the common mode choke ............... 118

5.10. Overview of the structures of the EMI filter and design considerations123

5.10.a. $\quad \mathrm{CMC}$ structure - case A ….............................................................. 124

5.10.b. $\quad \mathrm{CMC}-\mathrm{Y}$ structure - case B ..................................................... 125

5.10.c. $\mathrm{Y}-\mathrm{CMC}-\mathrm{Y}$ structure - case $\mathrm{C} 1$.............................................. 126

5.10.d. Y - CMC - Y structure - case $\mathrm{C} 2$.............................................. 127

5.10.e. $\mathrm{Y}-\mathrm{CMC}$ structure - case D1 ..................................................... 128

5.10.f. Y - CMC structure - case D2 ..................................................... 129

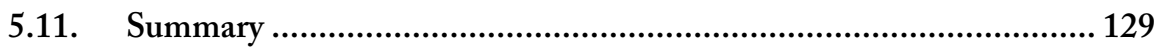

Chapter 6. A behavioural model of the cable input impedance ...................... 133

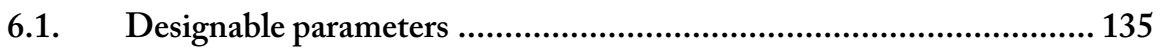

6.2. Behaviour of a single wire excited by a sinusoidal current ................. 136

6.2.a. Behaviour of a single wire in free space excited by a sinusoidal current

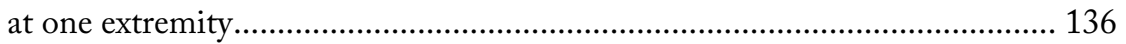

6.2.b. Behaviour of a single wire above a perfect ground plane excited by sinusoidal current at one extremity ............................................................. 136

6.3. Input impedance and the method of moments (MoM)................... 139

6.3.a. Short presentation of the Method of Moment (MoM) .................. 139

6.3.b. Model presentation in NEC-2 ........................................................ 139

6.4. Input common mode impedance and analytical methods ................ 140

6.4.a. Definition of the input impedance of an antenna ........................... 141

6.4.b. Image theory: antennas above a perfect ground plane...................... 141

6.4.c. Vertical monopole above a ground plane: current distribution determined by analytical method ............................................................. 142

6.5. Test set-up and measurements............................................... 147

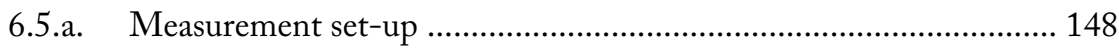

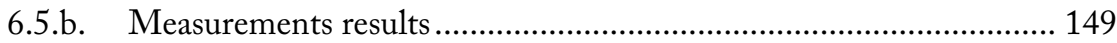

6.5.c. Influence of the designable parameter.............................................. 155

6.6. Comparison of the experimental results with models....................... 155 
6.6.a. Comparison of the simulated input impedance (MoM method) with

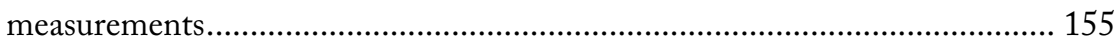

6.6.b. Comparison of the simulations (analytical methods) with

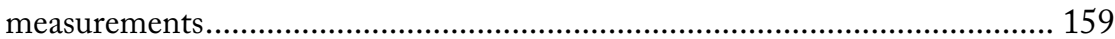

6.7. Minima of input impedance calculations ..................................... 162

6.7.a. Input impedance of a vertical impedance, determined by the EMF

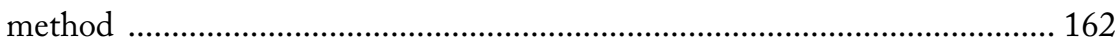

6.8. Equivalence between the input impedances ................................... 166

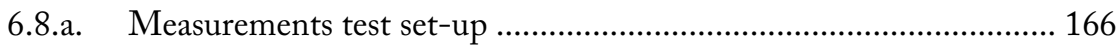

6.8.b. Type of Measurements performed ................................................ 168

6.8.c. Impedance measurements results and equivalence with the one of a wire above a ground plane........................................................................... 169

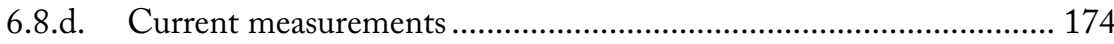

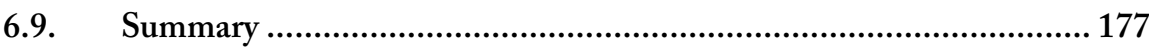

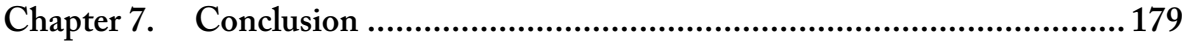

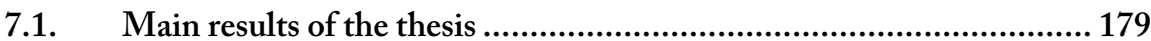

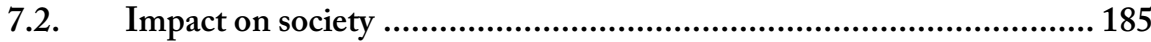

7.3. Recommendations for future work........................................... 186

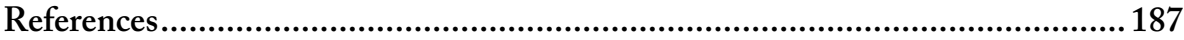

Appendix 1: EMI toolkit overview - Short description of the AC/DC converter

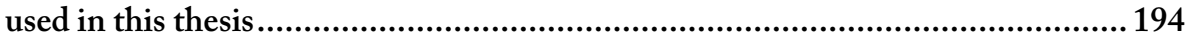

Appendix 2: Proposal of design process for an optimized EMI filter ................. 197

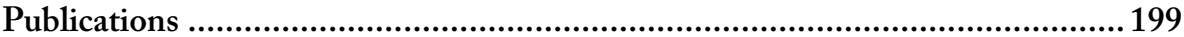

Acknowledgements ..........................................................................205

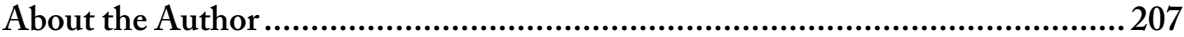




\section{Chapter 1. Introduction}

Electromagnetic Interferences (EMI) can be generated by any electrical and electronic devices or just about anything that uses or controls electrical energy. When electromagnetic energy enters where it is not wanted, it can interfere with a device's operation or use. It is therefore important to manage the production of electromagnetic noise as well as its susceptibility to it, in the product and the system design. If noise sources and possible susceptibilities are not taken into account during initial design, it can result in expensive and time-consuming fixes later in the design process, during production or even during deployment. Electromagnetic interferences are for instance a major issue in motor drives that produces undesirable effects on electronic devices around them. In the mean time an increased power density for a decreased cost and size have become market requirements in such power electronic systems. A considerable progress has been made in making power electronics such as frequency converters and switched mode power supplies more efficient by using IGBTs (Insulated Gate Bipolar Transistor) and switching them faster. The advantage of using IGBTs is that the dissipation is decreased which has a beneficial effect on reliability. The voltage swing of IGBTs is however higher compared to BJTs (Bipolar Junction Transistor), which, together with a higher voltage rise time, lead to adverse effects as an increased level of electromagnetic interferences spread over a larger frequency band. This trend continues with the modern $\mathrm{SiC}$ (Silicon Carbide) and $\mathrm{GaN}$ (Gallium Nitride) transistors which are even switching faster to reduce heat dissipation within the transistor.

Several techniques exists to contain and reduce noise in motor drives: a classification is proposed in [2]: the first category groups the filtering techniques, the second one 
the cancellation techniques and the third one the balancing techniques. The passive filtering is the traditional and the most common technique used to contain and reduce noise in motor drives. The benchmark is that twice the volume of the active components is needed for the passive component, and this ratio is more when transistors are switching faster.

However, while the level of electromagnetic interference in power system has increased in the recent years, passive EMI filters are still considered as 'black magic boxes'. Theirs successful and first time right designs can only be performed by a few experienced designers whose design choices are mainly based on years of practical experience. The overall design though is not necessarily optimized in terms of weight, cost and volume. This is not taken into account by the design engineer: the EMI filter is often considered as an add-on.

The goal of the research presented in this thesis is to enable industry to design faster and with lower risk, filtering techniques in motor drive system. In order to achieve this objective a specific concept of model is introduced: a link is to be made between the designable parameters of the electrical design engineer and the EMI performances of the filtering techniques he/she intends to introduce in the product. Objectives regarding the performance are to facilitate a reduction in EMI, reduction in volume and reduction in weight.

\subsection{The Research Project}

The research is part of the IOP EMVT programme. IOP means Innovatief Onderzoeks Programma (Innovative Research Program). EMVT means Electro Magnetische Vermogens Techniek (Electro Magnetic Power Technology). It is a research program financed by the Dutch Ministry of Economic Affairs. The EMVT programmes are seen as 'enabling technology for integrated electromagnetic system with a high power density, high frequency and a high efficiency'. The emphasis within the EMVT programme is on applications in the energy sector, whereby 'the immunity against electromagnetic influence and disturbance plays an important role' [3]. In this thesis the focus is on a motor drives and machine combinations as used in mechatronic applications. Other setups are comparable or even simpler with respect to EMI, and thus can be derived from this setup.

The common mode current has been only considered as it is the main source of interferences in electronic motor drive systems. This traditionally leads to the use of common mode EMI filters. 
The modelling of an EMI filter is a challenging effort which should combine:

- The characteristics of the noise source and the load, and their common interaction, over the frequency range of interest. These characteristics are often unknown beforehand to the designer and there is no behavioural model available, allowing neither a prediction of the levels of noise produced, nor describing how load and source interact, especially after the introduction of additional filtering components.

- The right choice of structure for the EMI filter. This choice mainly depends of the impedance presented by the source and the load, seen at the future place of the filter. These impedances are depending on the drive and its installation, and when they are not unknown to the designers.

- The right choice of components: the material, the size and the wiring of an eventual choke will have a direct impact on the volume and the weight of the final product. It should combine non linear effects, saturation level and losses in an optimal way over the desired frequency range. Eventual capacitances to ground have their value limited by the noise source characteristics and the rest of the filter. It also appears that many EMI filter are oversized.

In a nutshell, in order to properly evaluate the final performances of the EMI filter, the modelling of the electromagnetic environment is required as well. There is a static environment and a dynamic one. The static one is mainly composed of the cable and its motor. The parasitic capacitance of a motor as a load is causing a low impedance common mode current path and the cables are the main source of radiated electromagnetic interference. The dynamic one is the inverter-converter: another key problem of the inverter-converter sets is the resonance in the DC bus which give rise to high common mode over-voltages at the output, destroying motors. The noise produced by this combination also interacts with the filtering techniques inserted in the design. There is for instance a risk of overloading the IBGTs when the path of low impedance provided by the filter is not properly scaled.

This thesis proposes to predict the EMI filter performance with the support of a behavioural model which links the designable parameters of the motor drive to the performances of the filter to be inserted in it.

A behavioural model reproduces the required behaviour of the original analysed system, such that there is a one-to-one correspondence between the behaviour of the original system and the simulated system. That namely implies that the model uniquely predicts future system states from past systems states. The behavioural 
approach is motivated by the aim of obtaining a framework for system analysis that respects the underlying physics and sets up the appropriate mathematical concepts from there. A key question of the behavioural approach is whether a quantity $x_{1}$ can be deduced given an observed quantity $x_{2}$ and a model. If $x_{2}$ can be deduced given $x_{1}$ and the model, $x_{2}$ is said to be observable. In this thesis input variables (type $x_{1}$ ) will be the designable parameters of the filter, and the outputs variables (type $x_{2}$ ) will be the in-situ performances of the filter and theirs uncertainties.

\subsection{Outline of the thesis}

Chapter 2 of this thesis provides a description of a typical AC-AC motor drive and describes the generation and the propagation of the noise if no action is taken to reduce it or re-direct it. This chapter is a comprehensive summary of the relevant literature.

Chapter 3 is dedicated to the description of the two main components of the common mode EMI filter: the capacitance to ground (Y-capacitor) and the common mode choke (CMC). This last component is complex and often misunderstood. An equivalent circuit of the common mode choke is proposed and validated. Each of its impedance can be modelled using designable parameters, and is either acting on the differential mode or common mode. The synthesis made on how to link the designable parameters to the concerned impedances, as well as the equivalent circuit, are new.

Chapter 4 presents the behavioural model of the single common mode choke placed at the output of the power converter. The effect of each designable parameters on the attenuation of common mode current is studied. Sensitivity and deviation studies are introduced to evaluate the overall performance stability of the designed component once placed in the motor drive. This behavioural model is new and it is the first time sensitivity and deviation studies of the in-situ performances of a CMC are presented.

Chapter 5 describes a global behavioural model of the common mode filter. The formerly introduced model for the CMC is combined with Y-capacitors along with the dynamic behaviour of the noise source. It is the first time the dynamic behaviour of the noise source is included in such a model. All the configurations of EMI filter are considered along with their traditional design rules. A new equivalent circuit of each topology is proposed and validated via both impedance and current measurements. Their novelty stands in the use of the equivalent circuit of the CMC previously introduced and the introduction of a parasitic impedance of the CMC with its environment. These models of EMI filters are used to evaluate the 
modification of the level of common mode current at different points of the circuit after insertion of the filter. Traditional design rules are investigated and refined at the end of the chapter. The designer can now predict the in-situ performances of any filter topology at several points in the motor drive and adequately choose the relevant topology.

Chapter 6 investigates the input common mode impedance of an induction motor and its feeders. The common mode current flowing in the cables is the main contributor to the radiated emission level in the motor drive. Different models described in literature about the input impedance of thin linear antenna are investigated and compared. They are matched with the measured impedance of the input of a single bare wire above a ground plane. The equivalence between the input impedance of a motor and its feeder with the one of a single wire above a ground plane is also demonstrated via measurements. At the end of the chapter a link is made between the points of lower input impedance and the measured higher level of currents, leading to a higher level of electromagnetic field. These points of lower impedance belong to a same curve. Its equation is derived from one of the analytical models investigated. The novelty in this chapter is in the link made between the curve of lower input common mode impedance and the highest level of electromagnetic field. This 'worst case' scenario supports designers in estimating the level of electromagnetic field around the motor drive beforehand.

An overview of the structure of the $\mathrm{PhD}$ is shown in Figure 1. On top the functional diagram of a motor drive is drawn. The three constitutive parts are the power converter, the EMI filter and the motor with its cable. They are linked to the corresponding chapters in which they are addressed (Chapter 2 and 3). The common mode equivalent electrical circuit of the same motor drive is drawn below. It is constituted of the same three parts. The in-situ performance of the common mode choke are modelled in Chapter 4. The noise source and the in-situ performances of the asymmetric filter are address in Chapter 5. The modelling of the load is addressed in Chapter 6. 


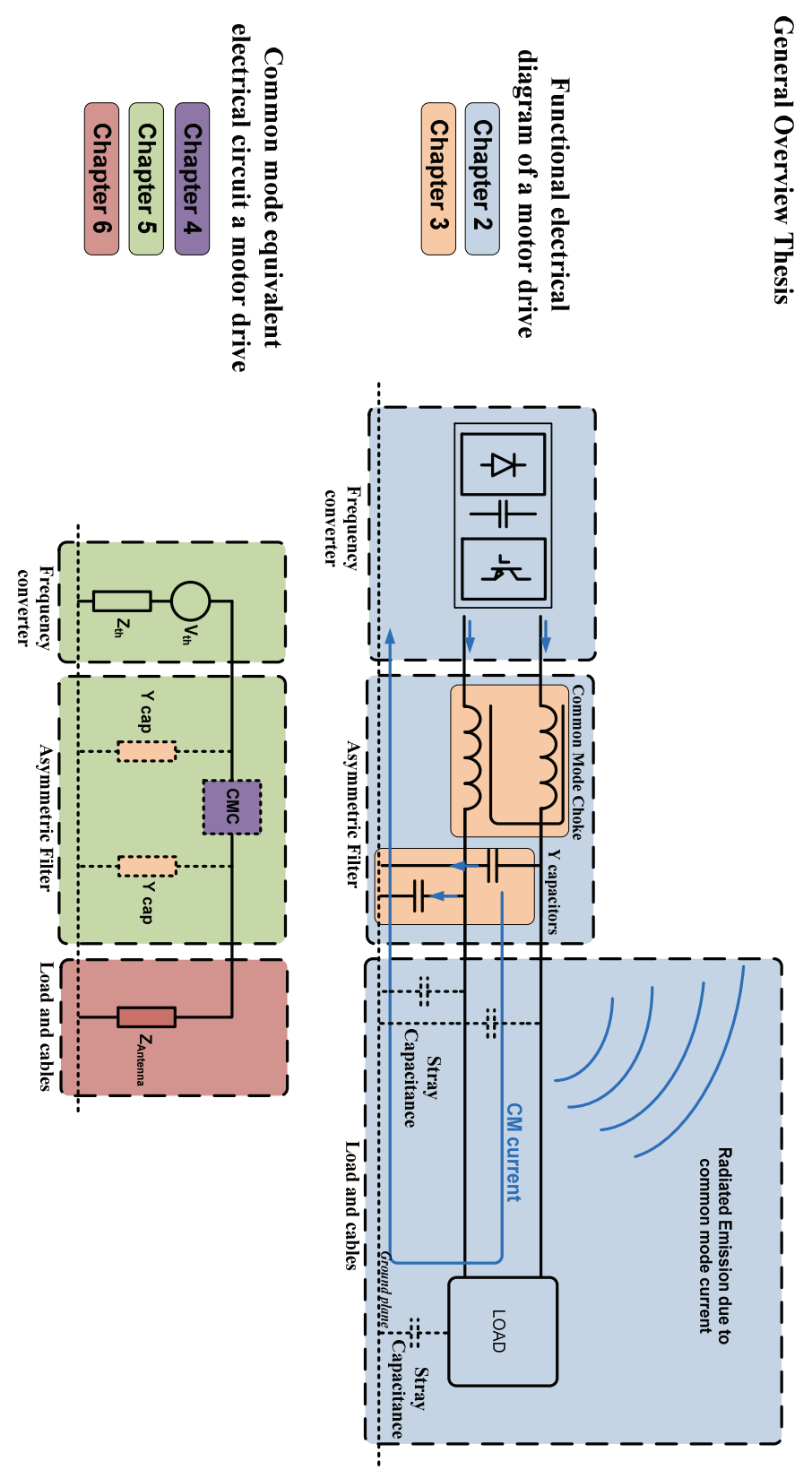

Figure 1: General overview of the thesis - Relation between chapters and either the functional electrical diagram of a motor drive, or its common mode equivalent circuit. 


\section{Chapter 2. Motor drive and noise generation}

In this chapter the focus is on motor drives and machine combinations as used in mechatronic applications. The $\mathrm{AC} / \mathrm{AC}$ motor drive used together with an induction motor is chosen as a guiding thread as it presents the most complete structure of all other setups of motor drive. These are indeed comparable or even simpler with respect to EMI, and thus can be derived from the described motor drive.

Section 1 introduces the main definitions related to the noise generation in motor drive. Section 2 describes a typical AC/AC motor drive. Section 3 explains the main mechanisms of the noise generation in this motor drive. Section 4 addresses noise currents in the motor itself.

\subsection{Main definitions}

The definition of key words used in this thesis is provided in this section: EMC, interference sources, disturbed equipments, propagation of interferences and common mode and differential mode current.

\section{1.a. EMC}

Electromagnetic Compatibility (EMC) is the ability of a device, equipment or system to function satisfactorily in its electromagnetic environment without introducing intolerable electromagnetic disturbance to anything in that environment. The term EMC, covers both electromagnetic emission and electromagnetic susceptibility. [4], [5], [6]. 


\section{1.b. Interferences source}

Interference sources: they are electrical equipments which emit electromagnetic interferences. We can distinguish two mains groups of interference sources corresponding to the type of frequency spectrum emitted. The first family of interferences sources have discrete frequency spectra and emit narrow band interferences. The second family of interferences sources spreads their interference energy over broad frequency bands and are considered to belong to the group of interference sources having a continuous frequency spectrum (for example: motor drives).

\section{1.c. Disturbed equipments}

Disturbed equipments include electrical devices or systems subjected to interferences and that can be adversely affected by it. In the same way as interference sources, disturbed equipment can also be categorized corresponding to frequency characteristics. A distinction can be made between narrow band and broadband susceptibility.

\section{1.d. Propagation of interferences}

It is essential to know how the interference propagates and to identify the coupling mechanisms. These information are used to choose the correct EMC measures to be implemented to reduce the interferences. In principle, the interference can be classified according to its propagation mode. The noise current will typically follow the path of least energy: at low frequency, it is the path of lowest resistance. The noise is mainly conducted. At high frequency where $1>\lambda / 4$, it is the smallest loop, i.e. the smallest inductance. The noise is then mainly radiated.

\section{1.e. Definition of Common mode (CM)/ Differential Mode (DM)}

The common mode current is a current flowing in all signal leads using the ground as a return path. The differential mode current is a current flowing in two complementary leads, it follows the same path as the functional current. A representation of both currents and their corresponding voltages is shown in Figure 2 in which an electrical unit and its three output leads are represented. The common mode voltage $V c m$ (also named asymmetric voltage Vasym) is the voltage between the ground and the (virtual) geometric centre of the leads. The nonsymmetric voltage $V d m$ is the voltage between one lead and the ground. The differential mode voltage is the voltage between two leads. 

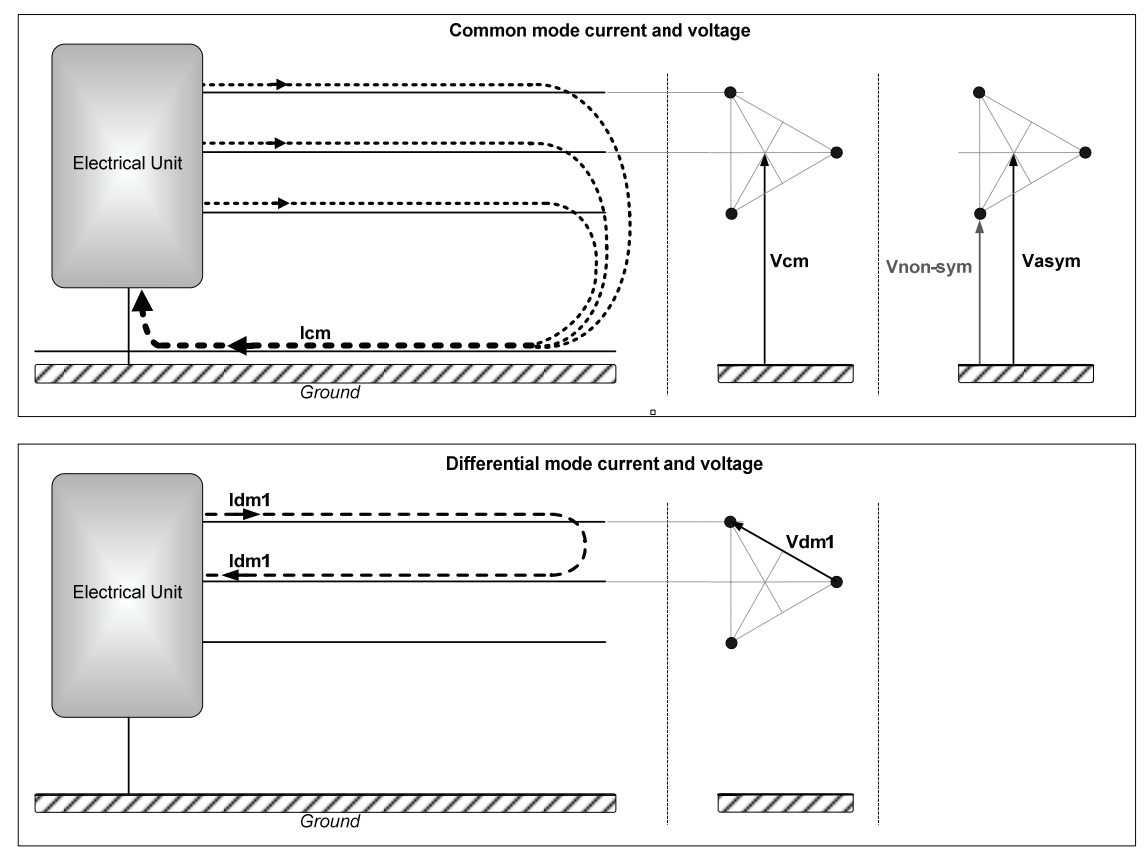

Figure 2: General representation of the common and differential mode propagation (side view on the left and sectional view on the right).

\subsection{Switch Mode Power Supply (SMPS) introduction}

\section{2.a. General introduction}

Motor drives are used in a very wide power range, from a few watts to many megawatts, in application ranging from precise, high performance positioncontrolled drives in robotics to variable-speed drives for adjusting flow rates in pump. In all drives where the speed and position are controlled, a power electronic converter is needed as an interface between the input power and the motor. A typical structure of motor drive is now presented and followed by an overview of the generation mechanism of conducted and radiated interferences.

\section{2.b. Typical structure}

The motor drive under consideration can be divided in 3 blocks: an AC-AC converter, filters and a load (here a motor). The AC-AC converter is itself composed of two blocs: a rectifier which provides an $\mathrm{AC}$ to $\mathrm{DC}$ conversion of the 
supplied power, and an inverter providing a $\mathrm{DC}$ to $\mathrm{AC}$ conversion adapted to the load. The structure is shown in Figure 3. Filters are addressed in the next chapters.

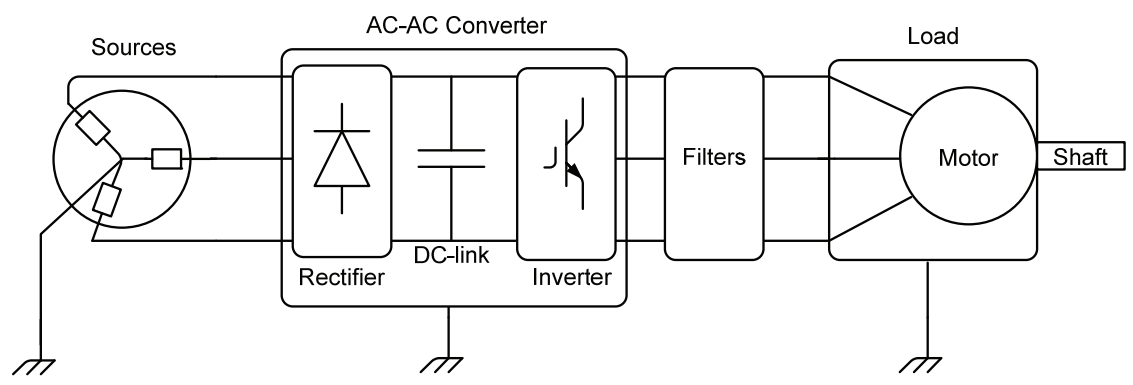

Figure 3: Typical motor drive under consideration.

\section{2.c. Conversion from $\mathrm{AC}$ to $\mathrm{DC}$}

In most power electronic applications, the power unit is a $50 \mathrm{~Hz}$ sine-wave $\mathrm{AC}$ voltage provided by the electricity utility. This is first converted to a DC voltage. The common approach is to use the inexpensive rectification with diodes. In such a rectifier, as presented Figure 4, the power flow can only stream from the utility AC side to the DC side. The DC output voltage of a rectifier should be as ripple free as possible in order to get a steady DC. Therefore a large capacitor is connected as a filter on the DC side.

\section{2.d. Conversion from $\mathrm{DC}$ to $\mathrm{AC}$}

Switch mode DC-to-AC converters are used in AC motor drives and uninterruptible $\mathrm{AC}$ power supplies where the objective is to produce a sinusoidal $\mathrm{AC}$ output whose magnitude and frequency can be controlled simultaneously. The structure is presented in Figure 5. In the presented AC drive, the switch mode inverter is a converter through which the power flow is reversible. However, most of the time, the power flow is from the DC side to the motor on the AC side which requires an inverter mode of operation.

The most important power switches in modern power converters are: Power Diode, Power Metal-Oxide semiconductor, Field Effect Transistor (Power MOSFET) and Insulated Gate Bipolar Transistor (IGBT). When a switch is considered ideal, it means that the switch can handle an unlimited current and blocks an unlimited voltage. The voltage drop across the switch and leakage current through the switch are zero. The switch is turned on and off with no rise and fall times. In a realistic case, ideal switches do not exist. During switching transients, there are significant 
switching losses associated with $d V / d t$ and $d I / d t$, that are the rise rate of the voltage and the current, respectively, during the transient. These phenomena depend on several issues such as characteristics of power switches, control signals, gate drives, stray parameters and operating points of the system.

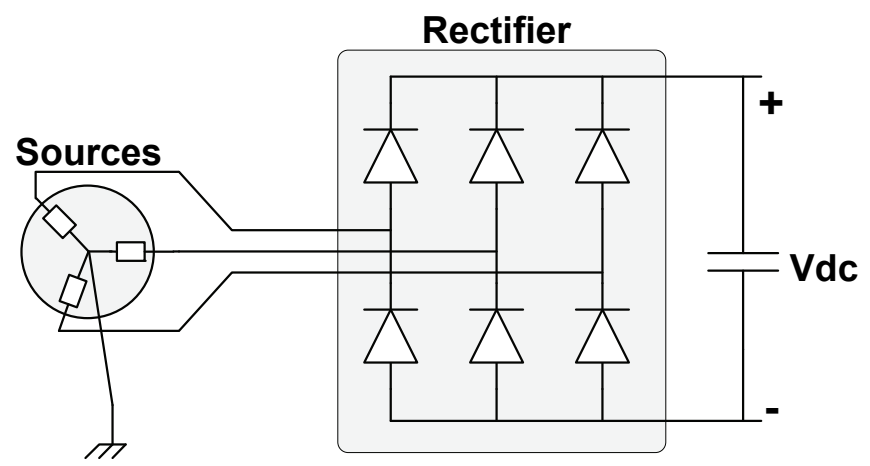

Figure 4: Block diagram of a rectifier.

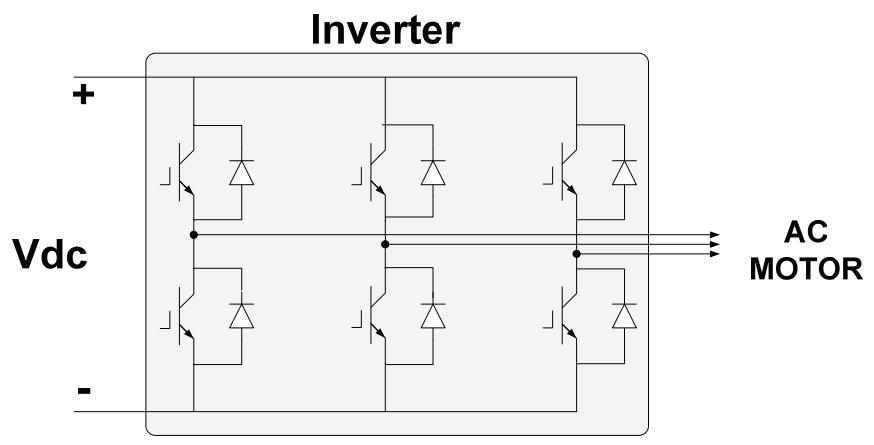

Figure 5 Block diagram of an inverter.

\subsection{Conducted interference overview}

\section{3.a. General introduction}

Adjustable speed electrical Power Drive Systems (PDS) are used in all kind of mechatronic applications for speed control. Introduction of modern semiconductors have enabled higher switching speeds which reduces the heat dissipation. For instance, the IGBT produces more than a 100 -fold increase in voltage rise-time and fall-time $(d V / d t)$ compared to the conventional BJT (Bipolar Junction Transistor). The drawback however is the high electromagnetic interference levels on power lines 
and motor cables. Motor drive systems generate considerable impulse currents through the power leads resulting in serious electromagnetic interference problems and significant voltage waveforms distortion in the power system.

The emissions levels depend on system configuration. The spectrum of emissions features a broadband range from tens of $\mathrm{kHz}$ to a few dozens of $\mathrm{MHz}$ [7]. The effect of waveform distortion in the power system appears especially in the line to ground voltage and line voltage as well as in the line current. It is possible to observe an impulse current in the frame of the motor or the inverter enclosure that will produce a common mode current in the leads of the mains. These impulse currents and notches occur simultaneously during the switching instance of the devices. If the motor and the inverter are isolated from ground the common mode current and the noise voltage was observed to decrease to a very small value. The voltage waveform of a motor contains a ringing lasting a few microseconds instead of an ideal square pulse from the inverter, especially the line to ground voltage of the motor. The current waveform of the motor also has an impulse current of a few ampères. The fundamental current and voltage of the inverter output seem to not affect the emission levels from the inverter motor system (less than a few $\mathrm{dB}$ ).

In the low frequency range the noise is mainly caused by PWM (Pulsed Width Modulated) switching. In the high frequency range where the noise is dominated by parasitic effects, the parasitic capacitance of IGBTs play a key role [8].

\section{3.b. Common mode current generation in a motor drive}

Common mode conducted emissions are due to currents which flow between the input phases and the ground of the system.

In a three-phase motor drive, the common-mode voltage is defined as the voltage between the star-centre and the ground and is given as follows (see also Figure 2):

$V_{c m}=\frac{V_{\text {non-sym } 1}+V_{\text {non-sym } 2}+V_{\text {non-sym } 3}}{3}$

where :

$V_{n o n-5 y m 1}, V_{n o n-5 y m 2}$ and $V_{n o n-5 y m 3}$ are the voltages of each leads with respect to ground.

In switched mode motor drive, the voltage supplied to the motor is not a perfect sinusoidal three phase voltage and therefore, according to (1), the common-mode voltage is always different from zero. According to Figure 2 the common mode voltage is defined as being the voltage between the ground and the electrical centre of the three lines. This centre can be found at the central connection of a star connected source and/or motor (stator neutral connection). It could also be the 
centre of the DC bus commonly referred to as 'zero point'. This point may not always exist physically.

The instantaneous values of the common mode voltage can be determined from (1) according to the switching state configuration depicted in Figure 6. In this figure the switching pattern of the IGBTs is linked to the common mode voltage to be expected between the ground and the zero point of the DC link. This dynamic common-mode voltage generates common-mode currents that flow to the ground, through parasitic capacitances in the drive. The amplitude of such currents depends on the rate of the $d V / d t$ of common-mode voltage and increases as the switching frequency of the converter rises. These rapid variation of voltages together with the various stray capacitances to earth at the output side of the drive are respectively the sources and the loads of the common mode currents in the motor drive. These stray capacitances are presented in Figure 7. The key parasitic impedances in a motor drive are the stray capacitances of cables to ground, switches to heat sink, heat sink to ground, and stray capacitances to the motor with respect to the ground (as the frame of the motor is grounded for safety reasons). Below a few megahertz, the common mode current contains significant components in two frequency ranges. The first is the high-frequency oscillation (Mode 1) immediately following the switching event, which has a frequency of around a few megahertz. The second is a much lower frequency oscillation (Mode 2) at around $100-200 \mathrm{kHz}$ also excited by the switching [9]. The high-frequency mode is mainly trapped between the IGBT inverter and the induction motor. While the lower frequency component flows on both sides, the higher frequency component is only significant at the output side. When the stray capacitance of the IGBT devices is small, the lower frequency components on both sides of the power electronic stage have similar magnitudes. Current paths of dominant common modes are presented in Figure 8. As this type of current travels through the ground and the input power cable, any electronic devices connected to the ground or the cable will be prone to interference from them. Since the common mode currents share most of their paths with other equipment, the level of EMI emission from them is usually higher than that from the differential mode coupling currents [11]. 
IGBT switching pattern and Voltage between ground and the zero point of the DC bus
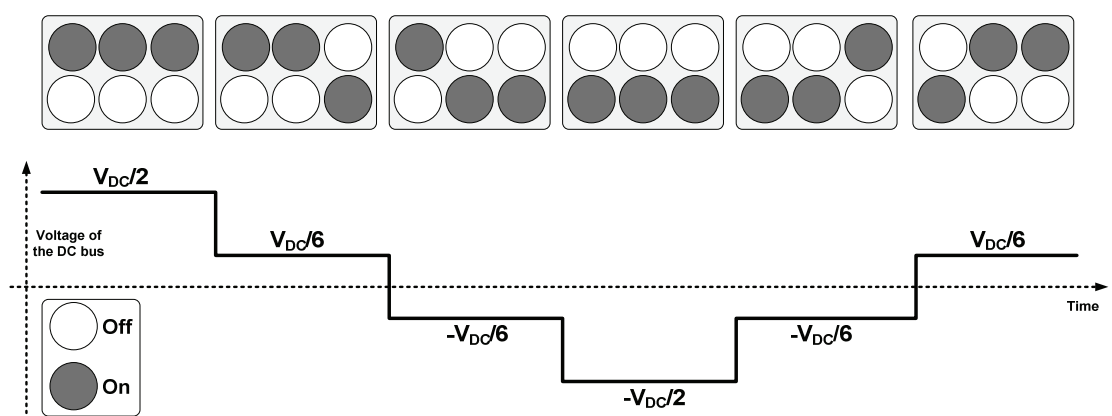

Figure 6: IGBTs switching pattern and Voltage between ground and the zero point of the DC bus.

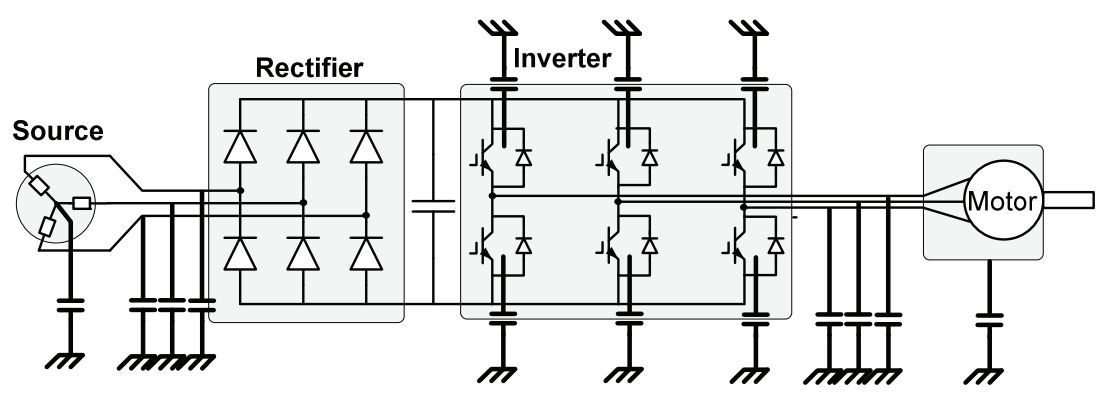

Figure 7: Stray capacitances and inductances involved in the common mode noise propagation.

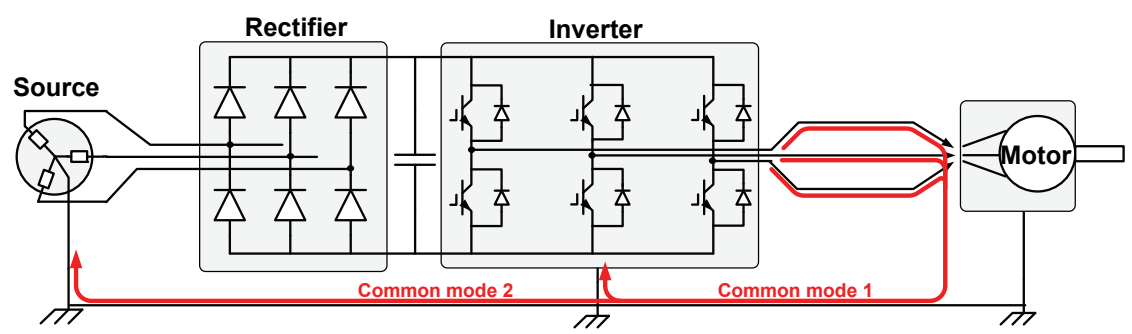

Figure 8: Current paths of the common dominant modes.

\section{3.c. Differential mode current generation in a motor drive}

Differential modes can be observed at the two sides of the drive part within the whole structure as depicted in Figure 9. 


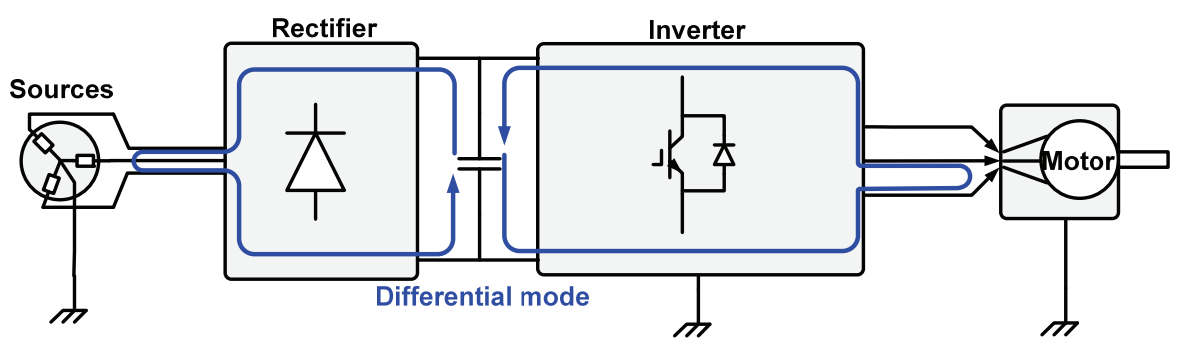

Figure 9: Current paths of the dominant differential modes.

\section{Coupling at the input side}

Differential mode emissions at the input side are created when a differential mode current between output phases couples to the input side through the high-frequency voltage developed across the DC-link.

\section{Differential mode at the output side}

Differential mode currents, characterized by high frequency oscillations, flow on the output side of the drive whenever one of the inverter phases is switched. Depending on the switching sequence, some of these currents flow through the DC-link capacitor, and a differential mode current is generated on the input side of the drive due to the finite impedance of the capacitor and any other decoupling components [10]. The proportion of the high-frequency current in the switched phase, which flows in the DC-link, can be determined by considering the three cases depicted in Figure 10.

Table 1: Current flow in DC-link capacitor.

\begin{tabular}{|l|l|l|l|}
\hline Cases & Previous state & Current state & $\begin{array}{l}\text { Rate of the current in the } \\
\text { switched phased, present in the } \\
\text { DC link }\end{array}$ \\
\hline CASE 1 & Freewheeling & Active & 1 \\
\hline CASE 2 & Active & Active & $1 / 2$ \\
\hline CASE 3 & Active & Freewheeling & 0 \\
\hline
\end{tabular}

Denoting an inverter state, where one output voltage is different from the others as an "active state" and one where all the voltages are either low or high as a "freewheeling state," the general rules given in Table 1 and Table 2 can be drawn up. Only cases 1 and 2 will contribute to differential mode currents on the input side, and Case 3 can be disregarded.

The differential mode coupling current comes mainly from the current flowing in parasitic capacitors between inverter phases, such as $C_{d}$ (see Figure 11) which 
represents the phase-to-phase parasitic capacitance of the motor windings. A high frequency coupling current is produced when the square-wave line-to-line voltages energize those parasitic capacitors. Just like the inverter load current, the current has to source from the DC link. Most of the differential mode coupling currents will circulate locally in the loop formed by the DC link capacitor, inverter poles and the motor as indicated by the bold line in Figure 11 .

However, as the impedance of the DC link is never equal to zero, the DC link may not be able to respond to the full coupling current demand; and a portion of the currents has to be drawn directly from the $\mathrm{AC}$ power source through the rectifier side. Under such a condition, a portion of the differential mode coupling currents must flow into the AC source as indicated by the dashed line in Figure 11. This portion of differential mode coupling currents flows outside the drive system and constitutes the conducted EMI emission in differential mode [11].

Table 2: Relationships between differential voltage and inverter switching transition.

\begin{tabular}{|l|l|l|l|}
\hline Previous state & Current State & $\begin{array}{l}\text { Sign of transition } \\
\text { on switched phase }\end{array}$ & DC link voltage \\
\hline Freewheeling & Active & + & +1 \\
\hline Freewheeling & Active & - & -1 \\
\hline Active & Active & + & $+1 / 2$ \\
\hline Active & Active & - & $-1 / 2$ \\
\hline Active & Freewheeling & + & 0 \\
\hline Active & Freewheeling & - & 0 \\
\hline
\end{tabular}



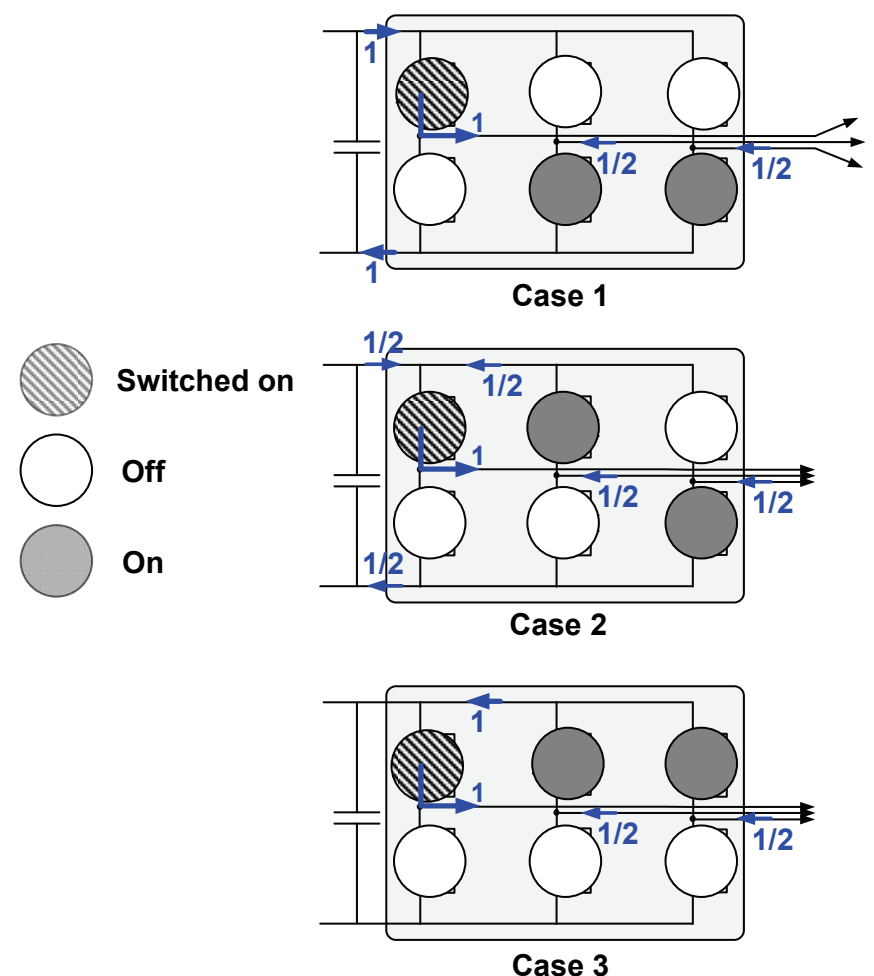

Figure 10: Relationship between differential mode current and switching pattern.

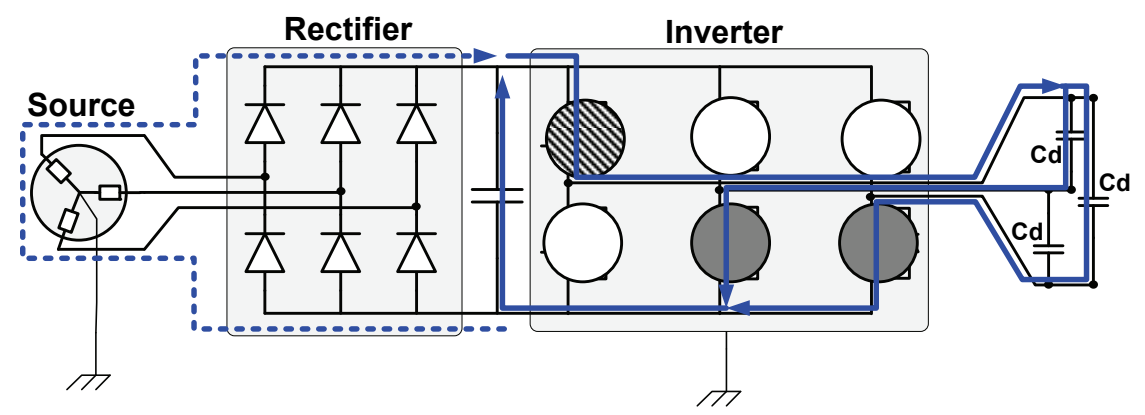

Figure 11: Differential mode coupling current contributes to conducted EMI (Case 1).

\section{Common Mode caused by Differential Mode Coupling Current}

The common mode coupling current flows in parasitic capacitors between drive components and the earth ground, such as $C_{c}$ in Figure 12, which represents the capacitance between the motor windings and grounded enclosure. Unlike the 
differential mode currents, the common mode currents will not return via the local path from the negative rail of the inverter poles to the negative DC bus. Instead, all of them flow into the ground and have to return via the ground to the source. Assuming a relatively high impedance between the negative dc bus and the ground, the main path (indicated by the solid line) for common mode coupling currents in an inverter drive with a rectifier input can be depicted as shown in Figure 12. In addition, due to parasitic capacitance across the bottom rectifier diodes, there may be some common mode currents which pass through the DC link capacitor as indicated by the light dashed line [11].

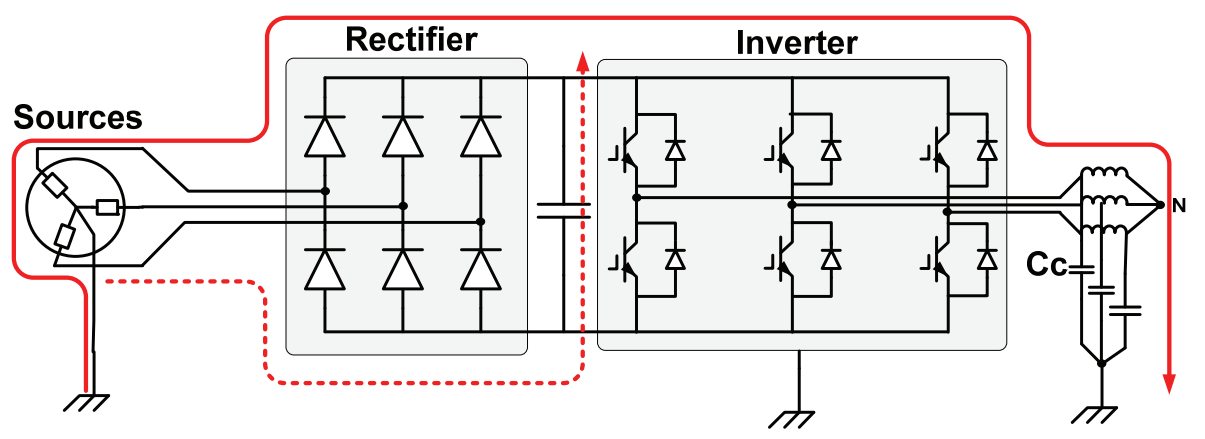

Figure 12: Differential mode coupling current contributes to conducted EMI (Case 2).

\section{3.d. Radiated emission}

Internal oscillation modes between the motor and the PWM drive are the source currents for radiated emissions [9]. The radiated field is assumed to be contributed by three types of sources only:

- Fields radiated directly from apertures or openings on the outer boundaries of units, modules and other components.

- Fields radiated by cables supporting ground loop currents.

- Fields radiated by units, modules and other large conducting objects supporting ground-loop currents.

The radiation from the flat and uniform conducting surfaces of the units and modules are relatively insignificant because when EMI currents spread out over flat surfaces they maintain a low-inductance current path. Units and modules have no significant discontinuities on their surfaces. An aperture or a hole would be significant only when its largest dimension is comparable to the free-space wavelength of the disturbance in question. Thus, to be a significant radiator at 
$300 \mathrm{MHz}$, an opening would have to be at least $\lambda / 10$, or $10 \mathrm{~cm}$. By contrast, the ground loop currents supported by cable shield conductors are highly localized and concentrated, which present large inductance(s); hence the fields radiated by them dominate the other two types of contributions [13]. Unshielded (or poorly shielded) drive wires act as antennas for the electromagnetic field set by the steep $d V / d t$ of the PWM drive output voltage. Efficient radiated emissions occur when standing waves settle down in the output cable due to reflection on the motor side. Unshielded drive input/output cables carrying common mode currents, may act as loop antennas for radiated emissions, due to the current path in these wires returning via the ground in Figure 13. The differential mode currents may also function as an antenna when the length of the loop area is a multiple of $\lambda / 2$, (if both wires are not bundled closely) as shown in Figure 13.

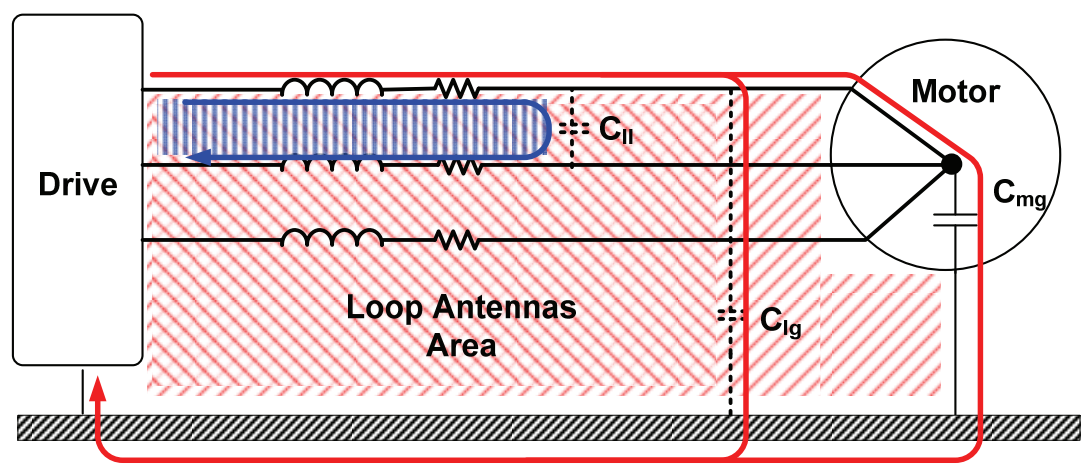

Figure 13: Radiated emissions loop area.

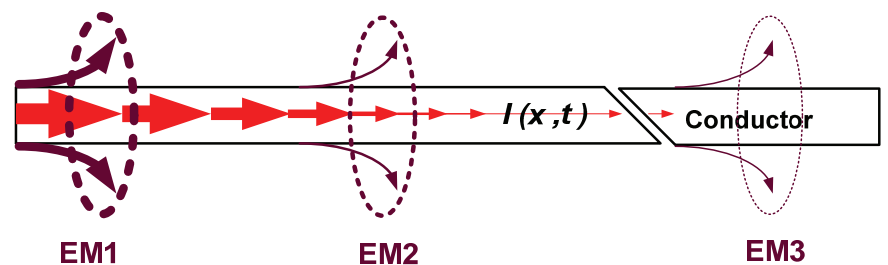

EM: Electromagnetic Field

$I(x, t)$ : diminishing current on the conductor

Figure 14: Radiation on an unshielded conductor. 
The cables towards the motor are long transmissions lines that do not support high frequency current flow, a large part of the high frequency differential or common mode current on a cable is lost as the result of radiation These high frequencies current are gradually decreasing along a cable [14]. The gradual reduction of common noise current due to radiation and reflection is shown in Figure 14.

\subsection{Bearing currents}

High frequency bearing currents are a consequence of the current flow in the common mode circuit of the AC drive system. It has been described in the previous sections of this chapter that the resulting neutral point voltage cannot be equal to zero. This voltage may be defined as a common mode voltage source. It is measurable at the zero point of any load (for example: the star point of the motor winding). Any time one of the three inverter outputs is changed from one of the possible potentials to another, a current proportional to this voltage change is forced to flow to ground via the ground capacitances of all the components of the output circuit. The current flows back to the source via the earth conductor and stray capacitances of the motor drive and the motor.

Bearing currents are the high frequency currents that flow through motor bearings and have the potential of creating premature damages to the motor. These currents are either localized in the bearing or are driven through the bearing due to asymmetries in the motor material properties or construction. The recent raise of the damage ratio is due to modern variable speed drives with fast rising voltages and high switching frequency. It consists in a repeated discharging through bearing that cause gradual damage.

There are different types of bearing currents [16], [17] :

- At low frequencies: the low frequency nature of bearing and shaft currents (also common mode current) in sine wave driven motors results in current paths through what are generally considered to be conductive materials (motor shafts, frames, bearing races and balls bearing). Interrupting the conducting current path with insulating materials can eliminate these low frequency shaft and bearing currents. 
- At high frequencies: current pulses are generated by modern AC drives. The switching frequency of these pulses ranges from $1 \mathrm{kHz}$ up to $20 \mathrm{kHz}$ and is referred to as the "carrier frequency." The ratio of change of the $d V / d t$ creates a parasitic capacitance between the motor stator and the rotor, which induces a voltage on the rotor shaft. If this voltage, referred to as "common mode voltage" or "shaft voltage," builds up to a sufficient level, it can discharge to ground through the bearings. An EMD or Electrical Machine Discharge occurs when the energy of the HF pulses is high enough.

Protecting motor bearings from an unpredictable occurrence of bearing currents is not an exact science, but a process of risk assessment and cost analysis [18], [19]. Amongst solutions available, designers can consider: a lower carrier frequency, adequate grounding, shielded cable, shaft grounding, insulated bearings, or decreasing undesired current from the power supply.

\subsection{Summary}

In this chapter the main definitions related the propagation of interferences in motor drive have been given. Modern motor drives and more specifically their converter are the source of an increased amount of conducted and radiated electromagnetic interferences. The main mechanisms for both common mode currents and differential mode currents have been described: they find their sources in the switching pattern of the inverter and voltage drops across the converter. These currents flow along the feeders and through the motor back to the converter, creating radiated electromagnetic interferences, potential overloading conditions for the power supply and risk of damages for the motor. These interferences needs to be minimized: a common solution is the use of EMI filters. They are described in the following chapter. An example of measured interferences is presented in the coming chapter in the introduction. 


\section{Chapter 3. Passive EMI Filter}

This chapter focuses on the analysis of passive common mode filtering techniques: it addresses the description and the characterization of the two structural components of the EMI filter: the common mode choke and the capacitor to ground. Passive filtering is the generic technique used to reduce or redirect the common mode current in motor drives. The common mode choke is a complex component which is described with a study of the ferromagnetic materials in the second section. The component is characterized in the third section: the designable parameters are related to the impedances used to describe the common mode choke. The equivalent circuit is validated with measurements. This model is compared with the ones available in the literature in the last section.

\subsection{Introduction}

The noise spectrum of power converter is usually spread from around $10 \mathrm{kHz}$ to several decades of $\mathrm{MHz}$. EMI filters are introduced in power systems in order to comply with the conducted emission regulatory requirements and to reduce the radiated emission. Filtering the main supply and motor cables adequately is a challenge which often leads to retro-designed filters, tested in a 'trial and error' process [20], [21], [22]. Design constraints such as size, cost and weight are common while working with such components. Availability of analytic methods to predict performances of the filter would reduce or avoid the need for construction of several, often oversized, prototypes. 
Common mode currents are frequently referred to as 'antenna-mode' currents and are the predominant mechanism for producing radiated electric fields in practical products [4]. Figure 15 presents the circulation of common mode current in the leads of a motor drive. These currents usually flow along the cable and return to the source via stray capacitances between the cable and the ground and to certain extent via capacitive coupling between the frame of the motor and the ground.

EMI filters are usually passive and involve a combination of capacitors and common mode chokes, because the value of the capacitance to ground is limited to reduce mains leakage current. The common mode choke is a key element in terms of performances, size, cost and weight of the overall filter. The two following examples show the impact of the common mode filter on the level of electromagnetic interferences: Figure 16 presents the attenuation of current, with respect of the frequency, at the output of a common-mode filter of an AC/DC converter in which a $\mathrm{MnZn}$ ferrite of $10 \mathrm{mH}$ is used in combination with two feed through Ycapacitors. The bottom curve is the initial level of noise current and the top curve is the one after the insertion of the EMI filter. The impact of a common mode filter on the level of radiated emission between $10 \mathrm{kHz}$ and $1 \mathrm{GHz}$ is shown in Figure 17. The top curve is the initial level of radiated emission and the bottom one the one after the insertion of the EMI filter. The horizontal line in between is the limits set by the specific EMC standard the Device Under Test (DUT) has to comply to. It marks in this case the maximum level of radiated emission allowed for this application. This filter has been built with nanocrystalline cores and constitutes an example of an alternative design to the classical iron choke solution as will be explained later in this chapter. Designs of both these filters are explained in [21] and [22].

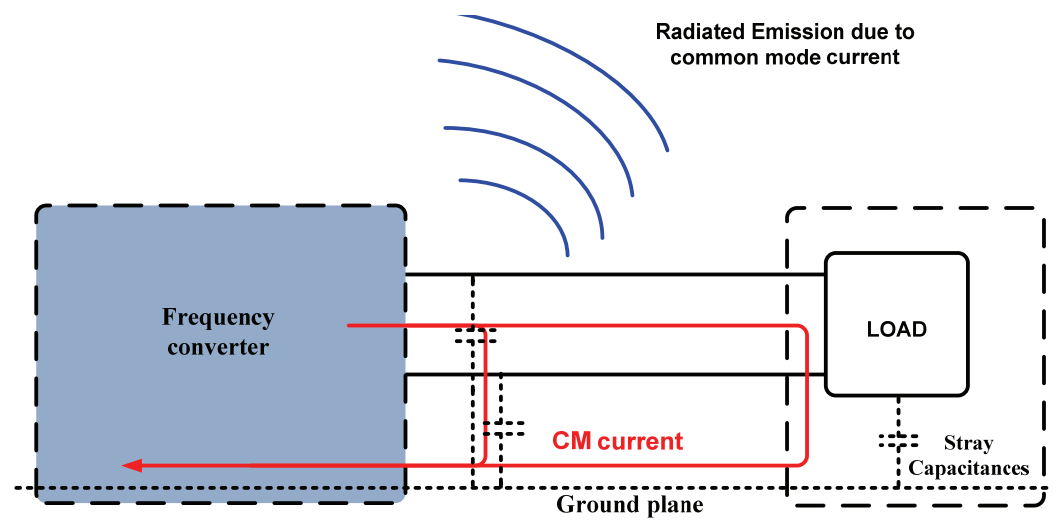

Figure 15: The common mode current path in a motor drive. 


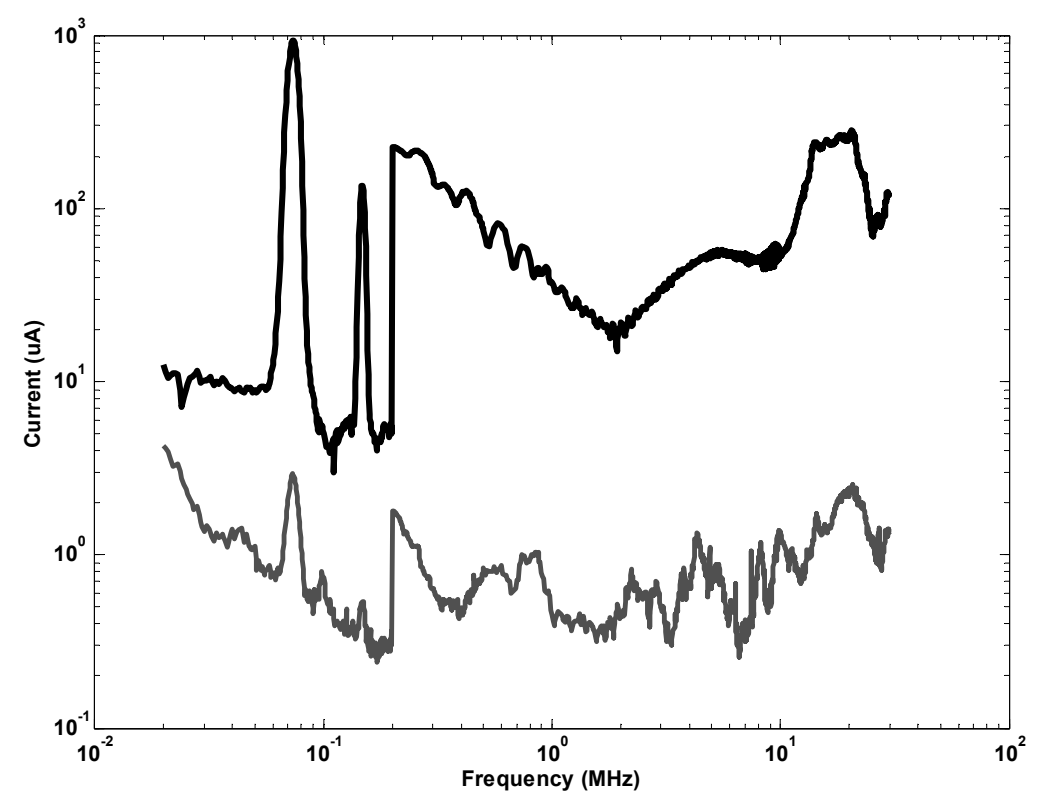

Figure 16: Attenuation of common mode current before (top curve) and after (bottom curve) the insertion of an output EMI filter for an AC/DC converter.

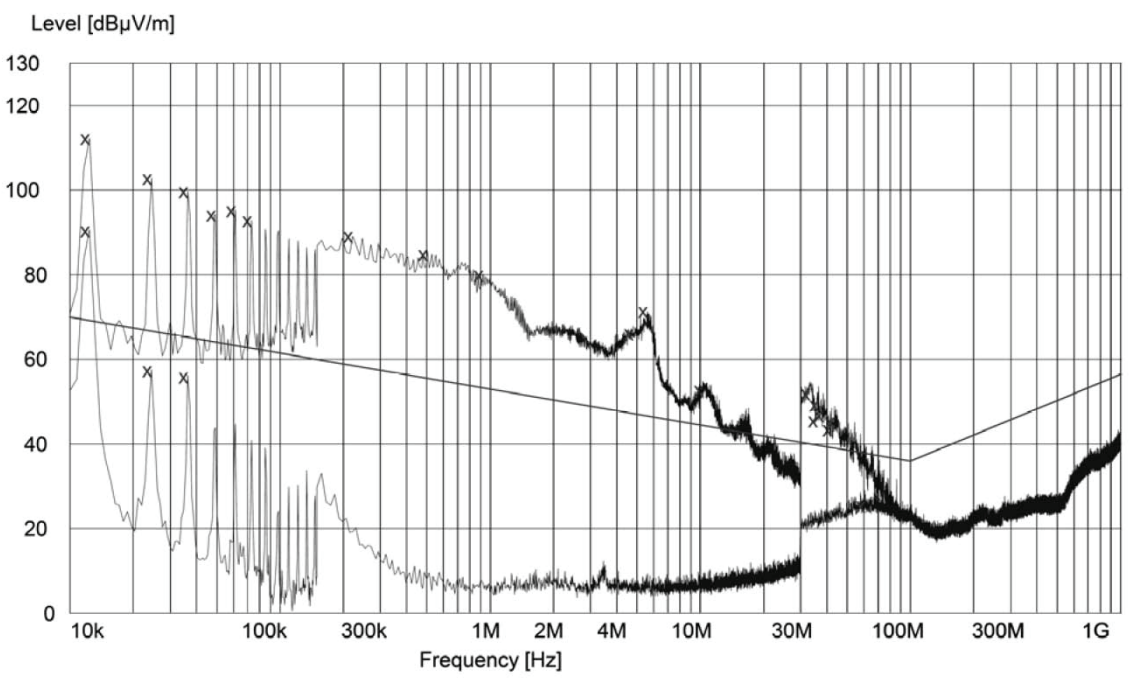

Figure 17: Radiated emission attenuation before (top curve) and after (bottom curve) the insertion of an output EMI filter for frequency converter from $10 \mathrm{kHz}$ to $1 \mathrm{GHz}$. 


\subsection{Capacitors to ground: presentation and design limitations}

\section{2.a. Structure of a feedthrough capacitor}

Every capacitor has an intrinsic value of inductance which, together with the inductance of internal connections and terminal leads, forms a series resonant circuit with the capacitance. In general, a conventional two-wire capacitor has very limited use as a suppressor beyond its self-resonant frequency. For metal film capacitors this is above approximately $1 \mathrm{MHz}$. If suppression performance is required above this frequency, feedthrough capacitors present advantages.

As represented in Figure 18, feedthrough capacitors have a structure in which the ground electrode surrounds the dielectric and the signal terminal goes through the dielectric. Feedthrough capacitors, or EMI suppression capacitors, are used by making a mounting hole in the shielding case and soldering the ground electrode directly to the shielding case (plate). Since this type of capacitor has no residual inductance on the ground terminal side as well as on the signal terminal side, it can provide nearly ideal insertion loss characteristics.

These capacitors are typically made of metalized film. It has the advantage to increase the stability of the component over time and temperature. They are also self healing: the components repairs itself after a voltage spike: each layer acts as a single capacitor, if any of them is damaged the total capacitance can decrease slightly without affecting the performance of the part. In a worst case scenario the failure mode is an open circuit. This specific structure also allows high values of capacitance (several $\mu \mathrm{F}$ ) [25]. In practice it also appears that it is difficult to find low values of capacitance and, in many cases the EMI filter requires these low values either to limit the value of the leakage current sent to ground or optimize the performances of the filter itself. These two aspects are addressed in the Chapter 5 of this thesis.

\section{2.b. Usage limitations and need for an additional component}

The Y-capacitors are connected from the line to the chassis: there is a risk of shock for the user if the capacitor is short-circuited or if the Y-capacitor drives too much common mode current into the ground/chassis. The value of these specific capacitors is therefore regulated by standards for safety. 


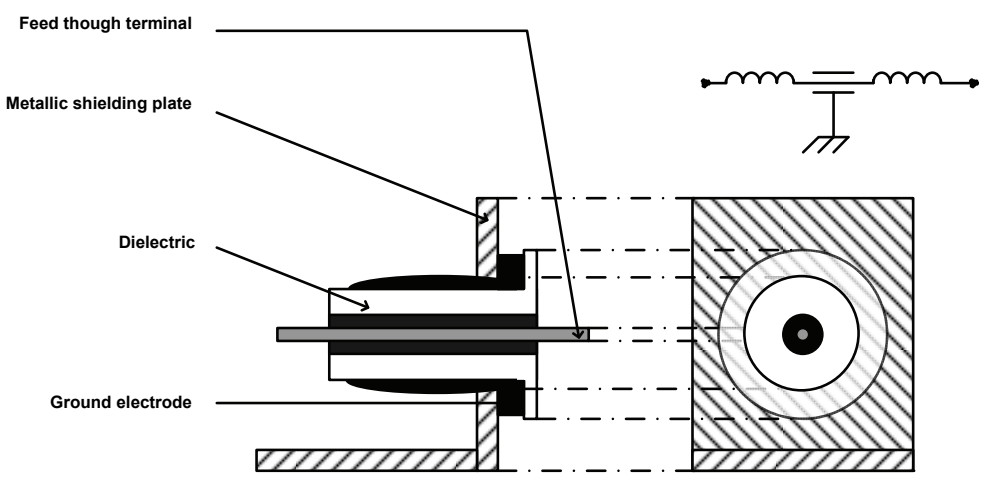

Figure 18: Structure of a feed through capacitor and its electrical schematic.

There is also a risk of creation of current loops with parasitic capacitances within the motor drive. The common mode current sent to the ground by the Y-capacitor travels in other part of the drive (typically towards the switches of the inverter via theirs stray-capacitance with the ground). These switches may be overloaded and damaged by the excess of current. To ensure safety of the user and also to increase the longevity of the motor drive the value of the capacitance to the ground and therefore the amount of current redirected, is limited. The common mode choke is used in combination with the capacitors.

\subsection{Common mode choke: presentation of the ferromagnetic materials}

The final objective of a common mode choke is to block the conduction of the electromagnetic interferences while the lower frequency range 'operational signals' are not affected. Common mode inductors are wound with two or three windings of equal numbers of turns. The number of windings is the same as the number of phases. As depicted in Figure 19, the windings are placed on the core so that the line currents in each winding create fluxes that are equal in magnitude but opposite in phase in the case of differential mode currents, and identical in the case of common mode currents. The fluxes of differential mode currents are thus ideally cancelling out each other and the related current is not influenced by the inductors. It will be shown later that the cancellation is in practice not complete, and this is called leakage inductance. The fluxes due to common mode currents, on the contrary, are adding. A common mode choke is used for its inductive behaviour and also for a 
transformation of the stored energy to into heat. The amount of common mode current that is transformed in heat by the common mode choke and the frequency range of efficiency is first determined by the material itself and then by the overall design. It is shown in Section 3.6.b. in Figure 27, that in low frequency a ferrite core is purely inductive while as the frequency increases the core becomes more and more resistive. At its peak, the resistivity represents half of the overall impedance of the core. During this process the inductive properties of the core are divided by three. This effect is further addressed in Section 3.5.b. Ferromagnetic materials which are typically used: iron powder material, ferrites and nanocrystalline. In this section the general material properties are first reviewed. It is followed by the comparison of the levels of permeability, saturation and Curie temperatures between the materials.

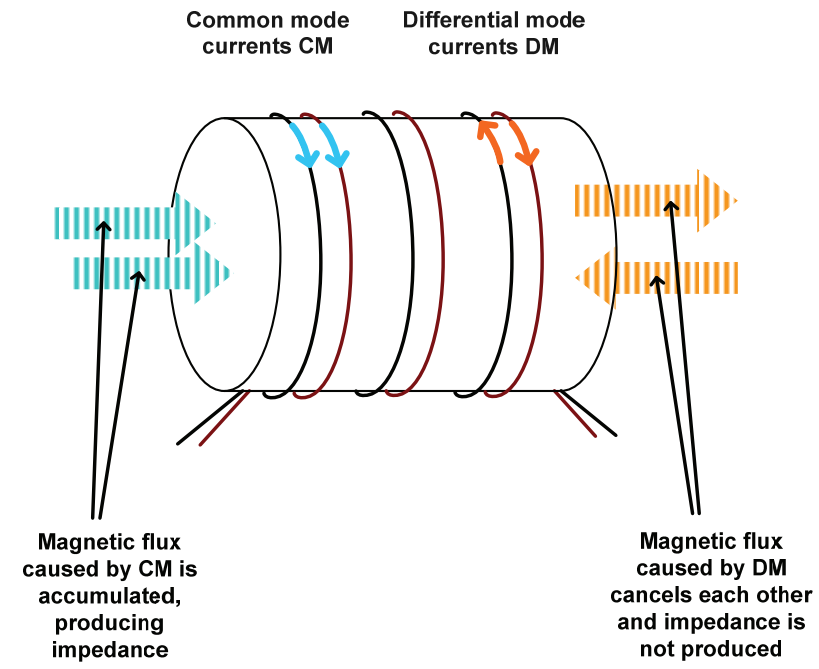

Figure 19: Magnetic flux in a common mode choke.

\section{3.a. Ferromagnetism}

In a ferromagnetic material there is parallel alignment of the atomic moment in a domain. Each domain thus becomes a magnet. Their size and geometry are formed to reduce the magnetic potential contained in the field lines connecting north to south outside the material. Each domain contains about $10^{15}$ atoms. In this condition the magnetic flux path never leaves the boundary of the material. The region where the magnetization is the same, is called a 'magnetic domain'. When an electromagnetic flux is created across a ferromagnetic material the domains become aligned to produce a strong magnetic field within the part. 


\section{3.b. Permeability}

In order to evaluate the total flux density in a ferromagnetic material it is useful to define the permeability $\mu$ which is the ratio of the induction $B$, to magnetizing field $H$. It is the most important parameter used to characterize a magnetic material. The relative permeability $\mu_{r}$ is the ratio of the permeability $\mu$ to $\mu_{o}$, where $\mu_{0}$ is the permeability of free space $\mu_{0}=4 \cdot \pi * 10^{-7} \mathrm{Hm}^{-1}$.

\section{3.c. Hysteresis loop and saturation level}

\section{Presentation}

As the current goes through one sine-wave cycle, the magnetization goes through one hysteresis loop cycle. Minor hysteresis loops are obtained when the maximum applied field is lower than that required to saturate the material. Figure 20 presents the shape of a hysteresis loop in a ferromagnetic material.

The externally applied field will create a flux density $B$ in the material. The atomic dipoles align themselves with the external field until they all are aligned. Even when the external field is removed, part of the alignment will be retained: the material has become magnetized.

The relationship between magnetic field strength $(H)$ and magnetic flux density $(B)$ is non-linear for ferromagnetic material. If the relationship between the two is plotted for increasing levels of field strength, it will reach a point where further increases in magnetic field strength will result in no further change in flux density. This condition is called magnetic saturation. It is the point 1 in Figure 20. When $H$ is reduced to zero, the curve will move from point 1 to point 2 . At this point, it can be seen that some magnetic flux remains in the material even though the magnetizing force is zero. This is referred to as the point of retentivity on the graph and indicates the remanence or level of residual magnetism in the material. As the magnetizing force is reversed, the curve moves to point 3 , where the flux has been reduced to zero. This is called the point of coercivity on the curve. The force required to remove the residual magnetism from the material is called the coercive force or coercivity of the material.

As the magnetizing force is increased in the negative direction, the material will again become magnetically saturated but in the opposite direction (point 4). Reducing $H$ to zero brings the curve to point 5. It will have a level of residual magnetism equal to that achieved in the other direction. Increasing $H$ back in the positive direction will return $B$ to zero. 
Figure 20 presents the shape of a hysteresis loop in a ferromagnetic material.

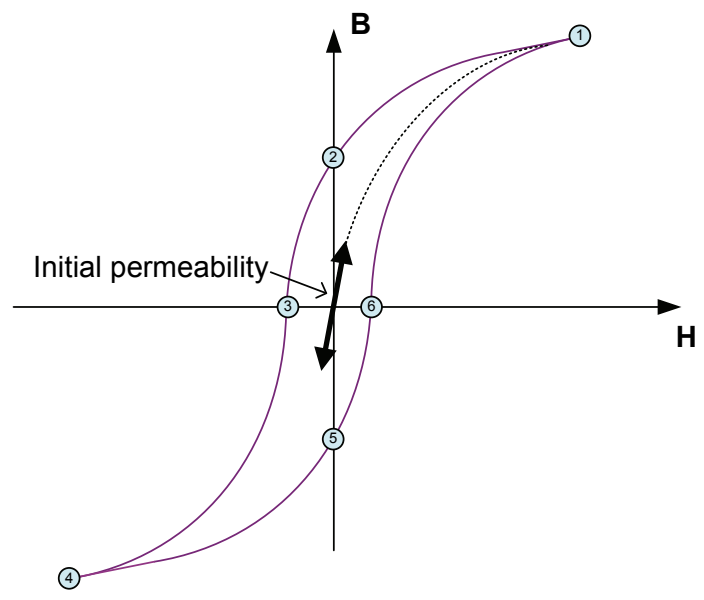

Figure 20: Hysteresis loop in a ferromagnetic material.

\section{Hysteresis loop modelling}

Permeability of the material is the slope of the $B H$ loop. It reduces to zero close to the saturation level. At this stage the common mode choke will also not absorb energy anymore. For these two reasons it is important for the designer to have knowledge about the shape of the $B H$-loop. In case of ferrites several approaches [26] have been developed to predict the major $B H$ loop of ferrites. In particular the Jiles-Atherton model [27] is convenient. It comprises of a first order non-linear differential equation which can be solved numerically to give the magnetization $M$, as function of the applied magnetic field $H$.

The $B H$ loop is dependent of the topology of the cores and the main drawback of this method in a predictive model, is the need of experimental extraction of the socalled 'Jiles Atherton parameters' on the common mode choke itself. They depend of the structure of the choke as well as its material. A solution is to combine the JilesAtherton model with the extraction parameters algorithm as described in [28].

The combination of these two methods needs parameters provided by manufacturer: the magnetic permeability $\mu$, coactivity $H_{c}$, remanence $B_{n}$ and the technical value of saturation magnetization $M_{s}$. Figure 21 presents an example of the modelling of several curves of the magnetizations versus flux. 


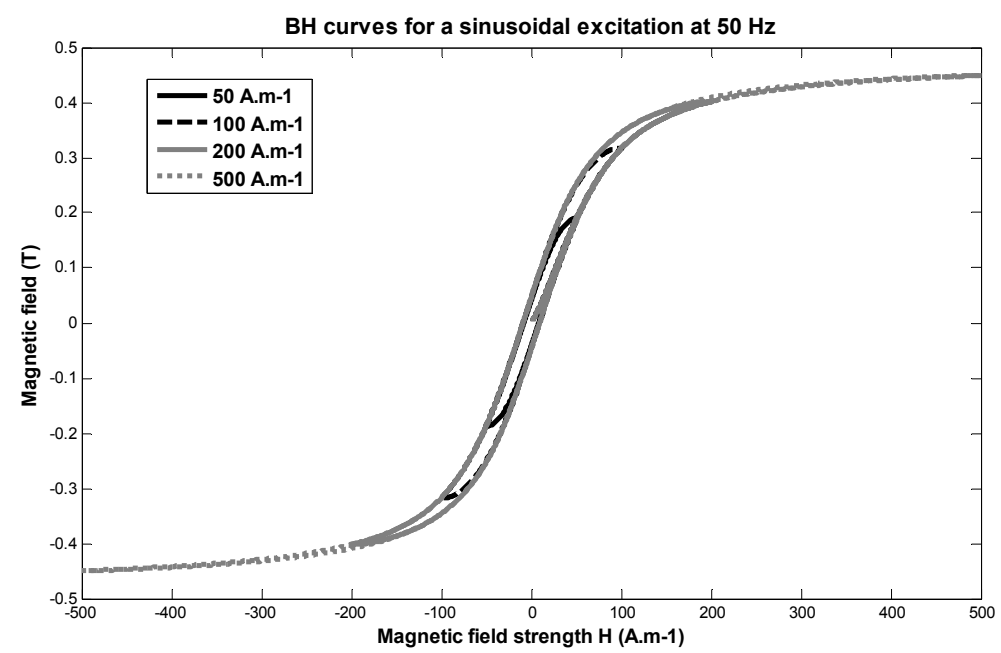

Figure 21: $B H$ curves for a sinusoidal excitation at $50 \mathrm{~Hz}$.

\section{Hysteresis loop in transient conditions}

The hysteresis loop as described in the previous section and its related Jiles-Atherton model are valid only when the current goes through a sine-wave cycle. In [29] the concept of volume fraction is introduced to model hysteresis loop of ferrite cores excited by a transient magnetic field. The Jiles-Atherton model is modified in a loop by loop technique in order to obtain the magnetization trajectory with an asymmetric minor loop excursion under arbitrary waveform magnetic field excitation. This technique is specially developed for applications such as power electronics converters in power transformers and chokes. For high frequency operation (above $400 \mathrm{~Hz}$ ) an additional technique has to be incorporated in this model to deal with rate dependent hysteresis effect [30], [31]. The hysteresis loop does indeed enlarge as the frequency increases. The permeability on the other hand decreases.

These models in transient conditions remain experimental as five parameters have to be extracted for each core (size and material) and are time consuming. They are useful for an accurate prediction of waveforms and hysteresis losses in time domain.

\section{Saturation level of a common mode choke}

Common mode choke materials belong to the soft magnetic material family and are characterized by a narrower $B H$ loop. An important assumption is to assume the choke is used relatively far from its saturation condition, and that the permeability 
(slope coefficient of the $B H$ loop) remains similar to the permeability in sinusoidal condition. This assumption is verified in the next chapter.

Hysteresis curves show the relationship between a magnetizing force $(H)$ and the resultant magnetic induction $(B)$. A magnetic material is saturated when increases in magnetizing force $(H)$ no longer appreciably increase the magnetic induction $(B)$. Saturation flux density $(B s)$ is the value of magnetic flux density when the material reaches its limit with respect to the number of flux lines per unit area it can efficiently conduct.

Once a core size is chosen, the maximum inductance which can be obtained per core can be calculated with the two following relations (details can be found in [21]):

- The relation between the saturation level and the dimension is given in (2) (for a toroid core),

- The relation between the inductance and the dimension is given in (3) (for a toroid core).

$$
\begin{aligned}
& B_{\text {sat }}=\frac{\mu_{o} * \mu_{e} * I_{C M} * N}{l_{e}} \\
& \mathrm{~L}=\frac{\mu_{o} * \mu_{e} * N^{2} * A_{e}}{l_{e}}
\end{aligned}
$$

Where

$\begin{array}{ll}B_{s a t} & \text { Saturation level of the magnetic field strength } \\ \mu_{e} & \text { Effective permeability } \\ \mu_{0} & \text { Permeability of free space } \\ I_{C M} & \text { Common mode current } \\ l_{e} & \text { Effective path length } \\ N & \text { Number of turns } \\ L & \text { Inductance of the core }\end{array}$

The final relation between the maximum inductance and the saturation level is as follow:

$$
\mathrm{L}=\frac{\mathrm{l}_{\mathrm{e}} * A_{e} * B_{\text {sat }}^{2}}{\mu_{o} * \mu_{e} * I_{C M}^{2}}
$$




\section{DC bias and saturation level}

When describing a periodic function in the frequency domain, the DC bias is the mean value of the waveform. When applied on a common mode choke a DC-biased loop is created within the major hysteresis loop. Its origin presents an offset with respect to the origin of the major hysteresis loop. As the DC bias value increases, the DC biased $B H$ loop reaches the saturation level. The effect of the DC bias on the hysteresis loop is further described in [32]. A DC bias on a common mode choke needs to be taken into account in the calculation of an adequate saturation level. The effect of a DC bias on the common mode choke has not been considered in this thesis.

An adequate and cost effective measure of saturation is actually to simply measure the inductance on an LCR meter and increase a DC bias current until the inductance decreases.

\section{Differential mode current and saturation}

The differential mode currents do not completely cancel each other within the choke as it is ideally described. This effect is further described in the Section 3.5. This leakage inductance does also contribute in reducing the design windows of the common mode choke. For instance if a leakage of differential mode current of $1 \%$ is assumed for a DM current of $15 \mathrm{~A}$, then the additional current the choke has to handle has an amplitude of $150 \mathrm{~mA}$. If the choke is assume to be designed for $1 \mathrm{~A}$ common mode current, then the actual CM current allowed is $850 \mathrm{~mA}$.

\section{Curie temperature}

The spontaneous magnetization of ferromagnetic material disappears at the Curie temperature. It is therefore important to ensure that the temperature of the choke remains below this temperature.

\subsection{General material properties overview}

The typical requirements of an optimized common mode choke are:

- A high impedance over the wanted frequency range, this is related to the complex permeability of the material.

- A high saturation level.

Three basic materials are used in the design of the traditional common mode choke for switched mode power supplies (SMPS): ferrites, powder materials (iron) and metal alloys (nanocrystalline and amorphous structure). Figure 22 presents an 
overview of the permeability of nanocrystalline, ferrites, iron and amorphous materials [33], [34], [35], [36].

The highest initial permeability is found in nanocrystalline materials (up to 100000 till $150 \mathrm{kHz}$ ). Powder iron cores have low permeabilities (10 to 100 till $100 \mathrm{kHz}$ ) while amorphous alloys have higher values (5000 to 80000 till $100 \mathrm{kHz}$ ). Ferrite cores can be used over a wide frequency range (up to several $\mathrm{MHz}$ for the $\mathrm{NiZn}$ cores). Higher flux density can be found in nanocrystalline and amorphous material, as well as in iron powder core. Ferrites exhibit a significantly lower level of saturation; this is depicted in Figure 23.

Iron based nanocrystalline materials are the new generation of magnetic alloys. A typical characteristic of these materials is their small nanometre grain size. The concept of nanocrystalline materials was introduced in 1981 [37]. Research on this new material has progressed after the development of the first nanocrystalline material in 1988. Nanocrystalline materials are a good alternative to the traditional chokes made of ferrite or iron powder: the main advantage of nanocrystalline material is its high level of saturation and its high permeability which allow a relatively smaller size of core. It is however more expensive than the other materials. This newer material enables major step towards volume and weight reduction, reaching $50-80 \%$ lower compared to a ferrite core and more than $90 \%$ lower compared to an iron core. The consequent volume and weight losses can be an important property in aerospace applications or any other area where weight is a design constraint. Two classes of nanocrystalline materials are available on the market. Nanocrystalline material were first developed in Japan in the late 80s and have stimulated a large amount of research and development worldwide to optimize the magnetic properties of the so-called 'Finemet' alloys. The 'Nanoperm' class belongs to a second generation of nanocrystalline (1997) containing more Fe (83-89 percent compared to 74 percent before). These new classes of nanocrystalline material allow a higher saturation level of the order of 1.6 to $1.7 \mathrm{~T}$ where the first generation have a saturation level of the order of $1.2 \mathrm{~T}$. The Finemet family has a grain size of about $15 \mathrm{~nm}$, and presents very good properties at high frequencies, comparable to some of the best Co-based amorphous materials. In the Nanoperm family the grain size is about $25 \mathrm{~nm}$ and provides less losses at $50-60 \mathrm{~Hz}$ which makes them suitable for transformer design. The Finemet family of alloys is marketed by Hitachi Special Metal of Japan and Vacuumschmelze GmbH of Germany. The Nanoperm alloys have been developed by Alps Electric Co. of Japan. Another important feature of the nanocrystalline material is their good behaviour with respect to the temperature. Figure 24 presents the evolution of the saturation level with the Curie temperature. 


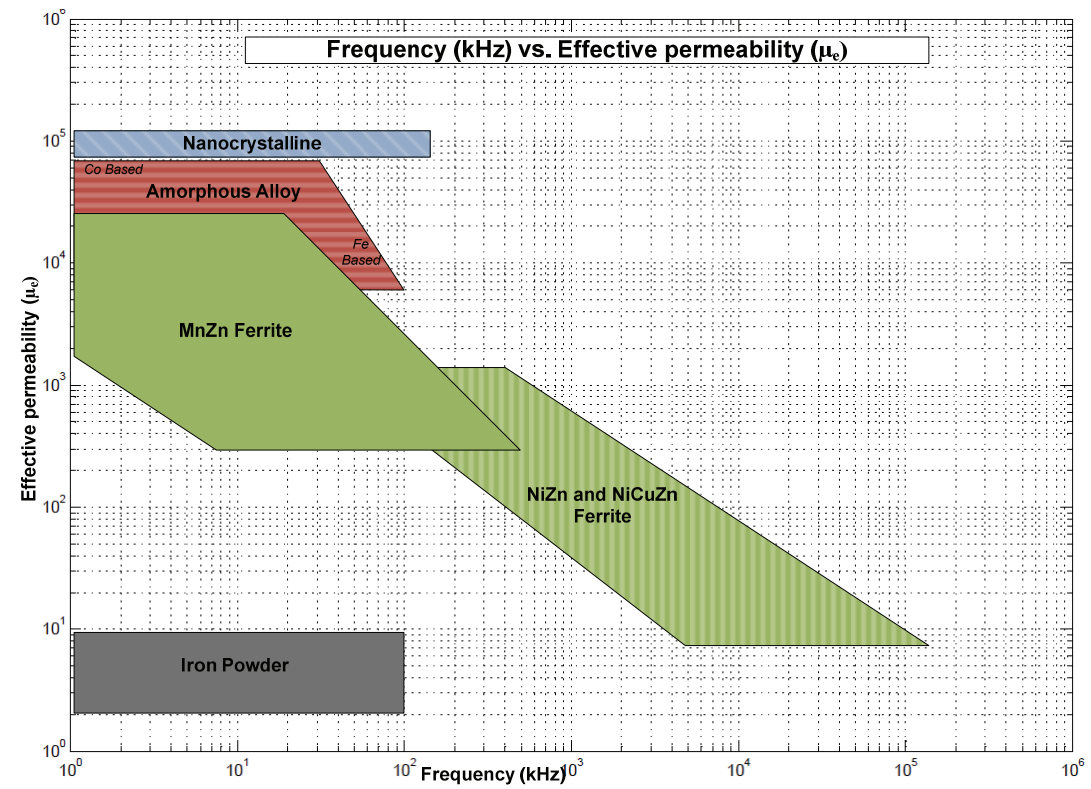

Figure 22: Main magnetic properties for the material ferrites, nanocrystalline and amorphous: Permeability versus Frequency.

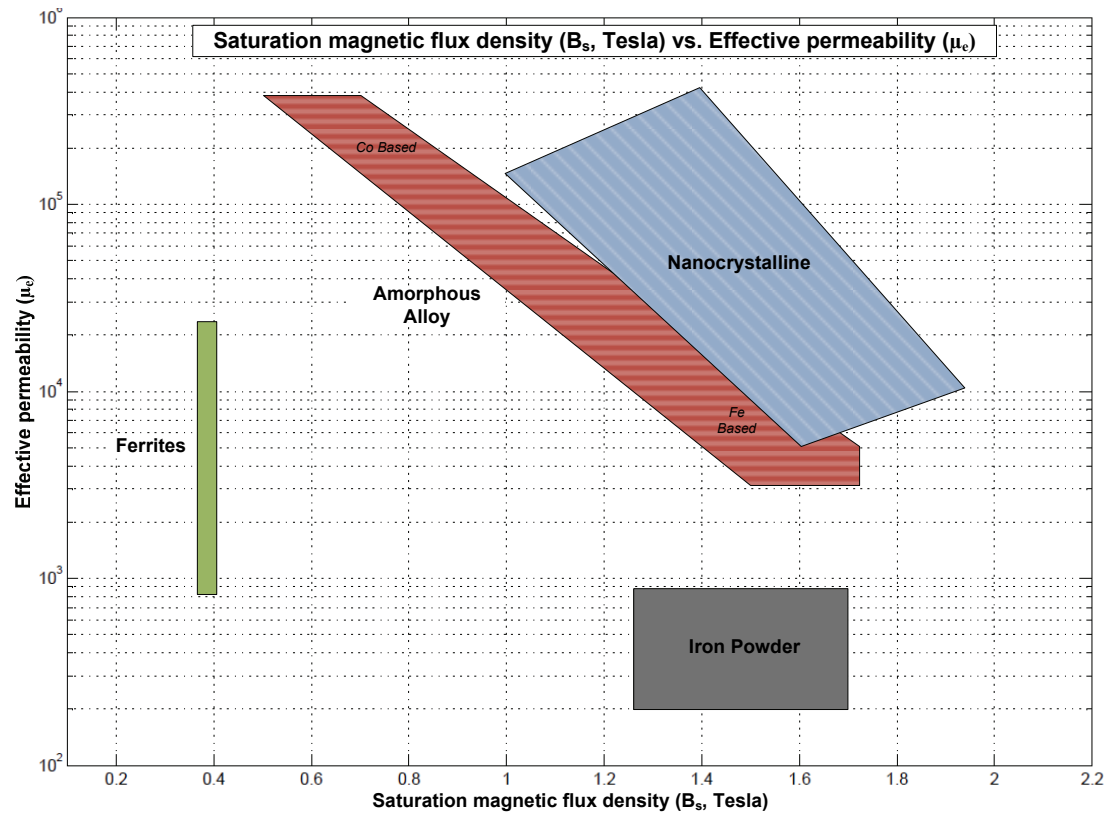

Figure 23 : Main magnetic properties for the material ferrites, nanocrystalline and amorphous: Saturation versus permeability. 


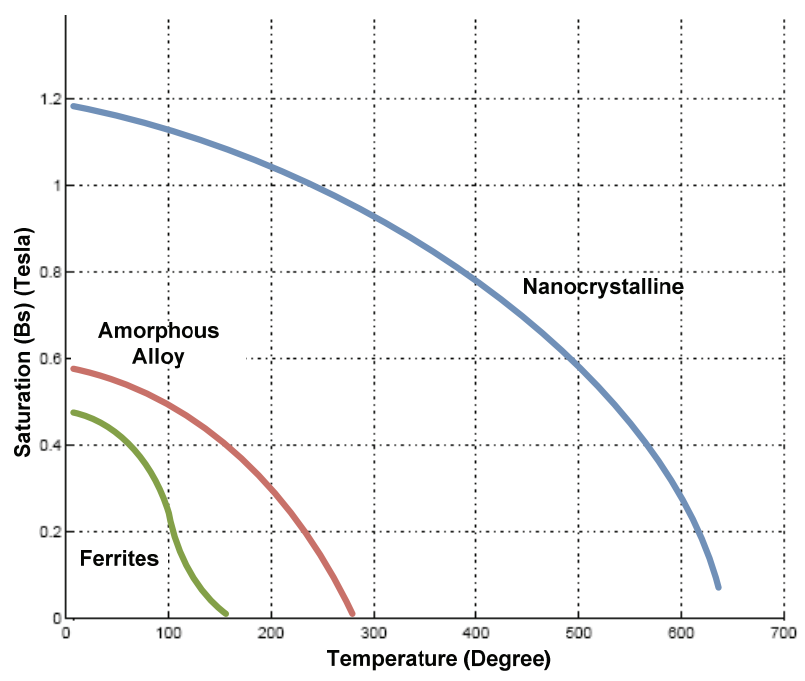

Figure 24: Temperature versus Saturation.

\subsection{Common mode chokes: existing models and limitations}

The objective is to develop a behavioural model of the common mode choke. As defined in section 1.1 this approach is motivated by the aim of obtaining a framework for the common mode choke analysis that respect the underlying physics and sets up the appropriate mathematical concept from that. The input of the model of the common mode choke to be developed are the designable parameters.

Many strategies are followed in the literature to model the common mode choke. Typically two equivalent circuits are proposed: one for the differential mode and one for the common mode. The equivalent common mode circuit is of interest in this thesis. These models can be organized in three categories:

- Models where the common mode choke is modelled with a single inductance, with or without parallel capacitance.

- Models where the common mode choke is modelled with an extracted equivalent circuit.

- Models where the common mode choke is modelled using the complex permeability of the core material. 


\section{5.a. Models of the common mode choke as a single inductance, with or without parallel capacitance}

These models are all based on the observation that the common mode current faces only one electromagnetic flux in the core of the choke. This flux is related to the inductance of one winding. (This aspect is further addressed in section 3.6.b).

In [42] a model of the EMI filter is proposed where the common mode choke is modelled with a single inductance in its equivalent common mode circuit: the one of one winding. This model is valid only in the low frequency range where the resistive behaviour of the common mode choke can be neglected. (This behaviour is further develop in the section 3.6.b).

In [43] the model of the common mode equivalent circuit of the component is extended to the higher frequencies with the use of a capacitance placed in parallel of the common mode inductance. This capacitance is presented as a parasitic one but this explanation is not correct. It is shown in section 3.6.b that actually no parasitic capacitance plays a role in the common mode impedance. The capacitive behaviour of the choke in the higher frequencies is related to the complex permeability characteristics in this specific frequency range and not to any parasitic capacitance.

\section{5.b. Model of the common mode choke as an extracted equivalent circuit}

In [44] the most advanced extracted common mode equivalent circuits of the CMC is described. The complexity of such circuits increases proportionally with the frequency range of validity. The extraction of each impedance value needs to be performed for each choke under consideration. While such models can have their own merits, their structure is not related in a clear manner to any physical phenomena. They do not allow the use of designable parameters.

\section{5.c. Model of the common mode impedance using the complex permeability of} the core material

In [41] and [45], the common mode impedance is related to the geometry of the coil and its complex permeability. These are all designable parameters.

The difficulty stands in the proper model of the complex permeability of the choke. This permeability is given by the manufacturer and therefore stored in a data base of material. When no data is available, the permeability needs be measured or modelled. The model proposed in [45] is not based on designable parameters: the permeability is approached with the use of Bessel functions whose coefficient needs 
to be extracted for each material. The link between the complex permeability and designable parameters is not straight forward.

\subsection{Common mode chokes, impedances and designable parameters}

This section focuses on the designable parameters of the common mode choke $(\mathrm{CMC})$ and the modelling of their related impedances.

\section{6.a. Impedances and designable parameters identification}

The designable parameters for the electrical design engineer are the quantitative aspects of physical characteristics of the common mode choke that are input to its design process. In this section the designable parameters of a common mode choke are related to their impedances in its equivalent circuit. Figure 25 presents a typical common mode choke under consideration: a choke with two symmetrical windings. The shape of the core is a toroidal.

The study of the behaviour of a common mode choke involves four types of impedances:

- Common mode impedance; it is the impedance faced by the common mode current in the choke.

- Differential mode impedance; it is the impedance faced by the differential mode current in the choke.

- Turn to turn capacitance; it is the parasitic impedance existing between two turns of a winding.

- Winding to winding capacitance; it is the parasitic impedance existing between the two windings of the choke.

Table 3 lists the impedances of the common mode choke and their respective designable parameters. These designable parameters are the parameters that can be modified by the designer and will be the inputs of the behavioural model of the common mode choke.

Figure 26 presents the general equivalent circuit of the common mode choke. The structure is validated in the section 3.5.c. $Z_{c m}$ is the common mode impedance, $Z_{d m}$ is the differential mode impedance, $C_{t t}$ is the turn to turn capacitance and $C_{w w}$ the winding to winding capacitance. This structure has not been presented before: the 
new aspect is the clear decoupling of the impedances related to the differential mode current with the one of the common mode choke.

\section{6.b. Related Impedance modelling}

\section{Common mode (CM) impedance}

The value of the CM impedance is strongly related to the value of the permeability of the core. As detailed in [41] the inductor introduces frequency variable impedances in the circuit. The impedance of a common mode inductor is complex, the real component represents the reactive component and the imaginary part represents the losses. $\mathrm{CM}$ impedance of a CMC can be represented by the series equivalent circuit of a suppression core: the loss free inductor $\left(L_{s}\right)$ is in series with the equivalent loss resistor $\left(R_{s}\right)$. The following equation relates the series impedance and the complex permeability.

$Z=R_{s}+j \omega L_{s}=j \omega L_{o}\left(\mu_{s}^{\prime}-j \mu_{s}^{\prime \prime}\right)$

where

$L_{o}=\mu_{0} \frac{A_{e}}{l_{e}} N^{2}$

$N$ : Number of turns.

$A_{e}$ and $l_{e}$ : Respectively the effective area and length of the choke under consideration.

Table 3. Designable parameter for common mode choke.

\begin{tabular}{|l|l|}
\hline Impedances of the CMC & Designable parameters \\
\hline$Z_{c m}$ & $\begin{array}{l}\text { Material (complex permeability) } \\
\text { Dimension of the choke } \\
\text { Number of turns } \\
\text { Effective length }\end{array}$ \\
\hline$Z_{d m}$ & $\begin{array}{l}\text { Number of turns } \\
\text { Dimensions of the choke } \\
\text { Angle of the winding free section }\end{array}$ \\
\hline$C_{w w}$ and $C_{t t}$ & $\begin{array}{l}\text { Number of turns } \\
\text { Dimensions of the choke } \\
\text { Wire dimensions and materials (isolation and } \\
\text { diameter) }\end{array}$ \\
\hline
\end{tabular}




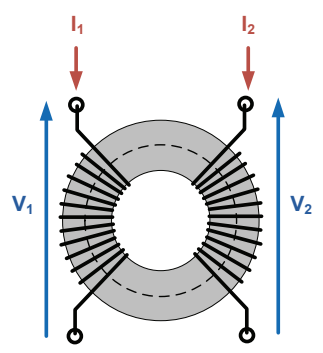

Figure 25: Typical CMC under consideration.

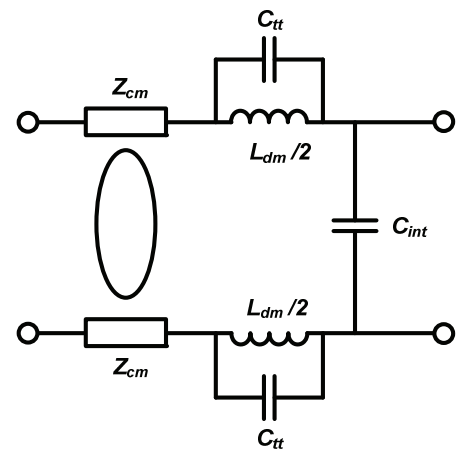

Figure 26: General equivalent circuit of the common mode choke.

The complex permeability of the material is assumed to be known from manufacturers' data sheets but could also be modelled thanks to the designable parameter of the material of the core. A model of frequency dispersion of complex permeability in ferrites is for instance proposed in [46]. The permeability spectra of ferrite materials can be described by the superposition of two kinds of resonance phenomena (domain-wall resonances and gyromagnetic spin rotation). They depend on the characteristic dispersion parameter and their values can widely differ from one material to another. Table 2 lists the values for two sintered materials. Figure 27 represents the complex permeability of a sintered $\mathrm{MnZn}$ ferrite. The real and imaginary parts of the complex permeability can be modelled with the following equations:

$$
\begin{aligned}
& \mu^{\prime}=1+\frac{\omega_{d}^{2} \chi_{d o}\left(\omega_{d}^{2}+\omega^{2}\right)}{\left(\omega_{d}^{2}-\omega^{2}\right)^{2}+\omega^{2} \beta^{2}}+\frac{\chi_{s o} \omega_{s}^{2}\left[\left(\omega_{s}^{2}+\omega^{2}\right)+\omega^{2} \alpha^{2}\right]}{\left[\omega_{s}^{2}-\omega^{2}\left(1+\alpha^{2}\right)\right]^{2}+4 \omega^{2} \omega_{s}^{2} \alpha^{2}} \\
& \mu^{\prime \prime}=\frac{\chi_{d o} \omega \beta w_{d}^{2}}{\left(\omega_{d}^{2}-\omega^{2}\right)^{2}+\omega^{2} \beta^{2}}+\frac{\chi_{s o} \omega_{s} \omega o\left[\omega_{s}^{2}+\omega^{2}\left(1+\alpha^{2}\right)\right]}{\left[\omega_{s}^{2}-\omega^{2}\left(1+\alpha^{2}\right)\right]^{2}+4 \omega^{2} \omega_{s}^{2} \alpha^{2}}
\end{aligned}
$$


Where:

$\omega \quad$ angular frequency $(\omega=2 \pi f$, with $f$ the frequency in $\mathrm{Hz})$

\section{Domain Wall components}

$\chi_{d o} \quad$ Magnetic susceptibility for domain-wall

$\omega_{d} \quad$ Resonance angular frequency for domain-wall

$\beta \quad$ Damping factor

\section{Spin components}

$\chi_{s o} \quad$ Magnetic susceptibility for gyromagnetic spin-motion

$\omega_{s} \quad$ Resonance angular frequency for spin components

$\omega_{r} \quad$ Relaxation angular frequency

$\alpha \quad$ Damping factor

Table 4. Permeability Dispersion Parameters Of Sintered MnZn and NiZn Ferrite For Spin And Domain Wall Resonance.

\begin{tabular}{|l|c|c|c|c|c|c|c|}
\hline & \multirow{2}{*}{$\begin{array}{c}\text { Density } \\
(\mathrm{g} / \mathrm{cc})\end{array}$} & \multicolumn{3}{|c|}{ Domain Wall Component } & \multicolumn{3}{|c|}{ Spin component } \\
\cline { 4 - 8 } & $\chi_{d o}$ & $\begin{array}{c}\mathrm{f}_{\mathrm{d} 0} \\
(\mathrm{MHz})\end{array}$ & $\beta$ & $\chi_{\text {so }}$ & $\begin{array}{c}\mathrm{f}_{\mathrm{s} 0} \\
(\mathrm{MHz})\end{array}$ & $\alpha$ \\
\hline MnZn Ferrite & 4.9 & 3282 & 2.5 & $9.3 \mathrm{e}+6$ & 1438 & 6.3 & 1.28 \\
\hline NiZn Ferrite & 5.2 & 485 & 2.8 & $3.5 \mathrm{e}+6$ & 1130 & 1100 & 161 \\
\hline
\end{tabular}

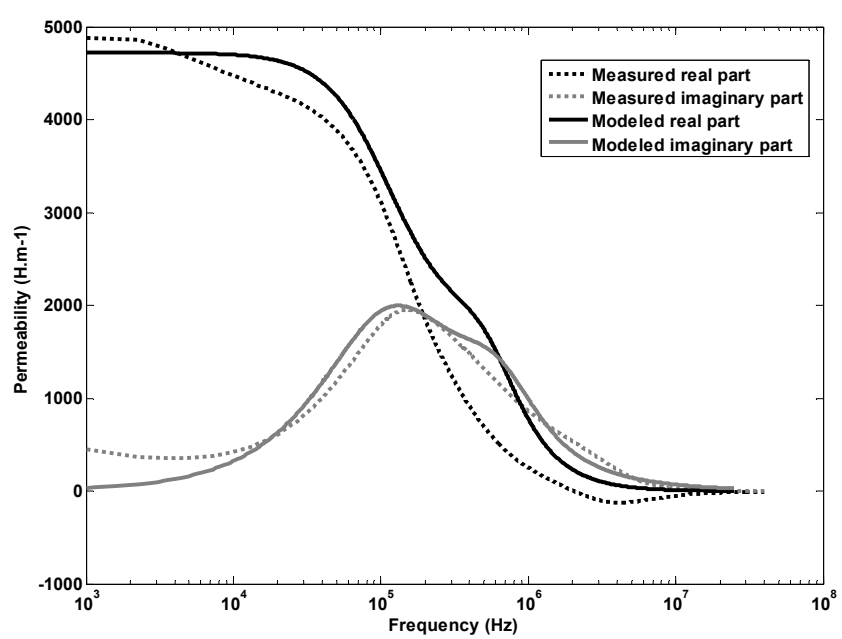

Figure 27. Complex permeability spectrum of a Sintered $\mathrm{Mn} \mathrm{Zn}$ ferrite. 
At low frequencies a ferrite core is purely inductive while as the frequency increases the core becomes more and more resistive. In the meantime inductive properties of the core are divided by three. At its peak, the resistivity represents half of the overall impedance of the core.

\section{Differential mode impedance}

The value of the DM impedance is related to leakage inductances. Fluxes created by the differential mode currents do not completely cancel each other: parts of these currents leak from the choke in between the wiring system. For a more accurate estimation, formulae are available in the literature [47] and presented in Table 4.

\section{Parasitic capacitances}

Parasitic stray capacitance is composed of the winding to winding capacitances $\left(C_{w s}\right.$, $\left.C_{w s}{ }^{\prime}\right)$ and the turn to turn capacitances $\left(C_{t t}, C_{t t}{ }^{\prime}\right)$. The winding capacitances tend to decrease the efficiency of the CMC while the turn to turn capacitances tends to improve the differential mode current attenuation. Intra winding capacitances are negligibly small in most applications. Approximations of theirs values are detailed in Figure 28. Details concerning these formulae are also available in [48] and [49].

Table 5. Equation to model the parasitic capacitances and leakage inductances of a CMC.

\begin{tabular}{|l|l|}
\hline $\begin{array}{l}\text { Intra winding capacitances } \\
\left(C_{w s}, C_{w s}{ }^{\prime}\right)\end{array}$ & $C_{w}=C_{t t} * 1.366=0.683 * \frac{\varepsilon_{0} \varepsilon_{r} h_{t} l_{t}}{h_{i}}$ \\
\hline $\begin{array}{l}\text { Turn to turn capacitances } \\
\left(C_{t t}, C_{t t}{ }^{\prime}\right)\end{array}$ & $C_{t t}=\varepsilon_{0} l_{t}\left[\frac{\varepsilon_{r} \theta^{*}}{\left.\ln \frac{D_{o}}{D_{c}}+\cot \left(\frac{\theta^{*}}{2}\right)-\cot \left(\frac{\pi}{12}\right)\right]}\right.$ \\
\hline $\begin{array}{l}\text { Leakages inductance } \\
\left(L_{d m}, L_{d m}{ }^{\prime}\right)\end{array}$ & $\theta^{*}=\operatorname{arcos}\left[\begin{array}{l}\ln \frac{D_{o}}{D_{c}} \\
\varepsilon_{r}\end{array}\right]$ \\
\hline
\end{tabular}



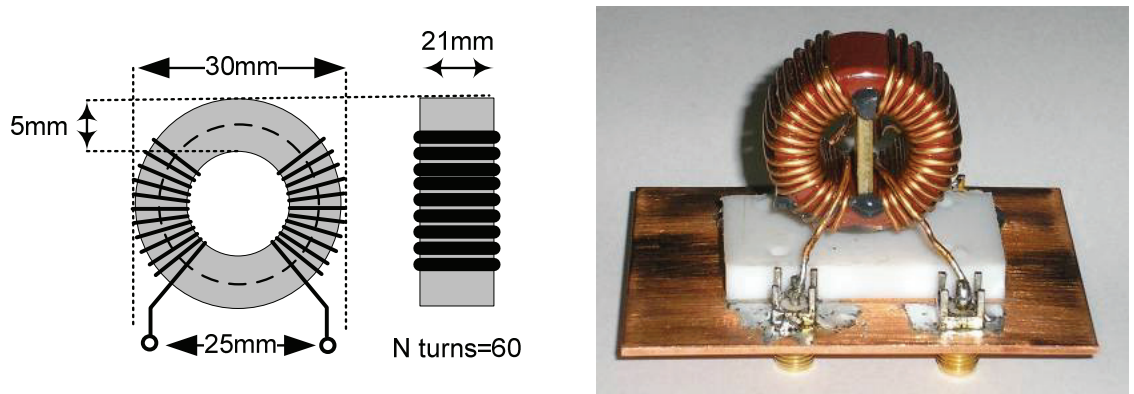

Figure 28: $\mathrm{CMC}$ under test.

\section{6.c. Measurements and equivalent circuit validation}

\section{Measurement setup}

Measurements have been performed by the author on a common mode choke presented in Figure 28. Four SMA connectors are connected to the four ports of the choke through the reference plane (a copper plate). It is then ensured that the ground of the measurement device is a reference plane which conducts the return currents. The core used as the main example in this chapter is a ferrite made of $\mathrm{MnZn}$. Its characteristics have been measured with an Impedance/Gain-Phase Analyzer (HP 4194A) between $100 \mathrm{~Hz}$ and $40 \mathrm{MHz}$. Results are presented from Figure 30 to Figure 33. This auto balancing bridge method [50] offers wide frequency coverage and is specially adapted to the ground device measurements. The test set-up used to measure the four characteristic impedances of the choke is detailed thereafter.

\section{Measurement of coil inductance}

Coil inductance can be measured directly by connecting the instrument as shown in Figure 29 (part A). All other windings should be left open. The inductance measurement includes the effects of capacitances. If an equivalent circuit analysis function is available, individual values for inductance, resistance and capacitance can be obtained. This measurement is used to extract the value of the turn to turn capacitances.

\section{Measurement of the leakage inductance}

The leakage inductance can be measured by connecting the output port of the first windings to the input port of the second winding to reproduce the circuit as seen by the differential mode current. The measurement is described in Figure 29 (part B). 


\section{Measurement of the winding to winding capacitance}

It is measured by connecting one side of each winding to the instrument as shown in Figure 29 (part C). The other sides are left open.

\section{Measurement of the common mode impedance}

Both windings are connected together and reproduce the circuit as seen by the common mode current, as shown in Figure 29 (part D).

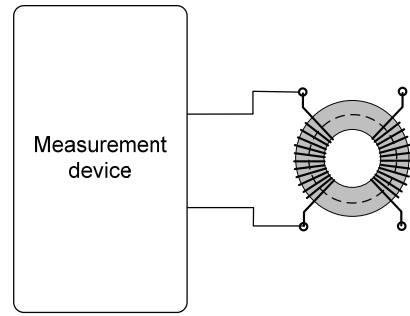

(A) Phase impedance.

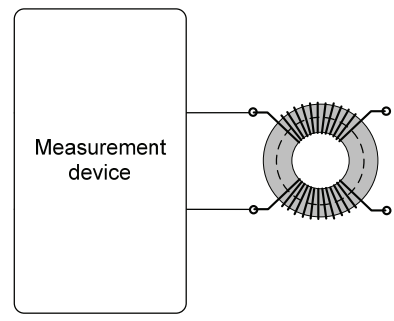

(C) Inter-winding impedance.

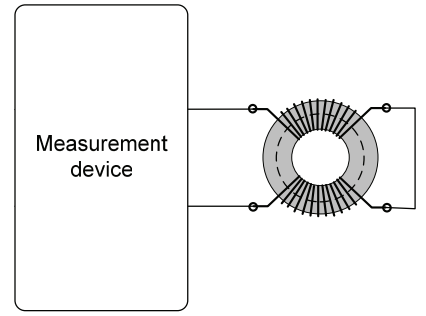

(B) Differential mode impedance.

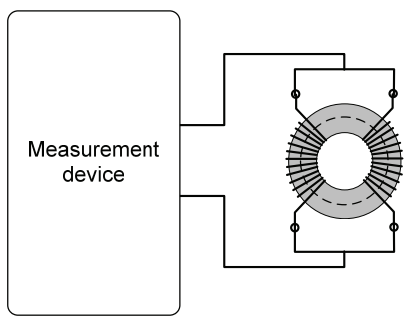

(D) Common mode impedance.

Figure 29 : Impedances measurement.

\section{Measurement results}

The choke under consideration is bonded with a copper wire with a diameter of $0.99 \mathrm{~mm}$. Its insulation in polyurethane has a thickness of $12 \mu \mathrm{m}$. The choke can be used with a rated current of $5 \mathrm{~A}$ and nominal voltage of $250 \mathrm{Vac}$. The measured impedances are presented from Figure 30 to Figure 33. The equivalent circuit of the measured impedances of the common mode choke can be extracted from these measurements. The final equivalent circuits of the measured impedances are shown in Figure 37. The measurement of the leakage inductance (Figure 31) is independent of the winding to winding capacitance which is short circuited (configuration B in Figure 29). The common mode fluxes generated by the windings 
cancel each other in this configuration. The leakage inductance resonates with the parallel turn to turn capacitance on each side of the choke This resonance can be used to extract the total value of the turn to turn capacitance which consists of two capacitances in series in this measurement configuration. The value of each turn to turn capacitance is double of the extracted value. The resonance between the turn to turn capacitance and the leakage inductance is also visible in the respective phase impedance in Figure 30 (configuration A in Figure 29). It suggests that the common mode impedance is in series with half the differential mode impedance. The phase impedance remains indeed identical to the common mode impedance before this resonance. It shows that the common mode impedance is not in parallel with the turn to turn capacitance which is then only parallel with half the leakage inductance. An explanation of this structure is that only the leakage flux within the wiring system interacts with the turn to turn capacitance while the main fluxes remaining inside the choke do not. The anti-resonance visible in the winding to winding capacitance is related to its position in series (configuration C in Figure 29) with the parallel structure formed by the differential mode impedance and the turn to turn capacitances in series with the common mode impedance. The measured common mode impedance presented in Figure 33 (configuration D in Figure 29) is independent of the leakage inductance. The leakage fluxes have cancelled each other. Figure 34 to Figure 36 compare the measured impedances of the choke with the modelled ones. The extracted values from the measurements have been used and the good agreement between the two confirms the structure of each equivalent circuit. These results allow a clear identification of the components related to the differential mode (leakage inductance, winding to winding capacitance and turn to turn capacitances) and the common mode (common mode impedance only). The common mode current flowing in the choke faces twice the common mode impedance in each winding as the flux created on both sides add to each other in each winding. Both the phases are in parallel with each other as far as the common mode current is concerned. The final equivalent circuit, presented in Figure 38 , is then equivalent to single common mode impedance.

\section{Discussion on the higher frequencies coupling}

The measured impedances of the choke show additional resonances in the very high frequencies $(50 \mathrm{MHz})$ : it is proposed by the author that theses resonances are not related to the winding to winding capacitance and are visible in the leakage inductance measurement where this capacitance is short-circuited. These resonances might be instead related to the fact that a part of leakage inductance is not in parallel with the turn to turn capacitances but in series. This smaller inductance then 
resonates at higher frequencies with the turn to turn capacitance in series. A possible equivalent circuit structure and a graphical representation of the impedances is presented in Figure 39. This more advanced model allows a better control on the level of differential mode current at higher frequencies.
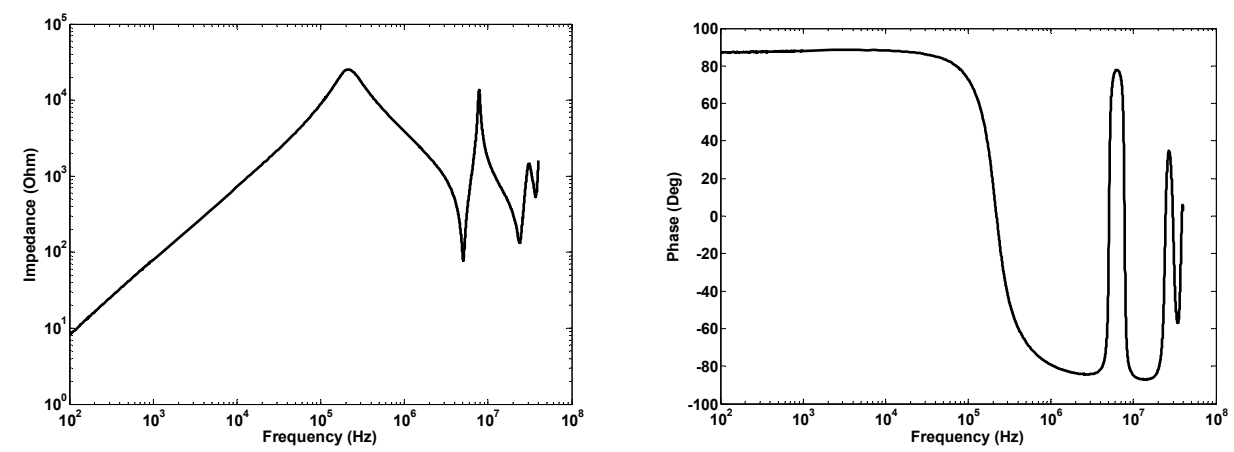

Figure 30: Phase impedance (magnitude and phase).
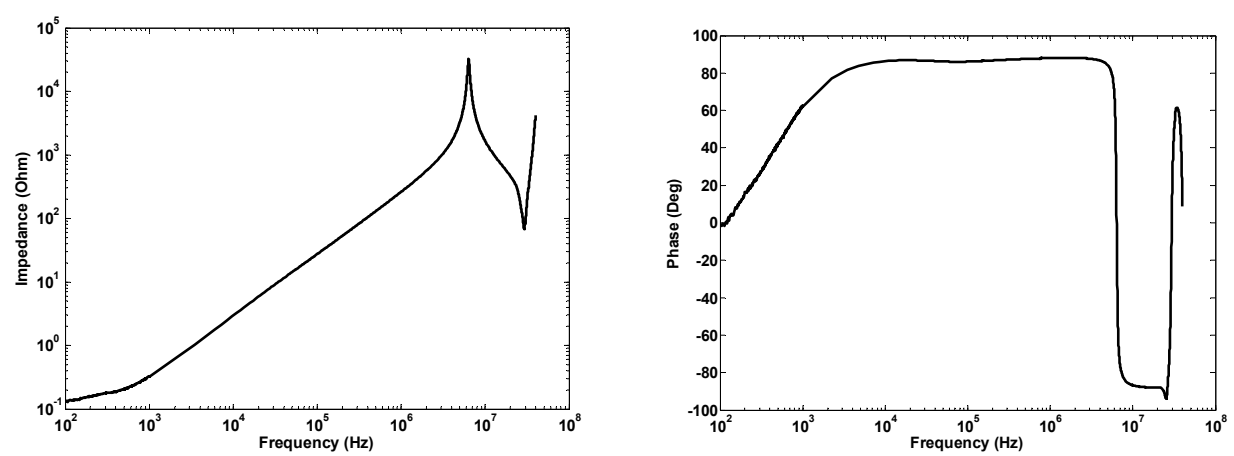

Figure 31: Differential mode impedance (magnitude and phase).
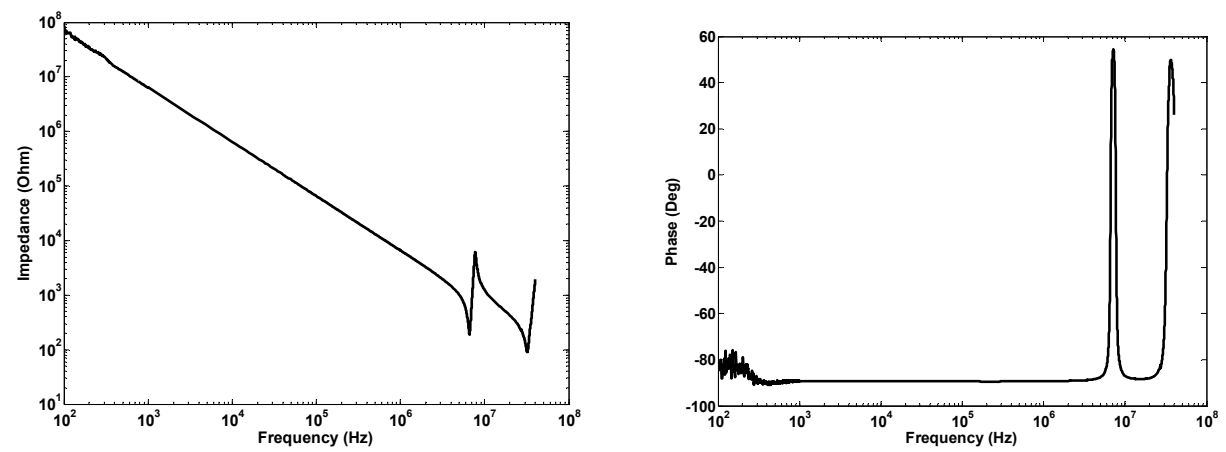

Figure 32: Winding to winding capacitance (magnitude and phase). 

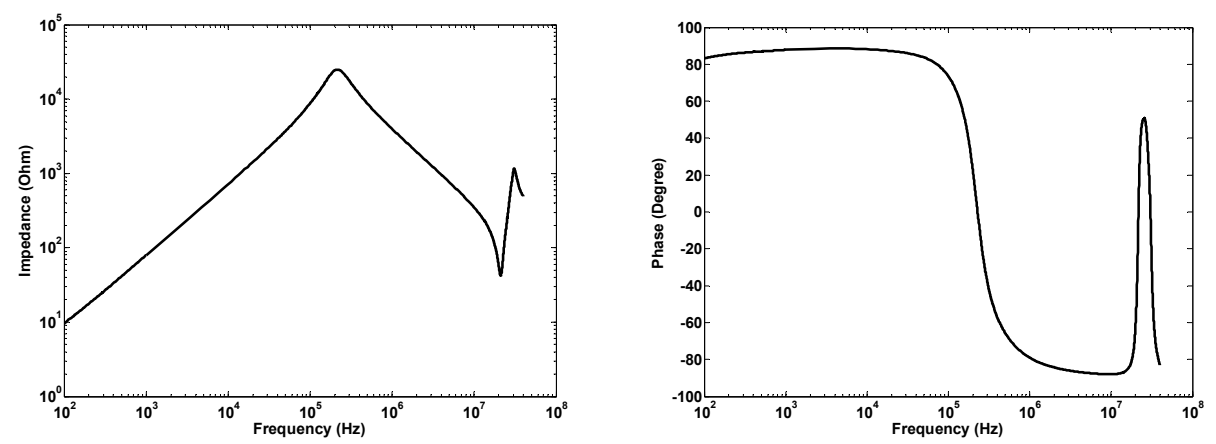

Figure 33: Common mode impedance (magnitude and phase).

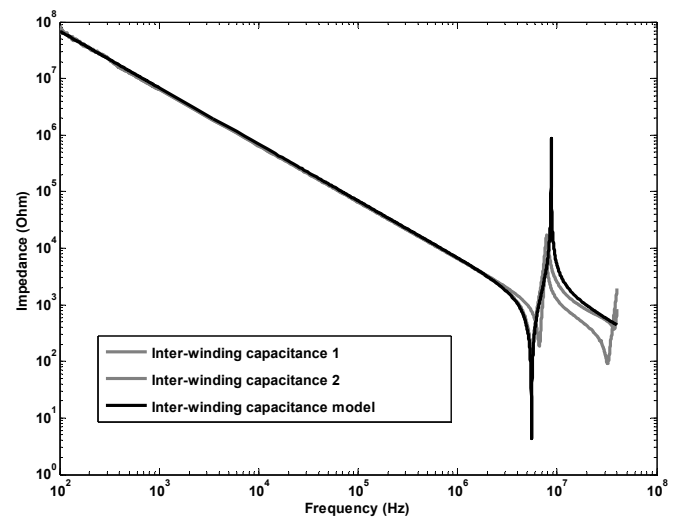

Figure 34 : Modelled impedances (Extracted values) - Winding to winding capacitance.

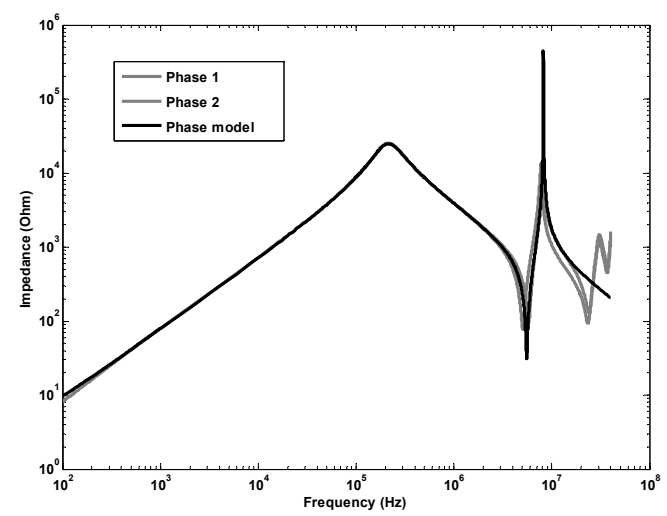

Figure 35 : Modelled impedances (Extracted values) - Phase Impedance. 


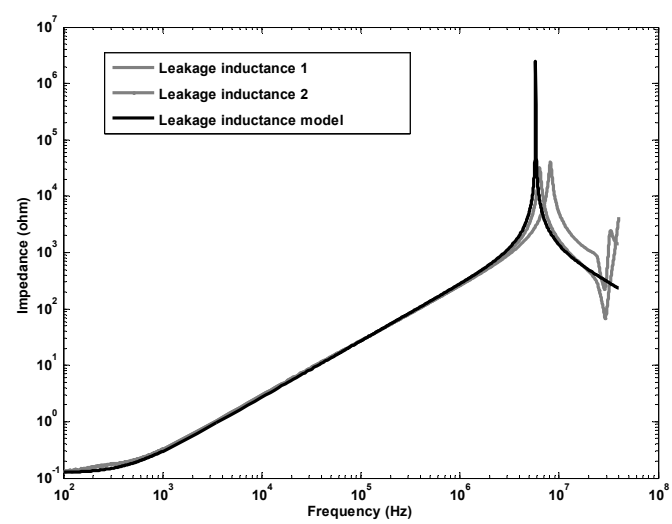

Figure 36 : Modelled impedances (Extracted values) - Phase Impedance.

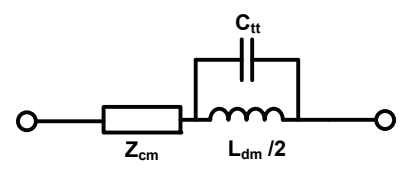

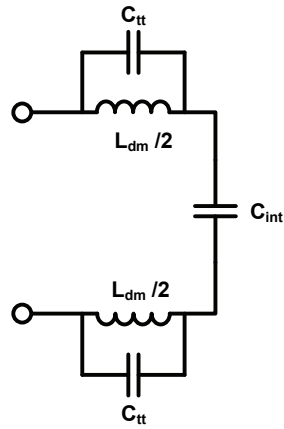

Inter-winding capacitance

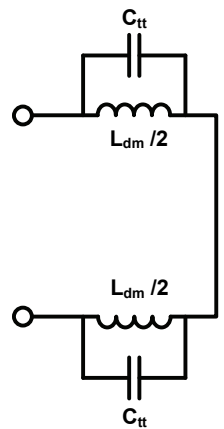

Leakage inductance

Phase impedance

Figure 37 : Equivalent circuits of the measured impedances.
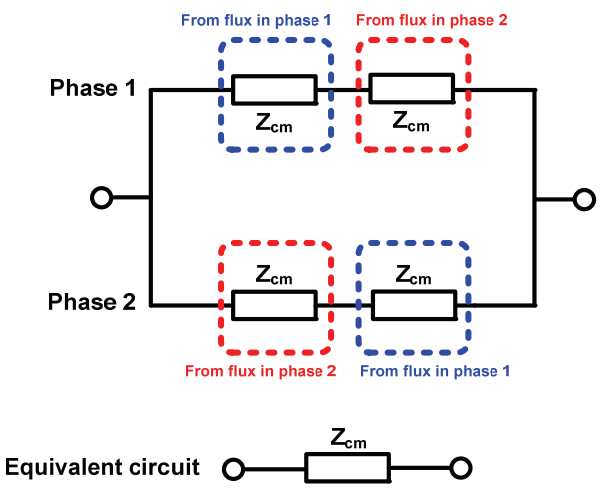

Figure 38 : Equivalent common mode circuit of the choke. 


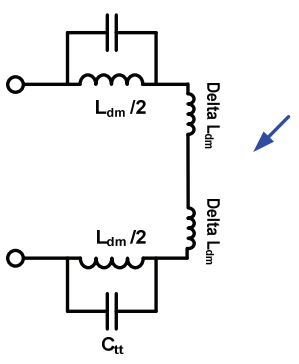

Leakage inductance

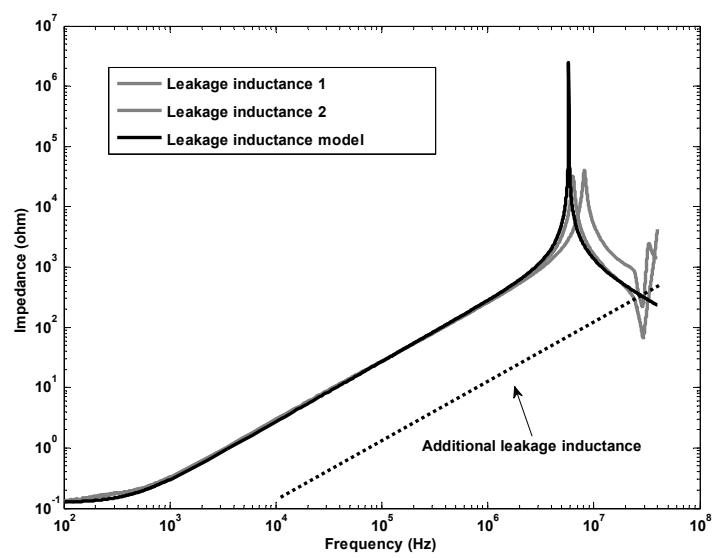

Figure 39: Possible equivalent circuit structure and a graphical representation of the leakage inductance at high frequencies.

\subsection{Towards a new behavioural model for the common mode choke}

\section{7.a. A behavioural model of the common mode choke}

The equivalent circuit presented in this chapter is a new structure which can be completely modelled from its the designable parameters and presents a clear decoupling between the CM and DM contribution. This decoupling is used in Chapter 5 in the modelling of the EMI filter as a whole.

\section{7.b. Limitations}

The essential mechanisms of the common mode choke are described. The secondary high frequency couplings are however not included in the equivalent circuit but addressed in section 3.6.d. It is a limitation of the upper limit of the frequency range of validity. Impedance measurements above $40 \mathrm{MHz}$ can be used to complete the model. The proper modelling of the common mode impedance is related to the knowledge of the complex permeability values over the frequency range. If these values are not always provided by the manufacturer, they can be measured and averaged out using different sampled chokes of the same dimension and different numbers of turns. Another way is to measure and record the common mode impedance value of commercial chokes to use it directly in the model. The common mode impedance is modelled in this thesis for a use away from the saturation 
condition. Close to the saturation the $B H$ loop flattened and the value of the permeability reduces. The overall common mode impedance is lower. The use of a choke close to its saturation condition is not recommended since it can create serious thermal issues.

\subsection{Summary}

The analysis of the two constitutive components of the EMI filter has been addressed: the common mode choke and the capacitor to ground.

The common mode choke is the most complex component of the filter. Materials typically used are iron, ferrites and nanocrystalline. The properties of each material have been described and compared with each other in the third section of this chapter.

The complex permeability of the material is used to model the common mode impedance, which is one of the five impedances used to fully characterize the common mode choke up to $40 \mathrm{MHz}$, along with two kinds of parasitic capacitances and the leakage inductance. Each impedances involved in the characterization of the choke is modelled and linked to the relevant designable parameters.

The resulting equivalent circuit is a new structure highlighting a decoupling of the impedances acting on the common mode current from the one acting on the differential current. This structure is a cornerstone in the development of the common mode choke behavioural model introduced in the next chapter. 


\section{Chapter 4. Behavioural model for common mode chokes}

A new equivalent electrical circuit of the common mode choke has been introduced in the previous chapter. This chapter aims at the integration of this equivalent circuit into a behavioural model. It relates the designable parameters to the in-situ performances of the component: the parameters listed in the previous chapter are related to the modification of the level of both common mode and differential mode currents after a potential insertion of the choke in the motor drive. It is the first time a behavioural model of the common mode is proposed.

Criteria of the behavioural model are first defined. Two important outputs of the model are the modification factors of the common mode current and the differential mode current. They are defined in the second section and measured in the third to validate the model. An in-depth investigation of these two modification factors is performed in the last section with sensitivity and deviation studies.

\subsection{Criteria of a behavioural model of a common mode choke}

\section{1.a. Major criteria for behavioural modelling of common mode chokes}

Major criteria for behavioural modelling of common mode chokes are: 
- The noise spectrum of EMI in frequency convertors (FCs) is usually spread from around $10 \mathrm{kHz}$ to several tens of $\mathrm{MHz}$. The frequency dependence of parameters of the choke has to be taken into account to provide an accurate model even at higher frequencies.

- The model is predictive: it is assumed that designers do not have access to a prototype and to experimental values. Any cut and try processes should be prevented.

- The usage of models as scaled circuit is not possible. Tuned or custom made equivalent circuits for each $\mathrm{CMC}$ to be tested is costly in term of time and requires the construction of many prototypes.

- The predictive model will be a black box for designers. It only requires several parameters as inputs: the designable parameters or, in other words the detailed description of CMC to be tested, as well as some circuit parameters such as currents or CM impedances of the circuit. Outputs provided are new levels of currents after the insertion in the motor drive as well as deviation and sensitivity studies. They aims at optimizing the design of the CMC.

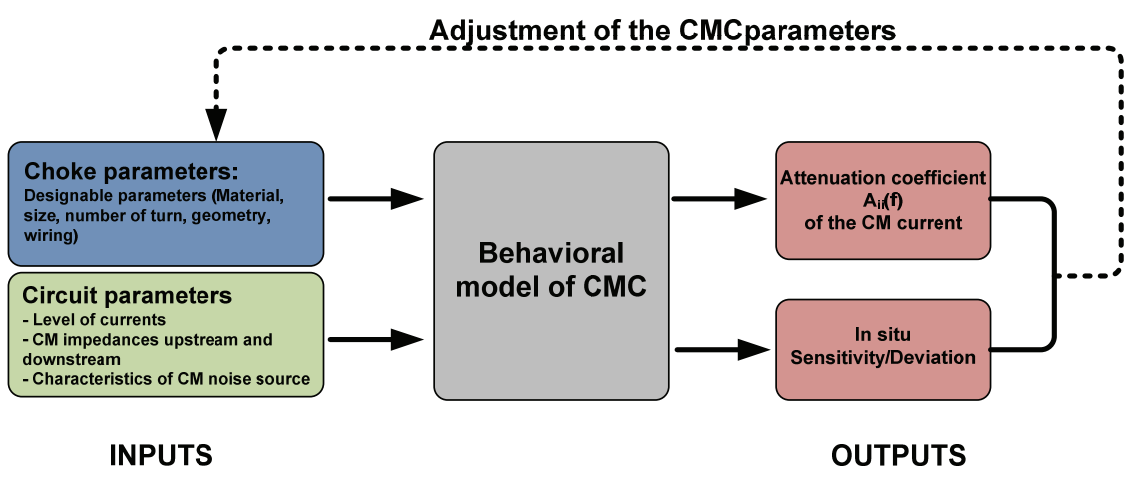

Figure 40: Topology of the behavioural model for CMC.

Figure 40 presents the topology of the model to be developed:

- The inputs on the one hand are the choke designable parameters ( material, size of the choke and number of turns), and on the other hand the circuit parameters (level of currents, $\mathrm{CM}$ impedance upstream of the converter and characteristics of the CM noise source) 
- The first output is the modification factor which express the current flowing in the circuit after the insertion of the $\mathrm{CMC}$ with respect to the one flowing before its insertion. The second outputs are the deviation and sensitivity studies of the modification factor.

- Both output families can be used to adjust back the choke parameters and improve the in-situ performance of the choke.

\section{1.b. General way of working of the behavioural model}

An overview of the topology of the model under consideration is presented in Figure 40. This topology is based on a translation of the common choke into its in situ performances. The electrical equivalent circuit used has been detailed in the previous chapter. It includes the following impedances: common mode impedance, differential mode impedance and parasitic capacitances (turn to turn and windings to windings). The designer has to provide values of currents, measured or simulated, flowing at the output of the converter where the CMC is to be inserted. The modification factors are calculated in the frequency domain.

\section{1.c. Test set-up specifics}

The common mode filter is placed as close as possible to the output of the converter. In this condition the characterization of the environment of the choke includes two impedances for a grounded system with two phases: the input asymmetric impedance of the cable and its load (upstream common mode impedance), and the input impedance of the converter, measured at the output of the inverter (downstream common mode impedance). This in situ characterization of the performances of the common mode choke allows all properties of the motor drive upstream of the converter to be included.

The common mode choke is considered isolated from the ground in this chapter in order to highlight only the link between the choke, its performances and its designable parameters. This means that the capacitance to ground of the common choke itself is neglected. In the measurements performed in this chapter the components is specially separated from the ground with the use of a $3 \mathrm{~cm}$ thick dielectric. The parasitic capacitance between the choke and the outside world will be introduced in the next chapter while the overall filter is characterised. 


\subsection{Modification factors calculations}

\section{2.a. Electrical equivalent common mode circuit of the motor drive}

Two electrical circuits are used to characterize the modification of the common mode current. Figure 41 presents the common mode equivalent circuit of the motor drive and its environment, before and after the insertion of the choke. In these circuits, $Z_{A}$ refers to the asymmetrical input impedance of the cable and its motor. This impedance fully characterizes the circuit upstream of the simulated common mode choke and therefore take into account all impedances acting on the common mode currents.

CM equivalent circuit before and after insertion of the choke
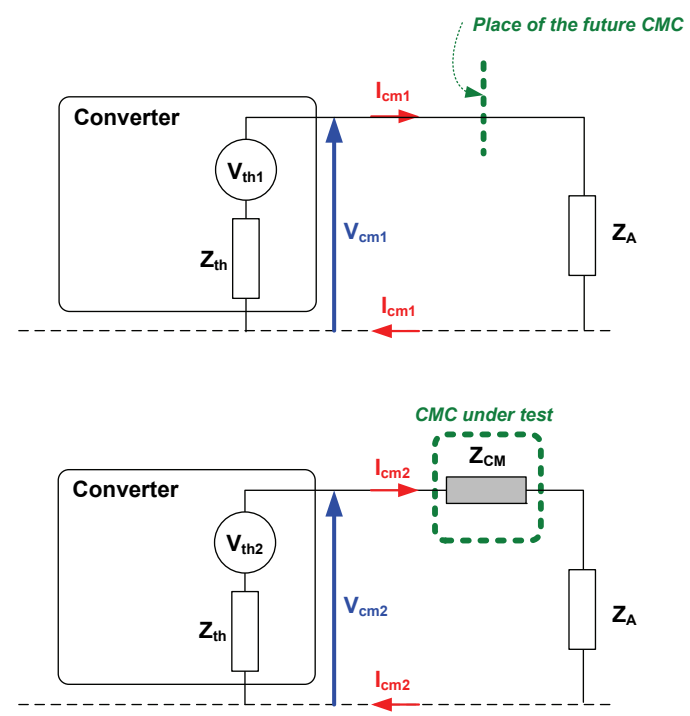

Figure 41: Common mode equivalent circuit before and after insertion of the choke. 


\section{2.b. Discussion on the stability of the noise voltage}

It is assumed that the common mode output noise voltages $V_{C M 1}$ and $V_{C M 2}$ remains nearly identical after the introduction of the choke in the circuit. This is not completely true but the changes between the two voltages are neglected in this section in order to focus on the effect of the designable parameters of the common mode choke on its performance in the circuit. This assumption is investigated and validated in the coming chapter. The variation of voltages can be inserted in the model: the expression of the modification factor when the noise voltage varies is also fully described in the next chapter.

\section{2.c. Expression of the modification factor for the common mode current}

In the setup described in Figure 41, the common mode currents in both circuits can be expressed as followed:

$$
\left\{\begin{array}{c}
V_{C M 1}=I_{C M 1} * Z_{A} \\
V_{C M 2}=I_{C M 2} *\left(Z_{A}+Z_{C M}\right)
\end{array}\right.
$$

The common mode current Modification factor $\operatorname{Mod}_{C M}$ is:

$$
\left\{\begin{array}{l}
I_{C M 2}=\operatorname{Mod}_{C M} * I_{C M 1} \\
\operatorname{Mod}_{C M} \approx \frac{Z_{A}}{\left(Z_{A}+Z_{C M}\right)}
\end{array}\right.
$$

The modification factor is equal to 1 when the current is not modified, is $>1$ when the current is amplified and $<1$ when the current is attenuated. The Table 6 relates the value of the linear modification factor to the one in $\mathrm{dB}$.

\subsection{Modification factors evaluation}

Figure 42 shows the overall structure of the model used to calculate the modification factors presented in this chapter. Two kinds of inputs are possible: measured impedances and/or designable parameters values. All impedances considered are complex numbers: arguments as well as phases have been included. 
Table 6: Modification factor: linear and dB.

\begin{tabular}{|l|l|}
\hline $\begin{array}{l}\text { Modification factor } \\
(\text { linear })\end{array}$ & $\begin{array}{l}\text { Modification factor } \\
(\mathrm{dB})\end{array}$ \\
\hline $10^{2}$ & 40 \\
\hline 15 & 24 \\
\hline 10 & 20 \\
\hline 5 & 14 \\
\hline 1 & 0 \\
\hline 0.5 & -6 \\
\hline $10^{-1}$ & -20 \\
\hline $10^{-2}$ & -40 \\
\hline $10^{-3}$ & -60 \\
\hline $10^{-4}$ & -80 \\
\hline
\end{tabular}

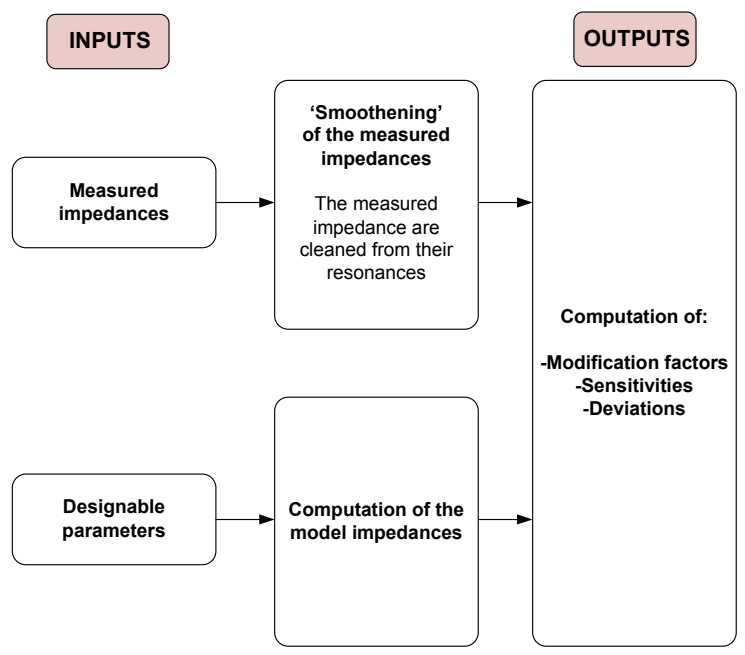

Figure 42: Overview of the model to calculate of the modification factors.

\section{3.a. Measured impedances as inputs of the model}

The measured impedances of the common mode choke and the circuit have been used in this chapter (as well as in the next chapter) as input of the model.

The purpose is not to show that each impedance can be modelled: this has been proven in the literature and in the last chapter for the common mode impedance. 
The purpose is to validate the behavioural model that links these impedances to the in-situ performance.

\section{3.b. Common mode chokes used in this thesis}

In this chapter as well as in the coming chapter (Chapter 5) several common mode chokes are used. They are listed and described in Table 7.

Table 7: Chokes used for measurements.

\begin{tabular}{|c|c|c|c|}
\hline Name & Material & Size $(\mathrm{mm})$ & Number of turns \\
\hline Choke 1 & \multirow{6}{*}{ Ferrite $\mathrm{MnZn}$} & \multirow{4}{*}{$25^{*} 15^{*} 5$} & 15 \\
\hline Choke 2 & & & 18 \\
\hline Choke 3 & & & 44 \\
\hline Choke 4 & & & 30 \\
\hline Choke 5 - XL & & \multirow{2}{*}{$35^{*} 15^{* 7}$} & 7 \\
\hline Choke 6-XL & & & 15 \\
\hline Nano 1 & \multirow{5}{*}{ Nanocrystalline } & \multirow{3}{*}{$32 * 12 * 7$} & 7 \\
\hline Nano 2 & & & 10 \\
\hline Nano 3 & & & 15 \\
\hline Nano 4 - XL & & \multirow{2}{*}{$100 * 22 * 11$} & 15 \\
\hline Nano 5 - XL & & & 15 \\
\hline
\end{tabular}

\section{3.c. Common mode modification factor}

Figure 43 presents the impedances of the chokes used for common mode current modification computation: the common mode impedance and the impedance to ground at the future position of the choke. The common mode chokes 1 and 4 are considered (graph (a) and (b) respectively). These two impedances have been chosen because their modification factor is expected to be distinctly different higher frequencies. The common mode impedances are the one measured in the last chapter with the Impedance Analyser HP4194A (details are given in Section 3.6.c). The impedance to ground $Z_{A}$ have been modelled as ideal capacitance. For both impedance, the absolute value have been represented. Figure 44 presents the expected common mode attenuations with variable impedance to ground. Four values of capacitance are considered between $500 \mathrm{pF}$ and $2 \mathrm{nF}$ for the input common mode impedance of the cable and its load. These modification factor are calculated according to the definition given in 4.2.c, with the measured common mode impedance $\left(Z_{C M}\right)$, and the modelled capacitance to ground $\left(Z_{A}\right)$ of the Figure 43 . These modelled capacitance to ground $\left(Z_{A}\right)$ are only used to highlighted the 
contribution of both impedances $Z_{A}$ and $Z_{C M}$ in the corresponding modification factor.

These attenuations are mainly driven by the resonances of the impedances to ground with the common mode impedance. The resonant frequency can be graphically evaluated at the intersection of the absolute value of the concerned impedances in Figure 43. For increasing frequencies, the first resonance happens between the common mode impedance and the impedance to ground and marks the beginning of the attenuation as well a substantial increase of common mode current. This increase can be a design issue for the designer. The study of the sensitivity and the deviation of the design can be used to design the choke accordingly. The importance of the increase of common mode current at the resonance is strongly related to the shape of the common mode impedance: a higher derivative coefficient of the impedance around the intersection point will result in a higher increase of common mode current.

The maximum attenuation is not necessarily reached at the maximum of common mode impedance. The shape of the attenuation at high frequencies is related to the difference of absolute value of impedance between the common mode impedance and the capacitance to ground. For the common mode choke 1, this difference of impedance and the attenuation remains constant after the maximum attenuation is reached. This point is reached at the maximum of common mode impedance. For the common mode choke 4 however the difference of impedance between the common mode impedance and the capacitance to ground increases after the initial resonance, the modification factor increases as well.

\section{3.d. Saturation level}

To predict the performance of common mode chokes accurately, a saturation model applicable under both steady state and transient magnetic excitation would be necessary. It is however possible in first approximation to consider that the initial permeability remains same, as described in the previous chapter (Section 3.3.c). It is especially true away from the saturation condition where the permeability decreases. The saturation level is usually provided by manufacturer. This depends on the material, the size of the core and the number of turns. 


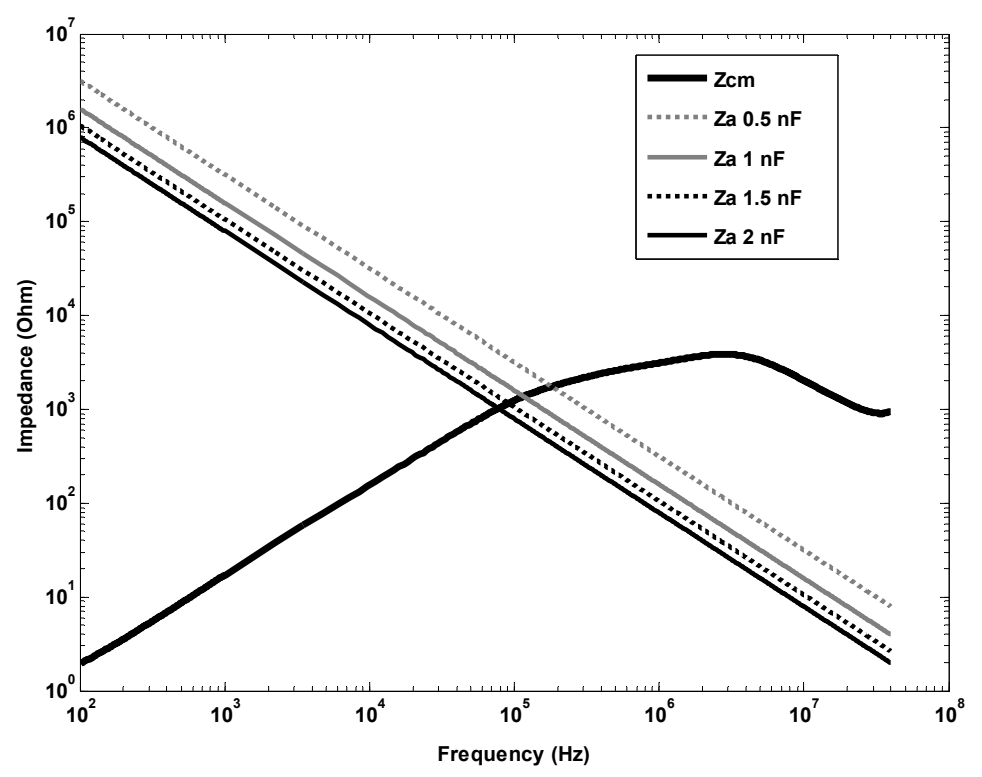

(a) Choke 1.

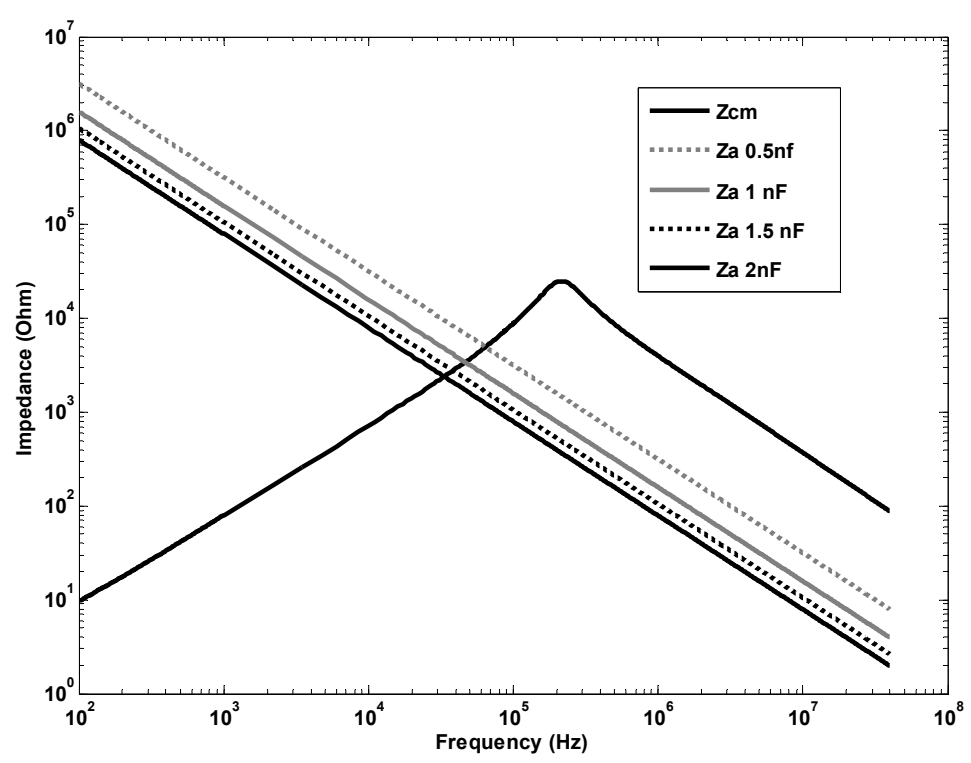

(b) Choke4.

Figure 43: Common mode impedances and variable capacitances to ground of chokes (absolute values) versus Frequency. 


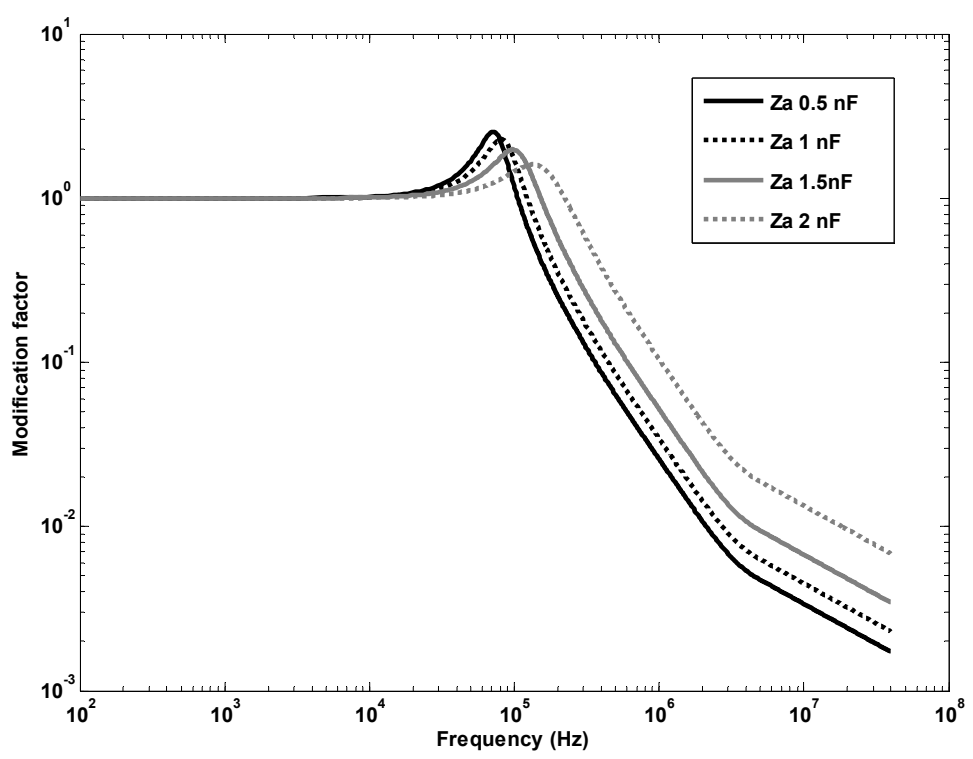

(a) Choke 1 .

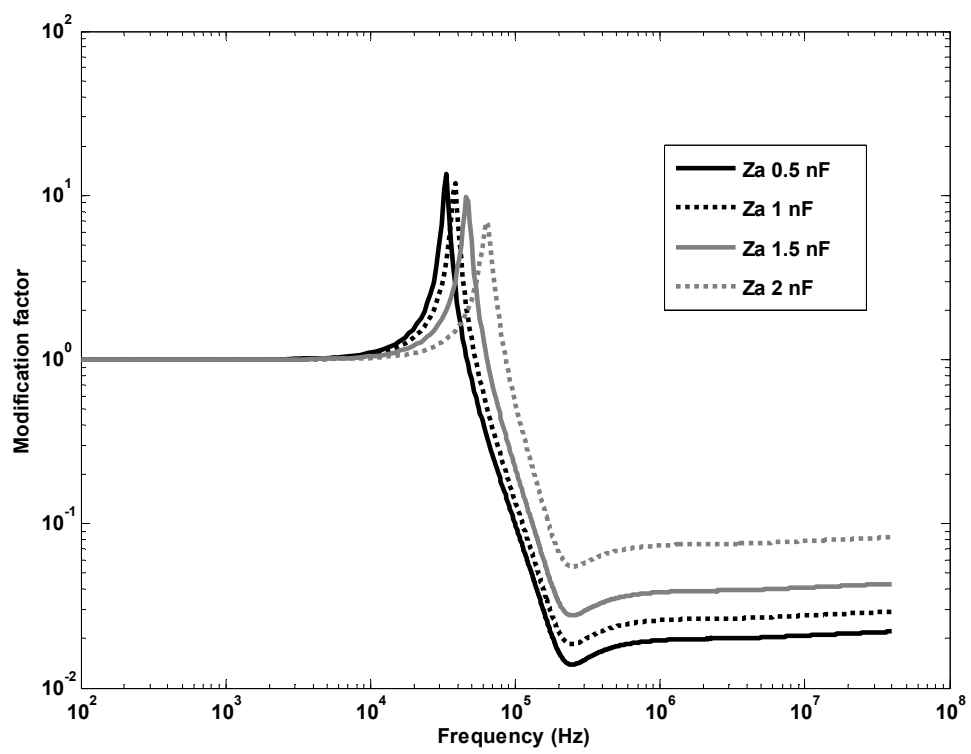

(b) Choke4.

Figure 44 : Common mode modification factors with variable capacitances to ground. 


\subsection{Measurements and validation}

Two kinds of measurements are performed to validate the behavioural model presented in this chapter: impedance measurements and current measurements.

The EMI self learning kit is described in [51] (and also detailed in Appendix 1) is used as test set-up. The chokes used for measurements are detailed in the Table 7, in the Section 4.3.

\section{4.a. Impedance measurements}

Two common mode impedances are measured:

- The input common mode impedance of the load and its cable at the future position of the choke.

- The same impedance with the choke under test.

The common mode modification is obtained by dividing the input common mode impedance (a) by the one including the choke under test (b).

\section{4.b. Measurement results and model validation via impedance measurements}

By measuring the input common mode impedance with and without choke, all the parasitic parameters to ground of the cable can be determined. The measurement of the performance of the choke is this way independent of the common mode current path upstream the converter.

Figure 45 presents the measurement set-up used to measure the common mode input impedance. This impedance is measured using an EMI receiver, its tracking generator and a current probe. The Device under Test (DUT) in this chapter is the choke (kept isolated from the ground), the load and a connecting cable. The DUT is excited by the tracking generator at a constant voltage of $96 \mathrm{~dB} \mu \mathrm{V}(63 \mathrm{mV})$. The current flowing in the circuit is measured by an appropriate current probe. The input voltage and the input current flowing in the DUT are then used to compute the value of the common mode input impedance of the DUT.

For any DUT the excited input is connected to the tracking generator via a metallic structure and a feedthrough connector. It is used to ensure that the ground of the tracking generator/ EMI receiver is as close as possible from the DUT, and thus a return path for possible parasitic currents. 
The input common mode impedance of the load and its cable is measured between $20 \mathrm{kHz}$ and $40 \mathrm{MHz}$. This impedance is showed in Figure 46. It is a capacitance of approximately $20 \mathrm{pF}$.

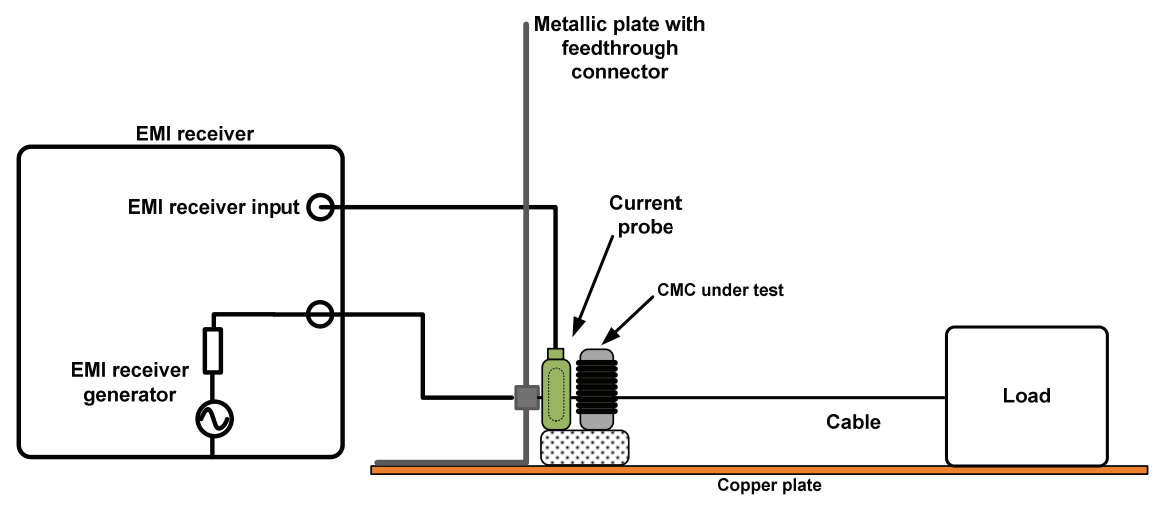

Figure 45: Test set-up for the common mode measurement.

\section{4.c. Validation of the common mode current attenuation}

The validation of the model of common mode current modification is pictured from Figure 47 to Figure 50: the modelled modifications are compared with the measured modifications for the chokes 1, 2, 3 and 4 respectively. The measured attenuations are obtained here via impedance measurements. There is a very good agreement between the modelled and the measured values. The differences in between the two curves of each choke are due to the approximation of the impedance to ground with a capacitance. It is always better for the designer to use the actual impedance to ground in the simulation. 


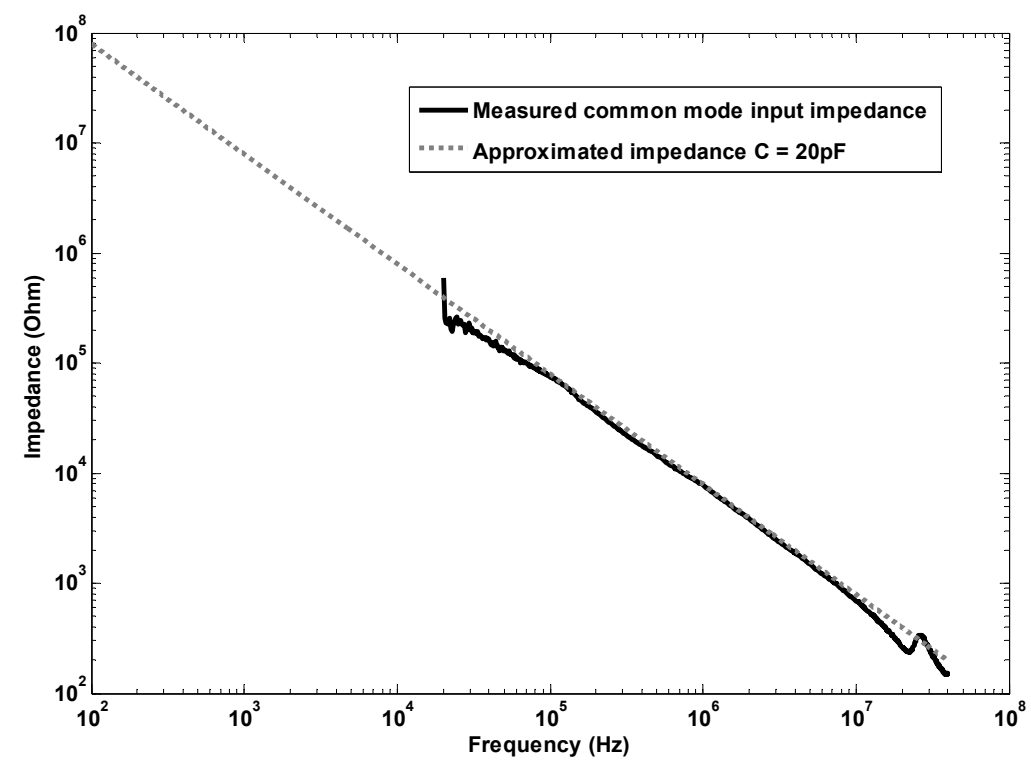

Figure 46: Input common mode impedance of the load and its cable.

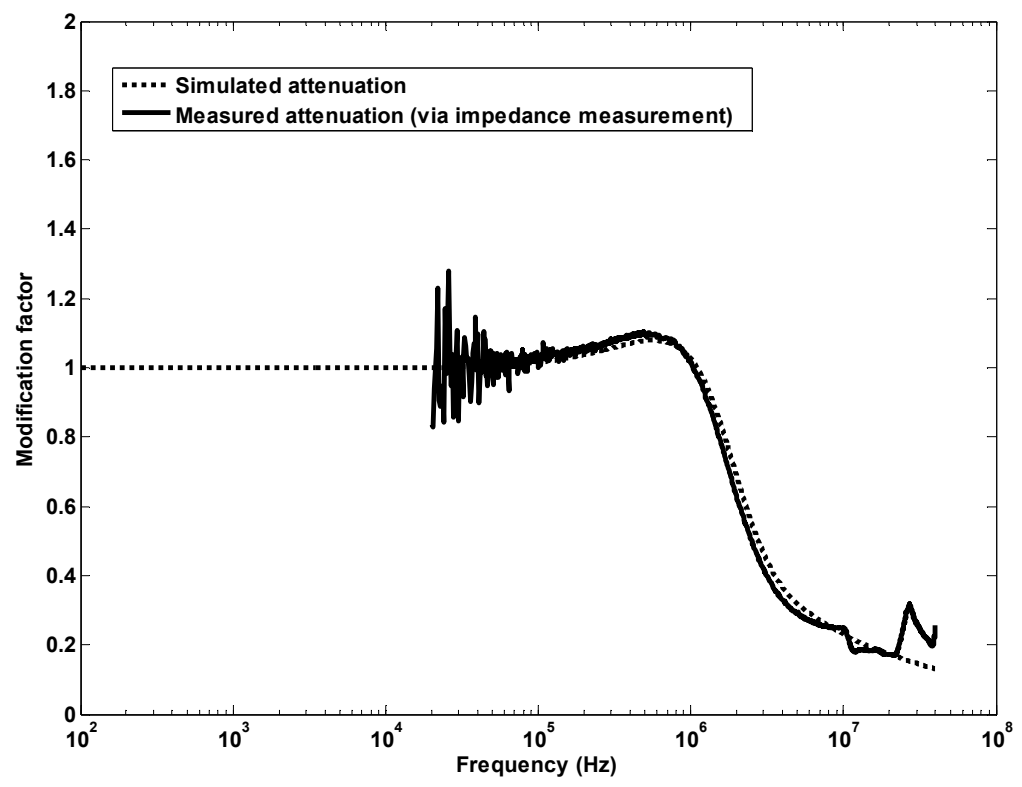

Figure 47: Modification factors: validation of the model via impedance measurements (Choke 1). 


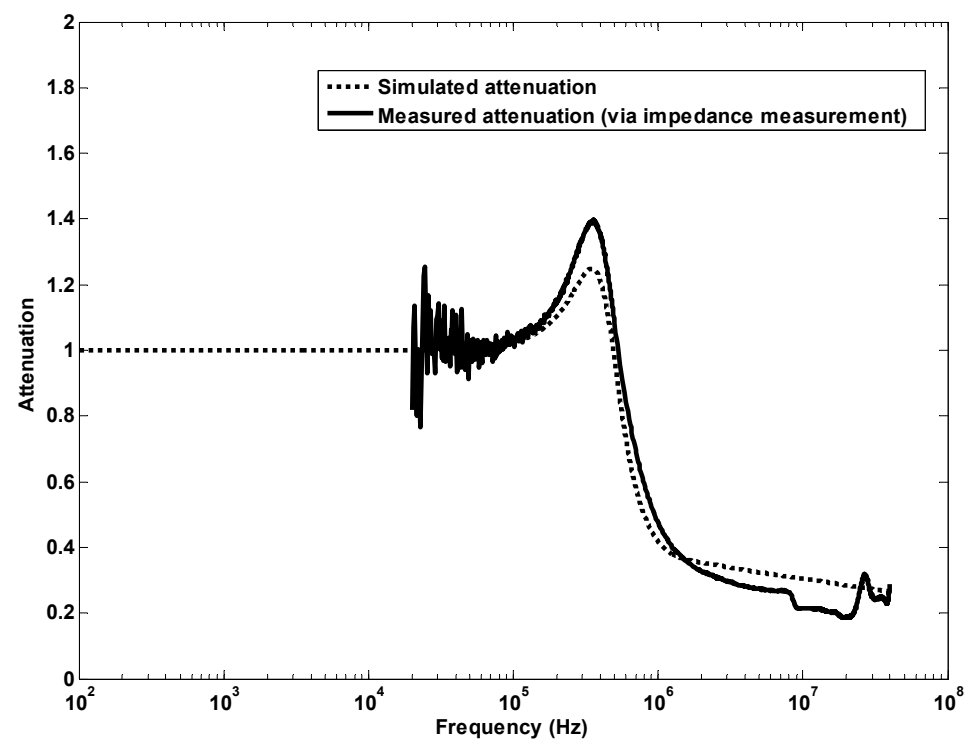

Figure 48: Modification factors: validation of the model via impedance measurements (Choke 2).

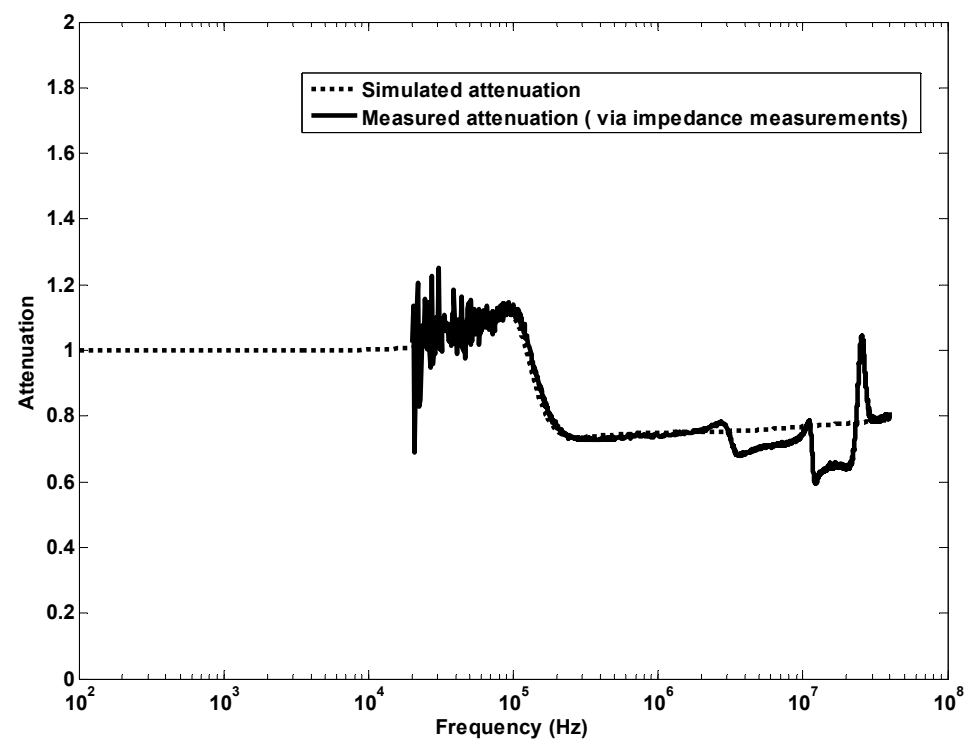

Figure 49: Modification factors: validation of the model via impedance measurements (Choke 3). 


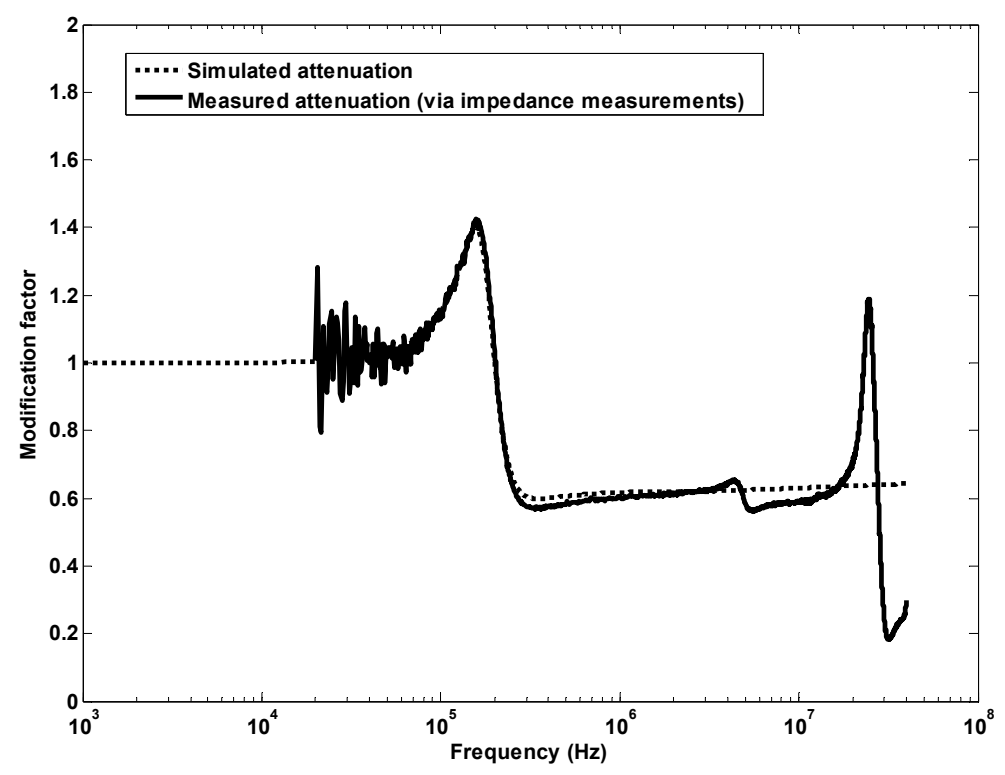

Figure 50: Modification factors: validation of the model via impedance measurements (Choke 4).

\section{4.d. Measurements set-up}

Two common mode currents are measured:

- The input common mode current of the load and its cable at the future place of the choke.

- The common mode current at the same position after insertion of the choke. A current probe together with an EMI receiver are used to measure the current at the output of the converter, with and without CMC. A photo of the test set-up is shown in Figure 51. The specifications of the measurements over the frequency range are given in Table 8. The receiver is set in MAX PEAK configuration. The same AC/DC converter is used in combination with the same load and the same family of chokes used in the impedance measurements of the previous section. In this chapter the choke is kept isolated from the ground with a thick layer of dielectric placed underneath. The position of the load and the cable is maintained and is the same throughout the measurements (the length of the cable is adapted accordingly). The position of the current probe is also the same in all measurements. 
Table 8: EMI receiver specifications for current measurements

\begin{tabular}{|l|l|l|l|}
\hline Frequency range & Step size & IF bandwidth & Measurement time \\
\hline $10 \mathrm{kHz}-20 \mathrm{kHz}$ & $0.1 \mathrm{kHz}$ & $1 \mathrm{kHz}$ & $2 \mathrm{~s}$ \\
\hline $20 \mathrm{kHz}-200 \mathrm{kHz}$ & $1 \mathrm{kHz}$ & $10 \mathrm{kHz}$ & $2 \mathrm{~s}$ \\
\hline $200 \mathrm{kHz}-1 \mathrm{MHz}$ & $5 \mathrm{kHz}$ & $100 \mathrm{kHz}$ & $2 \mathrm{~s}$ \\
\hline $1 \mathrm{MHz}-10 \mathrm{MHz}$ & $20 \mathrm{kHz}$ & $100 \mathrm{kHz}$ & $2 \mathrm{~s}$ \\
\hline $10 \mathrm{MHz}-30 \mathrm{MHz}$ & $80 \mathrm{kHz}$ & $100 \mathrm{kHz}$ & $2 \mathrm{~s}$ \\
\hline
\end{tabular}

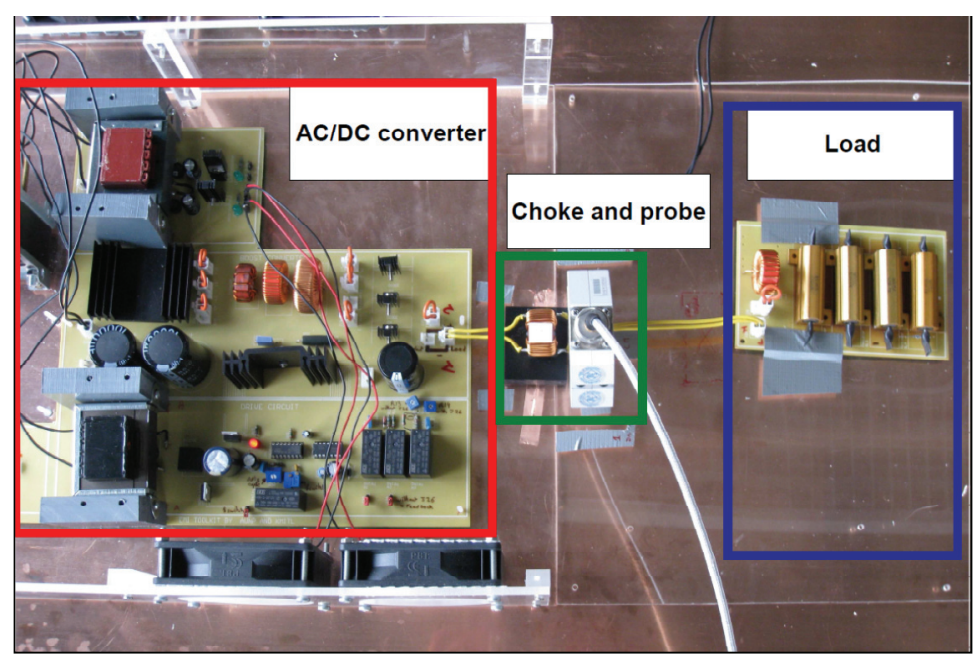

Figure 51: Test set-up used for current measurement [51].

\section{4.e. Validation}

Figure 52 presents an overview of the common mode current at the output of the $\mathrm{AC} / \mathrm{DC}$ converter. The common mode current measured without choke is compared with the one measured with the common mode choke 2 (CMC 2 - 18 turns) and common mode choke 3 (CMC 3 - 44 turns). The frequency A (120kHz) delimits the frequency at which the CMC 3 starts to attenuate the common mode current. Just before this frequency the resonance can be observed with an increase and a superposition of the current at one the main peak of common mode current which is the switching frequency of the converter $(700 \mathrm{kHz})$. In this design the higher number of turns of the CMC 3 is not relevant: the resonance is badly placed in low frequency and the current attenuation in the higher frequency is poor $(5 \mathrm{~dB}$ less above $800 \mathrm{kHz}$ ). The frequency B is related to the performances of the CMC 2. It shows a good attenuation above $500 \mathrm{kHz}$ (15 to $20 \mathrm{~dB})$ but the peak of current related to the resonances is spread from $200 \mathrm{kHz}$ to $500 \mathrm{kHz}$. 
The design of the common mode choke is a trade-off between the frequency at which the additional current due to the resonance with the impedance to ground is to be expected, and the level of attenuation expected.

The validation of the model of common mode current attenuation is demonstrated from Figure 53 to Figure 56: the modelled attenuations are compared with the measured attenuations, for the same 4 chokes tested in the previous section (impedance measurements). There is a good agreement between the modelled and the measured values.

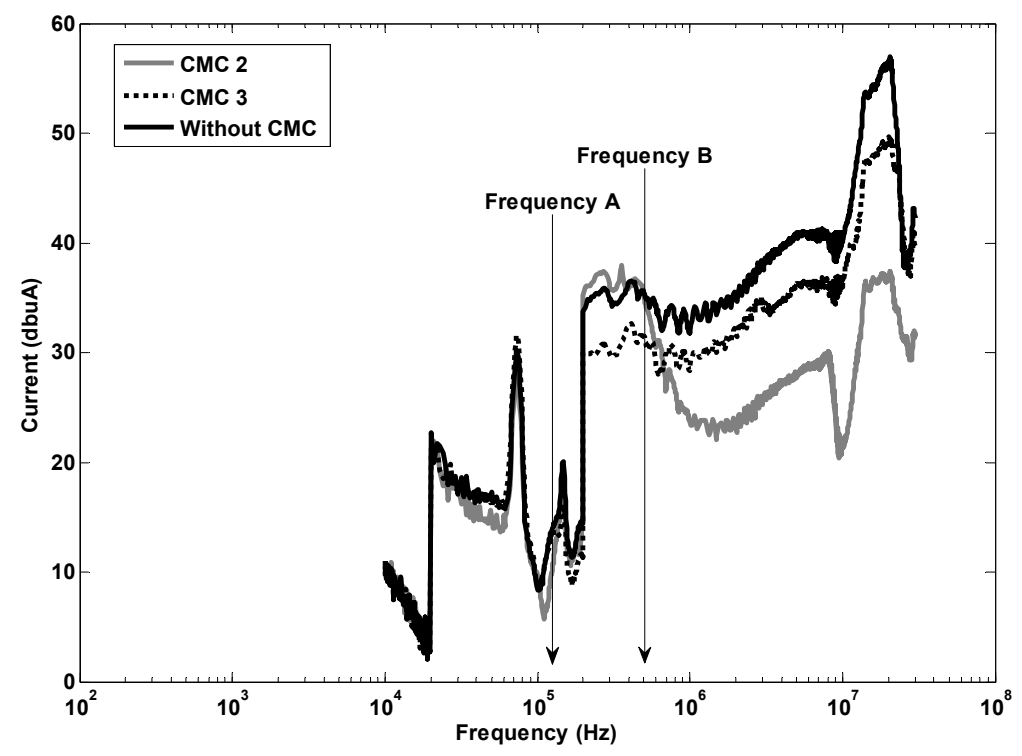

Figure 52: Common mode currents with and without choke. 


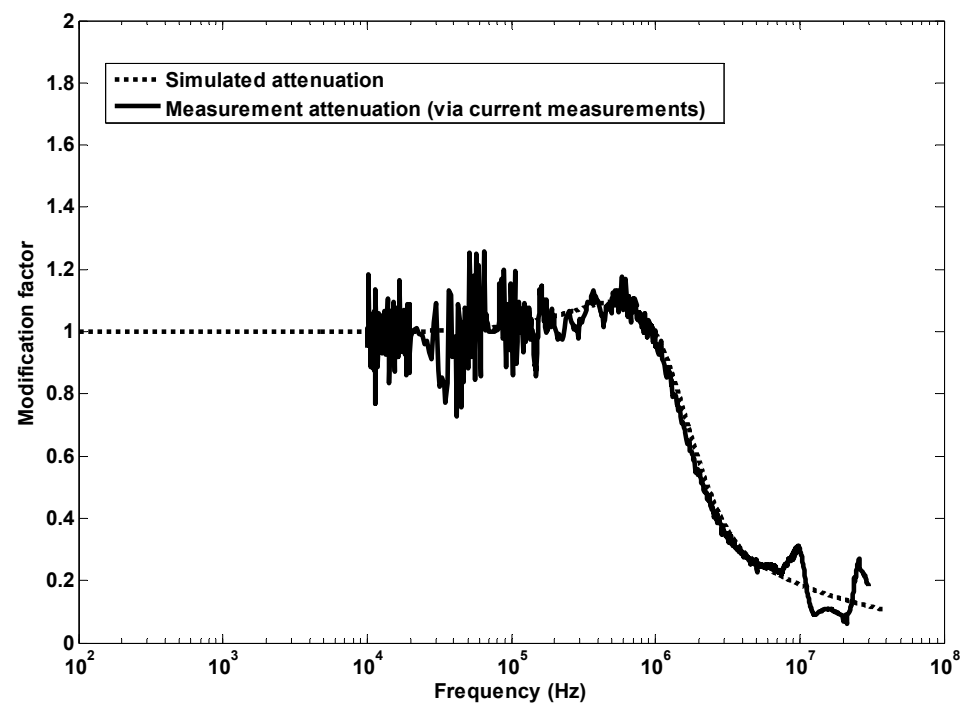

Figure 53: Modification factors: validation of the model via current measurements (Choke 1).

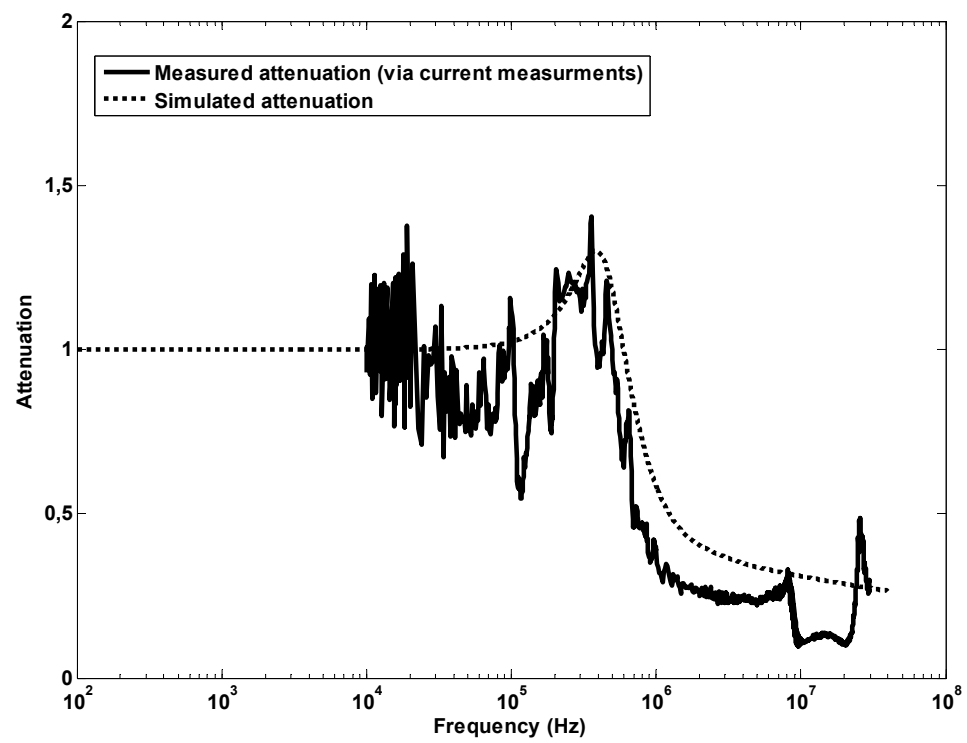

Figure 54: Modification factors: validation of the model via current measurements (Choke 2). 


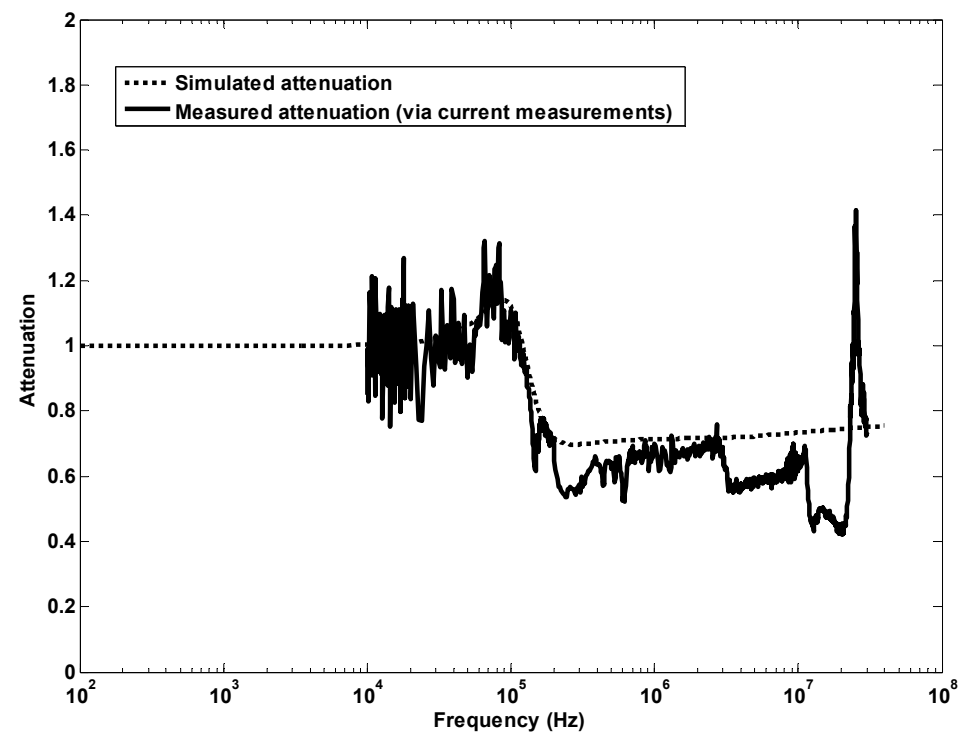

Figure 55: Modification factors: validation of the model via current measurements (Choke 3).

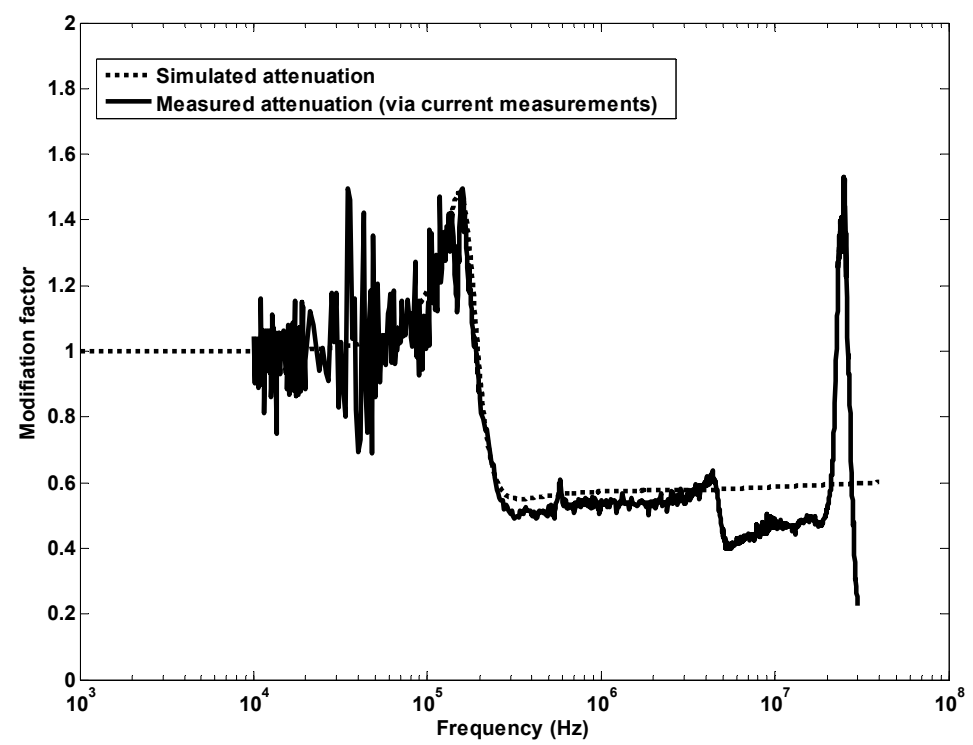

Figure 56: Modification factors: validation of the model via current measurements (Choke 4). 


\subsection{Sensitivity, deviation and designable parameters}

\section{5.a. Sensitivity}

Sensitivity studies provide additional insight into the behaviour of the choke by understanding of how variations of parameters, for instance values of elements, influence the performance [54], [55]. These studies are needed to take design variations into account.

Sensitivity studies can be performed at two levels. The local approach is based on a first order approximation and is not suitable for large variations. The local approach for instance is mainly used to evaluate the effect of the error related to modelling or measurements of impedance. The normalized simplest sensitivity is used; it is the derivative function $F$ with respect to any parameter $b$ :

$$
S_{h}^{f}=\frac{\partial \ln F}{\partial \ln h}=\frac{h}{F} \frac{\partial F}{\partial h}
$$

When a large change occurs in the system, large change sensitivity can be considered. This study is especially relevant when the designer wants to try designs drastically different from each other (change of material, size of choke or number of turns). The large change sensitivity is based on a modification of the original system (the modification factors) by a low rank matrix. Assuming that $m$ elements are subject to change, an $(m+1)^{*}(m+1)$ matrix, by means of which all the information can be obtained, is formed [55].

\section{5.b. Local sensitivity and the common mode current attenuation}

The common mode current attenuation is related to the common mode impedance and the impedance to the ground. The local sensitivity of the common mode impedance $S_{Z C M}$ and the local sensitivity of the impedance to ground $S_{Z A}$ are expressed as:

$$
\begin{gathered}
S_{Z A}=\frac{Z_{A}}{\operatorname{Mod}_{C M}} * \frac{\partial \operatorname{Mod}_{C M}}{\partial Z_{A}}=\frac{Z_{C M}}{Z_{C M}+Z_{A}} \\
S_{Z C M}=\frac{Z_{C M}}{\operatorname{Mod}_{C M}} * \frac{\partial \operatorname{Mod}_{C M}}{\partial Z_{C M}}=-\frac{Z_{C M}}{Z_{C M}+Z_{A}}
\end{gathered}
$$

Figure 57 presents the curves of local sensitivity of the common mode impedance and the impedance to ground for the common choke 1 and 4 presented in the previous section of this chapter. 
The common mode modification factor, with a impedance to ground chosen between $0.5 \mathrm{nF}$ and $2 \mathrm{nF}$, presents a peak of sensitivity at the resonance between 20 $\mathrm{kHz}$ and $200 \mathrm{kHz}$. A slight modification of the value of the common mode impedance and/or the impedance to ground will have as predominant effect to shift the resonance frequency of the attenuation and to change its amplitude. The amplitude can be multiplied up to 10 times (20dB) at the resonant frequency. After this resonance frequency, any change of value in any of the two concerned impedances will lead to a proportional change in its attenuation. For frequencies smaller than the resonance frequency, the sensitivity values are too low to change the attenuation significantly. For the higher frequencies any small modifications in the design leads to changes: the current is modified by the same amount of change introduced: the sensitivity in this area is stable and equals 1 . This graph gives insight to engineers into the stability of the design of a particular choke around the frequency of resonance. It can be critical if this resonance is close to a peak of common mode current existing in the initial set-up without choke.

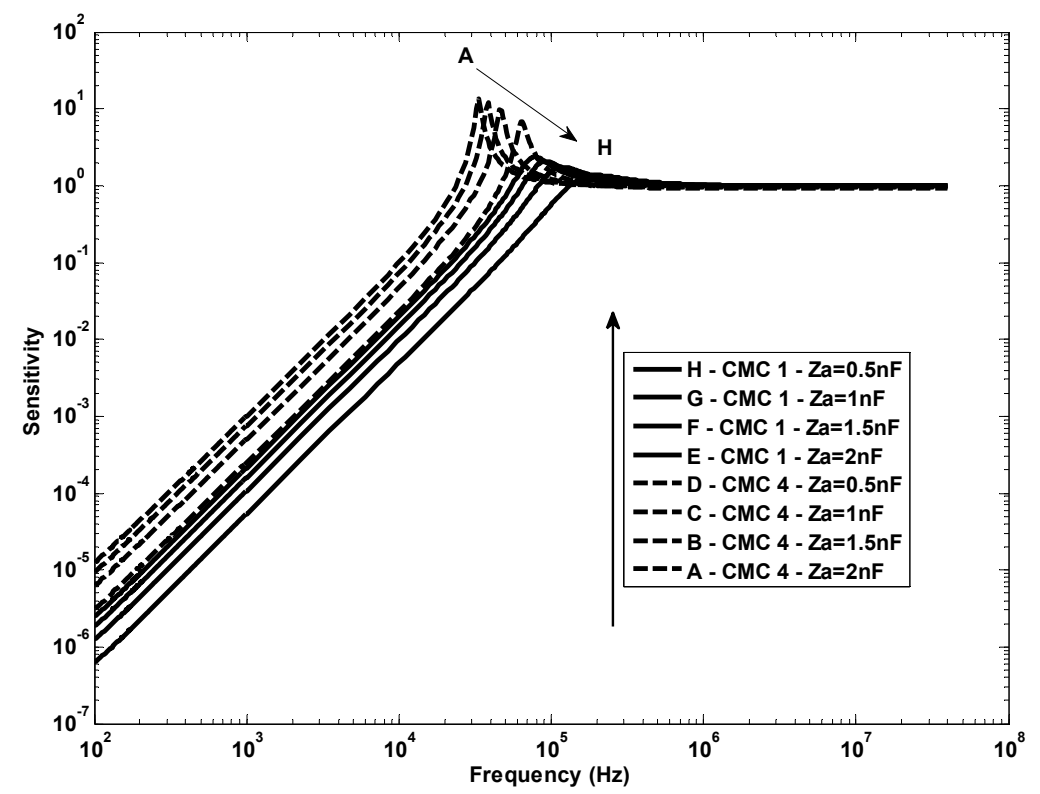

Figure 57: Local sensitivity of the impedance related to the common mode current attenuation. 


\section{5.c. Deviation}

Deviation studies are used to evaluate the consequences of an error in the initial designable parameters and/or measurements on the final modification factor . A percentage of error is used to evaluate two first upper and lower limits of the modification factors.

Figure 58 and 59 illustrate the upper and lower limits of the modification factor for a tolerance set between 10 and 30 percent, for the CMC 1 and the CMC 2 respectively. There is of course a direct link between the sensitivity and the deviation. The common mode choke 4 presents as expected a larger deviation around the resonant frequency : the current can be multiplied by a factor 2 to 20 (from $6 \mathrm{~dB}$ to $26 \mathrm{~dB}$ ) in a span of $40 \mathrm{kHz}$ of frequency. The common mode choke 2 is more stable with a current multiplied by a factor of maximum $2(6 \mathrm{~dB})$ in a span of $400 \mathrm{kHz}$ of frequency. The deviation of the attenuation in the higher frequencies (above the frequency of resonance) can be relevant to the engineer with a current divided from 200 to 260 times (- 47dB) for the CMC 1 and 80 to 100 times ( $40 \mathrm{~dB})$ for the CMC 2.

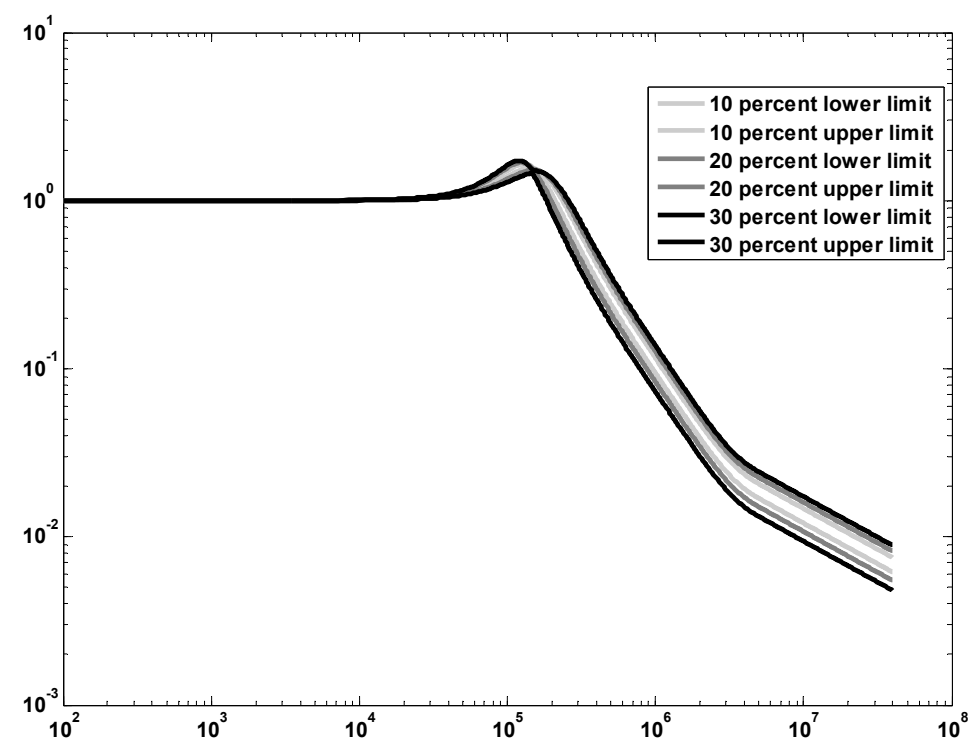

Figure 58: Upper and lower limits of the modification factor (Uncertainty from 10 to 30 percent) - Common mode choke 1 . 


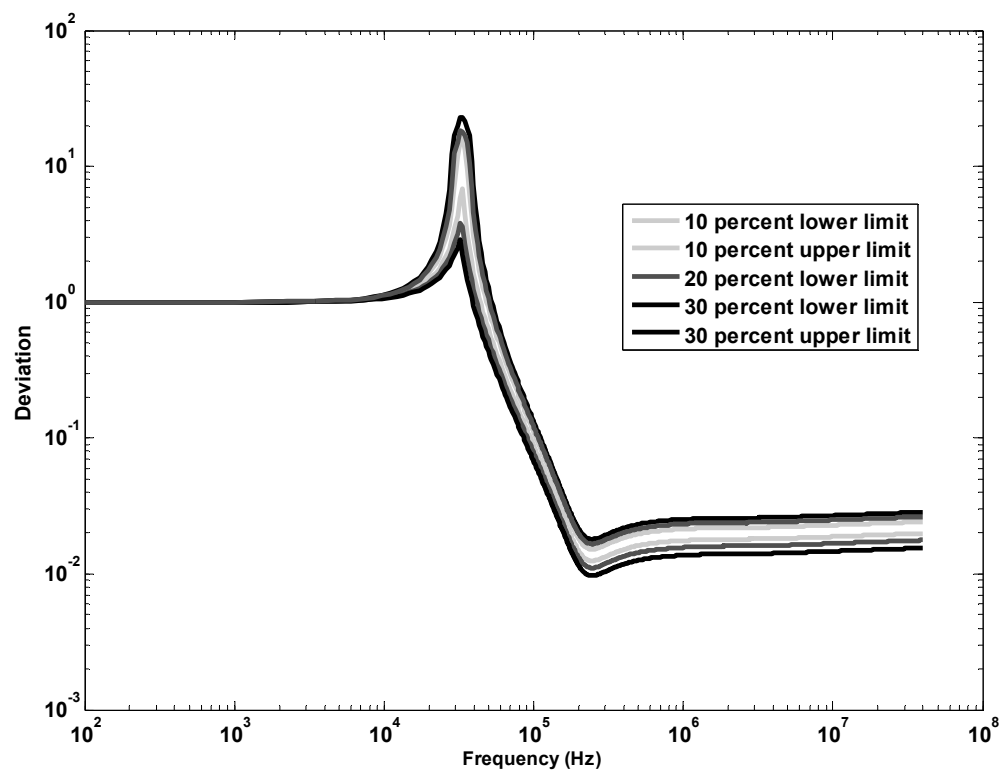

Figure 59: Upper and lower limits of the modification factor (uncertainty from 10 to 30 percent) - Common mode choke 4.

The final result is another tool allowing engineers to evaluate a best and a worst case scenario, that could be used together with statistic studies to get a better idea of the risk involved in the design.

\subsection{Designable parameters}

\section{6.a. Designable parameters: effect of the material}

Typically the choice of material will depend on the frequency of the noise to be filtered: a material will be efficient if the noise is located in the upper values (above $40 \%)$ of $\mu$ " [38]. The change of material is also an alternative to adjust the level of saturation. In Figure 60 the common mode impedance of two CMC are compared: both have the same number of turns (15) and a similar size of $32 * 12 * 7 \mathrm{~mm}$ for the nanocrystalline one and $35^{*} 12^{*} 7 \mathrm{~mm}$ for the ferrite one. The result shows that the intrinsic properties of the core material have indeed a key impact on the final properties of the CMC: for a same size and a same number of turns, the nanocrystalline CMC exhibits an impedance up to 20 times higher in the low frequency and up to 5 times higher in the higher frequency than the CMC made of ferrite. The modification factors of the two chokes are compared in Figure 61. It is 
clearly visible that the nanocrystalline choke provides a better attenuation, up to 20 times higher (26dB). In Figure 62 the modification factor of the same chokes but with less turns is compered (7 turns). Again the nanocrystalline CMC provides a better attenuation.

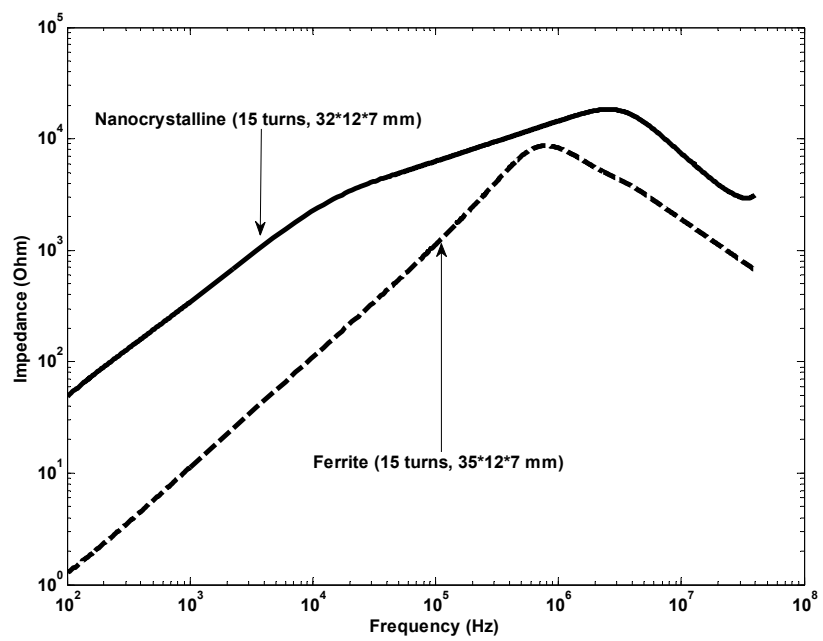

Figure 60: Common mode impedance of two chokes with same size, same number of turns - Nanocrystalline versus Ferrite.

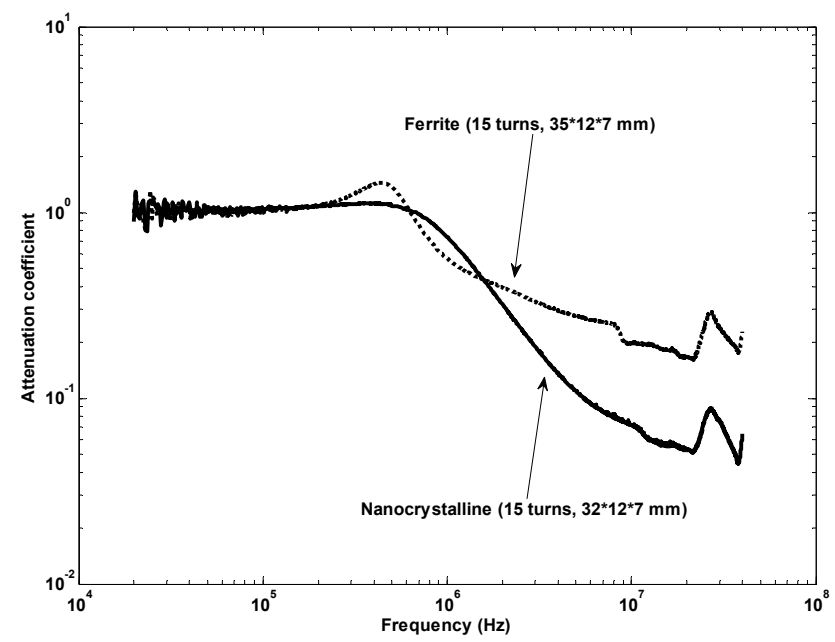

Figure 61: Measured attenuation coefficients of two chokes with same size, same number of turns - Nanocrystalline versus Ferrite. 


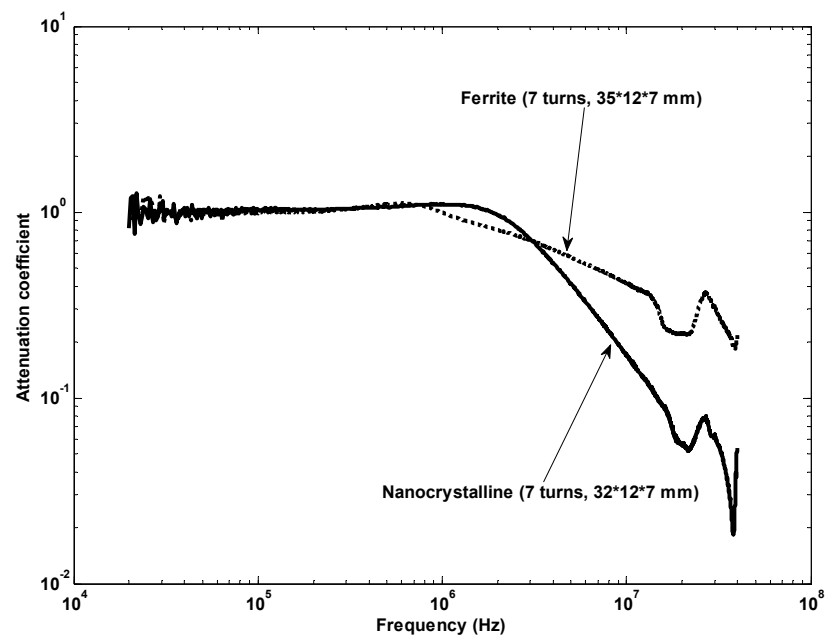

Figure 62: Measured attenuation coefficients of two chokes with same size, same number of turns - Nanocrystalline versus Ferrite.

\section{6.b. Designable parameters: effect of the size of the choke}

Figure 63 presents the effect of the size of the core by comparing the impedances of two common mode chokes with two different sizes: the choke $1\left(25^{*} 15^{*} 5 \mathrm{~mm}\right.$, copper wire thickness $1 \mathrm{~mm})$ and the choke $1-\mathrm{XL}\left(35^{*} 15^{*} 7 \mathrm{~mm}\right.$, copper wire thickness $1.5 \mathrm{~mm}$ ). The turn to turn capacitances and the leakage inductances remain similar in both the chokes (the ones of the choke 1-XL are a bit higher due to a thicker and a longer windings, but it is not significant).

The increase of the size of the choke tends to shift the maximum value of the common mode impedance towards the lower frequency. This shift may or may not change the frequency at which the attenuation of the common mode current will start: this frequency is indeed related to the resonance between the impedance to the ground of the system (a capacitance typically) and the common mode impedance. It translates graphically by an intersection of the two respective curves. The capacitance to ground is not represented in the graph but one can imagine a decaying line intersecting with the common mode impedance as introduced earlier in this chapter. If this intersection occurs where the common mode impedance is dissimilar between the two chokes, between frequency $\mathrm{A}$ and $\mathrm{B}$ on the graph, the attenuation of common mode current will then start at a lower frequency for the bigger choke. This frequency remains otherwise unchanged. 
On one hand, the change of material can be used to shift a frequency of resonance and to change its amplitude. The attenuation in the higher frequency can be maintained. On the other hand the change of material may not introduce any change in the modification factor of the common mode current.

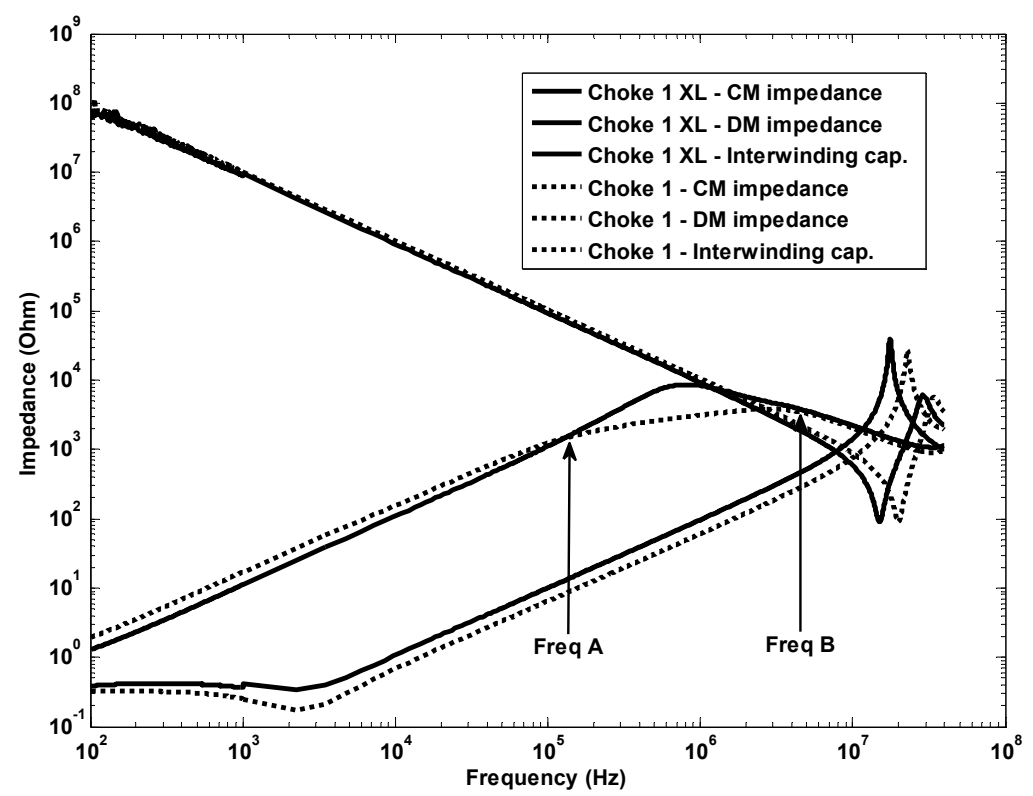

Figure 63: Impedances of two common mode chokes with different core size and same number of turns.

\section{6.c. Designable parameters: effect of number of turns}

Figure 64 shows the influence of the number of turns on the value of the common mode impedances, phase inductances, turn to turn capacitances and differential mode impedances. The core is same for all the four chokes tested.

The value of the common mode impedance increases with the square value of the number of turns. As the real part of the complex permeability is usually higher than its imaginary part, to increase the number of turns will also shift the maximum of common mode impedance towards the lower frequencies. The density of flux in the choke is increased and the saturation level is easier to reach so the choke will sustain a lower current. 


\section{6.d. Designable parameters: effect of the wiring system}

Two kinds of windings are possible: the sectional winding and the bifilar winding. Sectional winding consists of the same number of windings placed at diametrically opposite ends on the toroidal core and bifilar winding consists of a parallel wiring around the core. The two families of windings are pictured in Figure 65. Their respective impedances are presented in Figure 66. The sectional winding provides a high leakage inductance which allows the filtering of the differential mode current in addition of the common mode one. The small leakage inductance provides less attenuation of high frequency differential mode current and in the same time the graphical intersection between the leakage inductance and the differential mode impedance of the system occurs at higher frequencies. The attenuation and the resonance occurs at a higher frequencies. The best choice of windings system depends of the application.

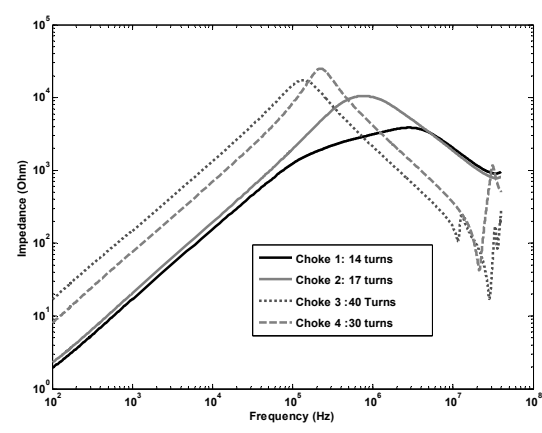

(a) Common mode impedance.

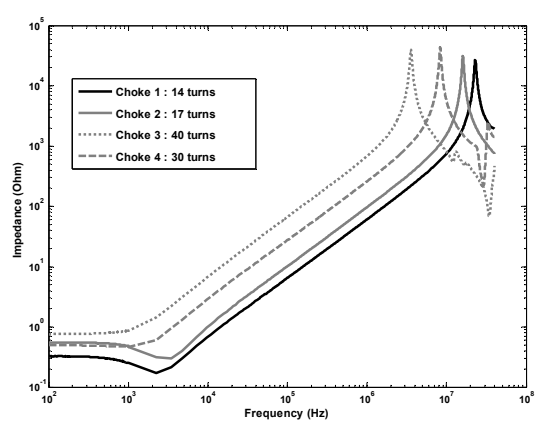

(c) Leakage inductance.

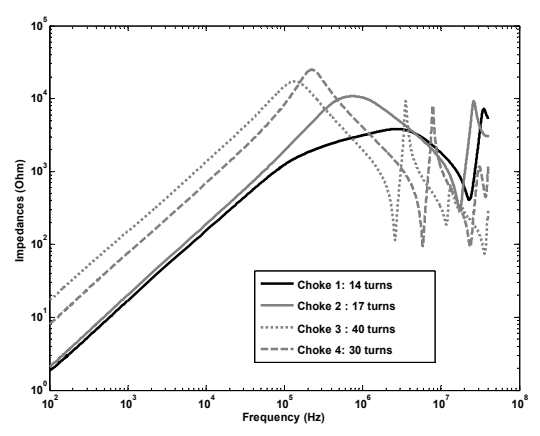

(b) Phase impedance.

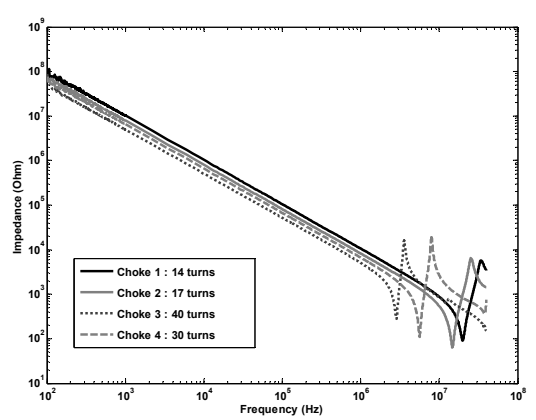

(d) Inter-winding impedance.

Figure 64: Influence of the number of the number of turns on: common mode impedances, turn to turn capacitances, differential mode impedances. 


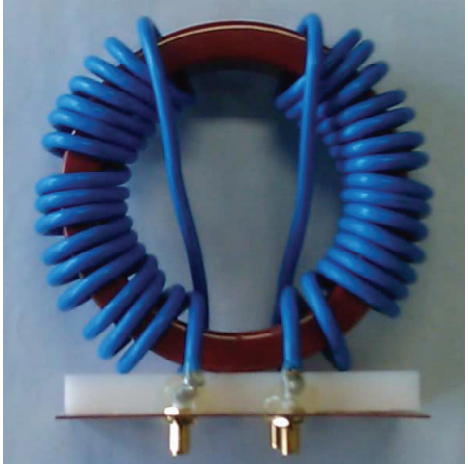

(a) Sectional winding.

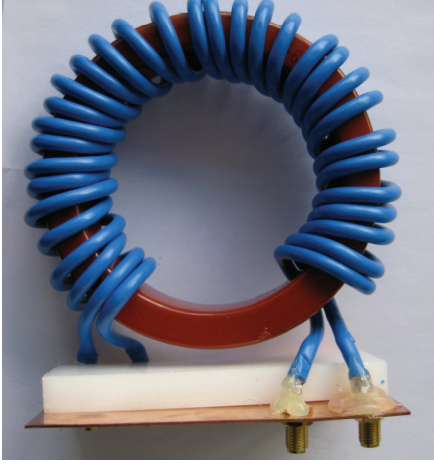

(b) Bifilar windings.

Figure 65: Sectional winding and bifilar winding of a common mode choke.

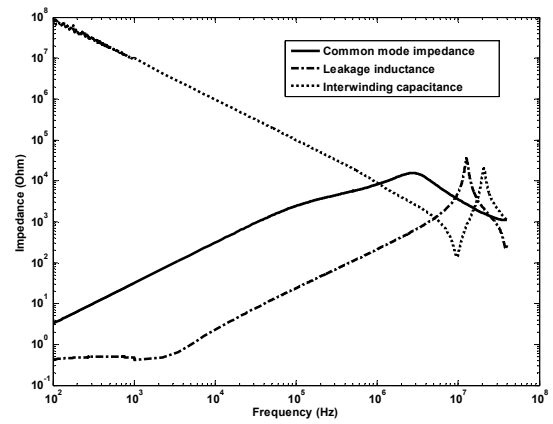

(a) Sectional windings.

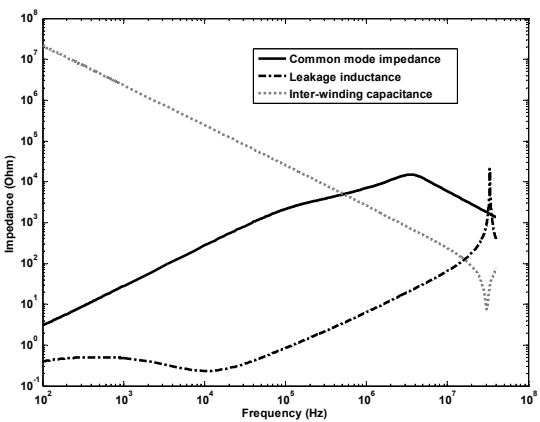

(b) Bifilar windings.

Figure 66: Impedances of a common mode choke with sectional and bifilar winding.

\section{6.e. Modification of the common mode current for very low impedance to ground}

It is possible that no graphical intersection exists between the common mode impedance of the choke and the impedance to the ground. This happens for very low value of capacitance to ground as depicted in Figure 68. It leads to a very low to practically ineffective modification factor.

\section{6.f. Designable parameters: effect of the wire dimension}

The wire dimension is chosen according to the density of current in the circuit. It has a small effect at very low frequencies where the resistance of the wiring is the main contribution to the impedances. This resistance is visible in the measurement of the leakage inductance at low frequency. 

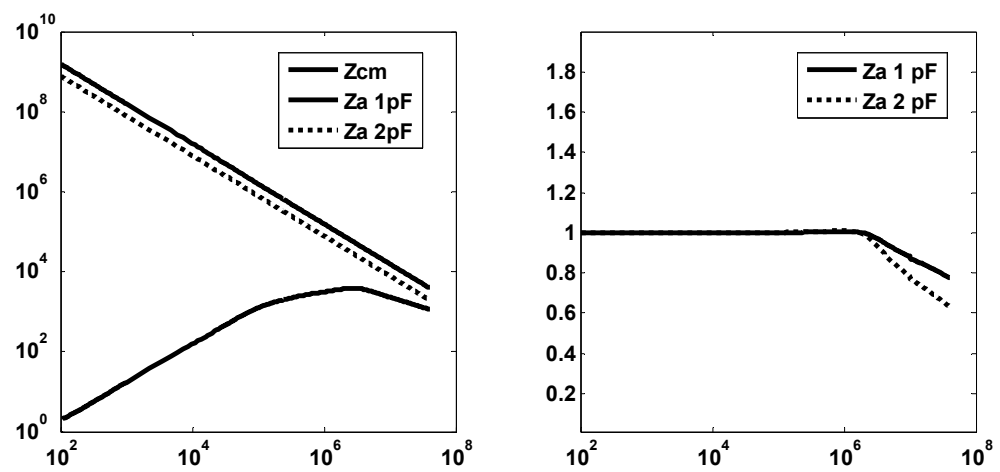

Figure 67 : Common mode modification factors with low capacitances to ground (CMC 1) - Left : Impedances, Right: Modification factors.
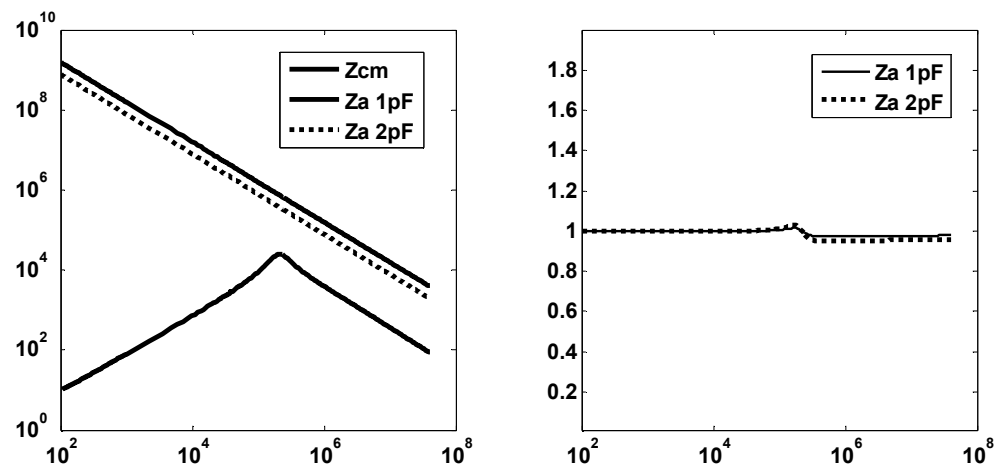

Figure 68 : Common mode modification factors with low capacitances to ground (CMC 4) - Left : Impedances, Right: Modification factors.

\subsection{Summary}

A new behavioural model of a common mode choke has been presented: it is using a validated electrical equivalent circuit of the common mode choke together with a description of the environment of the drive. Inputs of the model are the designable parameters of the common mode choke of the electrical design engineer. The main outputs are the modification factors of both the common mode current and the differential mode current. It allows to evaluate 'in situ' the final effect of each designable parameter via sensitivity and deviation studies. The model is validated with two different measurements techniques and the effect of the main designable parameters on the currents flowing in the drive is described. The design of the common-mode choke is a trade-off where the knowledge of the impedance to ground of the system is a key. 
This behavioural model of the common mode coke is not complete: an engineer would typically used a complete EMI filter to control the unwanted current in their motor drive. An overall model of the EMI filter is introduced in the next chapter. 


\section{Chapter 5. Behavioural model for EMI filters}

An EMI filter is commonly named the 'black magic' box [56] as it is often built without standards rules and most of the times requires a custom made design along with many trial and error processes.

The purpose of this chapter is to integrate a new behavioural model for common mode chokes previously developed in this thesis and extend it to a global behavioural model.

The test set-up (an AC/DC converter with its load) and the measurement techniques are first described: both input common mode impedances and currents are measured and studied for the different configurations of existing EMI filters.

They are typically built according to four different structures that are investigated from the section 4 to the section 9. For each of these structures an equivalent electrical circuit is proposed: it takes into account the components of the filter as well as its dynamic environment. Each structure is validated via measurements.

Each behavioural model links the designable parameters of the motor drive to the final values of common mode currents in the design.

The main designs strategies described in the literature are finally investigated thanks to the behavioural models. The relevance of these strategies and their limitations are highlighted in the last section of this chapter. Simplified modification parameters are calculated to allow a quick evaluation of the performance of each topology. 


\subsection{Strategies of filter designs in the literature}

Two components are used in the common mode filter: the Y-capacitor and the common mode choke. This component has been extensively presented and modelled in the two previous chapters (Chapter 3 and 4). The purpose of the capacitor to ground (or Y-capacitor) is to redirect the common mode current to the ground: this current will then remain in a coupling path within the equipment or leave the motor drive via the ground.

There are no standard methods to design an EMI filter. In [56] three main reasons are given to explain this absence. First, a variable impedance at the input and output of the filter, over the frequency range, which is difficult to measure or to guess. Second, the filter design insertion method used by most manufacturers is not adapted with design reality: the insertion losses are often measured with $50 \mathrm{Ohms}$ impedances. Third, the design method available in the literature are often very complex.

There is however a general rule of thumb commonly used, which is presented in [4]. It states that the structure of the final filter depends on the value of the impedances seen at either end of the filter network. The main rule, while choosing the configuration of the common mode filter, is to not provide a capacitance to ground where the end impedance is already low. Doing so would be mainly useless as it brings the impedance of the line towards zero while the impedance is already close to it. Figure 69 presents the typical filter configuration versus its end impedances.

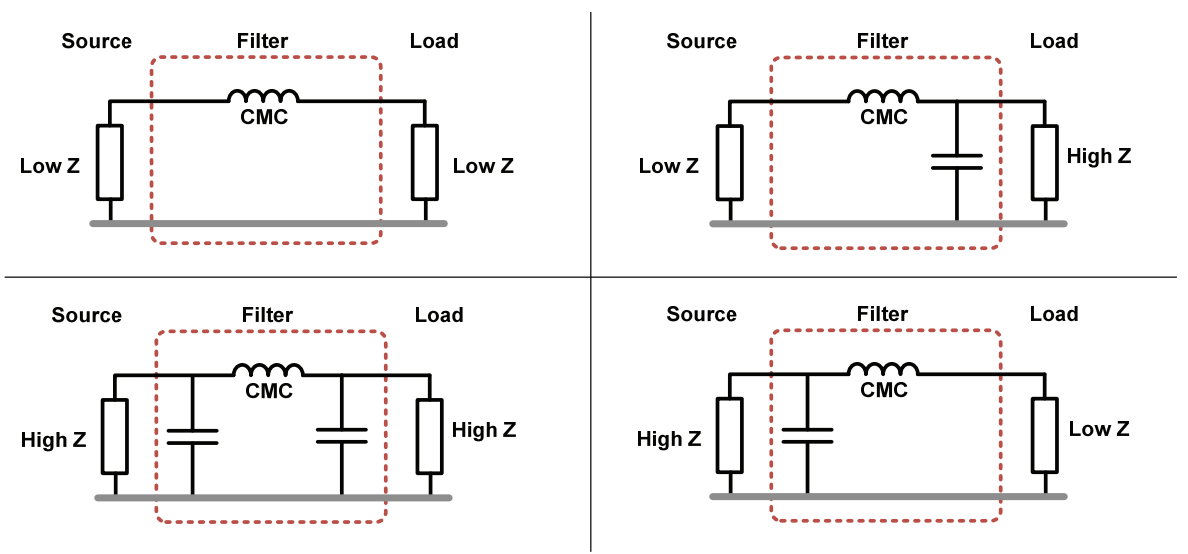

Figure 69: Filter configuration versus impedance. 


\subsection{Designable parameters of the filter and its environment}

The designable parameters are inputs of the global behavioural model of the EMI filter. The designable parameters of the EMI filter are: the ones related to its components, the ones related to the filter structure and the ones related to the environment (noise source and common mode load).

- Designable parameters of the components of the EMI filter: they are listed in Chapter 3 (section 3.6.a) for the common mode choke, to which we can add the impedance of the common mode choke with respect to the ground (this was reduced to a minimum with the use of an isolating dielectric in Chapter 4 (section 4.1.a), and the impedance of the $\mathrm{Y}$-capacitors).

- Designable parameters of the structure of the filter: if the filter is mounted on a board, it is the impedance to the ground of the board with respect to the ground, as well as a possible parasitic inductance related to the length the track.

The designable parameters of the environment of the filter (noise source and load):

- Designable parameters of the noise source: such a model is not available. It is assumed in this thesis that the noise source is characterized by the designer. A measurements technique is proposed in Section 3.6.e. Potential designable parameters are for instance: size of the PCB (Printed Circuit Board) with the ground plane, heat sink characteristics, switching frequencies, type of switches, type of modulation, DC bus structure...

- Designable parameters of the load: a behavioural model of the load is described in the next chapter. The main designable parameters will be the length and type of cable, the height of the cable with respect to the ground plane and the common mode impedance of the motor.

\subsection{Study of the different structures of common mode filters}

\section{3.a. Test set-up}

Figure 70 presents the load and the EMI filter used in the test set-up. They are placed at the output of a representative AC/DC converter (described in Appendix 1 and [51]). 
The twisted pair cable used to connect the filter to the load is $10 \mathrm{~cm}$ long. Because its length is much shorter than a wavelength, no sanding waves settle in the cable and no reflection of the current at the extremities of the cable are expected. The effect of the cable is addressed in Section 5.4.

The load can be set as either resistive or resistive and inductive. This last configuration is chosen for all the experiments presented in this thesis to remain as close as possible to a real situation with the use of a motor.

The EMI filter is fully configurable: each component can be included in or excluded of the functional design by means of manual switches. It includes:

- 1 common mode choke

- $4 \mathrm{X}$-capacitors, two on each side of the common mode choke (they will not be used in this chapter)

- 6 Y-capacitors (three capacitors of $4.7 n f$ in parallel for each phase) on one side of the filter. The Y-capacitors are connected to the copper plate underneath the test-set-up.

The filter is separated from the ground plane underneath with a dielectric of $0.5 \mathrm{~cm}$ thickness.

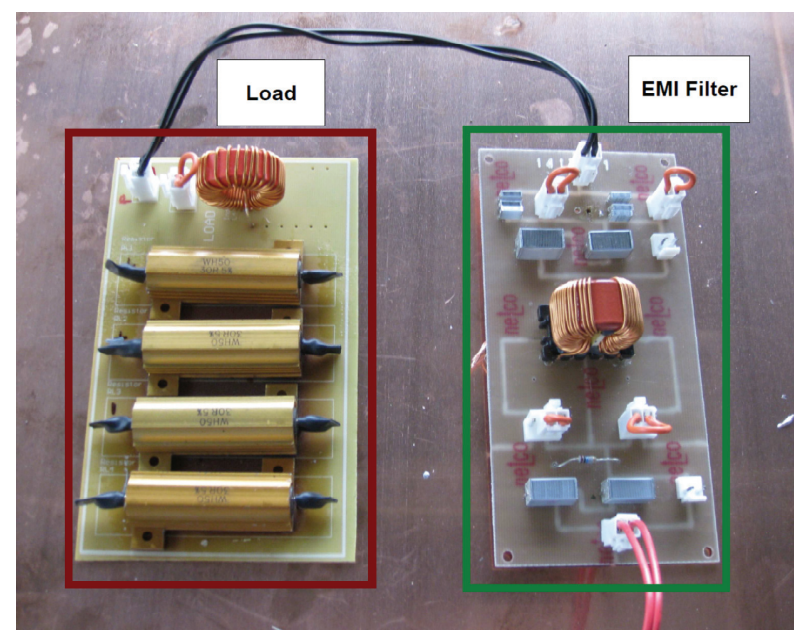

Figure 70: Load and EMI filter of the test-set-up. 


\section{3.b. Impedance measurements}

Figure 71 presents the test set-up used to measure the input common mode impedance of the load and its filter. In the test-set-up the EMI filter, the cable and the load are aligned along a straight line. The tracking generator of the EMI receiver is used to provide a constant voltage $(96 \mathrm{~dB} \mu \mathrm{V})$ at the input of the filter, the current flowing at this input is measured via a current probe. The uniqueness of the ground plane is ensured by the metallic plate inserted between the filter and the measurement device. This metallic plate is connected to the receiver via a high frequency co-axial cable. The vertical plate is also connected with conductive metallic tape to a $1 \mathrm{~m}$ by $1 \mathrm{~m}$ copper plate placed underneath the load and the filter.

The test-set up presents some limitations: above and below a certain value of current, the impedance can no longer be measured. For the highest impedance (lowest value of current) the measurable value is limited by the amount of current the EMI receiver can itself measure (noise floor). For the lowest impedances (highest values of current) the measurable value is limited by the amount of current the generator can produce. The lower values of measurable current have been evaluated by performing a measurement with the generator switch-off. The highest values have been measured by placing a big $\mathrm{Y}$-capacitor for high power system (470nF, 250VAC, 200A), instead of the filter, to drive a maximum current to the ground. The results are presented in Figure 72 . The lower value of measurable impedance is actually the one of the internal generator as the situation is close to a closed circuit of the generator $(50 \mathrm{Ohm})$.

\section{3.c. Current and impedance measurements}

The common mode current flowing in different part of the test set-up is measured using a current probe and the EMI receiver. An overview of all currents measured in this chapter is provided in Figure 73. An overview of all input common mode impedances measured is provided in Figure 74.

\section{3.d. Common mode chokes used in the experiment}

The common mode choke used for the measurements presented in this chapter are listed in Table 9. 


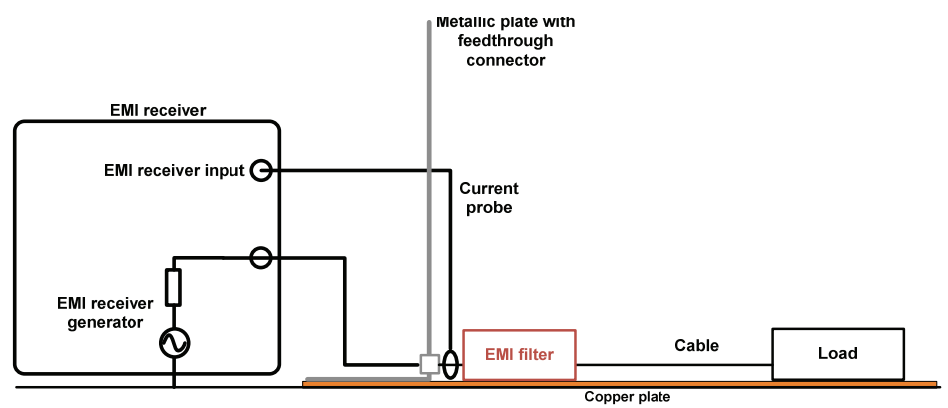

Figure 71: Test set-up of the measurement used for the measurements of the common-mode impedance of the filter and load.

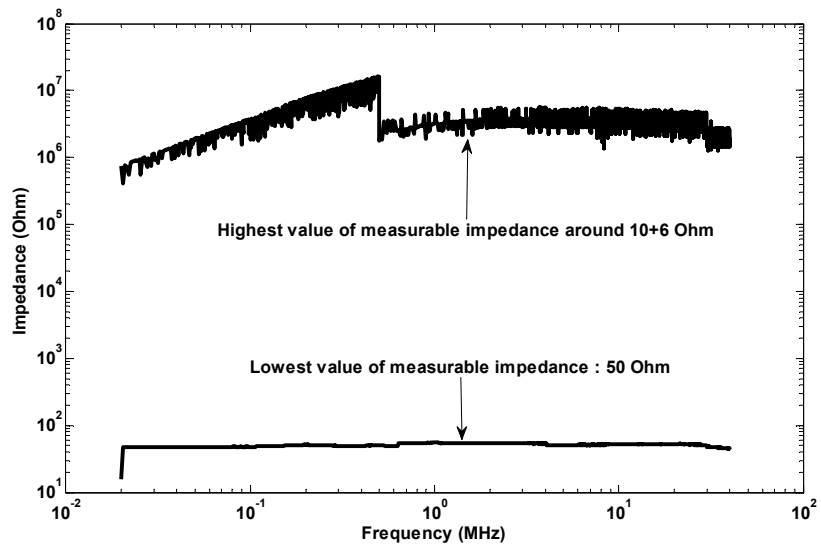

Figure 72: Range of measurable impedance with the EMI receiver.

Table 9: Chokes used for measurements.

\begin{tabular}{|c|c|c|c|}
\hline Name & Material & Size $(\mathrm{mm})$ & $\begin{array}{l}\text { Number of } \\
\text { turns }\end{array}$ \\
\hline Choke 1 & \multirow{6}{*}{ Ferrite $\mathrm{MnZn}$} & \multirow{4}{*}{$25 * 15 * 5$} & 15 \\
\hline Choke 2 & & & 18 \\
\hline Choke 3 & & & 44 \\
\hline Choke 4 & & & 30 \\
\hline Choke 5 - XL & & \multirow{2}{*}{$35 * 15 * 7$} & 7 \\
\hline Choke 6 - XL & & & 15 \\
\hline Nano 1 & \multirow{5}{*}{ Nanocrystalline } & \multirow{3}{*}{$32 * 12 * 7$} & 7 \\
\hline Nano 2 & & & 10 \\
\hline Nano 3 & & & 15 \\
\hline Nano 4 - XL & & \multirow{2}{*}{$100 * 22 * 11$} & 15 \\
\hline Nano 5 - XL & & & 15 \\
\hline
\end{tabular}



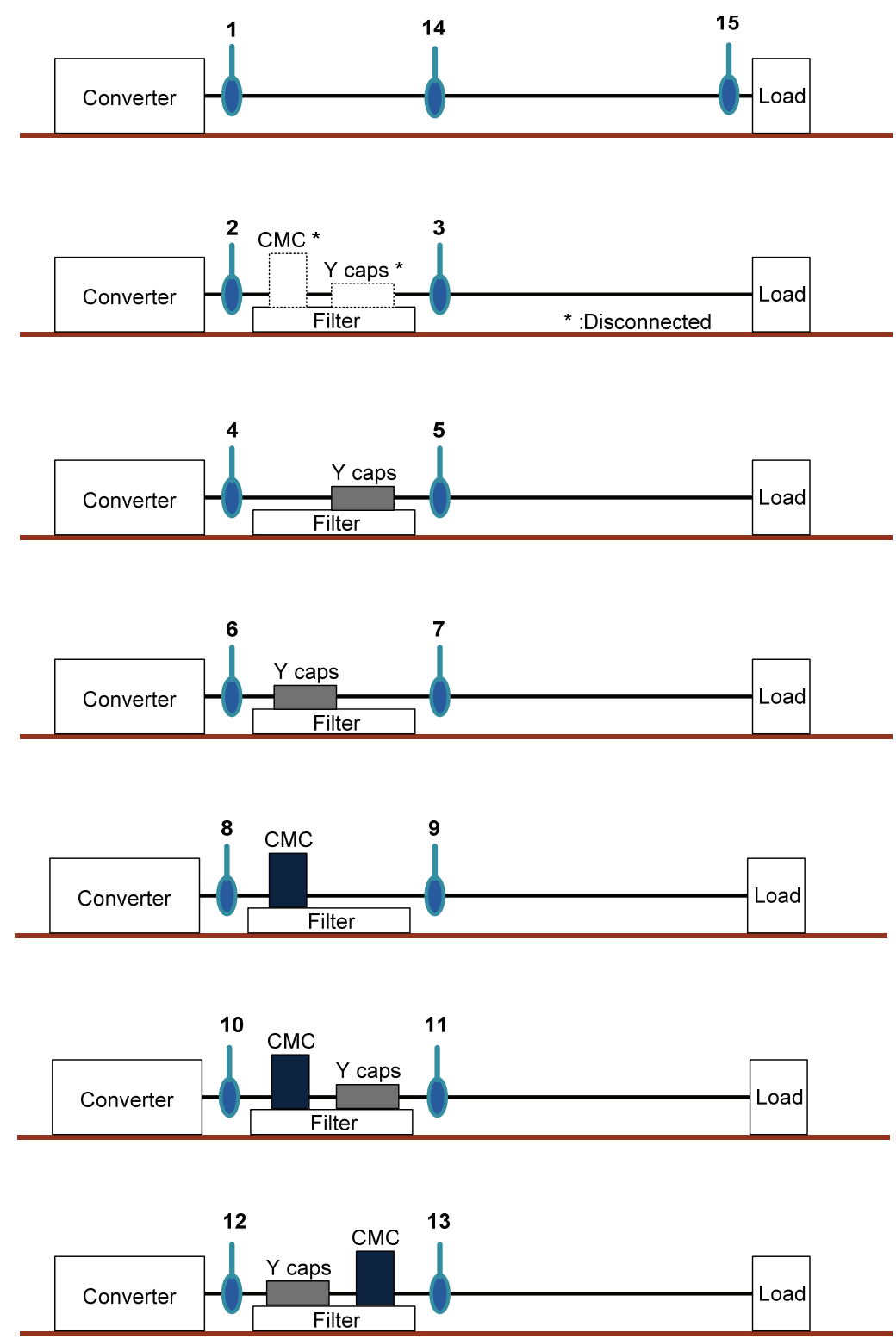

Figure 73: Overview of the common mode currents measured for this chapter. 

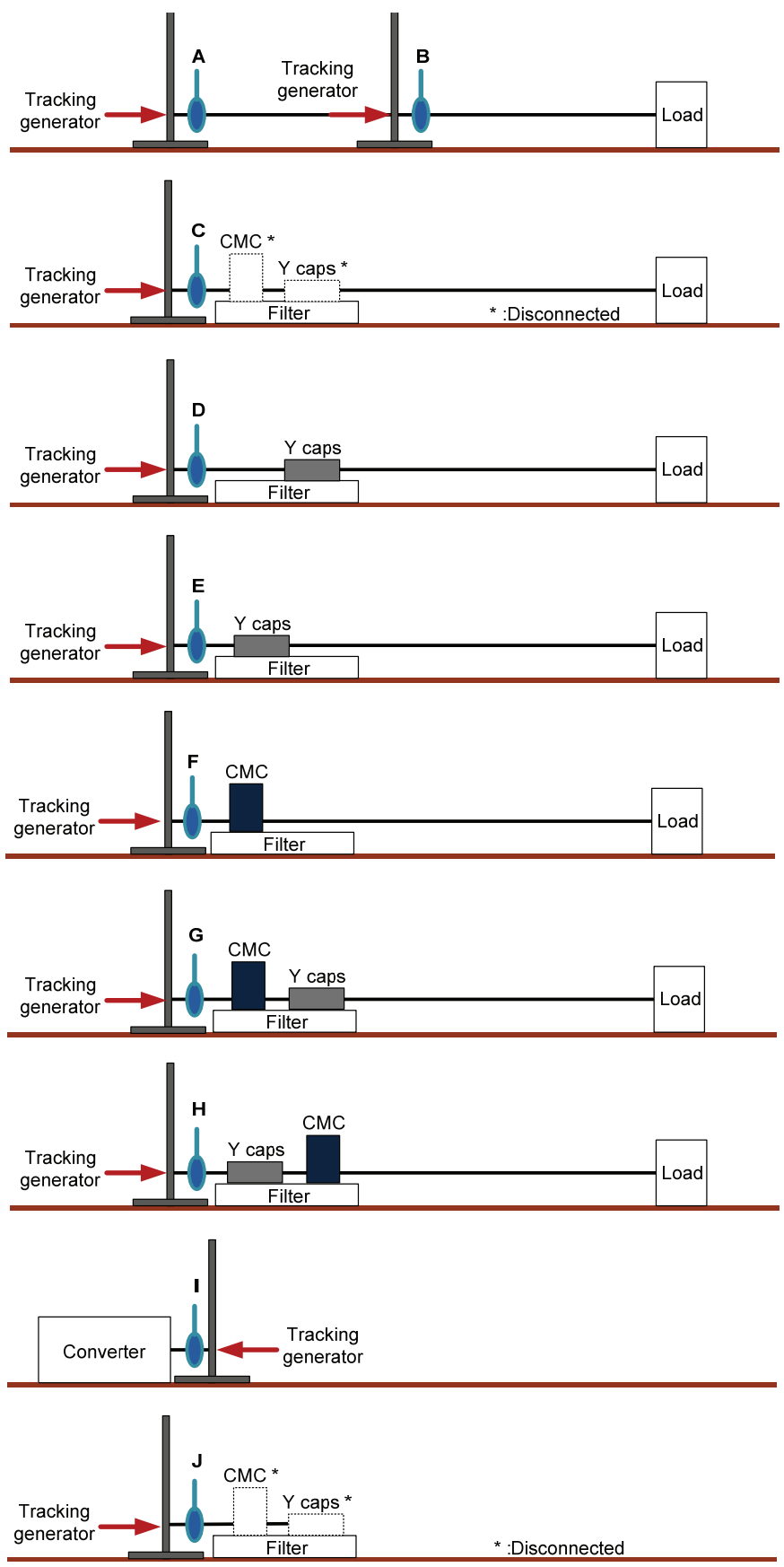

Figure 74: Overview of the common mode input impedances measured for this chapter. 


\section{3.e. Noise source characterization}

The generation of the common mode current by the converter and its downstream environment can be modelled with a dynamic noise source. The noise it generates towards the load will depend on the one hand on the structure of the converter and on the other hand on the structure of the load. It is assumed in this thesis that the structure of the converter is not changed, so that only the influence of a change of the load structure with the insertion of a filter is characterized.

A model of the noise source which relates the output common mode voltage of the converter to the designable parameters of the converter itself is desirable. The noise source can be characterized with an equivalent Thévenin (or Norton) structure as presented in Figure 75 . The unknown parameters $Z_{t h}, V_{t h 1}$, and $I_{n 1}$ are related as follows:

$V_{c m 1}=V_{t h 1}-I_{c m 1} * Z_{t h}$

$I_{c m 1}=I_{n 1}-V_{c m 1} / Z_{t h}$

$Z_{T H}$ is the source impedance to ground of the converter seen at the output of converter. This impedance is only related to the parasitic to ground of the converter and is assumed to be passive. The total parasitic impedance to ground at the output of the $\mathrm{AC} / \mathrm{DC}$ converter used in the test set-up is represented in Figure 76. It is a capacitance of $150 \mathrm{pF}$ (obtained in measurement I, Figure 74).
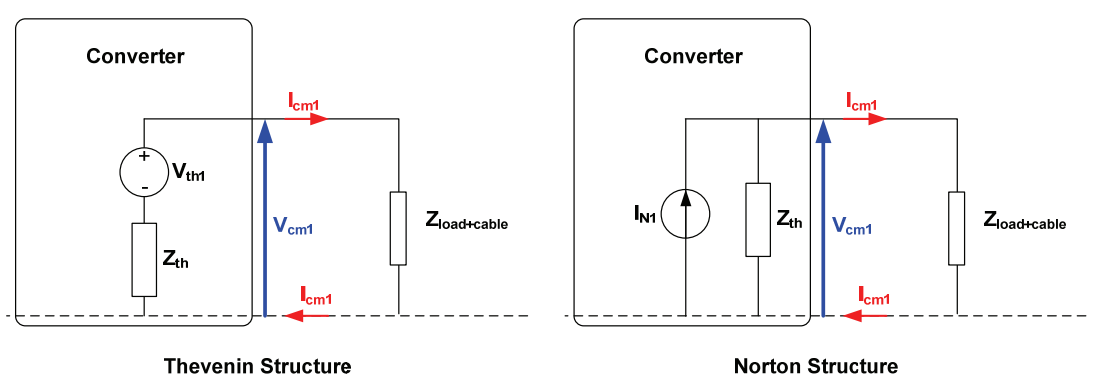

Figure 75: Representations of the common mode noise source of the converter. 


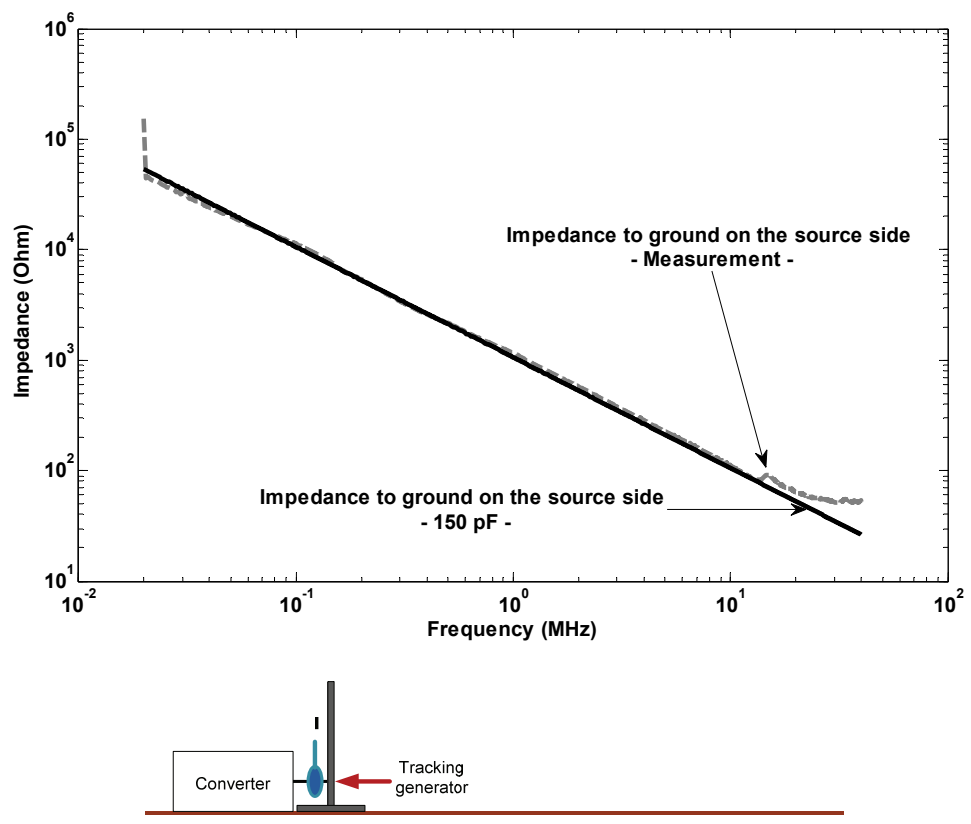

Figure 76: Impedance to ground measured at the output of the converter in the source side.

In order to completely characterize the noise source, the designer not only needs to know the value of the voltage across the Thévenin voltage source $\left(V_{T H 1}\right)$ but also its variation when a new load is introduced. If a model of this dynamic behaviour of the noise source is not available to the designer, it is possible to assess to variation of the common mode voltage of the equivalent Thévenin generator of the source via measurements. A set of known capacitances can be successively placed at the output. The measured currents will give insight into the dynamic behaviour of the Thévenin voltage. If the values of the capacitances are chosen wisely so that a wide range of the dynamic behaviour of the noise generator is characterized, the variation of the voltage occurring after the insertion of any filter can be predicted. As an example, Figure 77 illustrates the variation of the common mode voltage, in the test set-up, at the output of the converter, for different values of common mode load (feedthrough capacitances). The impedance of these test capacitances is known over the frequency range of concern. The corresponding Thévenin voltages are presented in Figure 78. In Figure 77 the common mode voltage of the load together with the Y-capacitors $(28 \mathrm{nF})$ is computed with a theoretical ideal impedance of $28 \mathrm{nF}$ after $100 \mathrm{kHz}$ because the value of the impedance is below $50 \mathrm{Ohms}$ and cannot be measured with the actual test set-up. 


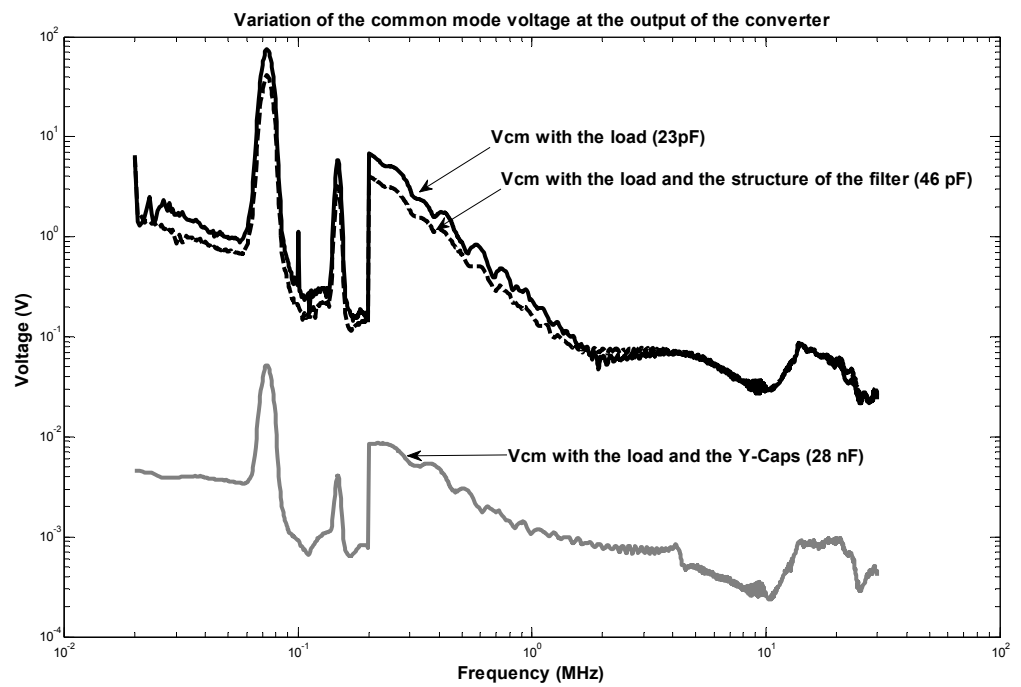

Figure 77: Variation of the common mode voltage at the output of the converter.

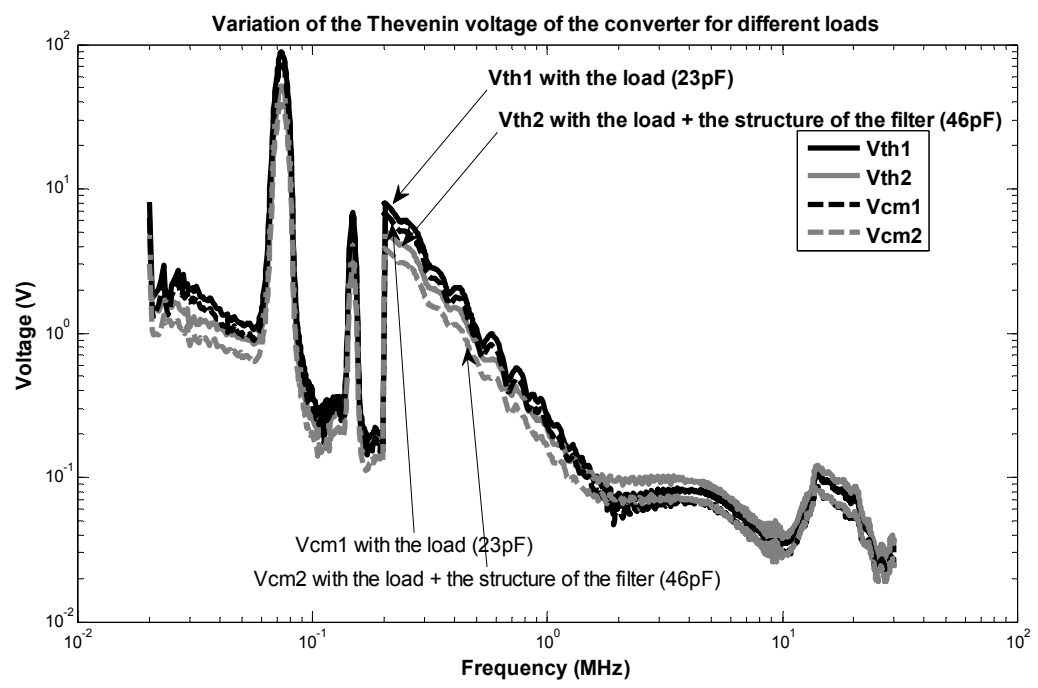

Figure 78: Variation of the Thévenin voltage of the converter for different loads. 

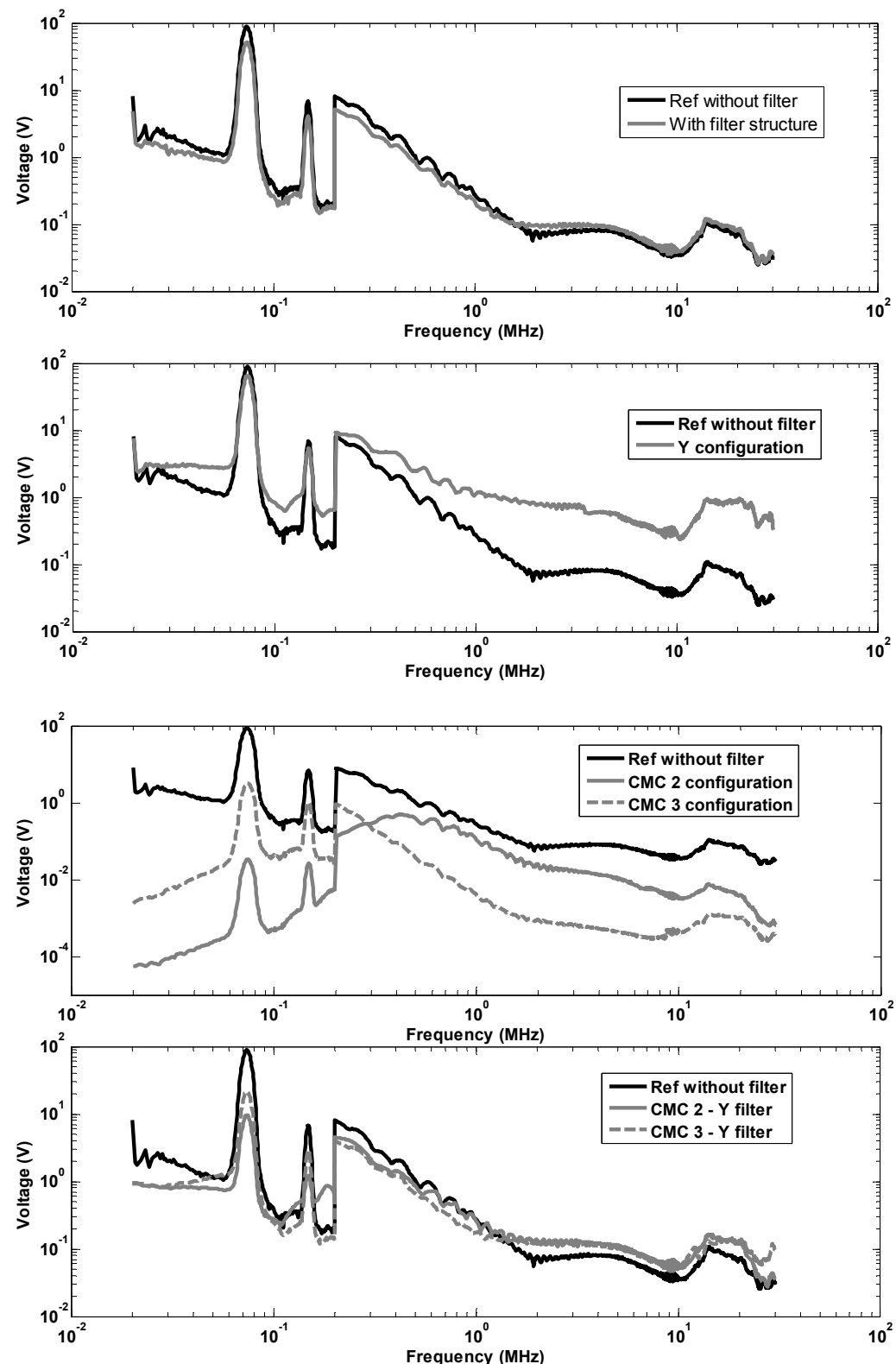

Figure 79: $V_{T H}$ in Volt versus Frequency $(\mathrm{MHz})$ for the different EMI filter configurations. 

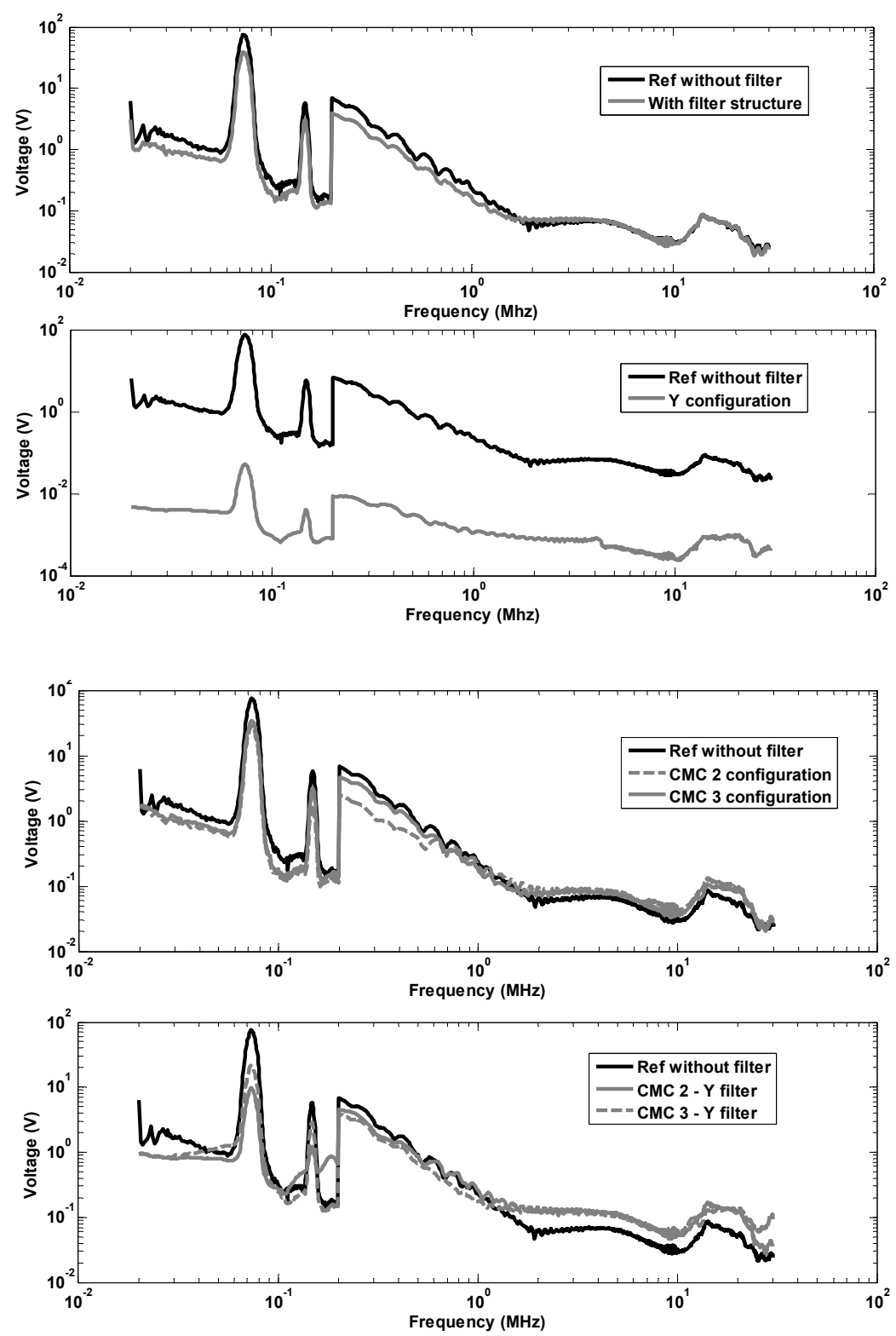

Figure 80: $V_{C M}$ in $V$ olt versus Frequency $(\mathrm{MHz})$ for the different EMI filter configurations. 
A complete characterisation of the noise source with a wide range of loads is required to predict the final current flowing in the cable after the insertion of any common mode filter. The study has been limited here to the value used in the test set-up. Even a small change in the value of the common mode load (23pf to 46pF in Figure 77) leads to a modification of the source voltage. Figure 79 presents the Thévenin voltage $V_{T H}$ in Volt versus Frequency $(\mathrm{MHz})$ for the different EMI filter configurations under test. Figure 80 presents the common mode voltage $V_{C M}$ in Volt versus Frequency $(\mathrm{MHz})$ for the different EMI filter configurations under test.

\section{3.f. $\quad$ EMI filter structures considered}

Different filter structures are tested:

- A first reference without filter.

- A second reference with the filter structure only (its components are disconnected).

- Just the Y-capacitors (on the structure).

- Just the common mode choke (on the structure),

- The common mode choke and the Y-capacitors ('CMC - Y configuration') (on the structure).

- The Y-capacitors and the common mode choke ('Y - CMC configuration') (on the structure).

Each structure will be studied in 3 phases: first the input impedance behaviour is described: it gives insight into the modification of the impedance seen by the common mode current when it leaves the converter towards the load. The impedance measurements are used to validate the equivalent circuit of the filter used in the model. Second the behaviour of the noise source is describe via current measurements. Third a modification factor is given for each structure, this modification factor allows the designer to model the current flowing in the set-up after the insertion of any filter of the same structure. Figure 81 presents the different input common mode impedances towards the load, at the output of the converter. The impedances measured are very different from each other and are investigated one by one in the next sections. The impedance of Y-capacitors is incomplete because of the limitation of the measurement set-up. An ideal impedance will be used in the next section based on the accurate measurement possible up to $100 \mathrm{kHz}$. The input impedance of the ' $\mathrm{Y}-\mathrm{CMC}$ ' configuration is the same as the one with just the capacitor. At low frequencies the current path is the one with the lowest impedance. The impedance of the Y-capacitor is lower by a factor of $10^{3}$ : as a consequence the current does not reach the common mode choke and flows through the capacitor to the ground. This effect is also described in this chapter. 


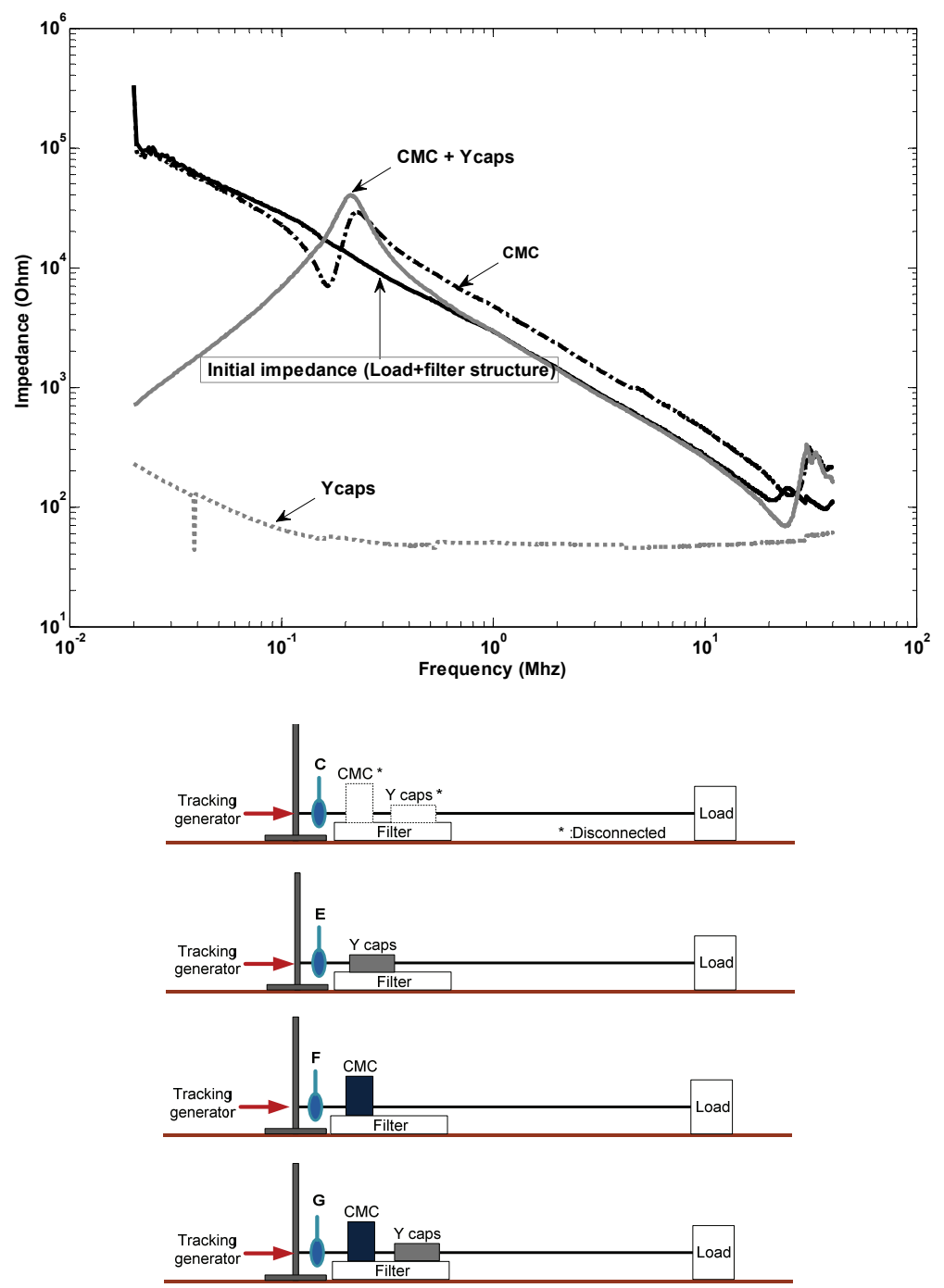

Figure 81: Input common mode impedances seen by the common mode current at the output of the converter according to the filter structure.

\subsection{No filter}

A first reference case is considered, where no filtering measures are inserted to the test set-up. Figure 82 presents the common mode current flowing at the output of the converter (current 1), along the cable (current 14, measured at the same position 
of the output of the filter used in the other measurements) and just before the load (current 15). There is an attenuation of the current along the cable up to $10 \mathrm{MHz}$. After this frequency the common mode current remains the same along the cable. A possible explanation is that the cut-off frequency of the transmission lien formed by the wire and the round plane has been reach. It is shown in the next chapter that a cable above a ground plane has a capacitive behaviour at low frequencies. The effect of a parasitic capacitance to ground at the output of the converter is described in the following section.

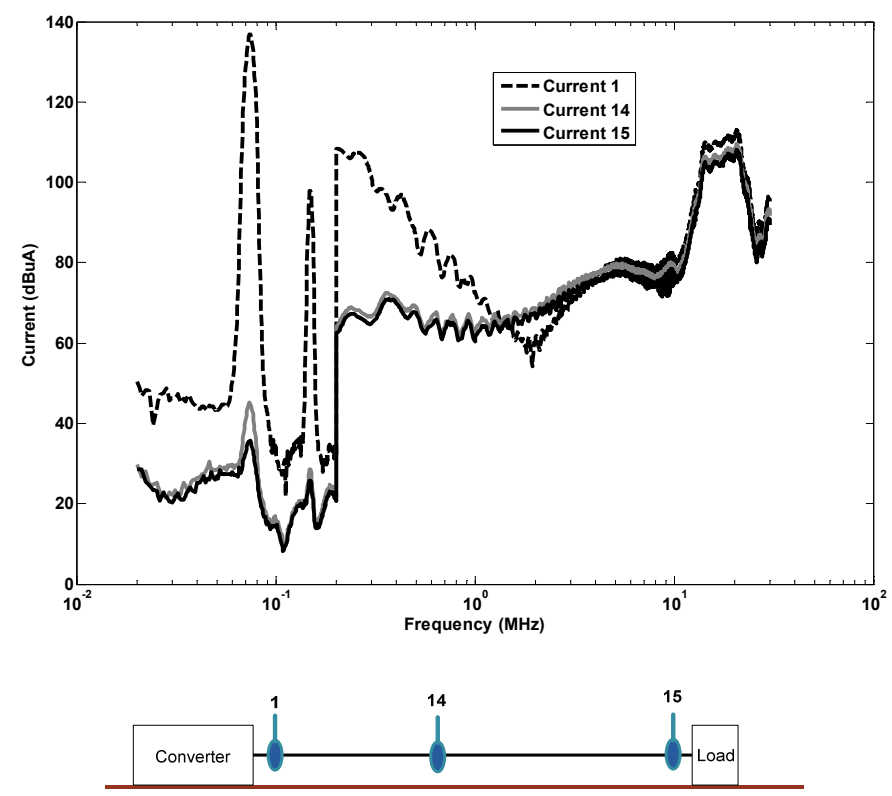

Figure 82: Common mode current flowing at the output of the converter, along the cable and before the load.

\subsection{Insertion of the filter structure only}

A second reference set-up is considered: the structure of the common mode filter is inserted at the output of the AC/DC converter. The components of the filter are disconnected so that the influence of the layout of the filter itself can be evaluated. It is shown that the structure of the filter inserts a new parasitic capacitance to the ground into the system. 


\section{5.a. Impedance overview}

The common mode current at the input (current 2) and the output (current 3) of the structure of the filter are compared with the initial common mode current flowing at the output of the AC/DC converter without filter (current 1).

Because of the similar size of the filter and the load, their parasitic capacitance to ground is same as presented in Figure $84(23 \mathrm{pF})$. The two capacitances are parallel to each other so their values add up and the overall parasitic capacitance of the new system is $46 \mathrm{pF}$.

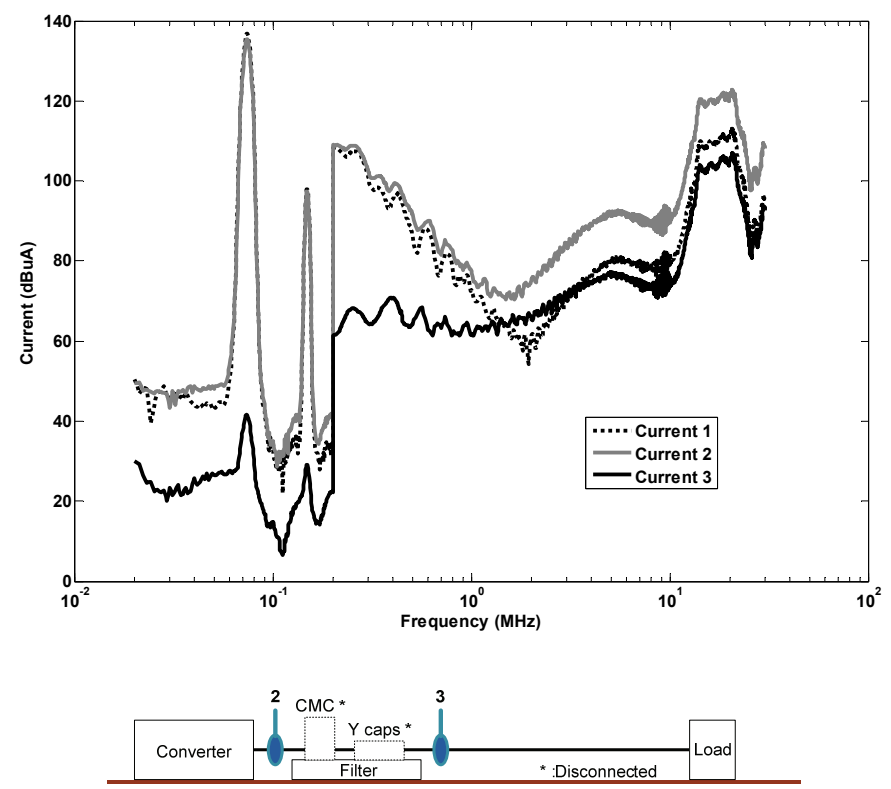

Figure 83: Common mode currents flowing before and after the filter with its component disconnected.

As measured and presented in Figure 84, the structure of the filter has an impedance to ground of $23 \mathrm{pF}$ in the overall frequency range of the measurement $(10 \mathrm{kHz}$ to $30 \mathrm{MHz}$ ). Figure 85 presents the common mode equivalent circuit of the load, its cable and the structure of the filter (its components have been disconnected). The impedance to ground of the structure of the filter is called $Z_{p}$ and is equivalent to a capacitance to ground of $23 \mathrm{pF}$ in the test set-up under consideration. 
The common mode current $I_{c m 2}$, flowing at the output of the converter in Figure 85 is the same as the current 2 in Figure 83. This current is indeed increased compared to the reference current 1 , as a part of the common mode current is directly sent to the ground via $Z_{p}$. The current after the filter is as a consequence decreased. If the decrease of current along the cable is beneficial, the increase of current flowing back to the converter has to be kept under control.
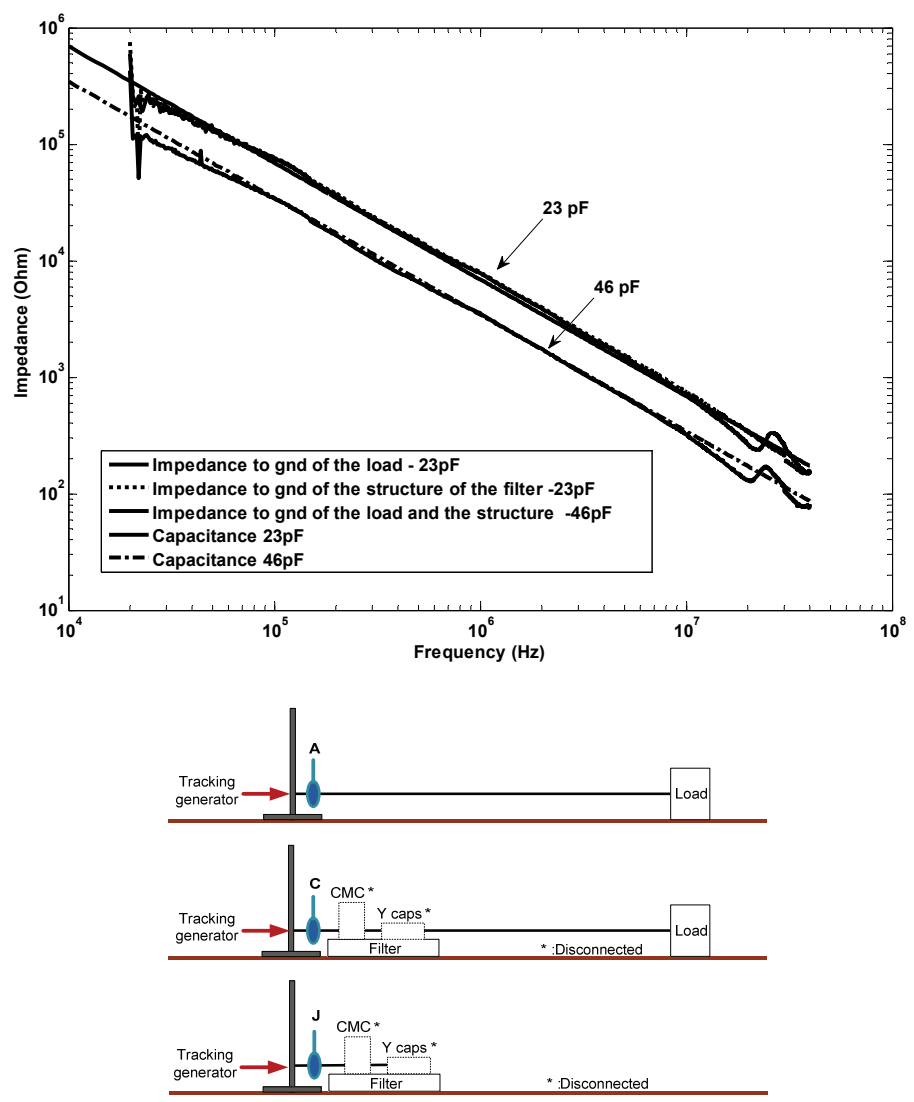

Figure 84: Modification of the parasitic capacitance to ground after the insertion of the structure of the filter (its internal components have been disconnected). 


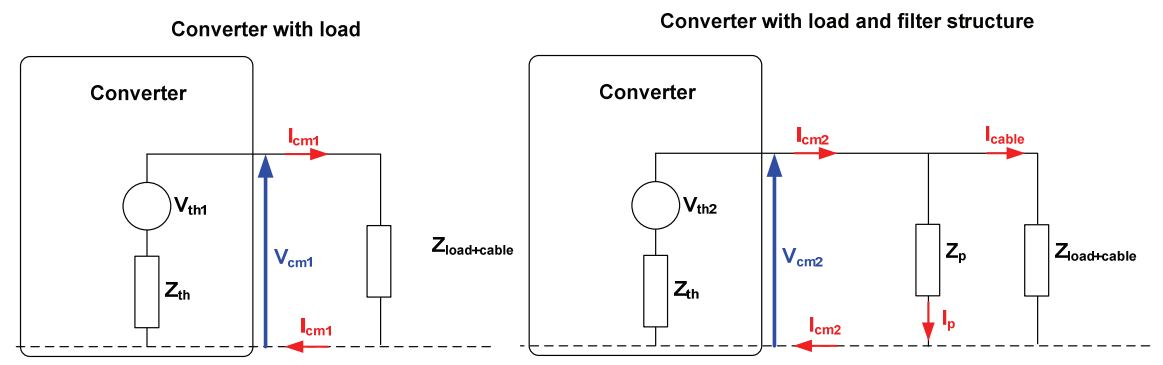

Figure 85: Common mode equivalent circuit of the load, its cable and the structure of the filter (its components have been disconnected).

The modification factor related to $I_{c m 2}$ and $I_{c a b l e}$ can be expressed as follows:

$$
\begin{aligned}
& \frac{I_{c m 2}}{I_{c m 1}}=\frac{V_{t h 2}}{V_{t h 1}} * \frac{Z_{L}+Z_{t h}}{\frac{Z_{L} * Z_{P}}{Z_{L}+Z_{P}}+Z_{t h}}=\frac{V_{t h 2}}{V_{t h 1}} * \frac{Z_{L}+Z_{t h}}{Z_{e q 1}+Z_{t h}} \\
& \frac{I_{c a b l e}}{I_{c m 1}}=\frac{Z_{P}}{Z_{L}+Z_{P}} * \frac{I_{c m 2}}{I_{c m 1}}=\frac{V_{t h 2}}{V_{t h 1}} * \frac{Z_{P}}{Z_{L}+Z_{P}} * \frac{Z_{L}+Z_{t h}}{\frac{Z_{L} * Z_{P}}{Z_{L}+Z_{P}}+Z_{t h}}
\end{aligned}
$$

The impedance $Z_{p}$ is not necessarily present in all motor drives, this impedance is intrinsic to the design of the filter: one can imagine a filter enclosed in a metallic structure well connected to the ground, with a common mode choke directly connected to possible Y-capacitors without further mechanical support placed underneath the choke. The impedance $Z_{p}$ is then equal to the impedance to ground of the choke with the ground/metallic structure of the filter.

Figure 86 and Figure 87 compare the measured modification factor with the modelled one, respectively for the current $I_{c m 2}$ and $I_{\text {cable }}$. The purpose here is to validate the equivalent circuit developed to analyze the EMI filter. There is a good agreement between the model and measurement. In Figure 87 it appears that the measured common mode current in the cable is even lower than the one predicted in the model. This filter has been designed for educational purposes and this difference of attenuation is related to an additional parasitic inductance due to the longer track required on the printed circuit board (PCB) of the filter. This aspect is further treated in the next section. This parasitic should not be present in a properly designed filter. 
In the configuration under study the insertion of the structure of the filter leads to an increase up to a factor $2(6 \mathrm{~dB})$ of the common mode current flowing back towards the converter, and an attenuation up to a half in the cable.

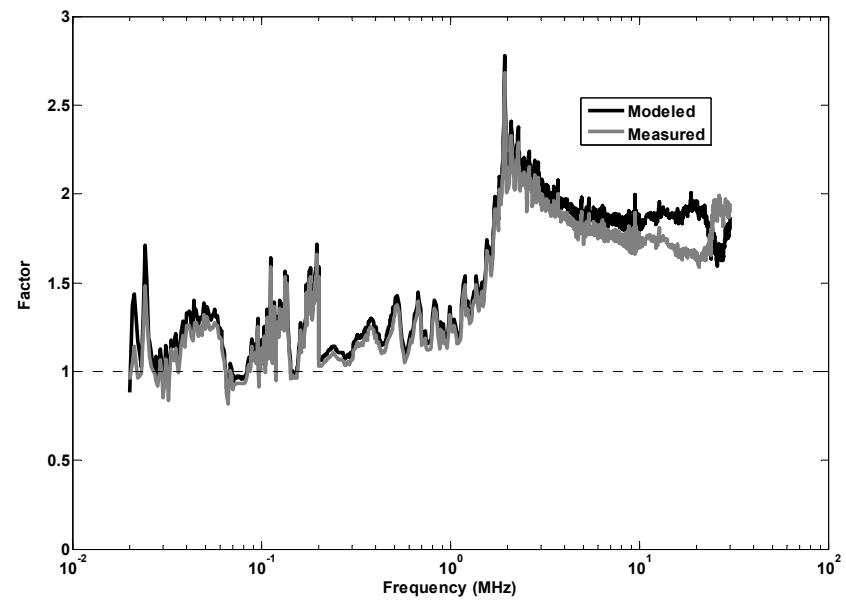

Figure 86: Comparison of the modeled and measured modification factors related to the current $I_{c m 2}$.

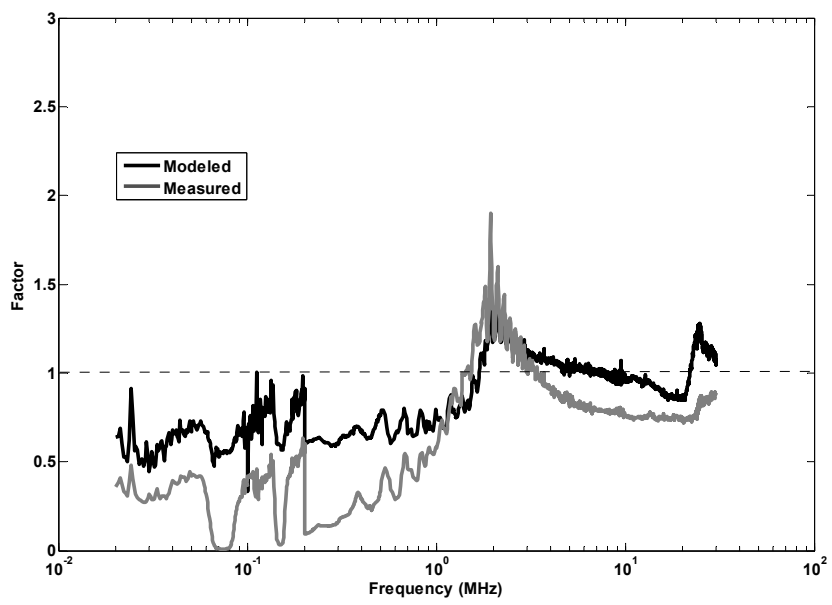

Figure 87: Comparison of the modeled and measured modification factors related to the current $I_{\text {cable }}$. 


\subsection{Insertion of the filter structure and the $\mathrm{Y}$-capacitors}

The structure of the common mode filter with only $\mathrm{Y}$-capacitors is inserted at the output of the AC/DC converter. The structure of the filter inserts a parasitic capacitance to the ground of $23 \mathrm{pF}$ in the system as presented in the last section.

At low frequencies, when the size of the components is significantly smaller than the wavelength, the current follows the path of the lowest impedance. The main objective of a $\mathrm{Y}$-capacitor is to reduce the value of the impedance to ground so that the common mode current does not reach the load but goes to the ground back to the source and/or the outside world. The limitation and risks of using $\mathrm{Y}$-capacitors are treated in section 3.2.b (p26). The filter is built with twice $3 * 4.7 \mathrm{nF}$ in parallel (for a total of $28 \mathrm{nF}$ ). The input impedance of the filter with $\mathrm{Y}$-capacitors together with the load could not be measured properly due to the limitation of impedance of the measurement set-up where the smallest impedance that can be measured is 50 Ohm. The Y-capacitor has been considered as ideal up to $30 \mathrm{MHz}$. If this measurement would have been possible the resonance observed in the measured modification factors could have also been visible in the input impedance of the system. Of course, the impedance can be measured on the component itself but then the filter has to be dismantled.

Two configurations have been tested and compared to the initial structure without filter. The following currents are presented in Figure 88: common mode current in the initial set-up $I_{c m 1}$ in the test-set-up (current 1 in Figure 88), common mode currents at the output of the converter with a filter with $\mathrm{Y}$-capacitors $I_{c m 2}$ in test setup (currents 4 and 6 in Figure 88) and the common mode currents $I_{\text {cable }}$ flowing in the cable after the filter (currents 5 and 7 in Figure 88). The currents 4 and 5 in Figure 88 are related to the configuration where the $\mathrm{Y}$-capacitor is placed the farthest from the output of the converter. The currents 6 and 7 refers to the configuration with Y-capacitor placed the closest. Figure 89 presents the respective equivalent circuit of the set-up without filter (top) and two equivalent circuits of the set-up with the Y-capacitor (bottom) placed respectively the closest or the farthest from the output of the converter. In this last configuration the common mode current first crosses the parasitic of the structure of the filter before reaching the Ycapacitor.

The modification factor related to $I_{c m 2}$ and $I_{\text {cable }}$ can be expressed as follows: 


$$
\frac{I_{c m 2}}{I_{c m 1}}=\frac{V_{t h 2}}{V_{t h 1}} * \frac{Z_{L}+Z_{t h}}{\frac{Z_{Y} *\left(\frac{Z_{L} * Z_{P}}{Z_{L}+Z_{P}}\right)}{Z_{Y}+\left(\frac{Z_{L} * Z_{P}}{Z_{L}+Z_{P}}\right)}+Z_{t h}}=\frac{V_{t h 2}}{V_{t h 1}} * \frac{Z_{L}+Z_{t h}}{Z_{e q 2}+Z_{t h}}
$$

$$
\begin{aligned}
\frac{I_{\text {cable }}}{I_{c m 1}}=\frac{Z_{P}}{Z_{L}+Z_{P}} * \frac{Z_{Y}}{Z_{Y}+\frac{Z_{P} * Z_{L}}{Z_{L}+Z_{P}} * \frac{I_{c m 2}}{I_{c m 1}}} \\
\quad=\frac{V_{t h 2}}{V_{t h 1}} * \frac{Z_{P}}{Z_{L}+Z_{P}} * \frac{Z_{Y}}{Z_{Y}+\frac{Z_{P} * Z_{L}}{Z_{L}+Z_{P}}} * \frac{Z_{L}+Z_{t h}}{Z_{e q 2}+Z_{t h}}
\end{aligned}
$$

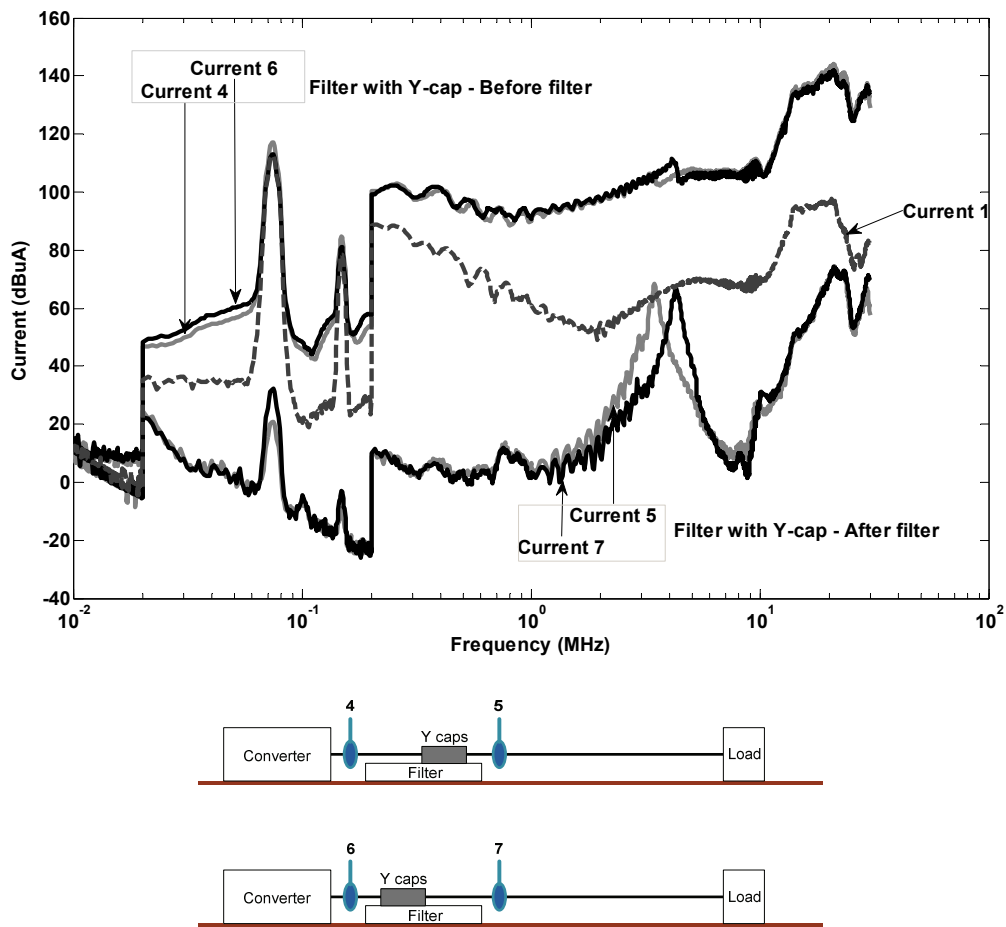

Figure 88: Comparison of the common mode current flowing in the initial set-up (current 1) with the ones flowing at the output of the converter after insertion of the Y-capacitors (current 4 and 6) and the ones flowing at the output of the filter with Y-capacitors (currents 5 and 7). 

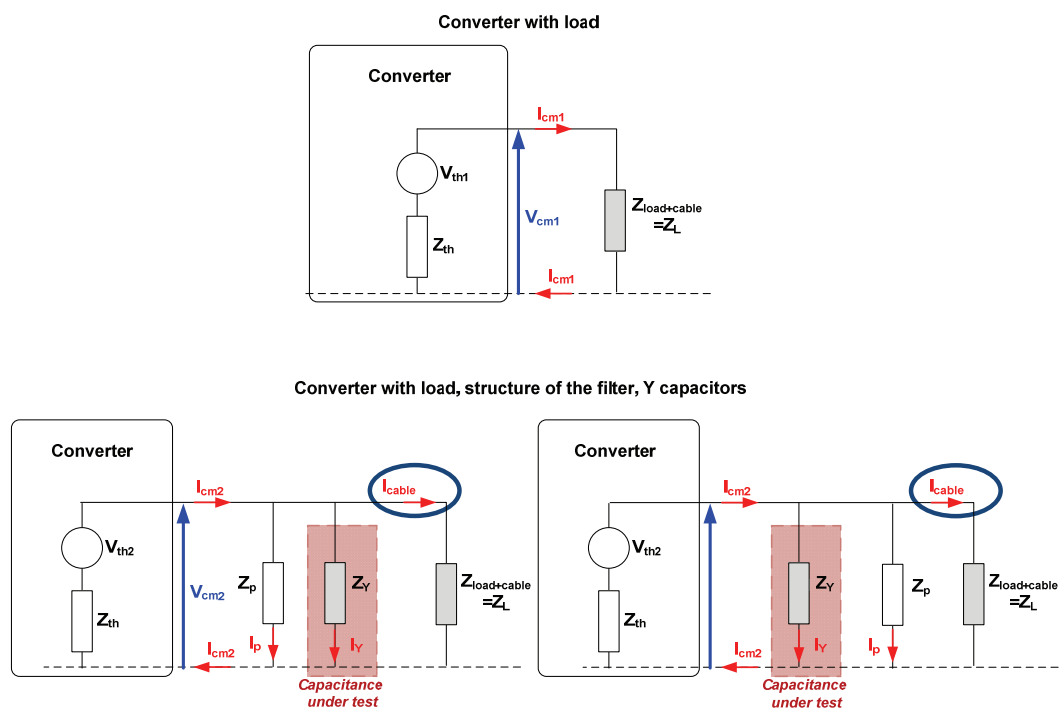

Figure 89: Common mode equivalent circuit of the load, its cable and the structure of the filter and the Y-capacitors.

These correction factors are valid for the structure where the Y-capacitor is placed closest to the output of the converter. For the second configuration considered, where the Y-capacitor is placed farthest from the output of the converter, the two impedances $Z_{p}$ and $Z_{y}$ have to be switched in the correction factors. Figure 90 and Figure 91 compare the measured modification factor with the modelled one, respectively for the current $I_{c m 2}$ and $I_{c a b l e}$. In Figure 91 both linear (top) and logarithmic scale (bottom) are presented. The configuration with the Y-capacitor placed the closest is chosen. The modelled attenuation factor of the current $I_{c m 2}$ matches very well the measured one. This current is amplified from a factor close to $2(6 \mathrm{~dB})$ in the low frequency range to a factor of the order of $20(26 \mathrm{~dB})$ in the high frequency range $(30 \mathrm{MHz})$. This increase of current is also clearly visible in Figure 88 (current 6).The modelled attenuation factor of the current $I_{\text {cable }}$ does not match well with the modelled one. A resonance around $3 \mathrm{MHz}$ is visible in Figure 88 (current 7). This resonance is related to the non-ideal behaviour of the Y-capacitor and shows why the designer should have the knowledge of the behaviour of each components involved in the design. This filter has been designed for educational purposes: it offers the possibility to add and remove each component independently. When components are not used (like in this configuration, there is no common mode choke, a long PCB track replaces it and introduces a parasitic inductance in the design. This explains the shift in the resonant frequency of resonance. When the Y-capacitor is placed away from the source, this track is longer. This should not 
happen in a properly designed EMI filter, and this structure has the advantage to illustrate it. Apart from the non-desired resonance around $300 \mathrm{kHz}$, where the current is not attenuated, the current in the cable is decreased by a factor $10(20 \mathrm{~dB})$ thanks to the $\mathrm{Y}$-capacitor.

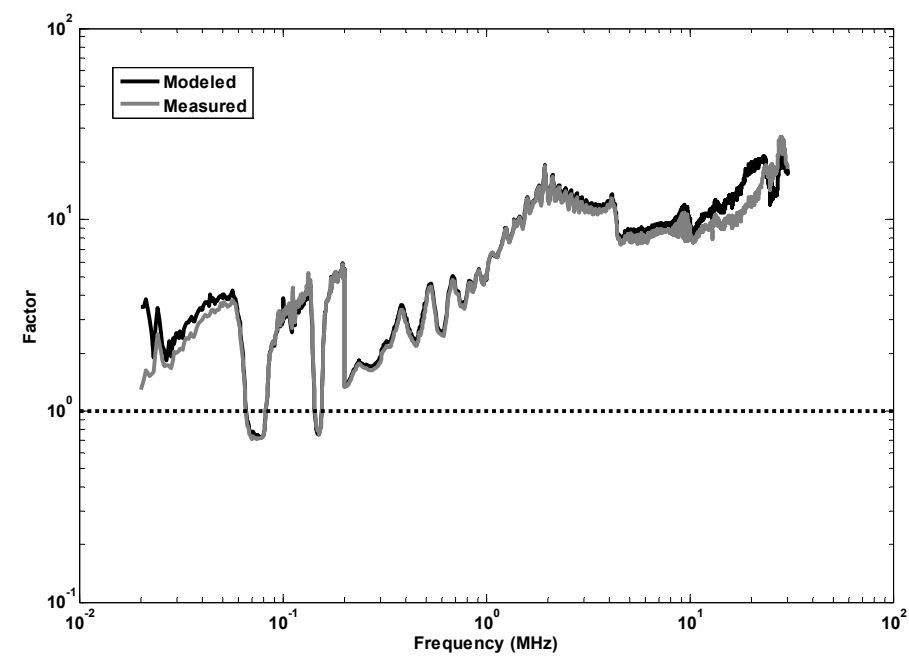

Figure 90: Comparison of the modelled and measured modification factors related to the current $I_{c m 2}$.
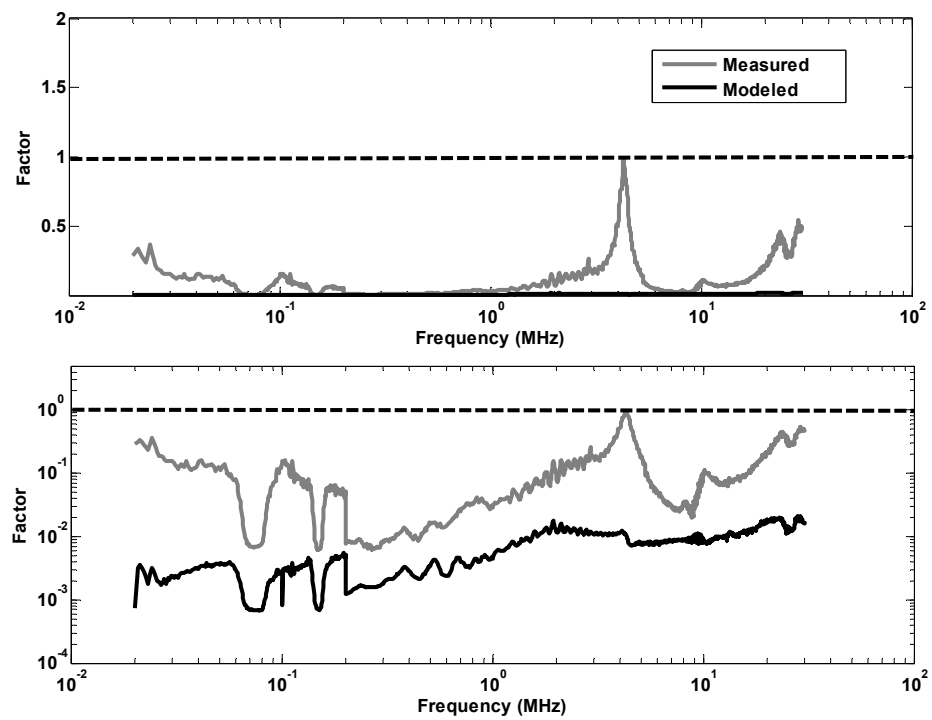

Figure 91: Comparison of the modeled and measured modification factors related to the current $I_{\text {cable }}$ (top graph in linear scale, bottom graph in $\mathrm{dB}$ scale). 


\subsection{Insertion of the filter structure and the common mode choke}

The CMC has been presented extensively in Chapter 3 and 4. This section starts with a set-up where only a CMC is inserted at the output of the AC/DC converter to first study the impact of the parasitic capacitance to ground of the component itself. The study of the choke inserted in the filter structure is presented subsequently, next to introduce the study of the complete EMI filter presented in the next section.

5.7.a. Discussion on the parasitic capacitance of the choke with respect to the ground

The overall capacitance to ground is modified by the insertion of the choke into the set-up. The value of this parasitic capacitance will depend on the position of the core with respect to the ground. If the choke is standing, the parasitic capacitance only exists between the closest areas of the windings from the ground and the ground itself. If the choke is lying above the ground, the capacitance is higher as one side of both windings is fully involved in the new parasitic capacitance. Figure 92 presents the parasitic capacitance to ground according to the position of the choke with the

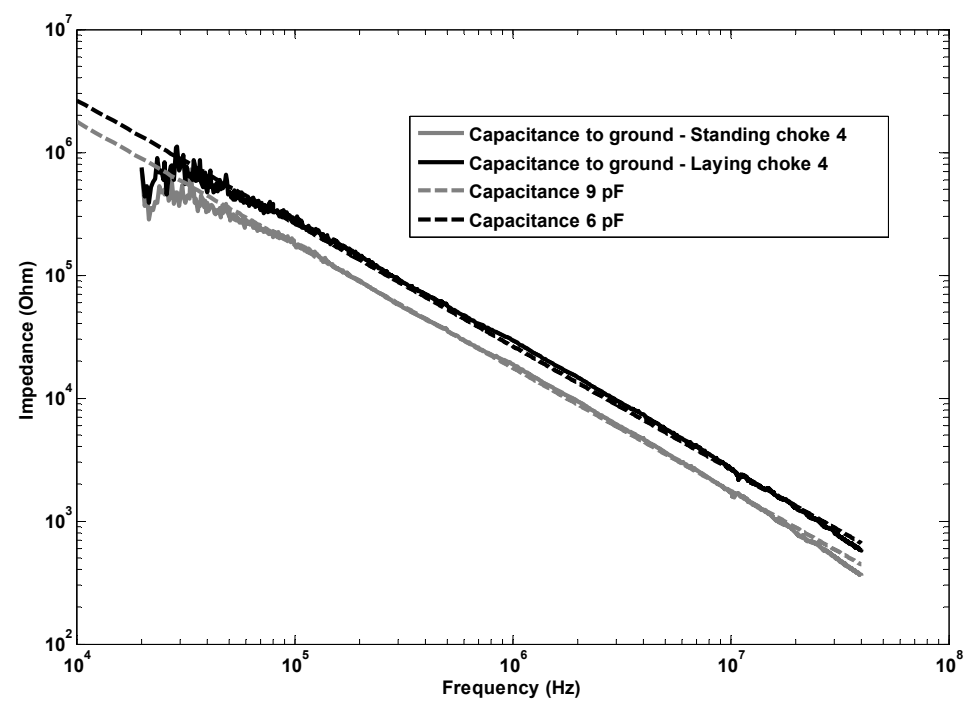

Figure 92: Parasitic capacitances to ground according to the position of the chokeMeasured without the structure of the filter. 
ground. Choke number 4 is used.When the choke is standing the capacitance is $6 \mathrm{pF}$ and when it is lying on the ground the value is increased to $9 \mathrm{pF}$. This value is rather small in this case but can be important in case of a bigger filter for high power applications where the choke can be 10 times bigger or more. It will be shown in the next section that the parasitic capacitance to ground of the choke plays a key role in the overall performances of the EMI filter.

\section{7.b. Insertion of the common mode choke}

Figure 93 presents the modification of the common mode input impedance with the insertion of chokes made of nanocrystalline. The common mode chokes used in these graphs are the same as those presented in Chapter 3 and 4 of this thesis. Their description can be found in Table 9 of this chapter. The choke is inserted at the very beginning of the cable (as close possible to the output of the converter).

The choke insertion should ideally increase the impedance seen by the common mode current: the additional impedance brought by this component should be interpreted by a proportional amount of current transformed in heat and eliminated. It does not to change the path of the current as in the case of the Y-capacitors.

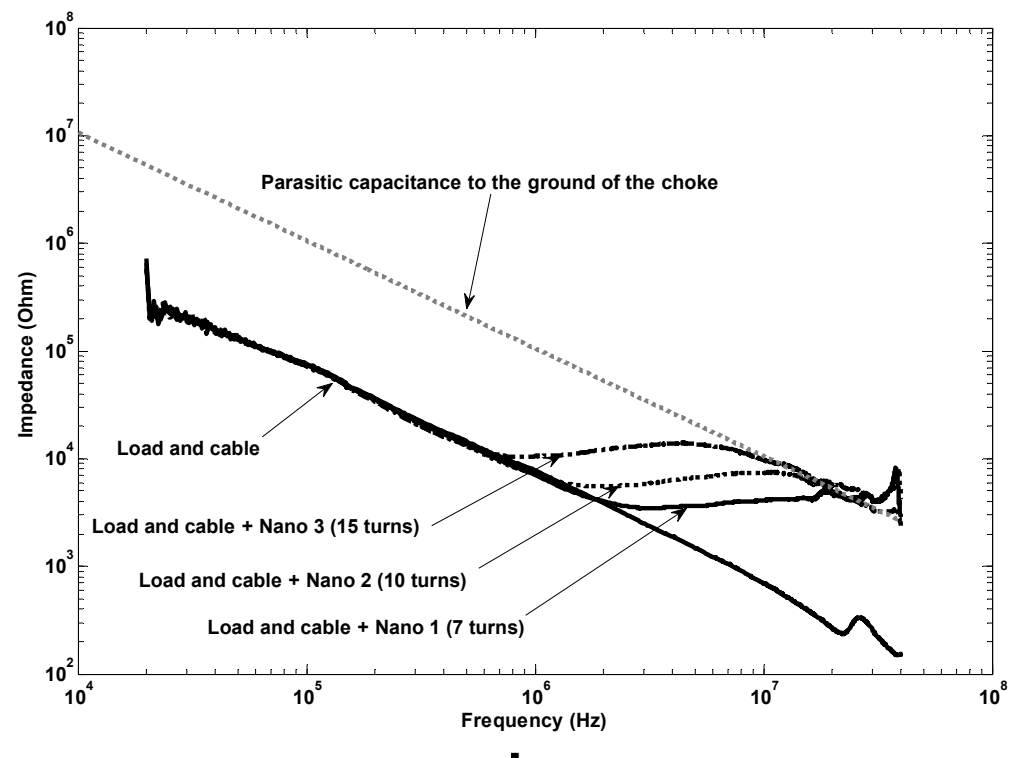

Figure 93: Input common mode impedance of the load, its cable and nanocrystalline chokes - Measured without the structure of the filter. 


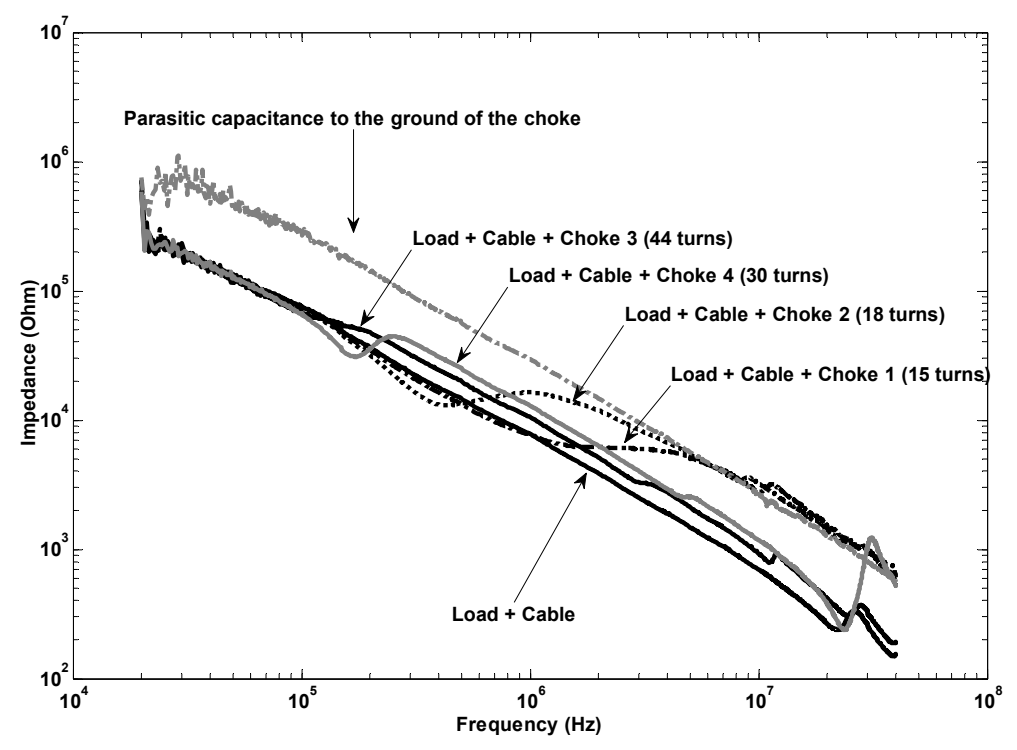

Figure 94: Input common mode impedance of the load, its cable and ferrite chokes Measured without the structure of the filter.

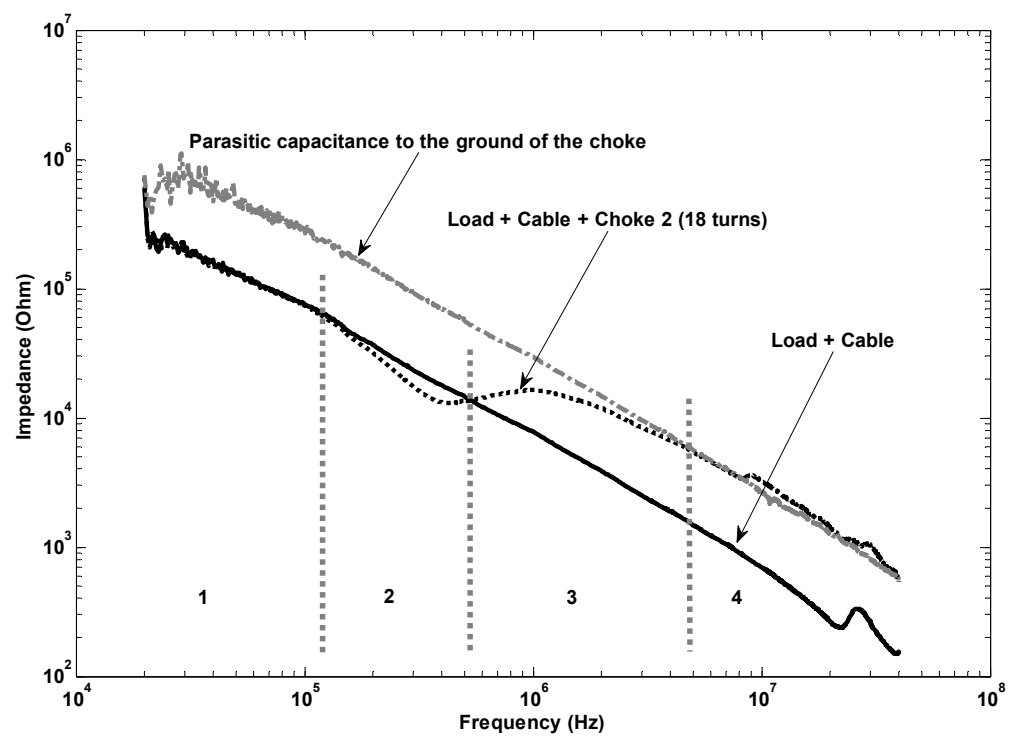

Figure 95: Input common mode impedance of the load, its cable and common mode choke 4 - Measured without the structure of the filter. 
It appears that the performances of a common mode choke can only be evaluated while taking into account the impedance of its own parasitic capacitance with the ground. The impedance after the insertion of the choke presents typically four parts (or less). These parts are illustrated in Figure 95 with the impedance modified by choke 2. The impedance modified by a common mode choke goes through the following parts (starting from low frequencies towards the high ones):

Part 1: At lower frequencies the impedance is not changed. At these frequencies the impedance of the common mode choke is built from the real part of the complex permeability, there is no transformation of the current into heat. The common mode current is not attenuated. In Figure 95 this occurs up to $1 \mathrm{MHz}$. The current goes through the choke and then the impedance to ground formed by the load and its cable.

Part 2: A resonance of current occurs when the impedance of the cable + load is equal to the one of the choke. Just before the resonance frequency, the modified impedance by the choke is below the initial impedance of the load and the cable. In this frequency range the common current is actually increased (lower impedance) between 1 and $5.5 \mathrm{MHz}$ as shown in Figure 95.

Part 3: At the frequencies after resonance, the impedance is increased due to the insertion of the choke. The more the impedance is increased the better is the attenuation, between 5.5 and $50 \mathrm{MHz}$ as shown in Figure 95.

Part 4: The input common mode impedance continues to be modified by the choke and becomes equal or higher to the parasitic capacitance to the ground of the choke itself. The path of lowest impedance is now going through the parasitic capacitance to the ground. The choke has a much more limited use when the parasitic capacitance is larger. The behaviour observed in part 4 does not always occur. It depends on the value of the parasitic capacitance of the choke with the ground: if the parasitic impedance is higher (or capacitance small enough) than the one of the choke and its cable the part 4 does not occur.

In Figure 93 the parasitic capacitance to the ground of the nanocrystalline is smaller. These chokes have 'home made' windings: a copper wire with plastic isolation has been used. Chokes made of ferrite (Figure 94) are off the shelf and a copper wire is used for the windings. The direct parasitic capacitance to ground is higher for the choke made of ferrite because of the windings material. 


\section{7.c. Insertion of the common mode choke and the filter structure}

Now the common mode choke is connected to the filter structure. Figure 97 presents the input common mode impedance of the load, its cable and a common mode choke with the filter structure. The behaviour of this impedance follows the same steps presented in Figure 95. Figure 98 shows how the common mode input impedance of the load is modified by the choke with and without filter structure. It shows how the value of the parasitic capacitance to ground of the choke or the structure on which it is mounted is influenced. On the one hand it increases the general value of the capacitance to ground and may limit the value of eventual Ycapacitors. On the other hand the resonance between the impedance to ground and the common mode impedance of the choke is shifted. It may result in a deviation of frequency range of use and/or in a more important increase of the value of the common mode current at this resonance. The shift of frequency is especially visible for chokes 1, 2 and 4. The increase of current at the resonance is significant for chokes 2 and 4 .

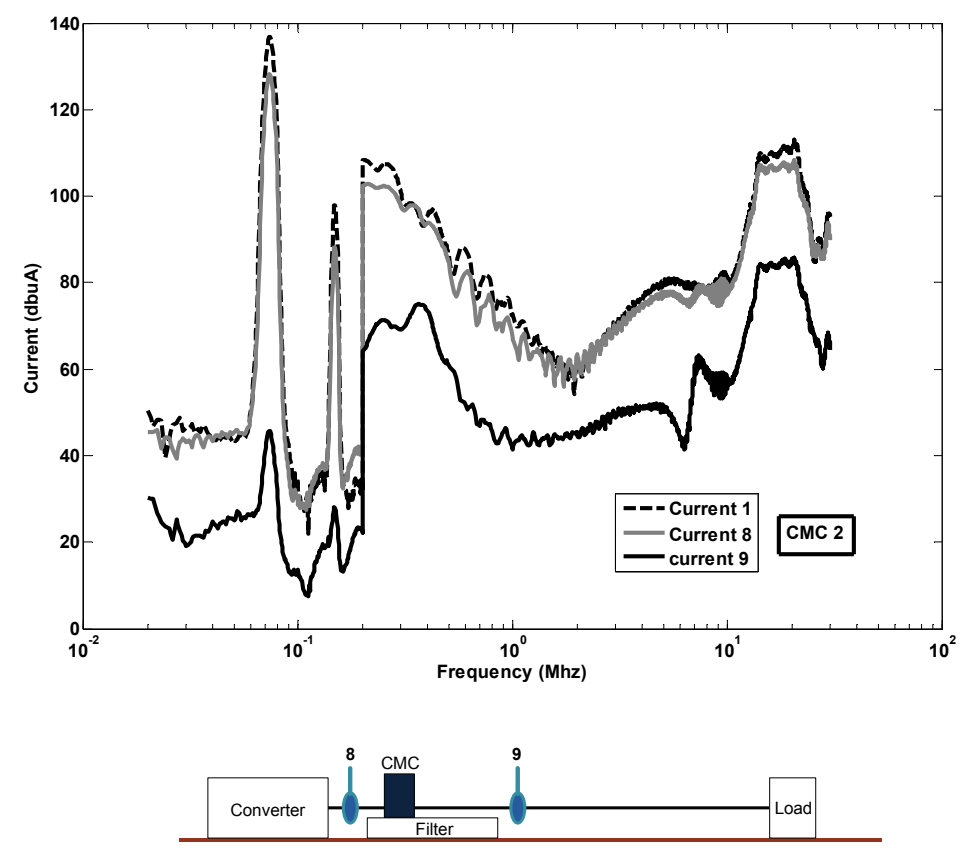

Figure 96: Comparison of the common mode current flowing in the initial test setup (current 1) with the ones flowing at the output of the converter and the filter after the insertion of the common mode choke 2. 


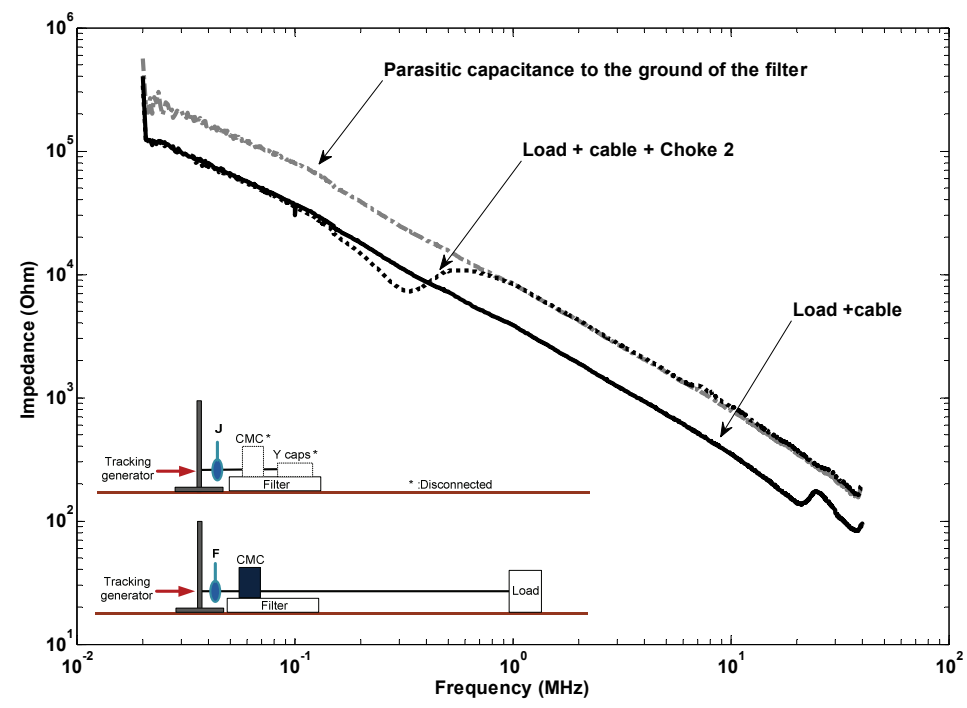

Figure 97: Input common mode impedance of the load, its cable and a common mode choke with the filter structure.

Figure 99 presents two common mode equivalent circuits: on the right the one for the converter with its load is the reference. On the left, the equivalent common mode circuit for the load, its cable, the structure of the filter and a common mode choke is presented. The parasitic impedance to ground formerly named $Z_{p}$ in the last sections is here divided into two equal impedances to ground $\left(Z_{p 1}\right.$ and $\left.Z_{p 2}\right)$ of $11.5 \mathrm{pF}$. The parasitic impedance to ground of the filter is divided in two as the common mode choke stands in the middle of the filter, and placed on both sides of the component. 

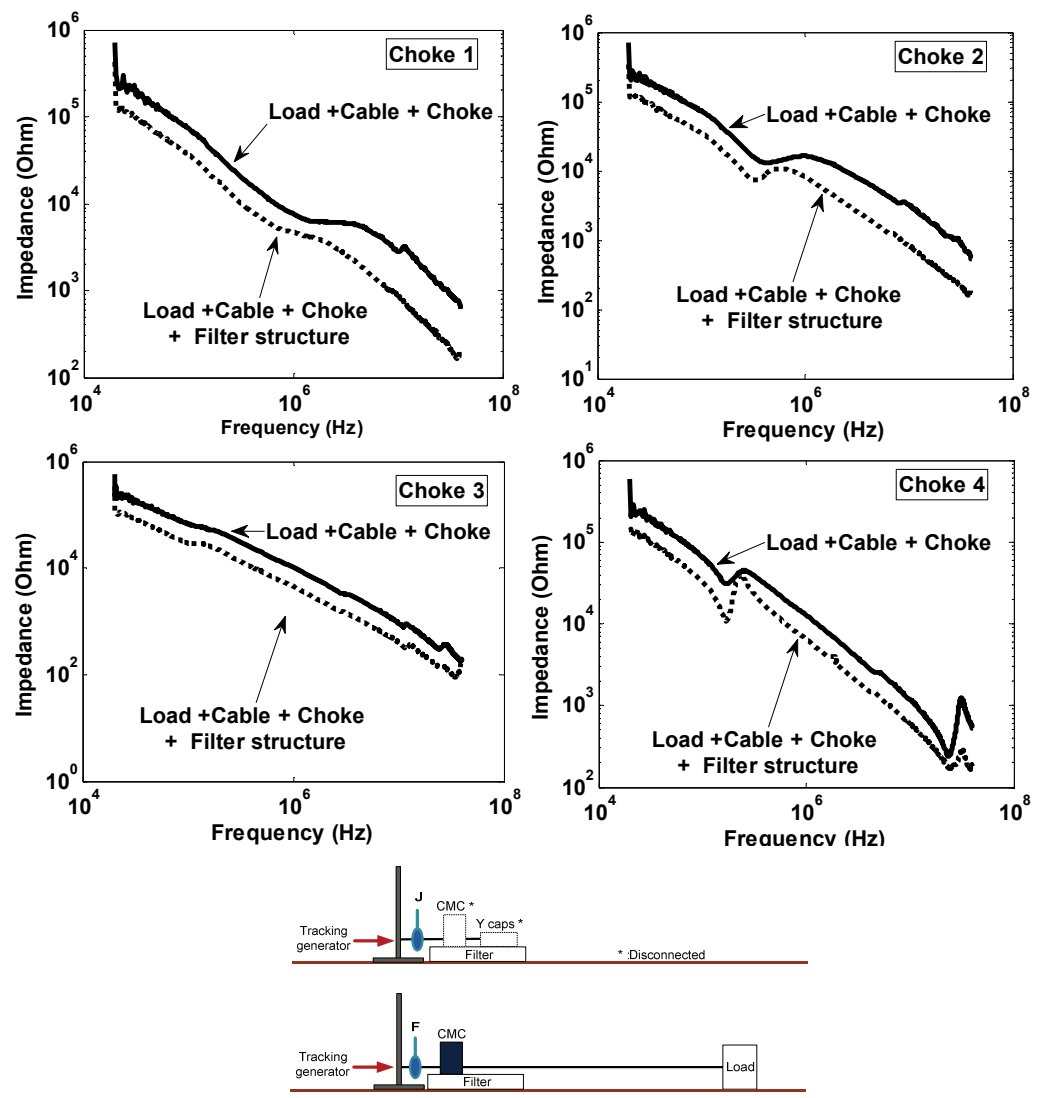

Figure 98: Comparison of the modified impedance of the load by the choke with and without filter structure.
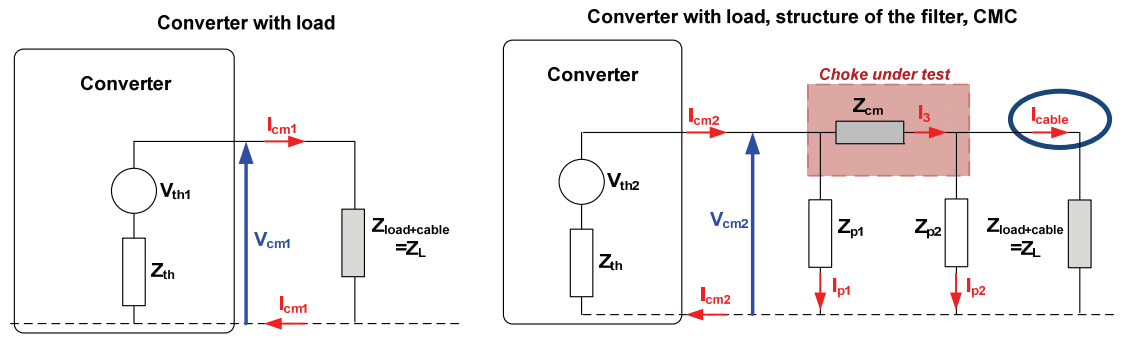

Figure 99: Common mode equivalent circuit of the load, its cable, the structure of the filter and common mode choke. 
The modification factor related to $I_{c m 2}$ and $I_{\text {cable }}$ can be expressed as follows:

$$
\frac{I_{c m 2}}{I_{c m 1}}=\frac{V_{t h 2}}{V_{t h 1}} * \frac{Z_{L}+Z_{t h}}{\frac{Z_{P 1} *\left(Z_{C M C}+\frac{Z_{L} * Z_{P 2}}{Z_{L}+Z_{P 2}}\right)}{Z_{P 1}+Z_{C M C}+\left(\frac{Z_{L} * Z_{P 2}}{Z_{L}+Z_{P 2}}\right)}+Z_{t h}}=\frac{V_{t h 2}}{V_{t h 1}} * \frac{Z_{L}+Z_{t h}}{Z_{e q 3}+Z_{t h}}
$$

$$
\begin{aligned}
\frac{I_{\text {cable }}}{I_{c m 1}}=\frac{Z_{P 2}}{Z_{L}+Z_{P 2}} & * \frac{Z_{P 1}}{Z_{P 1}+Z_{C M C}+\frac{Z_{L} * Z_{P 2}}{Z_{L}+Z_{P 2}}} * \frac{I_{c m 2}}{I_{c m 1}} \\
& =\frac{V_{t h 2}}{V_{t h 1}} * \frac{Z_{P 2}}{Z_{L}+Z_{P 2}} * \frac{Z_{P 1}}{Z_{P 1}+Z_{C M C}+\frac{Z_{L} * Z_{P 2}}{Z_{L}+Z_{P 2}}} * \frac{Z_{L}+Z_{t h}}{Z_{e q 3}+Z_{t h}}
\end{aligned}
$$

Figure 100 compares the measured values with the modelled common mode input impedances at the output of the converter when several CMCs and the structure of the filter are inserted. The very good agreement between the two families of curves confirms the structure of the common mode equivalent circuit (Figure 99) used to calculate the attenuation factors.

The modelled and the measured comparison factors are presented in Figure 101. In section 5 of this chapter the influence of the impedance of the track on the overall attenuation factor is addressed. The common mode chokes 2 and 3 are considered. This influence is also visible here and explains the deviation between the two curves. 

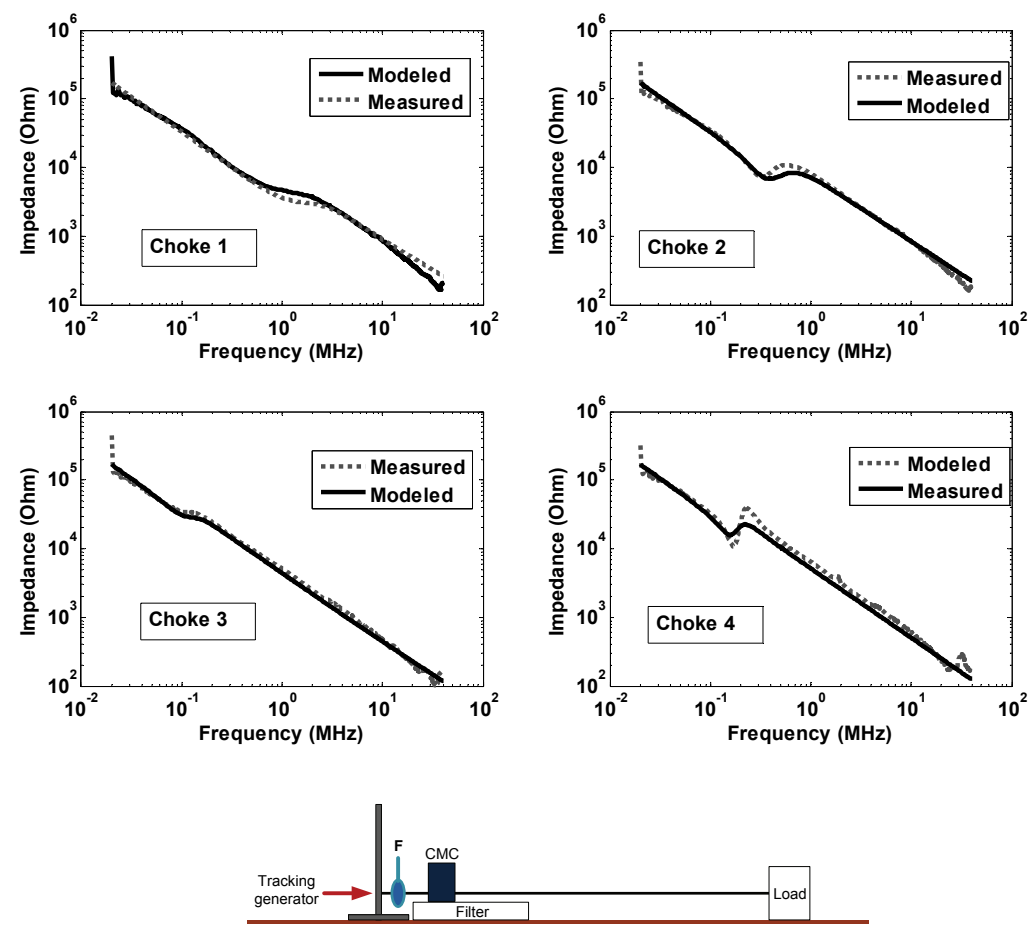

Figure 100: Measured and modelled common mode impedance at the output of the converter when different CMC and the structure of the filter is inserted.

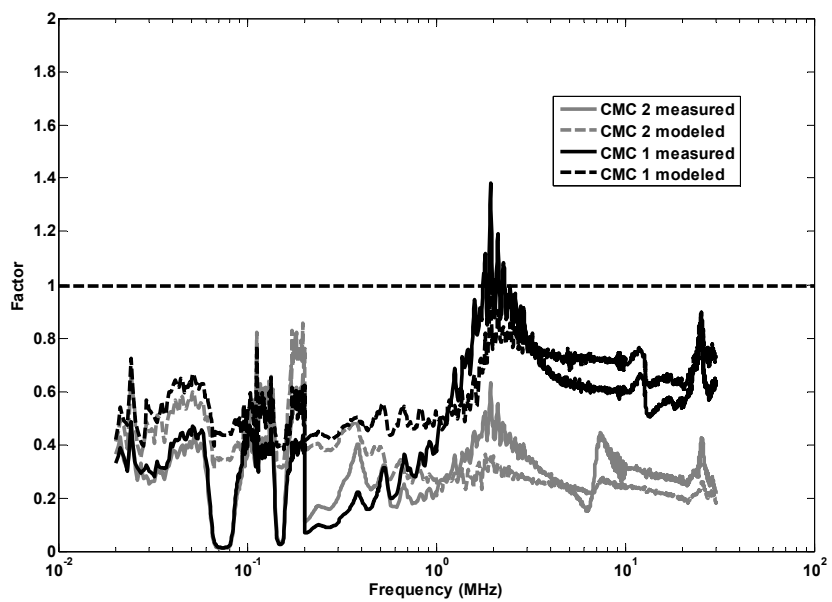

Figure 101: Modification factor of the common mode current at the output of the EMI filter after the insertion of the CMC 2. 


\subsection{Insertion of the common mode choke and the $\mathrm{Y}$ capacitor}

The structure of the common mode filter with the common mode choke and the $\mathrm{Y}$ capacitors is inserted at the output of the $\mathrm{AC} / \mathrm{DC}$ converter. The structure of the filter inserts a parasitic capacitance to the ground of $23 \mathrm{pF}$ in the system as presented in the last sections. The structure with only the Y-capacitor and only the common mode choke is presented in section 5 and 6 of this chapter, respectively. The combination of the two components is addressed in this section and the next. In this section the structure considered is formed first by the common mode choke, placed the closest to the output of the converter and second the Y-capacitor.

Figure 102 presents two common mode equivalent circuits: on the right the one for the converter with its load, it is the reference. On the left the structure of the filter has been inserted with a CMC followed by a Y-capacitor. The parasitic impedance to ground is here divided in two equal impedances to ground $\left(Z_{p 1}\right.$ and $\left.Z_{p 2}\right)$ of $11.5 \mathrm{pF}$ each.
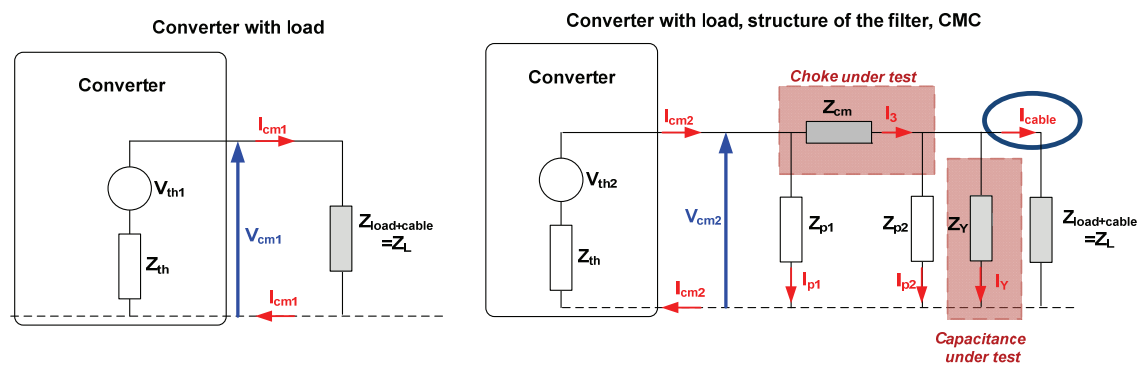

Figure 102: Common mode equivalent circuit of the load, its cable, the structure of the filter with the CMC and the Y capacitor (CMC-Y structure).

The modification factors related to $I_{c m 2}$ and $I_{c a b l e}$ can be expressed as follows:

$$
\begin{aligned}
& \frac{I_{c m 2}}{I_{c m 1}}=\frac{V_{t h 2}}{V_{t h 1}} * \frac{Z_{L}+Z_{t h}}{\frac{Z_{P 1} *\left(Z_{C M C}+Z_{e q 4}\right)}{Z_{P 1}+Z_{C M C}+Z_{e q 4}}+Z_{t h}}=\frac{V_{t h 2}}{V_{t h 1}} * \frac{Z_{L}+Z_{t h}}{Z_{e q 5}+Z_{t h}} \\
& Z_{e q 4}=\frac{Z_{P 2} * Z_{Y} * Z_{L}}{Z_{P 2} * Z_{Y}+Z_{L} * Z_{Y}+Z_{P 2} * Z_{L}}
\end{aligned}
$$


$\frac{I_{\text {cable }}}{I_{c m 1}}=Z e q_{8} * \frac{I_{c m 2}}{I_{c m 1}}$

$\frac{I_{c a b l e}}{I_{c m 1}}=\frac{V_{t h 2}}{V_{t h 1}} * Z e q_{8} * \frac{Z_{L}+Z_{t h}}{Z_{e q 5}+Z_{t h}}$

$Z e q_{8}=\frac{Z_{P 2} * Z_{Y} * Z_{P 1}}{\left(Z_{P 2} * Z_{Y}+Z_{L} * Z_{Y}+Z_{P 2} * Z_{L}\right) *\left(Z_{P 1}+Z_{C M C}\right)+Z_{P 2} * Z_{Y} * Z_{L}}$

The common mode currents flowing directly at the output of the converter and in the cable after the successive insertion of the common mode choke 2 and 3 together with a Y-capacitor are presented in Figure 103 and compared with the common mode current flowing in the circuit without filter. As observed in the previous section for the other configurations of the EMI filter, the common mode current measured directly at the output of the converter and before the filter is increased, as

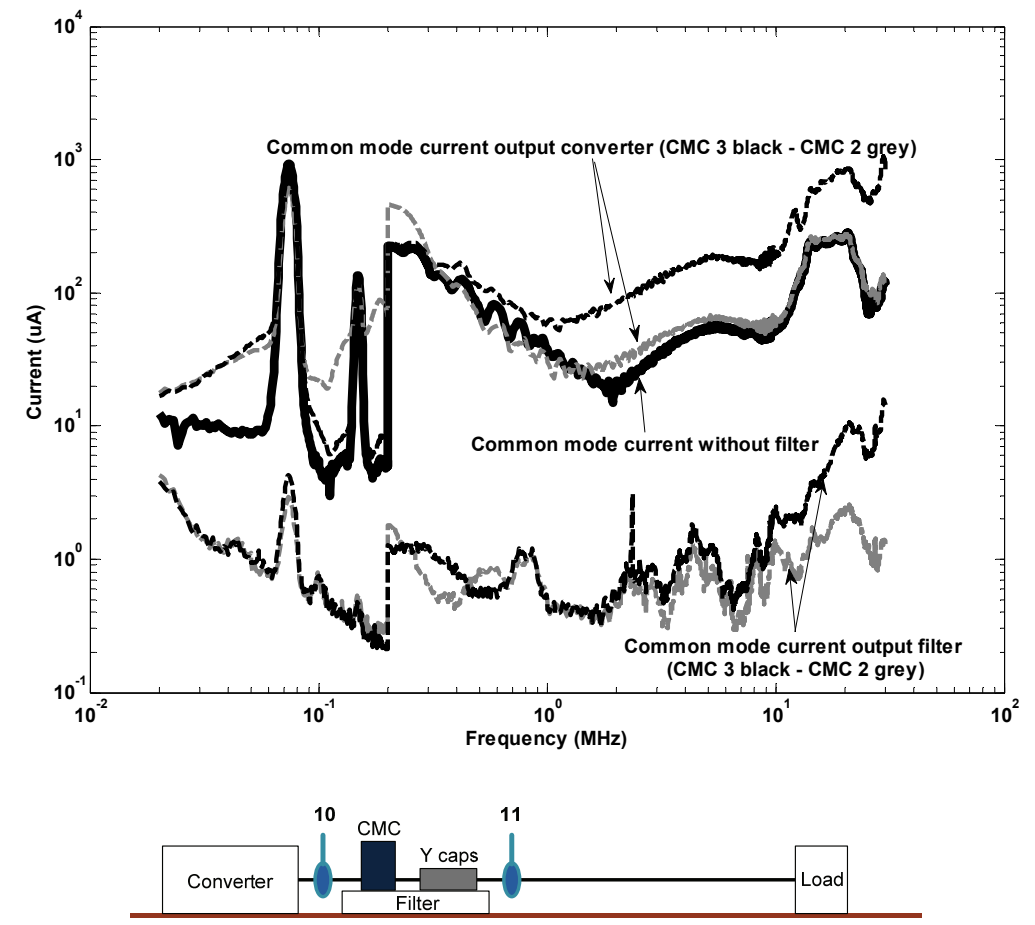

Figure 103: Common mode currents flowing directly at the output of the converter and in the cable after the successive insertion of the common mode choke 2 and 3 together with a $\mathrm{Y}$ capacitor. 
the $\mathrm{Y}$-capacitor and the parasitic capacitance to ground are diverting part of the current towards the ground before it reaches the load. This additional current is now flowing back and forward between the converter and the filter. The current flowing after the EMI filter is decreased, one part of it is absorbed by the common mode choke and the other part has been diverted by the components mentioned before within the filter. The measured common mode input impedance of the system formed by the load, its cable and the filter in the CMC-Y configuration are compared with the modelled one in Figure 104. The good agreement between the two families of curves confirmed the structure of the common mode equivalent circuits introduced in Figure 102. Figure 105 presents the input common mode impedance of the load, its cable, the structure of the filter, the choke 2 and a Ycapacitor. This impedance is compared with the one of an ideal Y-capacitor of $28 \mathrm{nF}$ and the impedance to ground of the filter.

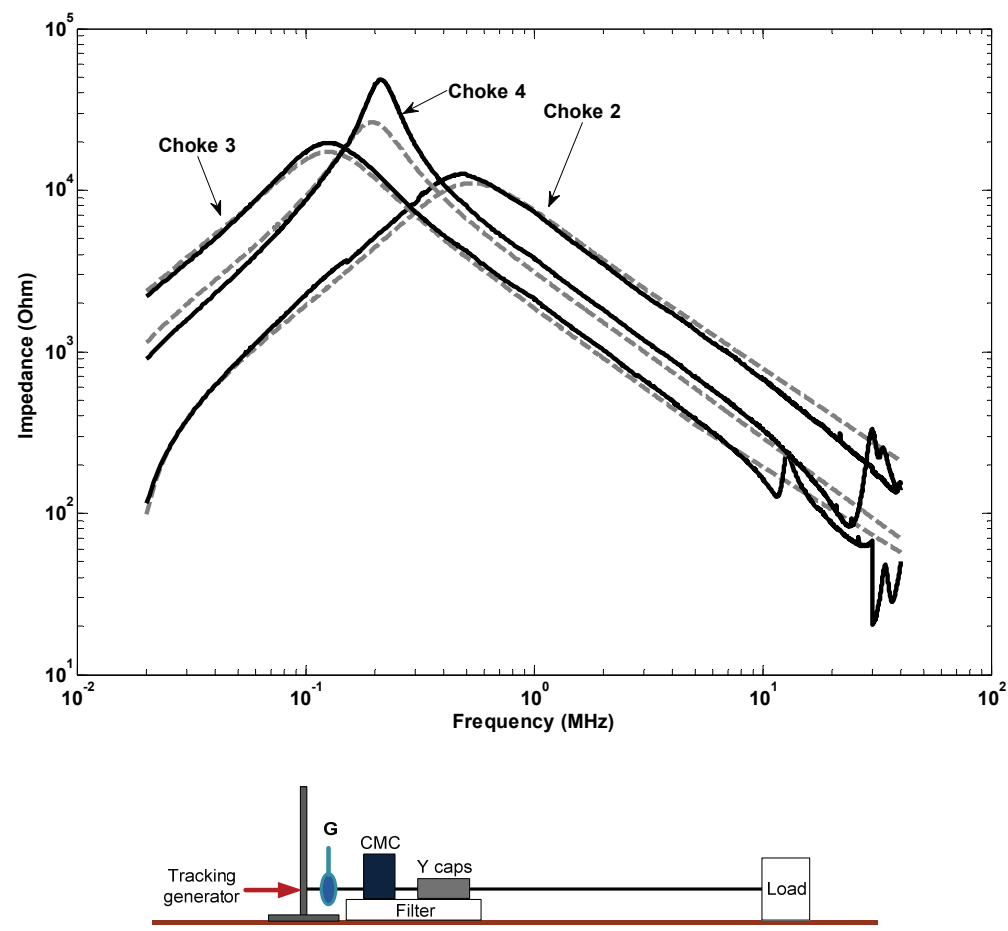

Figure 104: Comparison between measured and modelled common mode impedance at the output of the converter when different CMCs followed by a $\mathrm{Y}$ capacitor and the structure of the filter is inserted. 

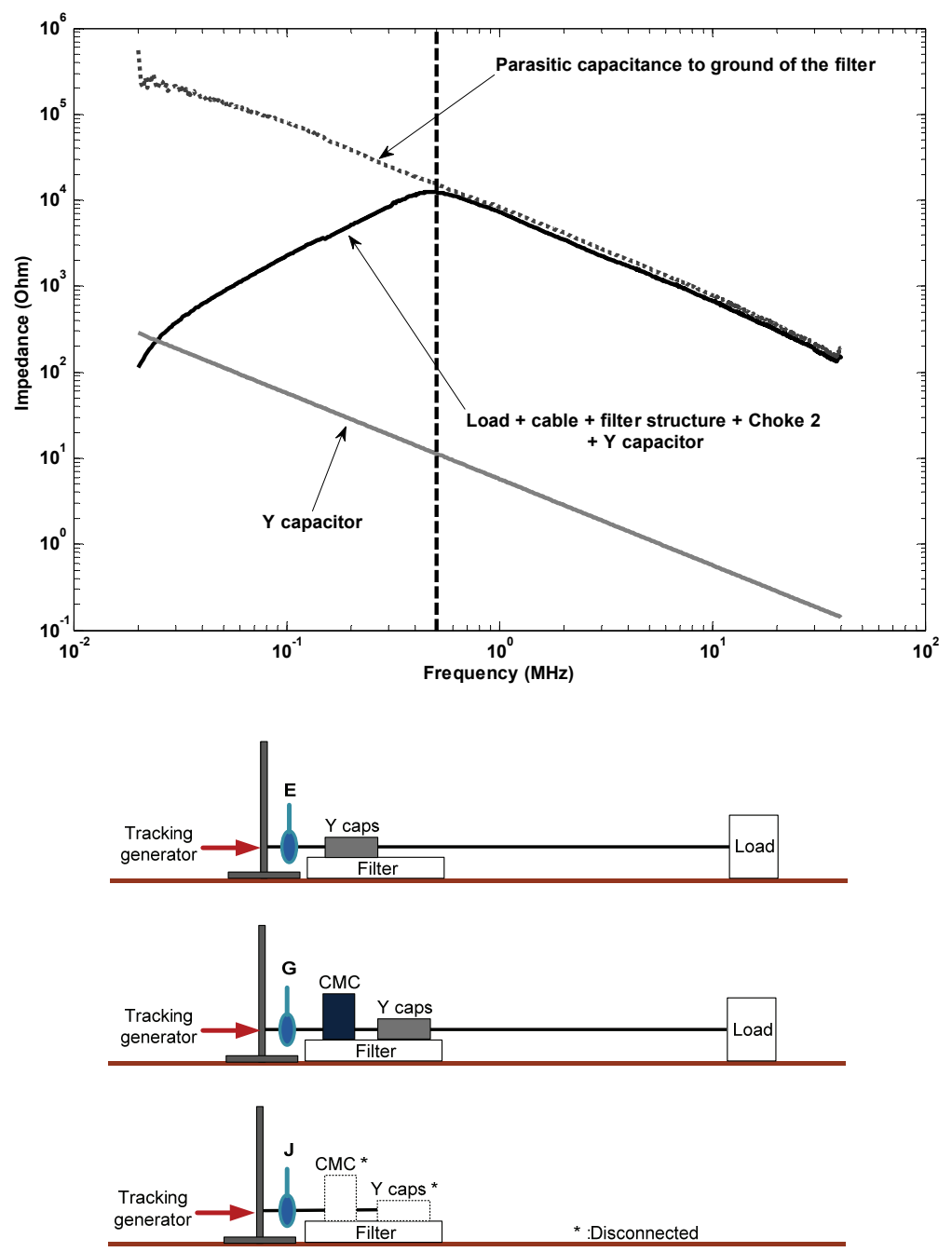

Figure 105: Input common mode impedance of the load, its cable, the structure of the filter, the choke 2 and a $\mathrm{Y}$ capacitor.

In the lower frequency range, below $500 \mathrm{kHz}$ marked by a vertical line in Figure 105, the common mode choke is built from the real part of the complex permeability and has an inductive behaviour, there is very little transformation of the current into heat. The common mode current is not attenuated. The current goes through the choke and then through the $\mathrm{Y}$-capacitor providing the path of lowest impedance after the choke. Instead of what had been presented in Figure 95 the impedance of 
the Y-capacitor is significantly smaller than the one of the common mode choke. The sum of both impedances in series results therefore in an increasing input impedance. The inductive behaviour of the choke is dominating the input common mode impedance in the CMC-Y configuration. In Figure 95 the impedance of the cable and the load and its cable is much higher than the one of the choke and dominates the input impedance (region 1). At higher frequencies in Figure 105, the highest contribution to the common mode input impedance is provided by the parasitic to ground of the filter, it is this contribution which is then measured. However, most of the common mode current flows through the $\mathrm{Y}$ capacitor which provides the path of lowest impedance to ground.

The performances of the common mode choke is still limited by the parasitic capacitance to ground of the filter in the high frequencies where the impedance of the common mode choke is higher than that of the filter to ground.

\subsection{Insertion of the $Y$ capacitor and the common mode choke}

The structure of the common mode filter with the common mode choke and the Ycapacitors is inserted at the output of the AC/DC converter. The structure of the filter inserts a parasitic capacitance to the ground of $23 \mathrm{pF}$ into the system as presented in the last sections. The $\mathrm{Y}$-capacitor is here placed as close as possible to the output of the converter followed by a common mode choke (Y-CMC structure).

Figure 106 presents two common mode equivalent circuits: on the right, the one for the converter with its load, which is the reference.
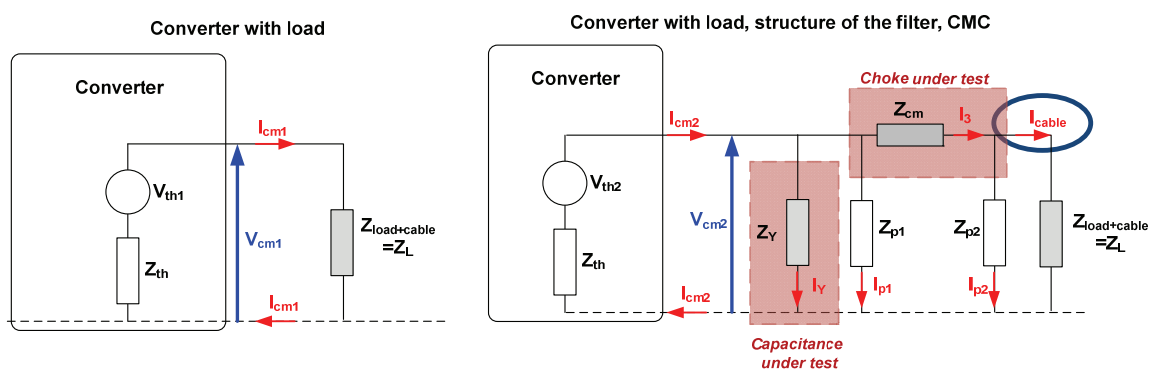

Figure 106: Common mode equivalent circuit of the load, its cable, the structure of the filter with the Y capacitor and the common mode choke (Y - CMC structure). 
On the left, the equivalent common mode circuit for the load, its cable, the structure of the filter and common mode choke followed by a Y-capacitor is presented. The parasitic impedance to ground is here divided in two equal impedances to ground $\left(Z_{p 1}\right.$ and $\left.Z_{p 2}\right)$ of $11.5 \mathrm{pF}$ each. The parasitic impedance to ground of the filter is divided in two halves as the common mode choke stands in the middle of the filter, and placed on both sides of the component. Figure 107 compares the common mode currents flowing directly at the output of the converter with and without filter with the one flowing at the output of the filter after its insertion into the Y-CMC configuration. In the test case the impedance path provided by the $\mathrm{Y}$-capacitor is smaller than the one formed by the common mode choke and the load. The amount of current going through the common mode choke is very limited. This is especially visible in this case as the non ideal behaviour of the $\mathrm{Y}$-capacitor is visible with a resonance between 4 and $5 \mathrm{MHz}$ that would have been filtered by the common mode choke otherwise, as it was the case in the CMC-Y configuration.

The modification factor related to $I_{c m 2}$ and $I_{\text {cable }}$ can be evaluated as follows:

$$
\begin{aligned}
& \frac{I_{c m 2}}{I_{c m 1}}=\frac{V_{t h 2}}{V_{t h 1}} * \frac{Z_{L}+Z_{t h}}{\frac{\left(Z_{Y} * Z_{P 1}\right.}{\left.Z_{Y}+Z_{P 1}\right) *\left(Z_{C M C}+\frac{Z_{L} * Z_{P 2}}{Z_{L}+Z_{P 2}}\right)}\left(\frac{Z_{Y} * Z_{P 1}}{\left.Z_{Y}+Z_{P 1}\right)+Z_{C M C}+\left(\frac{Z_{L} * Z_{P 2}}{Z_{L}+Z_{P 2}}\right)}+Z_{t h}\right.}=\frac{V_{t h 2}}{V_{t h 1}} * \frac{Z_{L}+Z_{t h}}{Z_{e q 6}+Z_{t h}} \\
& \frac{I_{c a b l e}}{I_{c m 1}}=\frac{V_{t h 2}}{V_{t h 1}} * Z_{e q 7} * \frac{Z_{L}+Z_{t h}}{Z_{e q 6}+Z_{t h}} \\
& Z_{e q 7}=\frac{Z_{p 2}}{Z_{p 2}+Z_{L}} * \frac{Z_{Y} * Z_{P 1}}{\left.Z_{Y}+Z_{P 1}\right)}\left(\frac{Z_{Y} * Z_{P 1}}{Z_{Y}+Z_{P 1}}\right)+Z_{C M C}+\left(\frac{Z_{L} * Z_{P 2}}{Z_{L}+Z_{P 2}}\right)
\end{aligned}
$$




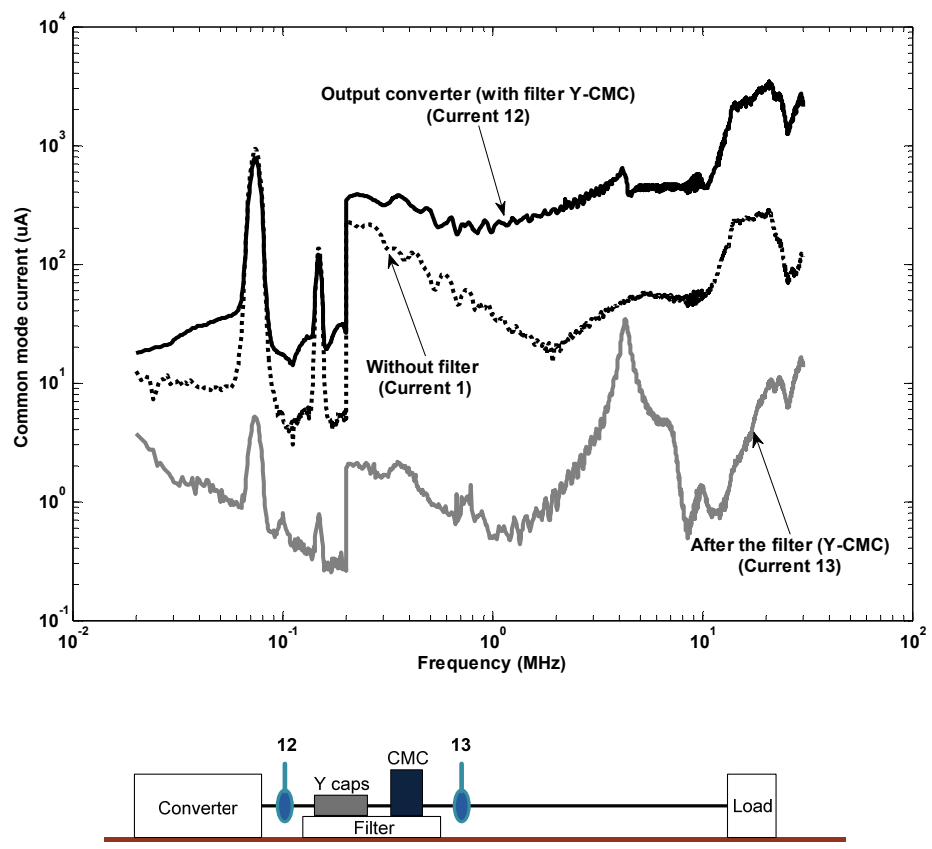

Figure 107: Common mode currents flowing directly at the output of the converter and in the cable after the successive insertion of the filter in Y-CMC configuration.

Figure 108 compares the modelled modification factor with the measured one for the common mode current flowing at the output of the converter, and at the input of the EMI filter in the Y-CMC configuration. There is a good agreement between the two curves. As the impedance of the $\mathrm{Y}$-capacitor to the ground becomes smaller with the growing frequency, the amount of current flowing through the component increases to reach a modification factor of the order of $20(26 \mathrm{~dB})$ at $30 \mathrm{MHz}$.

Figure 109 compares the modelled modification factor of the common mode current flowing at the output of the EMI filter in the Y-CMC configuration. Curves are provided both in linear and in logarithmic scale. The non-ideal behaviour of the Ycapacitor has not been taken into account in the simulation. This explains the missing resonance in the modelled factor. The general difference between the two curves is due to a measurement limitation, indeed the lowest current that can be measured is of the order of $10^{-1}(-20 \mathrm{~dB})$ for a modification factor of a minimum of $10^{-2}(-40 \mathrm{~dB})$. 


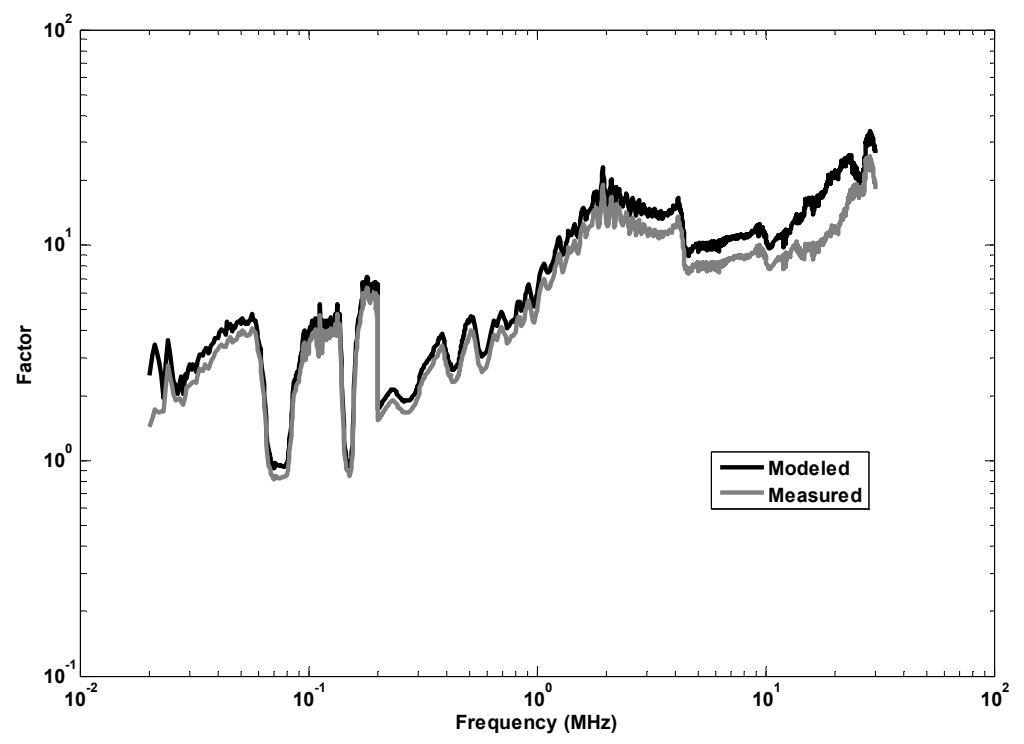

Figure 108: Modification factor of the common mode current at the output of the converter related to the introduction of the EMI filter in Y-CMC configuration.
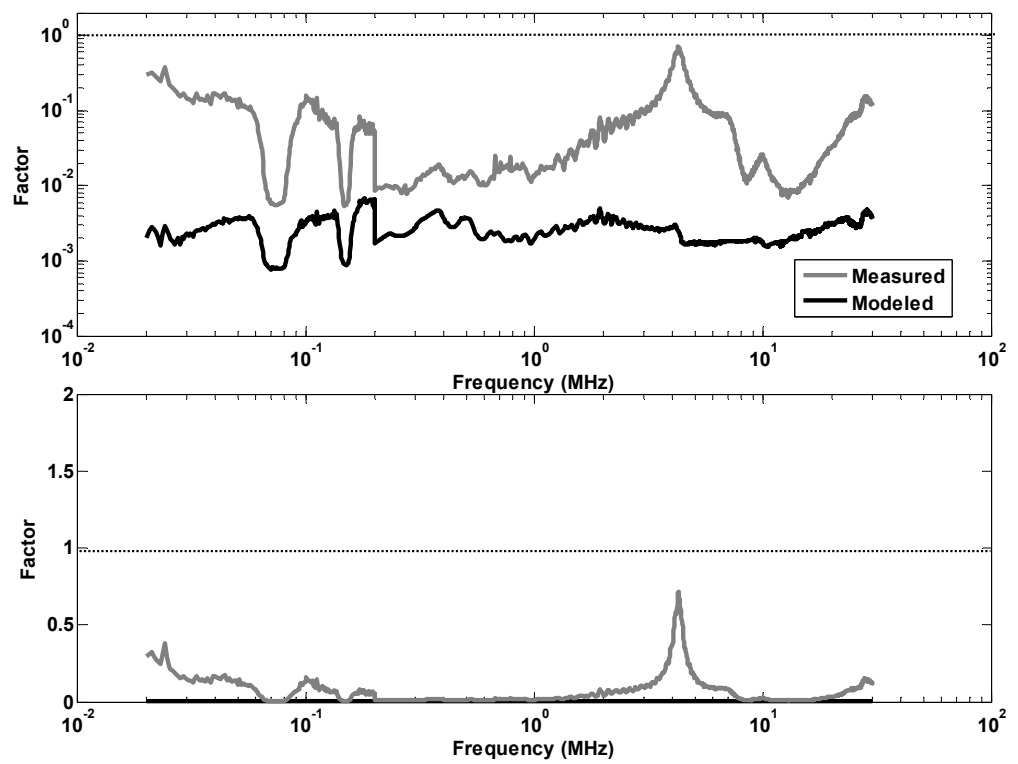

Figure 109: Modification factor of the common mode current at the output of the EMI filter in the Y-CMC configuration. 
Figure 110 presents an overview of the common mode current measured at the output of the EMI filter for different configurations and the common mode current measured without filter. Each configuration has been studied and a general model has been given to model the modification factors of the common mode currents both at the output of the converter and at the output of the EMI filter. Models have been validated via measurements. As shown in Figure 110 each EMI filter configuration leads to a very different common mode current attenuation where the environment, i.e. parasitic in the filter, impedance of the source and the load, as well as the dynamic behaviour of the noise course in the converter, play a role. An optimized filter should take into account all these parameters as it allows a more efficient attenuation of the final common mode current and also meets the typical requirements of the design of an EMI filter to keep space, cost and weight to a minimum.

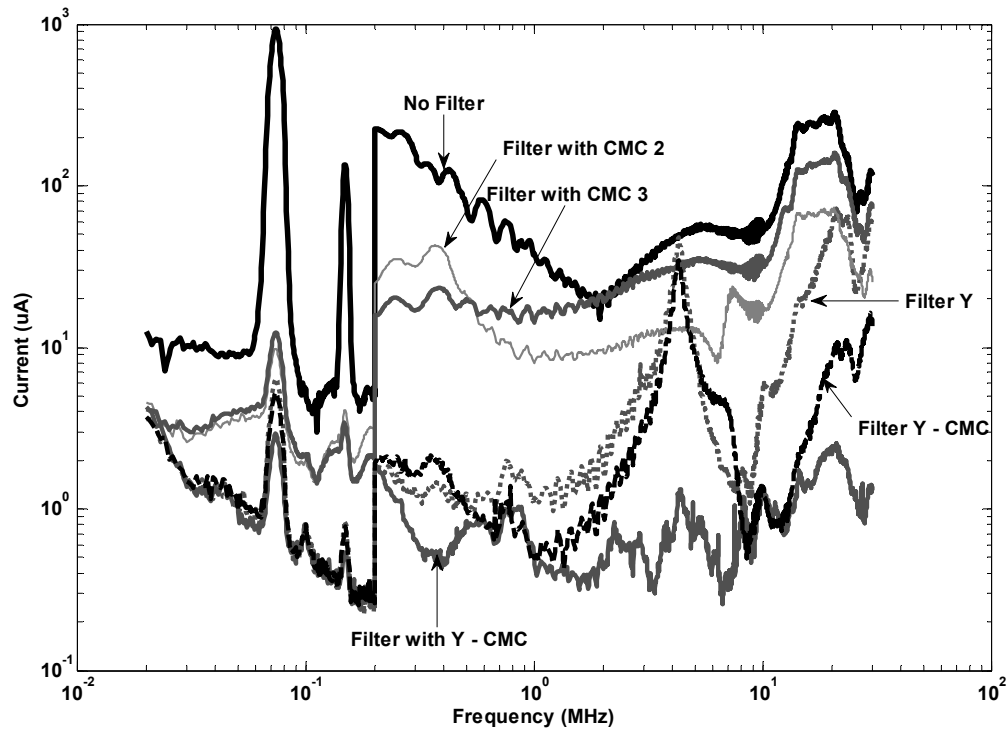

Figure 110: Overview of the common mode current at the output of the EMI filter for different configurations. 


\subsection{Overview of the structures of the EMI filter and design considerations}

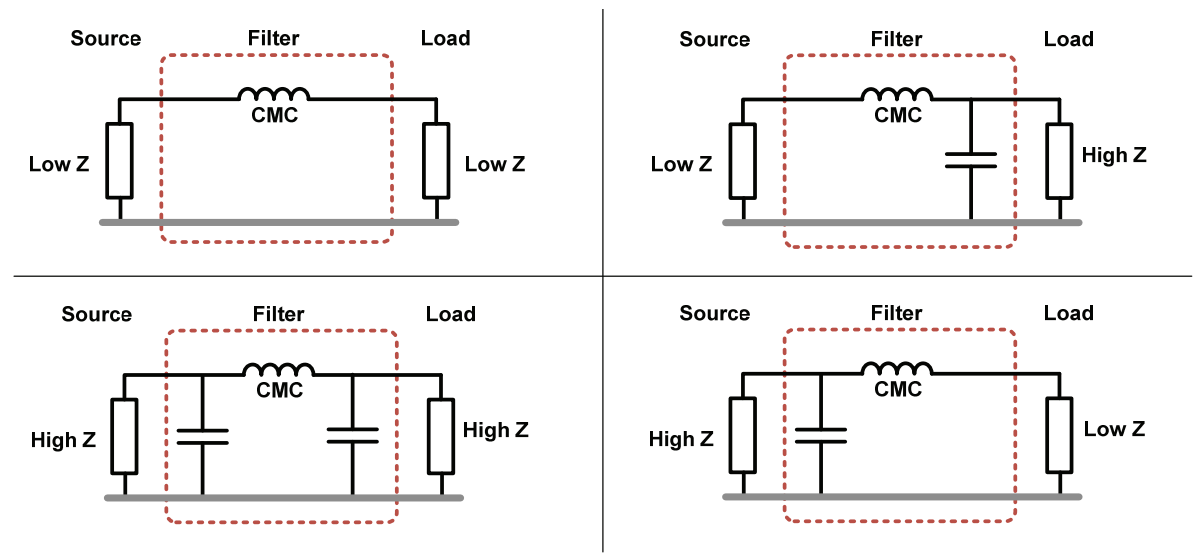

Figure 111: Filter configuration versus impedance.

The preceding study of the different EMI filter structures is used in this section to analyse the design rules presented in Figure 69 (and in this section Figure 111). Figure 112 presents the common mode current path that could be expected in the respective structure of Figure 111. The common mode impedance on both sides of the filter is assumed to be known (or measured) as seen from the filter itself. It means that all parasitic impedances upstream and downstream of the filter are taken into account.

Each of these structures is analysed in this section with a description of the common mode current path and the design limitations of each case. It is important to keep in mind the final objectives of the EMI filter which are to reduce the amplitude of the common mode current and/or divert from the load and its cables. This will prevent conducted and radiated emissions in and around the cable, as well as reflections of the common mode current at the load leading to possible damage to the load itself.

The status of low or high impedance introduced in Figure 111 is set with respect to the value of the component chosen in the EMI filter. For all structures the common mode current path and the performance of the EMI filter are addressed. 

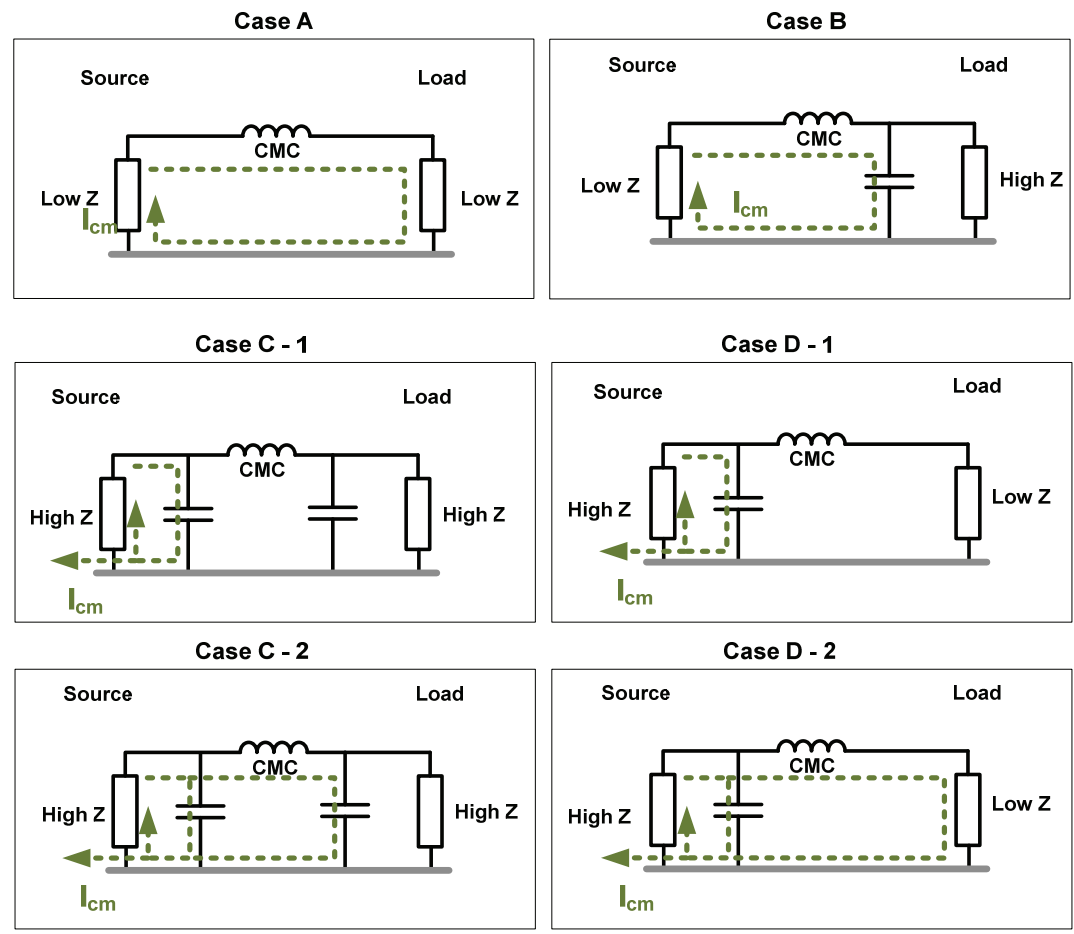

Figure 112: Filter configuration with common mode current flow paths.

\subsection{0.a. $\quad \mathrm{CMC}$ structure - case $\mathrm{A}$}

\section{Case A}

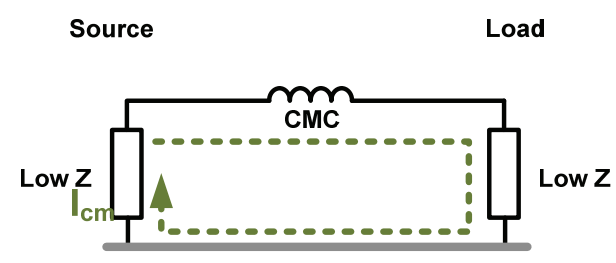

Figure 113: Case A/ CMC configuration.

In the case of a low impedance to ground on both sides of the filter, the use of a capacitor to ground would only be useful in case the value of the chosen capacitance is lower than the one of the load, providing then a path of lower impedance to the common mode current. Any impedance to ground higher than the one of the $\mathrm{Y}$ 
capacitor get a status of high impedance. These cases are addressed with the structures C-1 and D-1 of Figure 112.

Structure A of a common mode filter consists only of a common mode choke. The parasitic to ground of the common mode choke is neglected in a first step (if they cannot be, the case is equivalent to the situation $\mathrm{C}$ ), the modification factor of the common mode current $I_{c m 2}$ with respect to the initial one $I_{c m 1}$ can be expressed as follows:

$\frac{I_{c m 2}}{I_{c m 1}} \approx \frac{V_{t h 2}}{V_{t h 1}} * \frac{Z_{L}+Z_{t h}}{Z_{c m c}+Z_{L}+Z_{t h}}$

The attenuation of the common mode current will only be efficient if $Z_{c m c}$ is considerably bigger than the one of the source and the load. Indeed if both impedances of the source and the load are both 10 lower than the one of the CMC, the attenuation reaches a factor of $0.2(-14 \mathrm{~dB})$. It reaches $0.02(-34 \mathrm{~dB})$ for an impedance of the common mode choke 100 times bigger than the one of the load and the source. Other limitations are the saturation level of the common mode choke and its parasitic impedance to ground which also have to be taken into account.

This structure can of course also be used with any combination of values on the load and on the source side (low and/or high). In these cases the common mode current is only attenuated at certain frequencies but not redirected.

\subsection{0.b. $\mathrm{CMC}-\mathrm{Y}$ structure - case B}

\section{Case B}

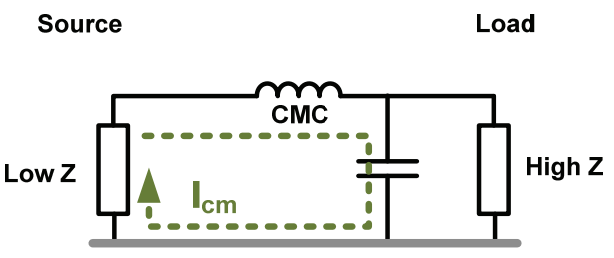

Figure 114: Case B/ Y configuration.

In case the impedance is low on the source side and high on the load side, there is an opportunity to provide a lower path of impedance to the common mode current with the use of a Y capacitor after the CMC. This is structure B in Figure 112. If the parasitic to ground of the common mode choke is neglected, and if the values of the capacitance of ground and the source are both small enough so that at least $Z_{L} \sim$ 
10* $Z_{y} \sim 10 * Z_{t b}$; then the modification factor of the common mode current $I_{c m 2}$ with respect to the initial one $I_{c m 1}$ can be expressed as follows:

$\frac{I_{c m 2}}{I_{c m 1}} \approx \frac{V_{t h 2}}{V_{t h 1}} * \frac{Z_{L}+Z_{t h}}{Z_{c m c}+Z_{Y}+Z_{t h}}$

For the modification factor of $I_{\text {cable }}$ the common mode current flowing in the cable towards the load can be then approximated as follows:

$\frac{I_{c a b l e}}{I_{c m 1}} \approx \frac{V_{t h 2}}{V_{t h 1}} * \frac{Z_{L}+Z_{t h}}{Z_{c m c}+Z_{Y}+Z_{t h}} * \frac{Z_{Y}}{Z_{L}+Z_{Y}}$

The lower $Z_{Y}$ and the higher $Z_{c m c}$ are, the better becomes the attenuation factor of the current flowing in the cable, at the output of the EMI filter. According to formula (31) the bigger the difference is between $Z_{L}$ and $Z_{Y}$ the better is the attenuation of the current in the cable. Designers should keep in mind the design limitations of the CMC and the limited value of common mode current allowed in the return path (here the ground).

\subsection{0.c. $\quad \mathrm{Y}-\mathrm{CMC}-\mathrm{Y}$ structure - case $\mathrm{C} 1$}

Case C - 1

Source

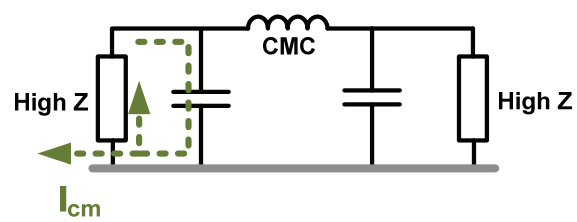

Figure 115: Case C1/ Y-CMC-Y configuration.

In case the impedance on both the source and the load side is high, one might want to reduce the impedance to ground on both sides of the EMI filter with the use of Y-capacitors. The case where the impedance of the Y-capacitor on the source side is much smaller than the one of the common mode choke plus the load is the structure $\mathrm{C}-1$ in Figure 112. The impedance of the Y-capacitor on the source side is called $Z_{Y 1}$, the one on the load side $Z_{Y 2}$.

The parasitic to ground of the common mode choke is neglected in the initial step. The $Y$ capacitor $Z_{Y 2}$ on the load size has a much smaller impedance than the one of the load (otherwise this capacitor is of no use). In this case C1, it is assumed the Ycapacitor $Z_{Y 1}$ is much smaller than the common mode choke in series with $Z_{Y 2}$. It is 
also assumed that there is a big enough difference of values between the impedance of the $Y$-capacitor and the one of the load and the source so that at least $Z_{L} \sim 10 * Z_{Y 1}$. To summarize the following assumption are made: $Z_{L} \sim 10 * Z_{Y 2}$ and $Z_{T H} \sim 10 * Z_{Y 1}$ and $\left(Z_{C M C}+Z_{Y 2}\right) \sim 10 * Z_{Y 1}$. The modification factor of the common mode current $I_{c m 2}$ with respect to the initial one $I_{c m 1}$ can be expressed as follow:

$\frac{I_{c m 2}}{I_{c m 1}}=\frac{V_{t h 2}}{V_{t h 1}} * \frac{Z_{L}+Z_{t h}}{Z_{z e q C}+Z_{t h}}$

$Z_{e q C}=\frac{Z_{Y 1} *\left(Z_{C M C}+Z_{Y 2}\right)}{Z_{Y 1}+\left(Z_{C M C}+Z_{Y 2}\right)} \approx Z_{Y 1}$

$\frac{I_{\text {cable }}}{I_{c m 1}}=\frac{I_{c m 2}}{I_{c m 1}} * \frac{Z_{Y 1}}{Z_{Y 2}+Z_{C M C}} * \frac{Z_{Y 2}}{Z_{Y 2}+Z_{L}}$

The impedance seen by the common mode current at the source side is the one of the Y-capacitor on the same side. Most of the common current is then flowing through this capacitance to ground and does not reach the common mode choke and the second Y capacitor to ground. On the one hand this common mode current does not travel along the cable and does not reach the load, on the other hand there is a risk that the common mode current sent back to the source is too high for safety as well as functional reasons. This additional current can lead to an overload of the switches in a power supply. Moreover two additional components in the EMI filter are either not used or used very little..

\subsection{0.d. $\mathrm{Y}-\mathrm{CMC}-\mathrm{Y}$ structure - case $\mathrm{C} 2$}

\section{Case C - 2}

Source

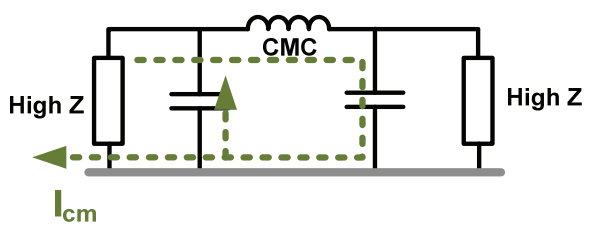

Figure 116: Case C2/ Y-CMC-Y configuration.

In this case, the same structure is considered and the same assumptions are made as in the last section. The difference is that in this case the system formed by $Z_{y 2}$ in series with the $\mathrm{CMC}$ has a smaller impedance than the impedance $Z_{y 1}$. To 
summarize the following assumption are made: $Z_{L} \sim 10 * Z_{Y 2}$ and $Z_{T H} \sim 10 \cdot Z_{Y 1}$ and 10 . $\left(Z_{C M C}+Z_{Y 2}\right) \sim Z_{Y 1}$.

The modification factor of the common mode current $I_{c m 2}$ with respect to the initial one $I_{c m 1}$ can be expressed as follows:

$\frac{I_{c m 2}}{I_{c m 1}}=\frac{V_{t h 2}}{V_{t h 1}} * \frac{Z_{L}+Z_{t h}}{Z_{\text {zeqC }}+Z_{t h}}$

$Z_{e q C}=\frac{Z_{Y 1} *\left(Z_{C M C}+Z_{Y 2}\right)}{Z_{Y 1}+\left(Z_{C M C}+Z_{Y 2}\right)} \approx\left(Z_{C M C}+Z_{Y 2}\right)$

Part of the common mode current flowing from the source is sent back to the source through the impedance $Z_{y 1}$, but substantially much less than in the first situation (Case C1) as it is no longer the path of lower impedance. The majority of the common mode current is going through the $\mathrm{CMC}$ and the second $\mathrm{Y}$ capacitor on the load side. The common mode current sent to the return path after leaving the common mode choke and the impedance $Z_{y 2}$ is coming back via the impedance $Z_{Y 1}$ which provides the path of lower impedance for this return current. Here stands the main advantage of this structure: the common mode current is kept in a loop away from the source and the load. This is only possible because both impedances on the load and the source side are high, and because $\left(Z_{c m c}+Z_{y 2}\right)<<Z_{y 1}$.

\subsection{0.e. $\quad \mathrm{Y}$ - CMC structure - case $\mathrm{D} 1$}

\section{Case D - 1}

\section{Load}

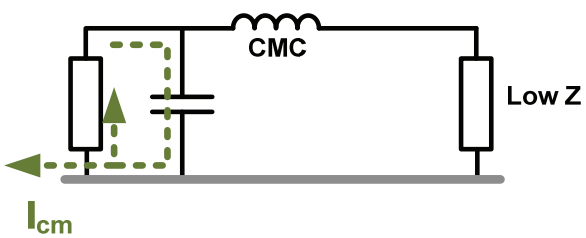

Figure 117: Case D1/ Y-CMC configuration.

In case the impedance on the load side is low while the one on the source side is high, there is an opportunity to provide a lower path of impedance to the common mode current with by using a of Y-capacitor before the common mode choke, on the source side. This the structure D in Figure 112.

The parasitic to ground of the common mode choke is neglected in a first step, and if the of values of the impedance to ground of the load and the one of the $\mathrm{Y}$ - 
capacitor are both smaller than the one of the source so that at least $Z_{t h} \sim 10 * Z_{y} \sim$ $10 * Z_{L}$. In the structure D1 of Figure 112, the impedance of the Y capacitor is also much smaller than the one of the common mode choke. This case then becomes similar to case $\mathrm{C} 1$.

\subsection{0.f. $\quad \mathrm{Y}-\mathrm{CMC}$ structure - case $\mathrm{D} 2$}

Case D - 2

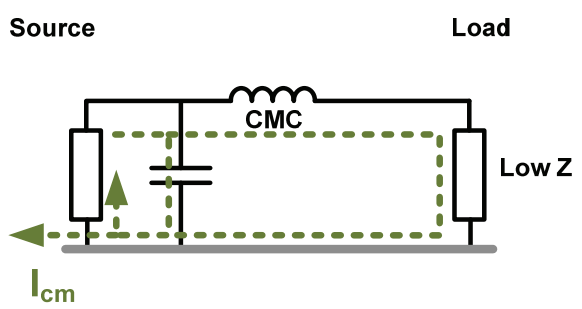

Figure 118: Case D2/ Y-CMC configuration.

In case the impedance on the load side is low while the one on the source side is high, there is an opportunity to provide a lower path of impedance to the common mode current by using a Y-capacitor before the common mode choke, on the source side. This the structure D in Figure 112.

The parasitic to ground of the common mode choke is neglected in a first step, if the values of the impedance to ground of the load and the one of Y-capacitor are both smaller than the one of the source so that at least $Z_{t h} \sim 10^{*} Z_{y} \sim 10^{*} Z_{L}$. In the structure D1 of Figure 112, the impedance of the Y capacitor is also much larger than the one of the common mode choke.

This case then becomes similar in some ways to the case C2. The impedance on the load side is low and the use of the $\mathrm{Y}$-capacitor on this side is not effective. The common mode current flows all the way to the load after being attenuated in the common mode choke. The return path is formed but the $\mathrm{Y}$-capacitor on the source side $\left(Z_{Y 1}\right)$ and the source is therefore protected from an extra current flowing back through it. This common mode current remains within the product. A higher level of radiation around the load is possible.

\subsection{Summary}

In this chapter an overall model of the common mode filter is proposed. The common mode filter is placed directly at the output of the converter. Several configurations are possible. The final purpose of this overall model is to link the 
designable parameters of the filter to its actual performance in the motor drive as well as providing advices to the designer on which configuration to choose.

A summary of the work presented in this chapter is presented in Table 10. The equivalent circuit of the main topologies of the EMI filter are provided. They are related to the design cases studied Section 4 and for each of them their simplified modification factor are given. This simplified factor are only meant as a first level approximation to determine whether or not the chosen structure is an adequate design choice.

After the designable parameters are identified, a first step consists in characterising the noise source of the converter: the common mode current and voltage it produces is dependent of the load. The insertion of any filter modifies the noise produced. This modification needs to be quantified. This is the dynamic environment of the filter.

A second step consists of characterizing the static environment of the filter: the impedance to ground upstream and downstream of the filter needs to be modelled or measured. The static environment is also an essential knowledge for both the choice of the general structure of the filter as well as the evaluation of the in-situ performances of the filter.

The third step followed in this chapter is to provide an equivalent model of each structure of EMI filter possible. For each configuration a formula for the calculation of the modification factor is proposed and validated.

Finally the limitations and the advantages of each structure are described along with a simplified modification factor. It can be used to perform a first general design (or estimate) to be refined and optimized with the more advance studies performed earlier in this chapter. 
Table 10: Summary of the EMI filter structures with their simplified modification factor.

Structure:

CMC only

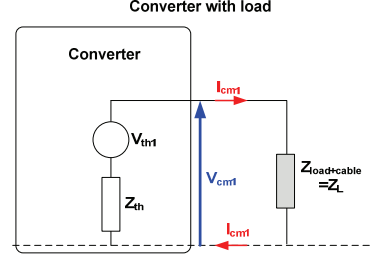

Converter with load, structure of the filter, CMC

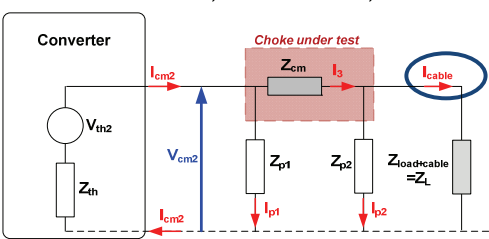

Case A

Source

Load

Related to

CASE A

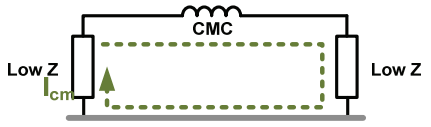

Simplified

modification

factor

CASE A

$$
\frac{I_{c m 2}}{I_{c m 1}} \approx \frac{V_{t h 2}}{V_{t h 1}} * \frac{Z_{L}+Z_{t h}}{Z_{c m c}+Z_{L}+Z_{t h}}
$$

$Z_{p_{1,2}}$ are neglected

Structure:

CMC - Y

Converter with load

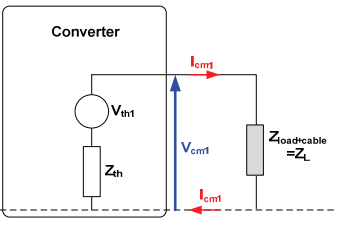

Converter with load, structure of the filter, CMC

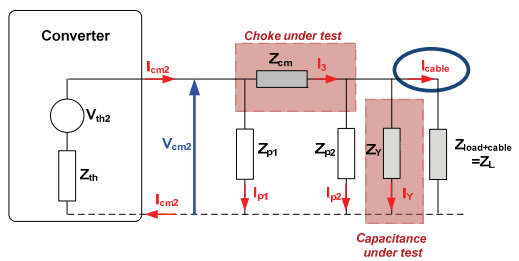

Case B

Load

Related to

CASE B

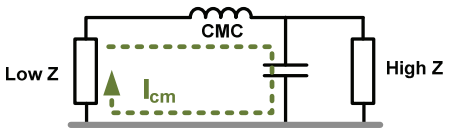

Simplified

$$
\frac{I_{c m 2}}{I_{c m 1}} \approx \frac{V_{t h 2}}{V_{t h 1}} * \frac{Z_{L}+Z_{t h}}{Z_{c m c}+Z_{Y}+Z_{t h}}
$$

modification

factors

CASE B

$\frac{I_{\text {cable }}}{I_{c m 1}} \approx \frac{V_{t h 2}}{V_{t h 1}} * \frac{Z_{L}+Z_{t h}}{Z_{c m c}+Z_{Y}+Z_{t h}} * \frac{Z_{Y}}{Z_{L}+Z_{Y}}$

$Z_{L} \sim 10 * Z_{y} \sim 10 * Z_{t h}$ and $Z_{p_{1,2}}$ are neglected 
Structure:

Y-CMC -Y

Simplified

Related to

CASE C-1

modification

factors

CASE C-1

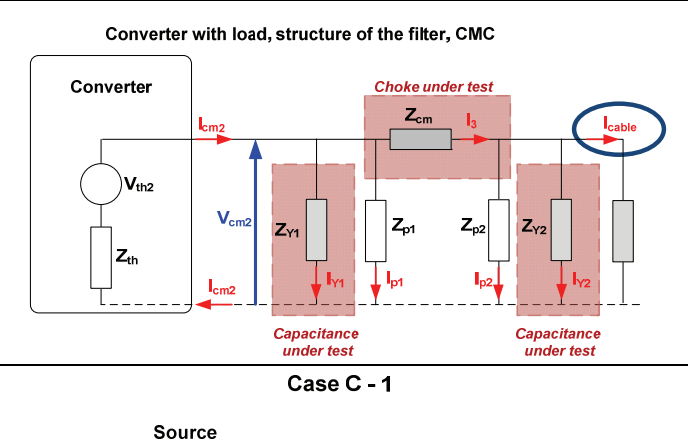

$$
\begin{aligned}
& \text { High Z } \\
& \quad \frac{I_{c m 2}}{I_{c m 1}} \approx \frac{V_{t h 2}}{V_{t h 1}} * \frac{Z_{L}+Z_{t h}}{Z_{Y 1}+Z_{t h}} \\
& \frac{I_{c a b l e}}{I_{c m 1}} \approx \frac{I_{c m 2}}{I_{c m 1}} * \frac{Z_{Y 1}}{Z_{Y 2}+Z_{C M C}} * \frac{Z_{Y 2}}{Z_{Y 2}+Z_{L}}
\end{aligned}
$$

$Z_{L} \sim 10 * Z_{Y 2}$ and $Z_{T H} \sim 10 * Z_{Y 1}$ and $\left(Z_{C M C}+Z_{Y 2}\right) \sim 10 * Z_{Y 1}$.

$$
Z_{p_{1,2}} \text { are neglected }
$$

\section{Case C - 2}

Source

Related to

CASE C-2

Simplified

$$
\begin{aligned}
& \text { High z } \\
& \frac{I_{c m 2}}{I_{c m 1}} \approx \frac{V_{t h 2}}{V_{t h 1}} * \frac{Z_{L}+Z_{t h}}{I_{Y 2}+Z_{C M C}+Z_{t h}} \\
& \frac{I_{c a b l e}}{I_{c m 1}} \approx \frac{I_{c m 2}}{I_{c m 1}} * \frac{Z_{Y 1}}{Z_{Y 2}+Z_{C M C}} * \frac{Z_{Y 2}}{Z_{Y 2}+Z_{L}}
\end{aligned}
$$

modification

CASE C-2

$Z_{L} \sim 10 * Z_{Y 2}$ and $Z_{T H} \sim 10 * Z_{Y 1}$ and $\left(Z_{C M C}+Z_{Y 2}\right) * 10 \sim Z_{Y 1}$. 


\section{Chapter 6. A behavioural model of the cable input impedance}

The EMI interference levels produced by power switching converters in motor drive depend on a number of factors such as [57]:

- The switching frequency of the converter.

- The slope of the current and voltage at switching.

- The impedance of the mains power supply.

- The length of cables from the converter to the motor.

The common mode currents flowing along the cable are directed in the same direction in all phases. These are not intended to be present, but are present in practical systems as a result of impedance unbalances. These currents are frequently referred as 'antenna-mode' currents and are the predominant mechanisms for producing radiated electric fields in practical products [4]. Figure 119 presents the circulation of common mode currents in a motor drive system. These currents usually flow along the cable and return to the source via stray capacitances between the cable and the ground and to certain extent via capacitive coupling between the frame of the motor and the ground. The design engineer has in general a very limited knowledge on the mechanism of creation of electromagnetic field interference.

The level of electromagnetic field generated by the motor drive is a key knowledge for the designer of the frequency converter. The modelling of these common mode (or asymmetric) currents is however not widely addressed for higher frequencies, 
where most radiated emission occurs. The designer's first interest stands in the knowledge of the maximum level of emission of the drive which has to remain below the concerned standards. The electromagnetic field cannot be determined without the knowledge of the distribution of current and charge along this conducting wire. These depend on the length and radius of the wire and on the mechanism and frequency of the excitation [58], [61].

A new approach in the evaluation the environment is proposed in this chapter: it consists in modelling the input impedance of the system 'cable and motor' and to relate it to the designable parameters of the motor drive.

As it has been presented in the previous chapter, the noise source can be modelled with a Thévenin structure. The simulated input impedance or 'antenna impedance' is then used to evaluate the flowing current in the cable. The emission level associated is calculated afterwards, taking into account the shape of the asymmetric structure, only for the frequencies where the highest level of electromagnetic field is expected. These frequencies are the resonance frequencies of the input impedance in case of a linear antenna. An overview of the model is presented in Figure 119 and Figure 120.

The structure of this chapter is as follows:

- Investigation of the current distribution along the cable.

- Input impedance modelling with the Method of Moments (with the software NEC).

- Input impedances modelling with analytical methods.

- Test set-up and measurements of inputs impedances of cables, analysis of the influence of the designable parameters.

- Comparison of the experimental results with models.

- Curves of minimum impedances.

- Equivalence of the behavioural model results with measurements performed in a motor drive.

- Summary. 


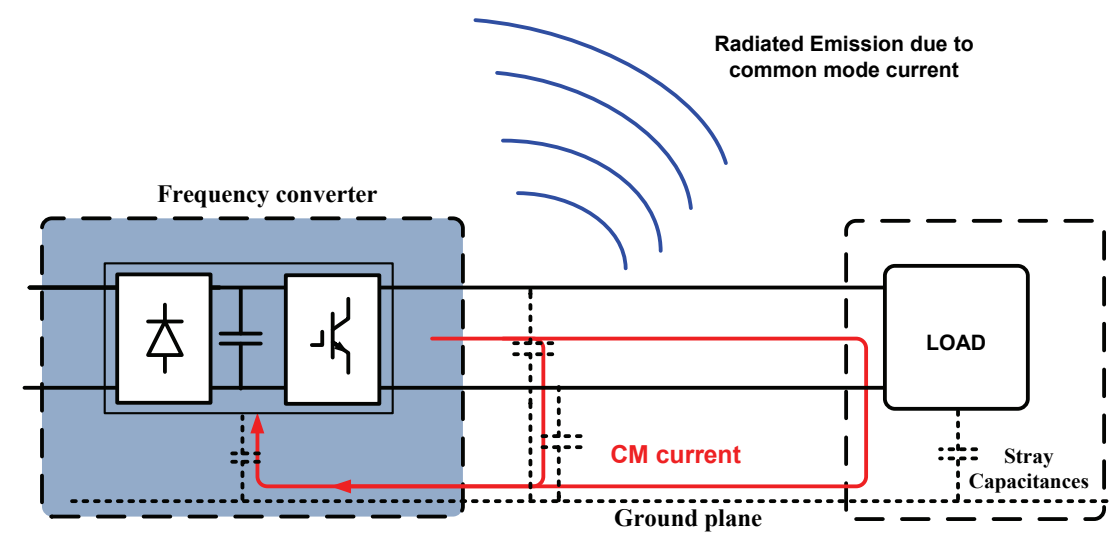

Figure 119: Circulation of the common mode current in a motor drive.

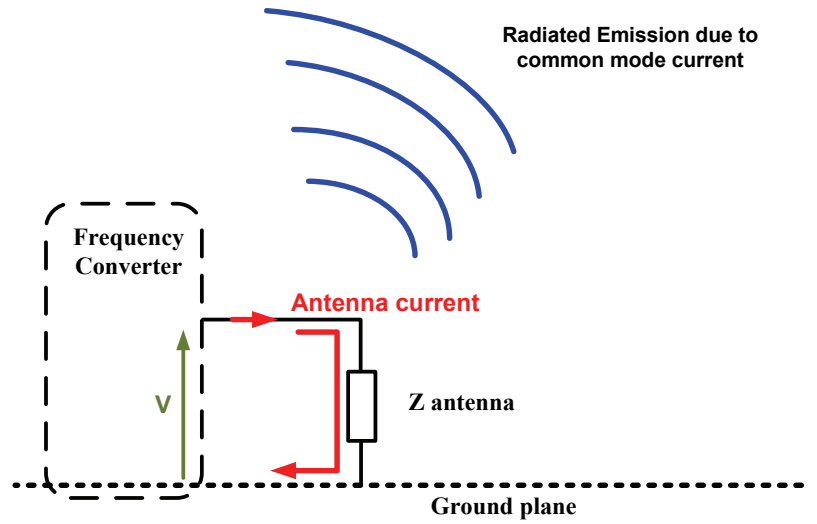

Figure 120: Overview of the model.

\subsection{Designable parameters}

The following designable parameters are considered:

- Length of the cable,

- Height of the cable with respect to ground,

- The common mode impedance of the load.

The thickness of the cable has not been considered in this chapter.

These designable parameters are all involved in the final value of the common input impedance of the cable and its load. They are inputs of the behavioural model. 


\subsection{Behaviour of a single wire excited by a sinusoidal current}

\section{2.a. Behaviour of a single wire in free space excited by a sinusoidal current at one extremity}

Different models are available in the literature describing the behaviour of a single wire above a ground plane excited by sinusoidal currents. Typically models from the family of the transmission lines, Lenz's and Faraday's law could be considered. These laws are approximations of the general electromagnetic model based on Maxwell's equations, and the limitations in their frequency range of validity. The antenna model and the Method of Moments are directly derived from Maxwell's equations and can be used on the overall spectrum. More details on these methods are provided in the subsequent sections.

A single floating wire of a length $l$ with a sinusoidal excitation at one of its extremity is considered, two types of current distributions along the cable can be observed:

- The sinusoidal current distribution along the wire is such that there is no standing wave and a negligible difference in the phases between the two extremities. In this case the wire length is less than a part of a wavelength, or typically $k<\lambda$.

- The sinusoidal current distribution along the wire is such that reflections occurring at the end of the wire have an influence on the overall current distribution. Standing waves can be observed along the wire with maximum current amplitudes. In this case the wire length is more than a part of the wavelength, or typically $l>\lambda$.

6.2.b. Behaviour of a single wire above a perfect ground plane excited by sinusoidal current at one extremity

When the wire is placed above a ground plane: lengthwise, a similar behaviour as described in 6.2.a will be observed. The height of the cable from the ground is the additional parameter: typically if the height $b$ above a large metallic plane is smaller than a part of the wavelength $(k<\lambda)$, then the cable above the plane can be reflected in the plane forming a new equivalent open two wire system: it actually becomes a transmission line. For larger height and if the ground plane can be considered as infinite, the wire can be considered in free space. The image theory is further developed in the next section of this chapter. 
Figure 121 presents distributions of the standing waves according to the condition sets at the end of the cable: open ended or short circuited to the ground. The condition sets at the end of the cable determine the overall position of the two families of standing waves. The knowledge of both voltage and current standing waves is important to evaluate the input impedance of the cable with the ground. When the input current is at its maximum then the voltage is at a minimum: the input impedance is also at a minimum, it is a frequency of anti-resonance for the input impedance. The same way, when the input current is at its minimum then the voltage is at a maximum: the input impedance is also at a maximum, it is a frequency of resonance for the input impedance. The resonance frequencies of the input impedance are presented in the Table 11 for a perfect sinusoidal distribution of the current and the voltage along the wire.

Table 11: Resonances frequencies of the input impedance of a cable above a ground plane.

\begin{tabular}{|l|l|l|}
\hline & Open cable & Shorted cable \\
\hline $\begin{array}{l}\text { Resonance (or } \\
\text { maximum) of } \\
\text { input impedance }\end{array}$ & $l=n * \frac{\lambda}{2}$ & $\quad l=\frac{\lambda}{4}+2 * n * \frac{\lambda}{4}=(2 * n+1) * \frac{\lambda}{4}$ \\
\hline
\end{tabular}




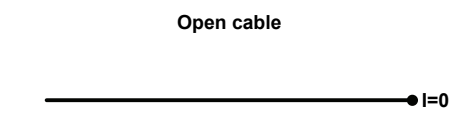

Source

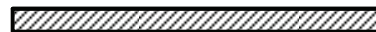
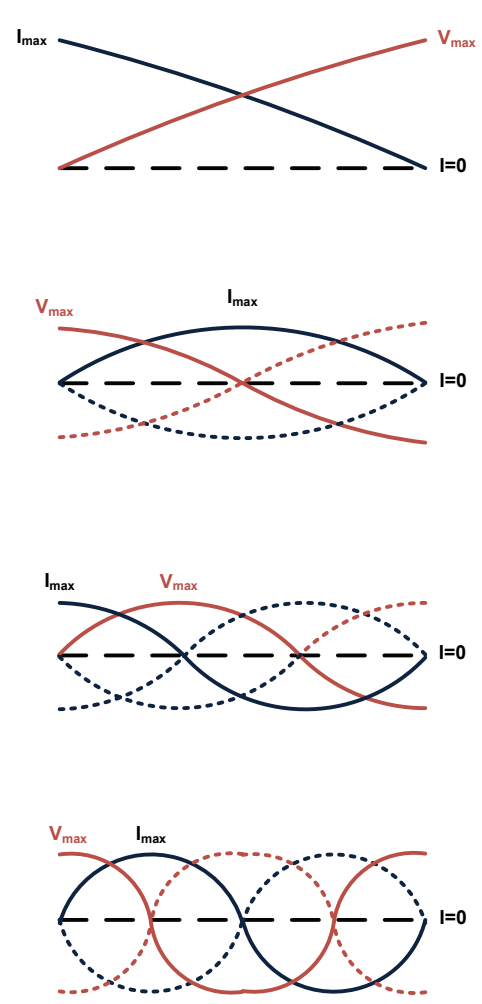

Shorted cable

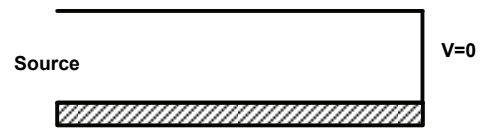

$\lambda / 4$

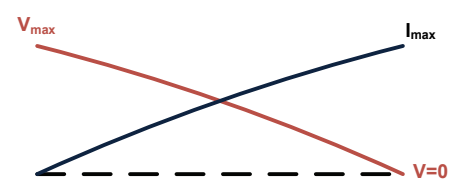

$\lambda / 2$

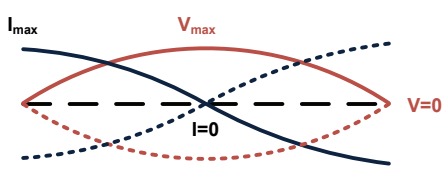

3. $\lambda / 4$

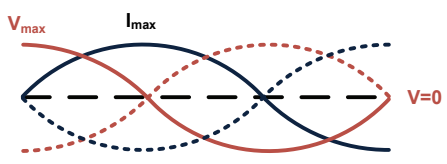

$\lambda$

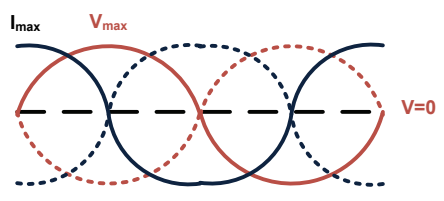

Figure 121: Standing waves positions according to the condition set at the end of the cable. 


\subsection{Input impedance and the method of moments (MoM)}

\section{3.a. Short presentation of the Method of Moment (MoM)}

This Method of Moments is a general method for solving integro-differential equations by converting them into matrix equations. This method has been introduced by Roger Harrington in 1967 [59]. The method of moments is a mathematical technique that subdivides an antenna element into segments, calculates the correct properties and then combines the results to provide a set of results for the entire element. It uses the integral equation approach, where the strength of the field is described by an integral representation involving the current densities in the structure. The current are expressed as weighted sum of basic functions. The current distribution is then used to calculate the radiation pattern and feed point impedance.

\section{3.b. Model presentation in NEC-2}

NEC stands for Numerical Electromagnetic Code. This software is especially adapted for antennas made of round wires. A short historical overview is available in [60]. The model has been built according to the following guidelines.

- A wire should have at least 9 segments per half wavelength.

- The segment length should be at least 3 times larger than the wire diameter.

- To the degree possible, within a model, all segments must be made of equal length.

Figure 122 represents the 3 different antennas modelled with NEC. A vertical monopole with open end is considered in (a), an horizontal monopole with open end in (b), and an horizontal monopole terminated by a capacitance to ground in (c). The longest part of the antenna has been divided in 100 segments, the shortest one in 3. The load for the configuration (c) is also divided in 3. The simulation is run from $10 \mathrm{MHz}$ to $1 \mathrm{GHz}$ with steps of $1 \mathrm{MHz}$. The source is a constant voltage of $1 \mathrm{~V}$, the capacitance in the case (c) has a value of $2.2 \mathrm{nF}$. The wires are set as copper, the ground is perfect. In all simulation the length of the antenna is $2.7 \mathrm{~m}$.

Results of the simulations are directly compared to measurements in Section 6.6.b. 


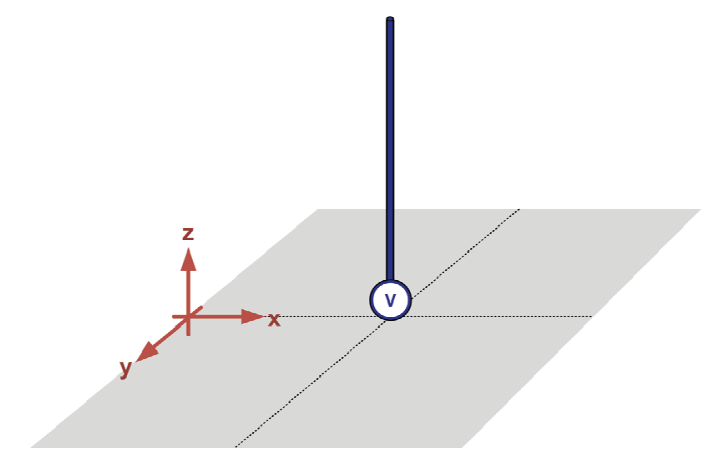

(a) Vertical Monopole above an infinite ground plane.

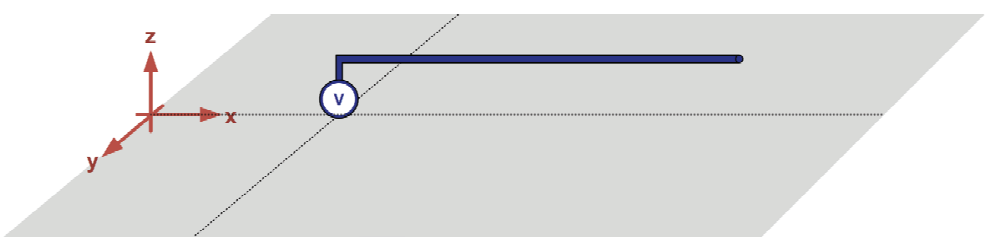

(b) Horizontal monopole above an infinite ground plane.

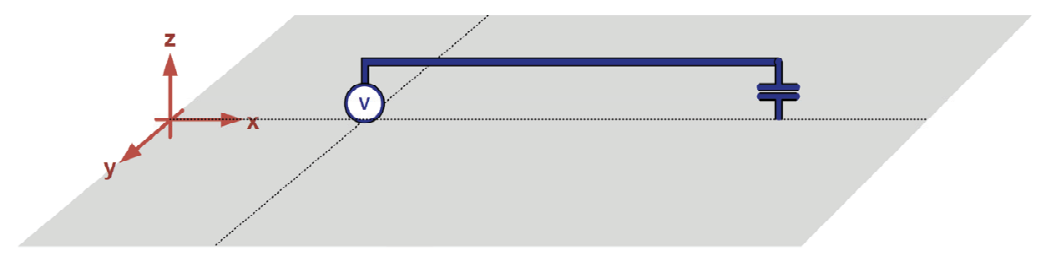

(c) Horizontal monopole terminated with a capacitance connected to an infinite ground plane.

Figure 122: Representation of the antenna modelled with NEC.

\subsection{Input common mode impedance and analytical methods}

As mentioned in the first part of this chapter the main objective is to help designers in getting a 'first time right' design. In this case it translates to a proper evaluation of the maximum electromagnetic field around the system 'cable and motor' to ensure designers that the motor drive respects the relevant standards in terms of radiated and conducted emissions levels. 
The input impedance of an antenna is first defined. In the family of linear cylindrical antenna, the vertical monopole antenna above a ground plane and in free space has been widely investigated. It is a first simple representation of the situation investigated in this thesis.

\section{4.a. Definition of the input impedance of an antenna}

The antenna input impedance $Z_{\text {in }}$ is defined in[62]:

$Z_{I N}=\frac{V(z=0)}{I(z=0)}=R_{I N}+j * X_{I N}$

Where

- $\quad V(z=0)$ is the complex amplitude of the excitation voltage across the input of the antenna.

- $\quad I(z=0)$ is the complex amplitude of the excitation current across the input of the antenna.

- $R_{I N}$ is the input resistance $(\mathrm{Ohm})$.

- $X_{I N}$ is the input reactance $(\mathrm{Ohm})$.

The input resistance $R_{I N}$ is related to the radiation resistance $R_{R A D}$ by

$R_{I N}=R_{R A D}+R_{O H M I C}$

Where $R_{\text {OHMIC }}$ is the ohmic loss resistance of the antenna. If the monopole element is assumed to be of infinite conductivity, $R_{O H M I C}=0$. Accordingly $R_{I N}=R_{R A D}$.

\section{4.b. Image theory: antennas above a perfect ground plane}

A ground plane in its ideal form is infinite in extent and perfectly conducting, and is often referred to as perfect ground plane. A solid metal sheet that is large compared to the antenna size is in most cases well approximated as a perfect ground plane. It is the case in this thesis and a perfect ground plane will be assumed to initially simplify the structure.

The vertical monopole antenna may be modelled as a dipole with one-half of the input impedance. The infinite ground plane prevents monopole radiation into the hemisphere below the ground plane but it gives a radiation pattern identical to that of the dipole in the upper hemisphere. The method of images is illustrated in Figure 123. The input impedance of a monopole element of length $b$ on a ground plane of infinite extent of one-half that of a dipole of total length $2 h$ in free space. A simple 
explanation is that double the energy is located in the upper half plane with respect to a dipole in free space.

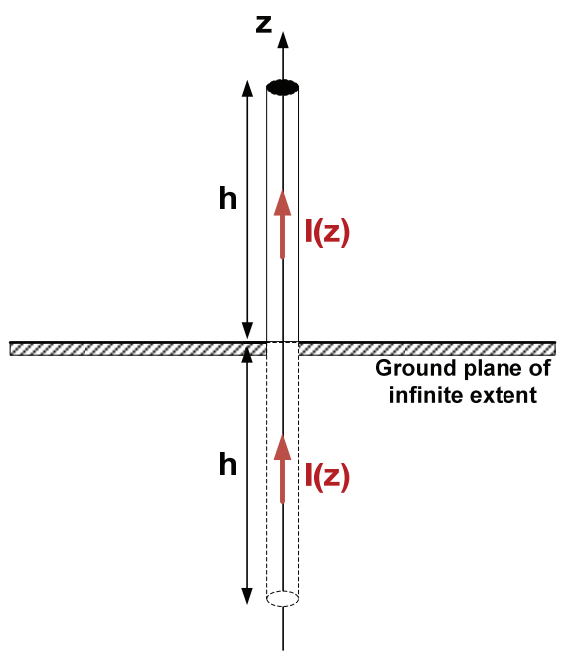

Figure 123: Method of imaged for a monopole element at the centre of a circular ground plane of infinite extend.

\section{4.c. Vertical monopole above a ground plane: current distribution determined by analytical method}

The determination of the input impedance of an antenna starts with a determination of the exact form of the current along the antenna. A cylindrical antenna is presented in Figure 124. Here we are only considering the antenna in a transmitting mode which is driven by a generator voltage applied to its input terminals. We will refer to this external source field as the "incident" field $E_{i n}$. The incident field $E_{i n}$ induces a current on the antenna. In turn, the current generates its own field $E$, which is radiated away. The total electric field is the sum $E_{t o t}=E+E_{i n}$. Assuming a perfectly conducting antenna, the boundary conditions are that the tangential components of the total electric field vanish on the antenna surface. These boundary conditions are enough to determine the current distribution induced on the antenna. We will assume the "thin wire approximation", where the density is azimuthally symmetric with no dependence on the azimuthal angle $\varphi$. 


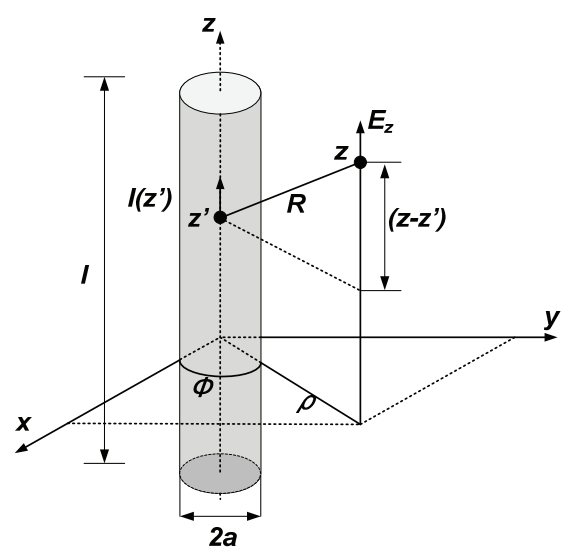

Figure 124: Cylindrical antenna.

It can be shown [58] that the $z$ component of the incident field can be expressed as follows:

$$
\left(\partial_{z}^{2}+k^{2}\right) * A_{z}(z)=-j * w * \mu * \epsilon * E_{\text {in }}(z)
$$

Where

$k \quad$ wave number

$A_{z} \quad$ z-component of the potential vector

$w \quad$ angular frequency

$\mu \quad$ permittivity

$\varepsilon \quad$ permeability

It can also be shown that the z-component of the potential vector can be expressed as follows:

$A_{z}(z, \rho)=\frac{\mu}{4 * \pi} \int_{-l / 2}^{l / 2} I\left(z^{\prime}\right) * G\left(z-z^{\prime}\right) d z^{\prime}$

Where the exact thin wire kernel is expressed as follows: 
$G\left(z-z^{\prime}\right)=\frac{1}{2 * \pi} \int_{0}^{2 \pi} \frac{e^{-j * k * R}}{R} d \phi^{\prime}$

With

$R=\sqrt{\left(z-z^{\prime}\right)^{2}+a^{2}}$

If $a \rightarrow 0$ (thin wire approximation), the approximate thin wire kernel can be expressed as follows:

$G_{a p p}\left(z-z^{\prime}\right)=\frac{e^{-j k R}}{R}$

Depending on how the equations (39) and (47) are combined, the Hallén or the Pocklington equations can be solved for the current $I(z)$ :

Hallén equation

$$
\frac{\mu}{4 * \pi} \int_{-l / 2}^{l / 2} I\left(z^{\prime}\right) * G\left(z-z^{\prime}\right) d z^{\prime}=-j * \omega * \mu * \epsilon *\left(\partial_{z}^{2}+k^{2}\right)^{-1} * E_{i n}(z)
$$

Pocklington equation

$\frac{\mu}{4 * \pi} *\left(\partial_{z}^{2}+k^{2}\right) \int_{-l / 2}^{l / 2} I\left(z^{\prime}\right) * G\left(z-z^{\prime}\right) d z^{\prime}=-j * \omega * \mu * \epsilon * E_{\text {in }}(z)$

For the Hallén equation, two formulas are developed in [63] to model the impedance and the admittance of a centre driven antenna of half length as drawn in Figure 125. This two models of impedances have been respectively developed by Hallén and King-Middleton and are described hereafter. In both methods the calculation of the input impedance is based on a mathematical expression of the current distribution along the antenna. This exact expression is complex and the impedance is approximate by a sum of $m$-order impedances. 


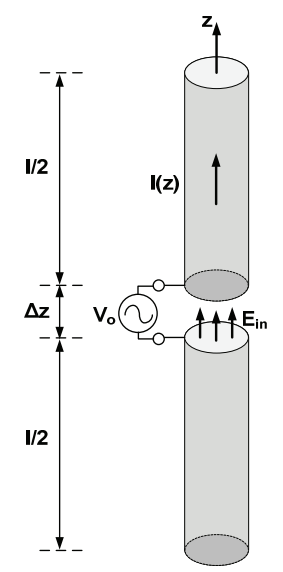

Figure 125: External sources acting on a linear antenna.

The 'delta gap' model is used to express the value of the incident field $E_{i n}$ : a generator voltage is applied between the upper and the lower halves of the antenna across a short gap of length $\Delta z$. The applied voltage $V_{0}$ can be thought of as arising from an electric field which exists only within the gap, such that:

$V_{0}=\int_{-\Delta z / 2}^{\Delta z / 2} E_{i n}(z) d z$

\section{Hallén's solution for a centre driven antenna}

Hallén's solution frequently given in the literature is a zeroth-order solution. In this solution the current along the antenna is sinusoidal. This assumption is refined with King and Middleton's solution presented in the next section.

Details of the demonstration are available in [63] and [61]. The real part and the imaginary part of the input impedance are the sum of a radiation component and a dissipative component, so that

$R_{0}=R_{0}^{e}+R_{0}^{i}$

$X_{0}=X_{0}^{e}+X_{0}^{i}$

$R^{i}$ is an internal resistance due to dissipation in the conductor and $R^{e}$ an external resistance due to radiation. These resistances are additive and independent in the zeroth order. For higher orders the distribution of current is determined by radiation and thermal dissipation in a complex manner. The internal resistance due to dissipation can be neglected. Its value is negligible compared to the one due to radiation. 


$$
\begin{aligned}
R_{0}^{e}=\frac{\eta}{4 * \pi} *[(1 & \left.-\cot ^{2}\left(\beta_{0} * h\right)\right) * \operatorname{Cin}\left(4 * \beta_{0} * h\right)+4 * \cot ^{2}\left(\beta_{0} * h\right) \\
& * \operatorname{Cin}\left(2 * \beta_{0} * h\right)+2 * \cot \left(\beta_{0} * h\right) *\left(\operatorname{Si}\left(4 * \beta_{0} * h\right)\right. \\
& \left.-2 * \operatorname{Si}\left(2 * \beta_{0} * h\right)\right]
\end{aligned}
$$

$$
\begin{aligned}
X_{0}^{e}=\frac{\eta}{4 * \pi} *[(1 & \left.-\cot ^{2}\left(\beta_{0} * h\right)\right) * \operatorname{Si}\left(4 * \beta_{0} * h\right)+4 * \cot ^{2}\left(\beta_{0} * h\right) \\
& * \operatorname{Si}\left(2 * \beta_{0} * h\right)+2 * \cot \left(\beta_{0} * h\right) *(2 \\
& \left.* \operatorname{Cin}\left(2 * \beta_{0} * h\right)-\operatorname{Cin}\left(4 * \beta_{0} * h\right)-2 * \ln \left(\frac{h}{a}\right)\right]
\end{aligned}
$$$$
R_{0}^{i}=X_{0}^{i}=\frac{1}{2 * \pi * a} * \frac{\omega * \mu}{2 * \sigma} *\left(\beta_{0} * h * \csc ^{2}\left(\beta_{0} * h\right)-\cot \left(\beta_{0} * h\right)\right)
$$

$\operatorname{Ci}(x)=0.5772+\ln (x)-\operatorname{Cin}(x)$

$\operatorname{Cin}(x)=\int_{0}^{x} \frac{d t}{t}(1-\cos (t))$

$\operatorname{Si}(x)=\int_{0}^{x} \frac{\sin (t)}{t} d t$

Where

$b=l / 2 \quad$ length of one half of the antenna

$\beta_{0}=k \quad$ wave number

King and Middleton's solution for a centre driven antenna

The zeroth-order solution of the King-Middleton solution is expressed as follows (the proof can be found in [63]):

$$
Z=60 * \Psi *\left|\frac{a_{1}+j * b_{1}}{c_{1}+j * d_{1}}\right| * \exp \left[j *\left(\tan ^{-1}\left(\frac{b_{1}}{a_{1}}\right)-\tan ^{-1}\left(\frac{d_{1}}{c_{1}}\right)\right)\right]
$$

Where

$$
\begin{gathered}
a_{1}=\frac{1}{2}\left[\cos \left(\beta_{0} * h\right) *\left(\operatorname{Si}\left(4 * \beta_{0} * h\right)-2 * \operatorname{Si}\left(2 * \beta_{0} * h\right)\right)+\sin \left(\beta_{0} * h\right)\right. \\
\left.* \operatorname{Cin}\left(4 * \beta_{0} * h\right)\right]
\end{gathered}
$$




$$
\begin{aligned}
& \begin{aligned}
& b_{1}=-\left[\Psi * \cos \left(\beta_{0} * h\right)\right. \\
&+ \frac{1}{2}\left[\cos \left(\beta_{0} * h\right) *\left(\operatorname{Cin}\left(4 * \beta_{0} * h\right)-2 * \operatorname{Cin}\left(2 * \beta_{0} * h\right)\right)\right. \\
&\left.\left.-\sin \left(\beta_{0} * h\right) * \operatorname{Si}\left(4 * \beta_{0} * h\right)\right]\right] \\
& c_{1}=\Psi * \sin \left(\beta_{0} *\right.h) \\
&+\frac{1}{2}\left[\cos \left(\beta_{0} * h\right) *\left(4 * \operatorname{Si}\left(2 * \beta_{0} * h\right)-\operatorname{Si}\left(4 * \beta_{0} * h\right)\right)\right. \\
&+\sin \left(\beta_{0} * h\right) *\left(2 * \operatorname{Cin}\left(2 * \beta_{0} * h\right)-\operatorname{Cin}\left(4 * \beta_{0} * h\right)\right. \\
&+4 * \ln (2))] \\
& d_{1}=\frac{1}{2}\left[\operatorname { C o s } \left(\beta_{0} *\right.\right.h) *\left(\operatorname{Cin}\left(4 * \beta_{0} * h\right)-4 * \operatorname{Cin}\left(2 * \beta_{0} * h\right)\right)+\sin \left(\beta_{0} * h\right) \\
&\left.*\left(2 * \operatorname{Si}\left(2 * \beta_{0} * h\right)-\operatorname{Si}\left(4 * \beta_{0} * h\right)\right)\right]
\end{aligned}
\end{aligned}
$$

With

$\Psi=2 * \ln \left(\frac{2 * h}{a}\right)$

Both Hallén's and King and Middleton's solution are directly compared with measurements in Section 6.6.b . Another comparison of analytical and MoM solutions with the input impedance of an horizontal monopole can be found in [61].

\subsection{Test set-up and measurements}

As mentioned in the first part of this chapter, the good evaluation of the input impedance of the system 'cable and motor' is a key in the future evaluation of the level of electromagnetic field around this system. A first step consists of in a simpler representation of the motor drive structure: the cable to the motor is replaced by a single copper wire and the common mode impedance of the motor by variable impedances. This simplified structure allows a more specific study of the impact of the following designable parameters on the value of the equivalent input impedance of the system 'cable and motor'.

- Length of the wire.

- Height of the wire above the ground plane.

- Load terminating the wire.

This simplified representation is illustrated in Figure 126. 


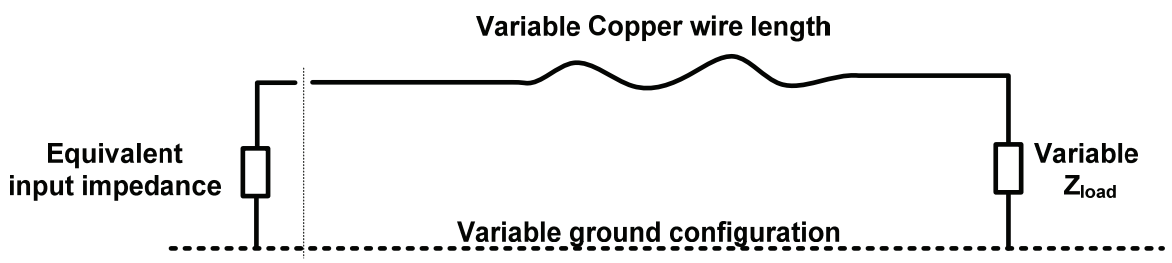

Figure 126: Simplified representation of the system 'cable and motor'.

\section{5.a. Measurement set-up}

EMI receiver

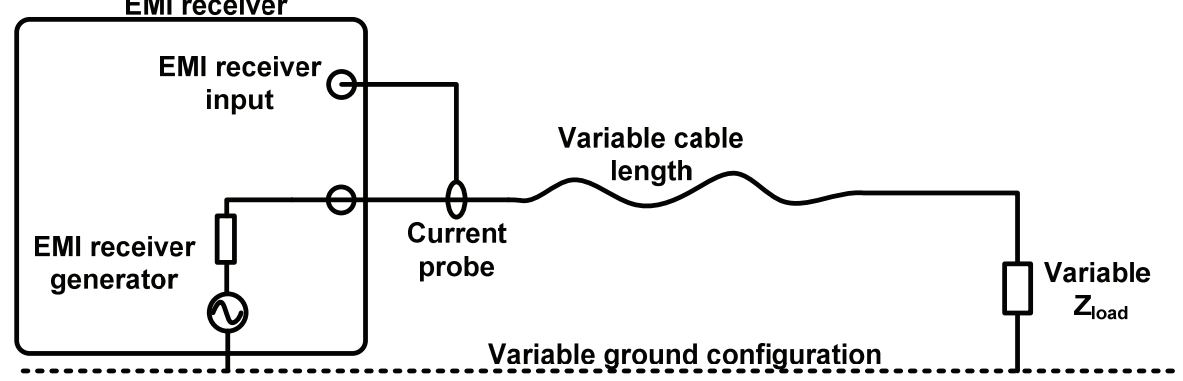

Figure 127: Test set-up used for the measurements the input common mode impedance of the system 'cable and motor'.

The input common mode impedance is measured using an EMI receiver, its tracking generator and current probes. The Device under Test (DUT) (in this case a copper wire with a diameter of $2 \mathrm{~mm}$ ) is excited by the tracking generator at a constant voltage of $96 \mathrm{~dB} \mu \mathrm{V}$ with respect to ground. The current flowing in the DUT is measured by a current probe that is appropriate for its frequency range. The input voltage and the input current flowing in the DUT are then used to compute the value of the input common mode impedance of the DUT. The test set-up is presented in Figure 127.

For any DUT the excited input is connected to the tracking generator via a metallic structure and a feedthrough connector. It is used to ensure that the ground of the tracking generator/ EMI receiver is as close as possible to the DUT. In addition this metallic structure can be used to support the DUT at a certain height above the ground plane via additional feed-through connections at higher heights on the metallic structure. Photos of the test set-up are presented in Figure 128. 

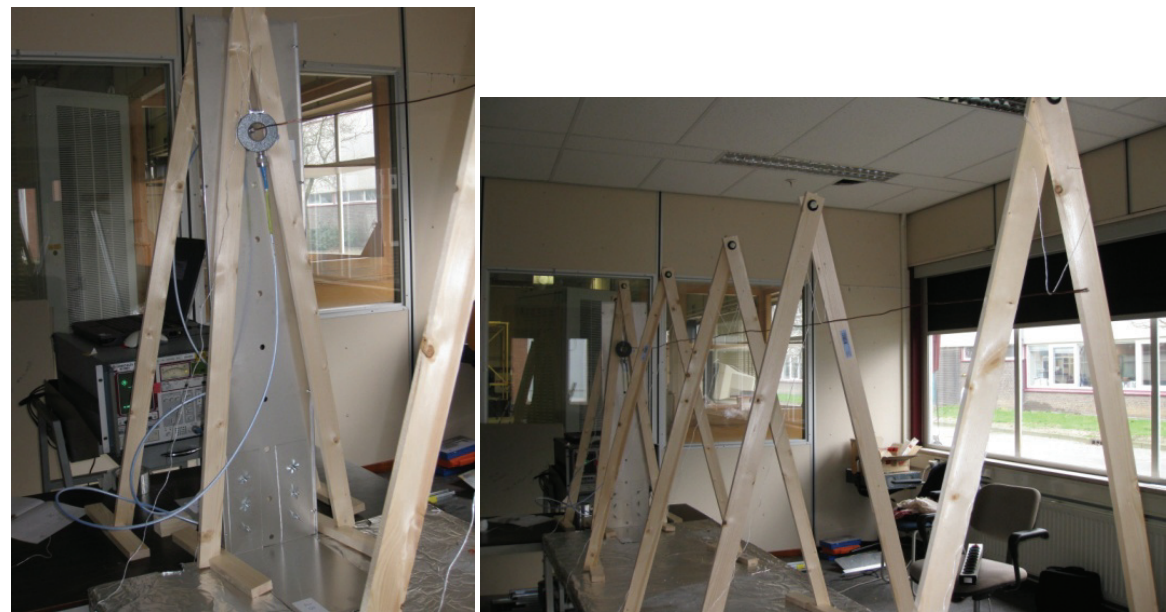

Figure 128: Test set-up for the measurement of the input common mode impedance of a single copper wire above a ground plane.

In case of the loaded single wire, a feedthrough load is fixed on a second similar metallic structure as used on the excitation side. The connection of the feedthrough load on the wire is pictured in Figure 129. A larger metallic structure does not have any influence on the value of the measured input common mode impedance.
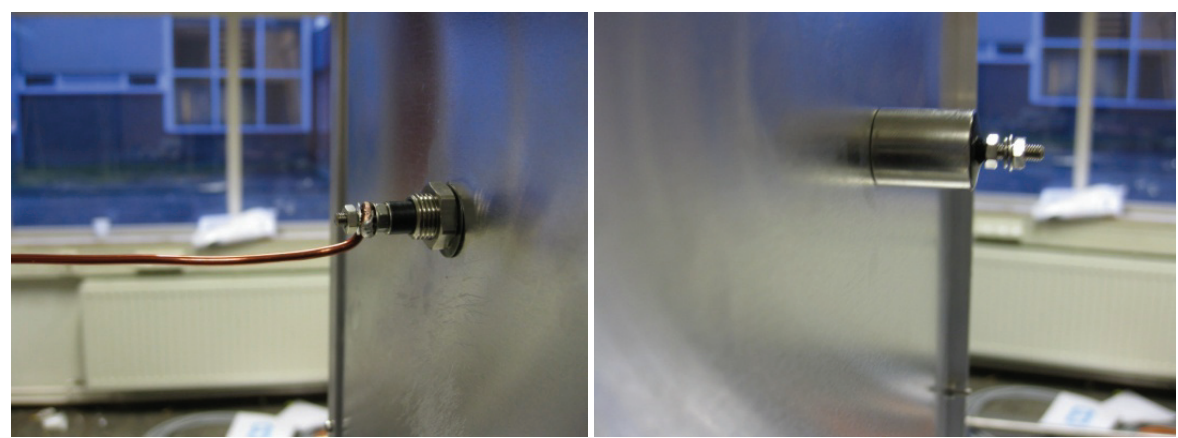

Figure 129: Connection of the feedthrough load on the wire test set-up.

\section{5.b. Measurements results}

Single wire above a ground plane, unloaded

The input impedances of an unloaded single wire at different heights above a ground plane is presented in Figure 130. The heights considered are between $2 \mathrm{~cm}$ and 80 $\mathrm{cm}$. The diameter is $1 \mathrm{~mm}$. 


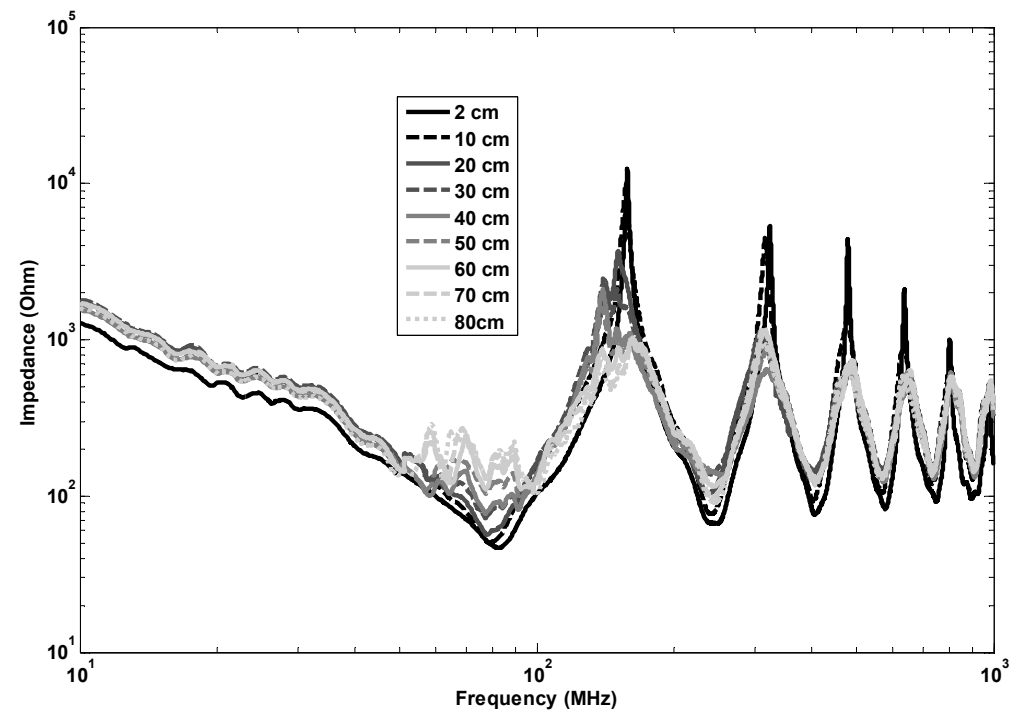

Figure 130: The input impedances of an unloaded single wire at different height above a ground plane.

At low frequencies, below the key value of $f=\lambda / 4$ which is the first anti-resonance of the input impedance $(83 \mathrm{MHz}$ for a cable of length $0.9 \mathrm{~m})$ the wire is behaving as a capacitance to ground. For $f=\lambda / 4$, the first standing wave occurs, the current is maximum at the input of the cable, the voltage is minimum. For the higher frequencies Table 12 presents the anti-resonance frequencies of a single copper wire above a ground plane.

The anti-resonance frequencies of the cable are slightly shifted to the left as the height increases: this is because radiation losses become higher and the cable appears shorter to the current. This effect will however be neglected in this study as it represents a shift smaller than $3 \%$. The general value of the input impedance increases proportionally with the height. Figure 131 presents the impedances of an unloaded single wire above a ground plane with the comparison of the effect of the length for 2 different heights to the ground $(2 \mathrm{~cm}$ and $80 \mathrm{~cm})$. A similar behaviour is observed for the three lengths with an initial capacitive behaviour and an antenna behaviour in the higher frequencies with resonances due to standing waves. 
Table 12: Anti-resonances frequencies of single copper wire $(0.9 \mathrm{~m})$ above a ground plane.

\begin{tabular}{|l|l|l|l|l|l|l|}
\hline $\begin{array}{l}\text { Frequency }(\mathrm{MHz}) \\
\text { Height }(\mathrm{cm})\end{array}$ & $1^{\text {st }}$ & $2^{\text {nd }}$ & $3^{\text {rd }}$ & $4^{\text {th }}$ & $5^{\text {th }}$ & $6^{\text {th }}$ \\
\hline Theory & 83 & 250 & 417 & 583 & 750 & 917 \\
\hline 2 & 83 & 247 & 406 & 577 & 752 & 920 \\
\hline 10 & 78 & 240 & 402 & 573 & 734 & 900 \\
\hline 80 & n. a. & 244 & 405 & 574 & 736 & 905 \\
\hline
\end{tabular}

The value of lower impedances, or anti-resonances, occurs when there is a maximum current at the input of the wire and a minimum voltage. These points of lower impedance remain along a line in the logarithmic scale of Figure 131: in the top graph the values of lower impedance for a height of $2 \mathrm{~cm}$ go from $47 \mathrm{Ohm}$ at $30 \mathrm{MHz}$ to $100 \mathrm{Ohm}$ at $1 \mathrm{GHz}$. In the second graph the values of lower impedance for a height of $80 \mathrm{~cm}$ go from $65 \mathrm{Ohm}$ at $30 \mathrm{MHz}$ to $150 \mathrm{Ohm}$ at $1 \mathrm{GHz}$. Moreover the lower values of impedance remain on the same line independently of the length of the cable. Figure 132 is the same as Figure 131 but expressed in terms of length of cable instead of frequency. It shows the consistency in the location of the resonant frequency as a function of the length of the cable: the resonances and antiresonances occur as predicted by the theory, independently of a change of length.

In the low frequency region, the input impedances of the wire at a height of $40 \mathrm{~cm}$ and higher show variations up to $150 \mathrm{MHz}$. This is related to the measurement setup itself. A metallic structure is used to maintain the wire at a certain height and to ensure the ground of the measurements set-up is as close as possible to the excited extremity of the wire. The variations occur when the size of this structure is of the order of the wavelength. When the wire gets longer these effects are attenuated: it appears in Figure 131 where the first resonance of the wire of $2.7 \mathrm{~m}$ is still visible.

Table 13: A measured minimum value of impedance $(\mathrm{Ohm})$ for different length of wire - wire set at $80 \mathrm{~cm}$ above ground.

\begin{tabular}{|l|l|l|l|l|l|l|l|l|}
\hline $\begin{array}{l}\text { Wavelength } \\
\text { Wire length }\end{array}$ & $1 / 4$ & 3 & $1+$ & $1+$ & $21+$ & $21+$ & $31+$ & $31+$ \\
$0.9 \mathrm{~m}$ & Nan & 91 & 116 & 128 & 135 & 143 & - & - \\
\hline $1.5 \mathrm{~m}$ & Nan & Nan & 126 & 132 & 128 & 139 & 147 & 150 \\
\hline $2.7 \mathrm{~m}$ & Nan & Nan & Nan & 140 & 168 & 147 & 170 & 139 \\
\hline
\end{tabular}



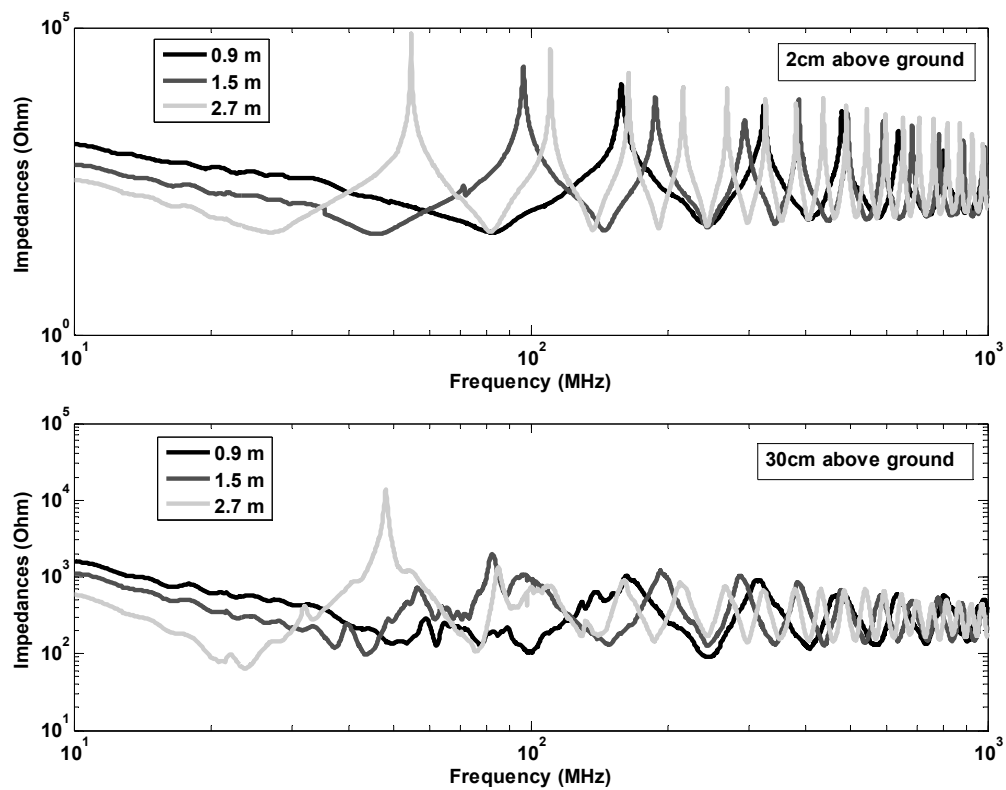

Figure 131: Input impedances of an unloaded single wire above a ground plane, comparison of the effect of the length for 2 different heights to the ground $(2 \mathrm{~cm}$ and $80 \mathrm{~cm}$ ).
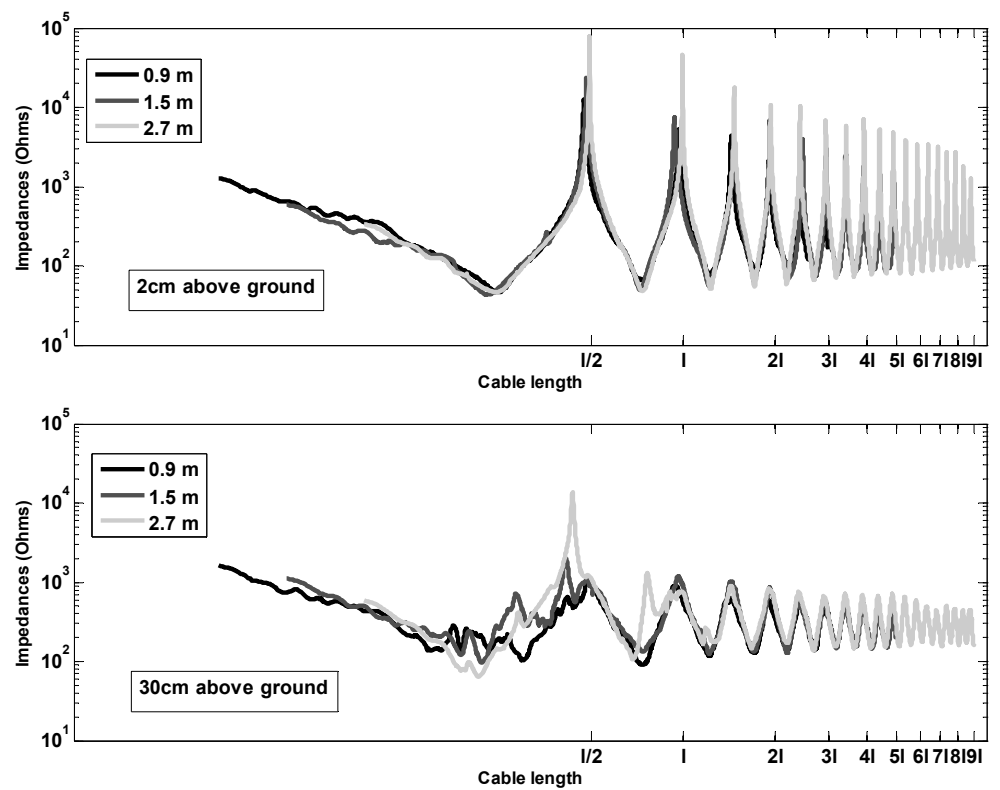

Figure 132: Same as Figure 131 expressed in terms of length of cable instead of frequency. 
Single wire above a ground plane, closed or loaded with an impedance of 50 ohms

The condition set at the non-excited extremity will determine the value of the reflection coefficient of the waves at this extremity and set the position of the standing waves along the wire. When the wire is connected to the ground the reflected signal at the end of the cable has the same amplitude as the incident signal but the opposite phase. The standing waves settle in the cable at frequencies for which the standing waves were cancelling each other when the wire was left open ended. The anti-resonances of the open-wire are the resonances of the closed wire. It is verified in Figure 133. The load of $50 \mathrm{Ohms}$ has for only effect to absorb a part of the current at the end of the wire, or in other word to reduce the reflection occurring at this extremity. The amplitude of the current is reduced, and the values of minimum impedances are higher than for a closed wire.

\section{Single wire above a ground plane, loaded with feedthrough capacitance}

In order to come closer to the real situation of a structure with a motor and its feeders, the copper wire is loaded with a feedthrough capacitor. It represents the capacitive coupling occurring between the motor and the ground. Typical values of these equivalent capacitances of the motor to the ground are of the order of a few nanofarads. Tree values of feedthrough capacitance have been used in the experiment: $2.2 \mathrm{nF}, 10 \mathrm{nF}$ and $100 \mathrm{nF}$. Their low parasitic inductance allow the capacitance to be considered perfect over the frequency range.

Figure 134 presents the input impedances of a single wire above a ground plane loaded with a $2.2 \mathrm{nF}$ feedthrough capacitance. The effect of the height for 2 different lengths $(0.9 \mathrm{~m}$ and $2.7 \mathrm{~m})$ is compared. Figure 135 presents the input impedances of a single wire above a ground plane with a length of $1.5 \mathrm{~m}$ or $0.9 \mathrm{~m}$ and loaded with different feedthrough capacitors: $2.2 \mathrm{nF}, 10 \mathrm{nF}, 100 \mathrm{nF}$ or short-circuited to the ground. These points are of special interest as they allow the prediction of the worst case scenario in terms of level of common mode current.

The general behaviour of the impedance of the wire loaded with a capacitance is same as the one closed at the end. There is also hardly any differences between the value of the impedance of the wire loaded with $2.2 \mathrm{nF}, 10 \mathrm{nF}$ and $100 \mathrm{nF}$. This is because the values of the impedance of the capacitances are very small compared to the one of the cable ( $100 \mathrm{Ohms}$ or more).

Figure 136 presents surfaces of the input impedance of a single wire with respect to frequency and height. The wire is above a ground plane, has a length of 3 meters and is loaded with a $2.2 \mathrm{nF}$ capacitance. The lower graph presents a bottom view of the upper graph. The lines of lowest points of impedances are then more visible. 


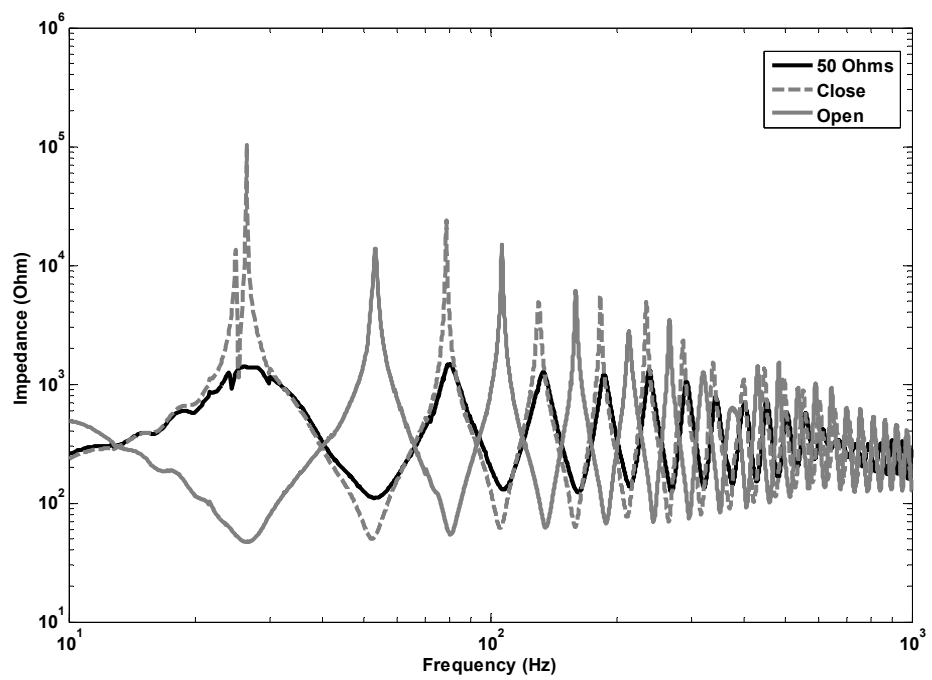

Figure 133: Input impedances of a single wire above a ground plane, comparison of the effect of the load: $50 \mathrm{Ohm}$ versus open and short circuited to ground. Reflection coefficient $=-1$ for the one closed at the end).
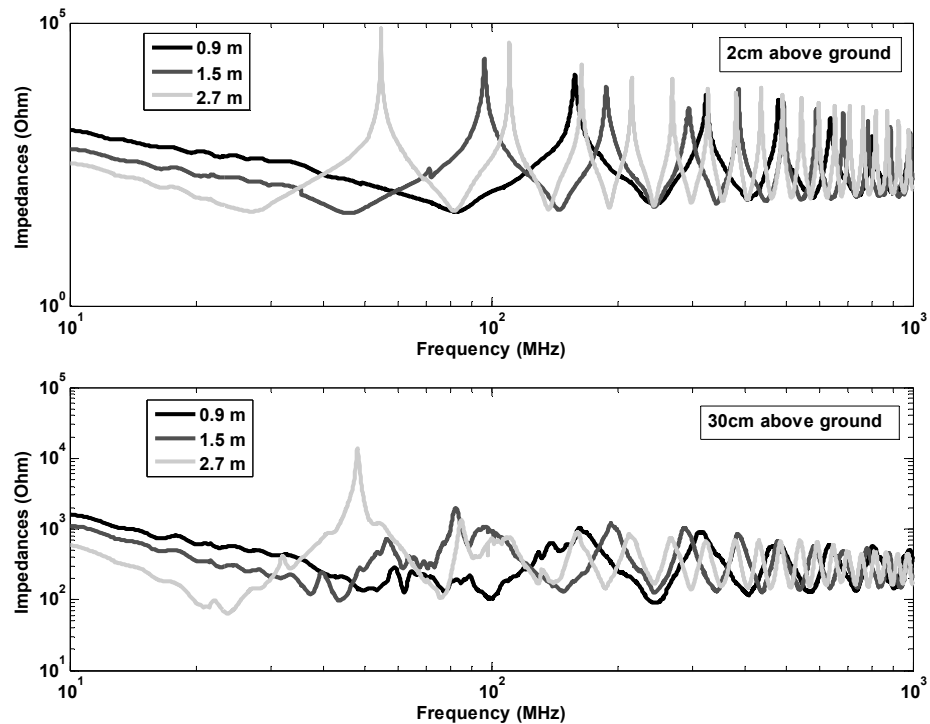

Figure 134: Input impedances of a single wire above a ground plane loaded with a $2.2 \mathrm{nF}$ feedthrough capacitance, comparison of the effect of the height for 2 different lengths $(0.9 \mathrm{~m}$ and $2.7 \mathrm{~m})$. 


\section{5.c. Influence of the designable parameter}

The following designable parameters have been considered:

- Length of the cable: the length of the cable determines the frequencies of the resonances and anti-resonances of the input common mode impedance.

- Height of the cable with respect to ground: as the height of the cable with the ground increases the general value of the impedance increases. As the distance between the cable and the ground increases, the structure comes closer to the monopole without ground plane. Its input impedance is double of the one of monopole above a ground plane. This extreme case will be the upper limit of the value of the input impedance.

- The common mode impedance of the load: the resonances of the input impedance of an open ended cable are the anti-resonances of the cable shorted to the ground at its end. If the load is capacitive a similar behaviour as the shorted cable is observed. A load of $50 \mathrm{ohm}$ will partially absorb the current during the reflection and will attenuate the value of the input impedance at both resonances and anti-resonances.

All these designable parameters are involved in the final value of the common input impedance of the cable and its load.

\subsection{Comparison of the experimental results with models}

6.6.a. Comparison of the simulated input impedance (MoM method) with measurements

The results of the MoM simulations for the structure (a), (b) and (c) are presented in Figure 137, Figure 138 and Figure 139 respectively, and are compared with the measurements. Details on the MoM simulation are given in 6.3.

The simulated input impedance with MoM simulation of a vertical monopole is a good match with the one measured in term of frequencies and values, especially for the points of anti-resonances. These points are the ones of special interest for the designer as they are the ones where a maximum current is to be expected at the input of the cable. The other simulated input impedances with MoM simulations (horizontal structures loaded or not) are also a good match with measurements. But the values of the lower frequency points are not well matched. These simulations have been performed with a thin wire and results could be improved by increasing the diameter of the wire and therefore the losses. 

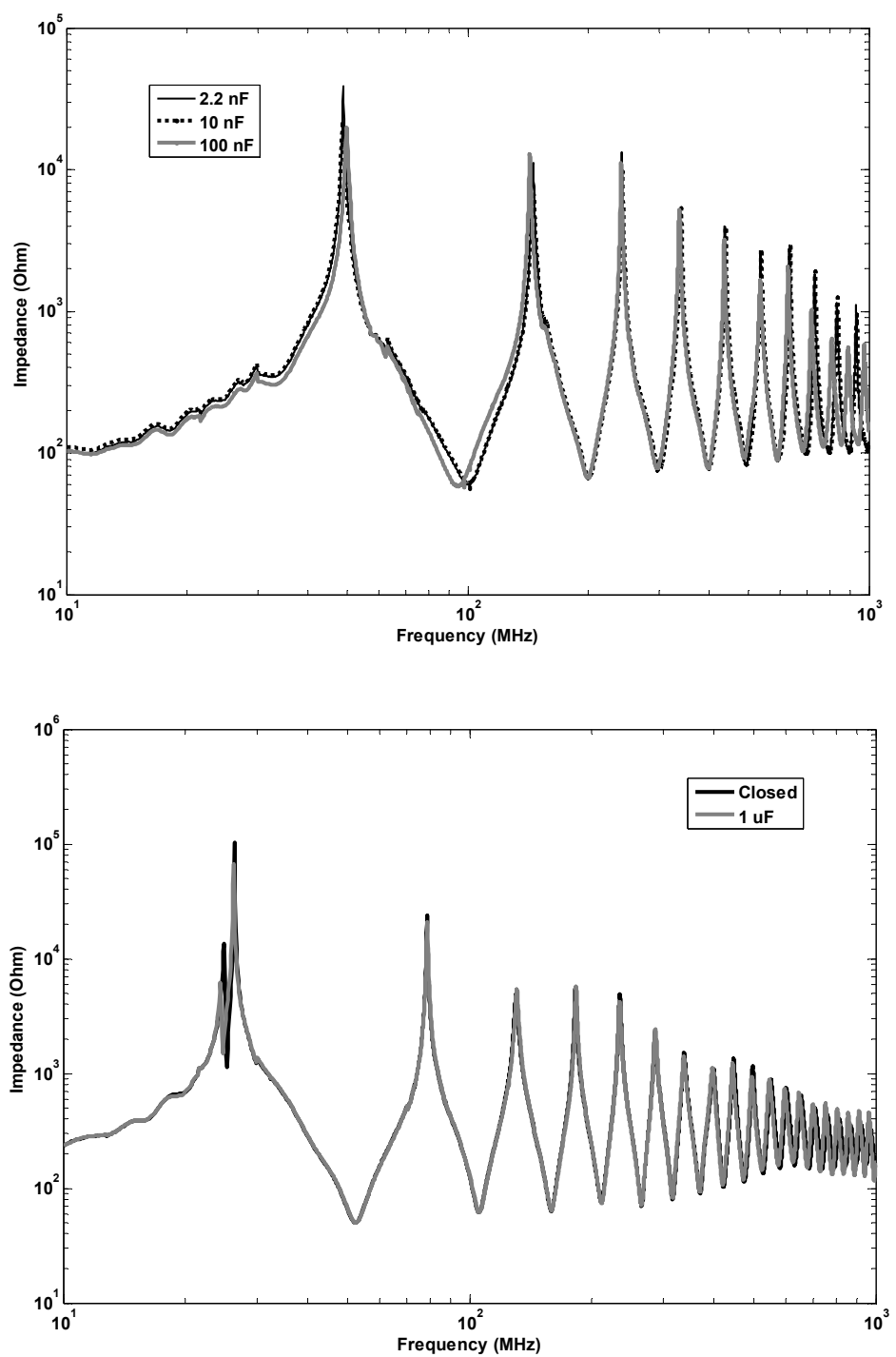

Figure 135: Input impedances of a single wire above a ground plane with a length of $1.5 \mathrm{~m}$ or $0.9 \mathrm{~m}$ and loaded with different feedthrough capacitors: $2.2 \mathrm{nF}, 10 \mathrm{nF}, 100 \mathrm{nF}$ or short circuited to the ground. 

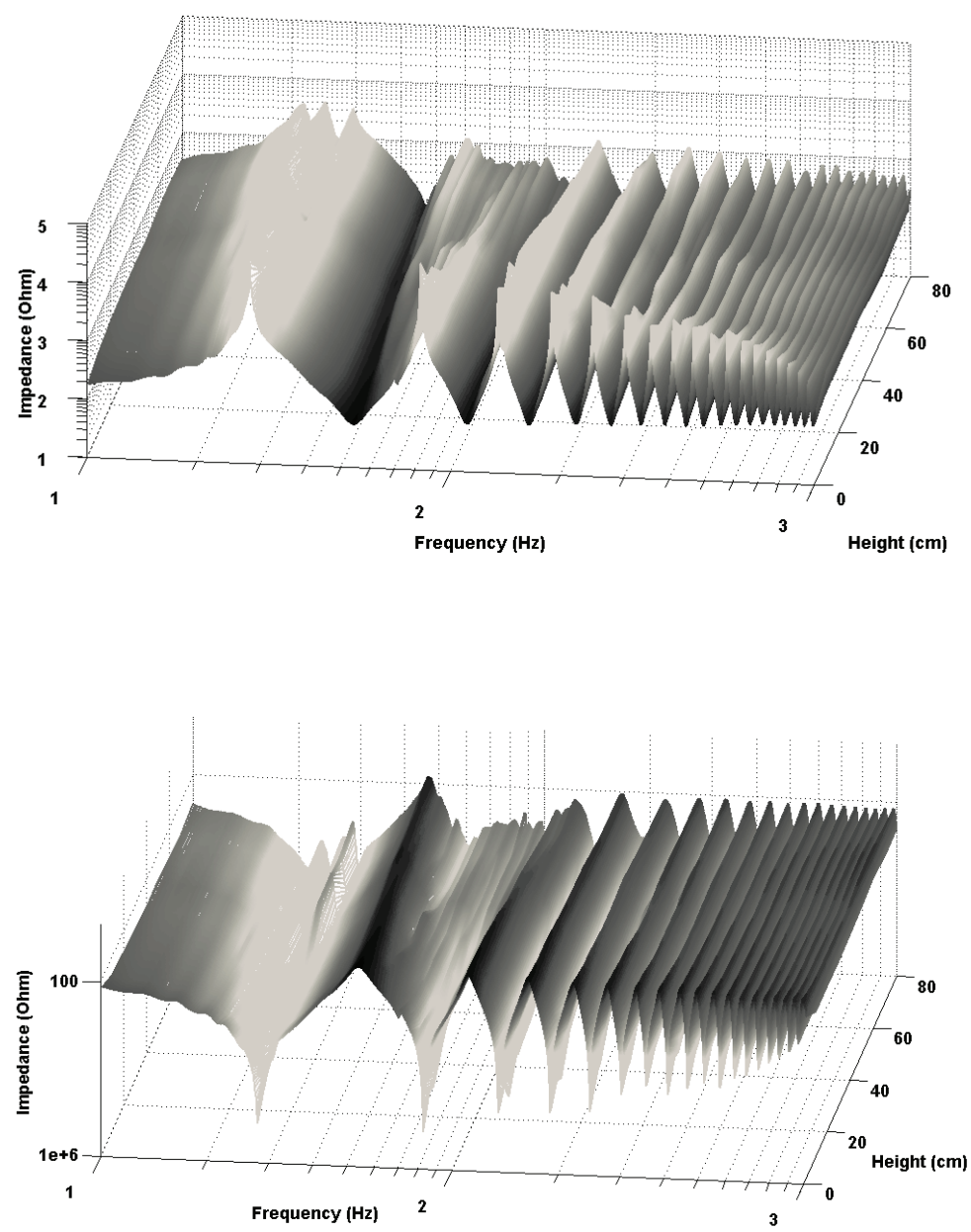

Figure 136: Surfaces of input impedance of a single wire with respect to frequency and height (top view and bottom view) - the vertical scale is logarithmic. 


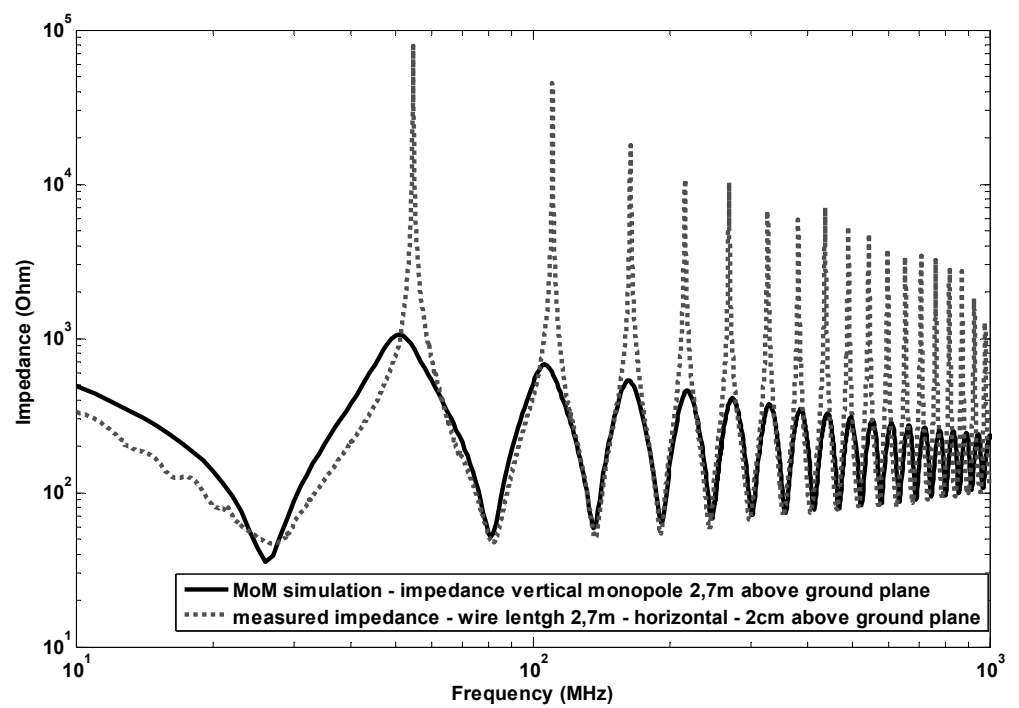

Figure 137: Comparison of the impedances of the NEC simulation of a vertical monopole (structure A) with the measured impedance of a wire placed $2 \mathrm{~cm}$ above the ground (open termination) with the test set-up of this chapter.

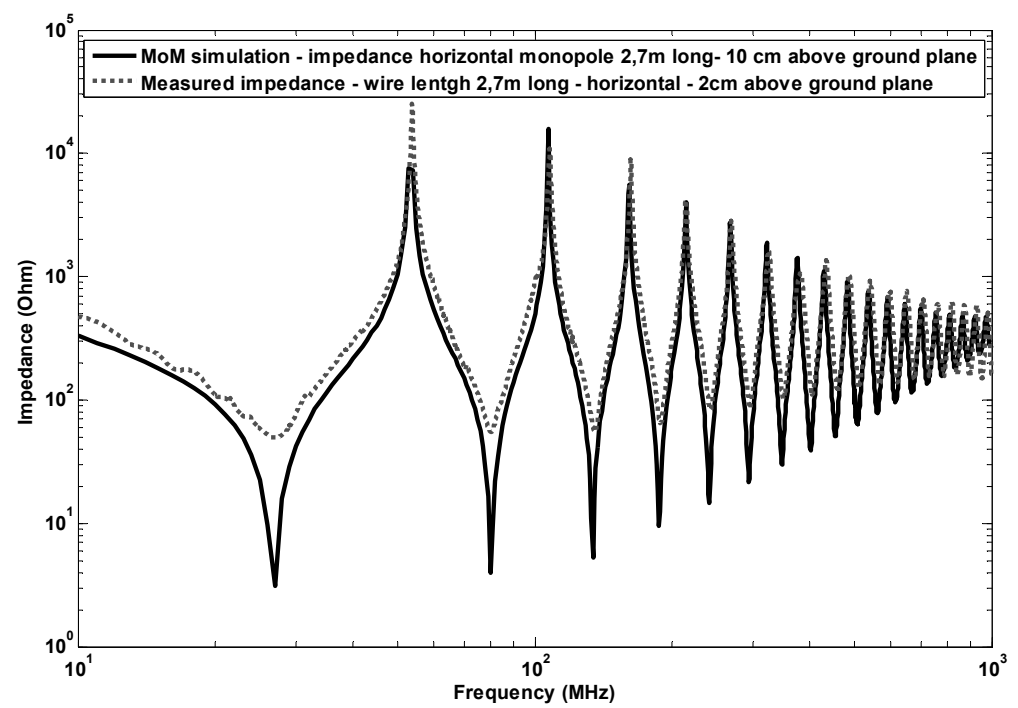

Figure 138: Comparison of the impedances of the NEC simulation of an horizontal monopole (structure B) with the measured impedance of a wire placed $10 \mathrm{~cm}$ above the ground (open termination) with the test set-up of this chapter. 


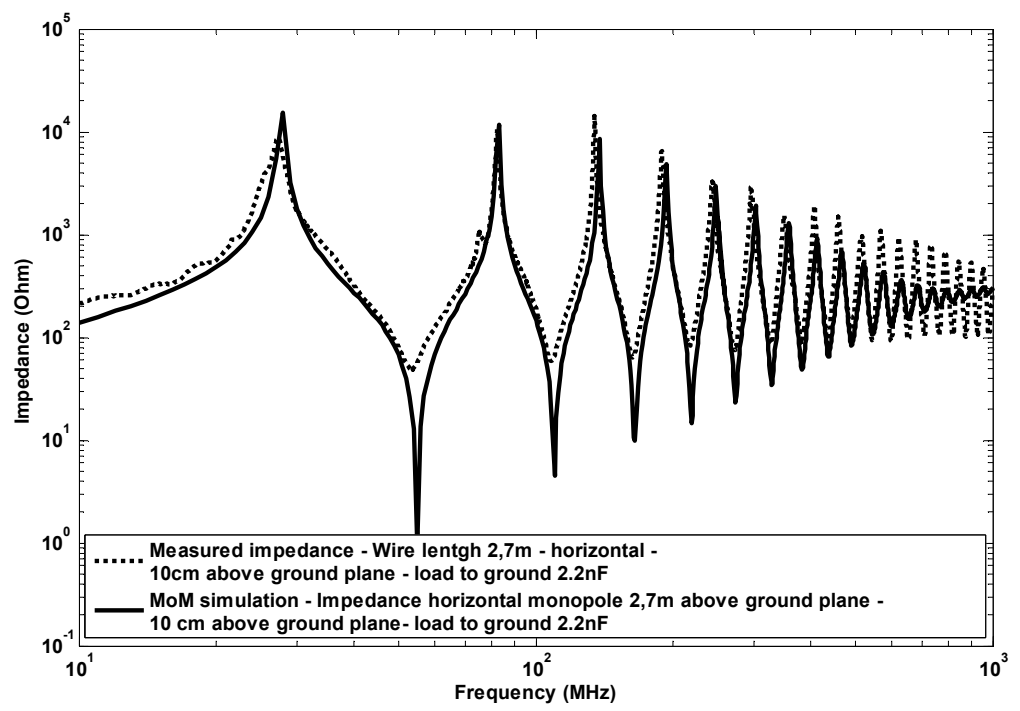

Figure 139: Comparison of the impedances of the NEC simulation of an horizontal monopole loaded with a capacitance to ground (structure $\mathrm{C}$ ) with the measured impedance of a wire placed $10 \mathrm{~cm}$ above the ground (same load $2.2 \mathrm{nF}$ ).

\section{6.b. Comparison of the simulations (analytical methods) with measurements}

Simulated input impedances with both Hallén and King relations are compared with measurements for the following configurations:

- Wire placed $2 \mathrm{~cm}$ above a ground plane $-0.9 \mathrm{~m}$ long - Open ended in Figure 140.

- Wire placed $30 \mathrm{~cm}$ above a ground plane $-0.9 \mathrm{~m}$ long - Open ended in Figure 141.

- Wire placed $2 \mathrm{~cm}$ above a ground plane $-2.7 \mathrm{~m}$ long - Open ended in Figure 142.

- Wire placed $30 \mathrm{~cm}$ above a ground plane $-2.7 \mathrm{~m}$ long - Open ended in Figure 143.

These comparisons show first that both methods from Hallén and King give a relatively good approximation of the input impedance of a wire placed above a ground plane when the distance to the ground is kept small. For higher distance to the ground the structure approaches the one of a monopole without ground plane and the King and Hallén relation are is efficient to describe them amplitude wise. 


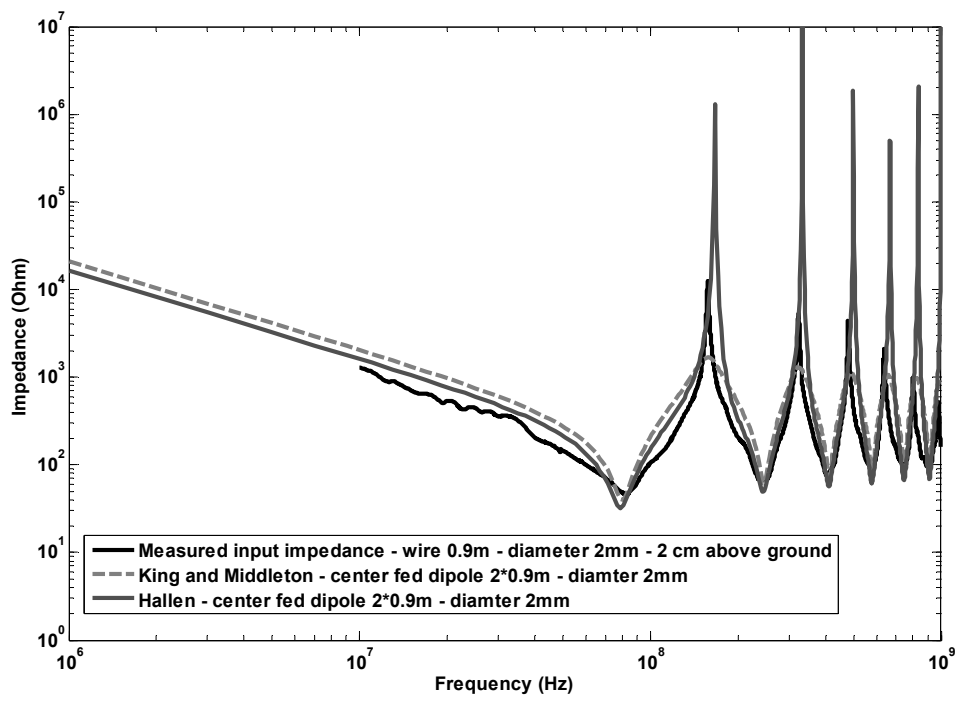

Figure 140: Comparison of the absolute value of the measured input impedance with both Hallén and King models for a wire $0.9 \mathrm{~m}$ long, placed $2 \mathrm{~cm}$ - open ended - above a ground plane.

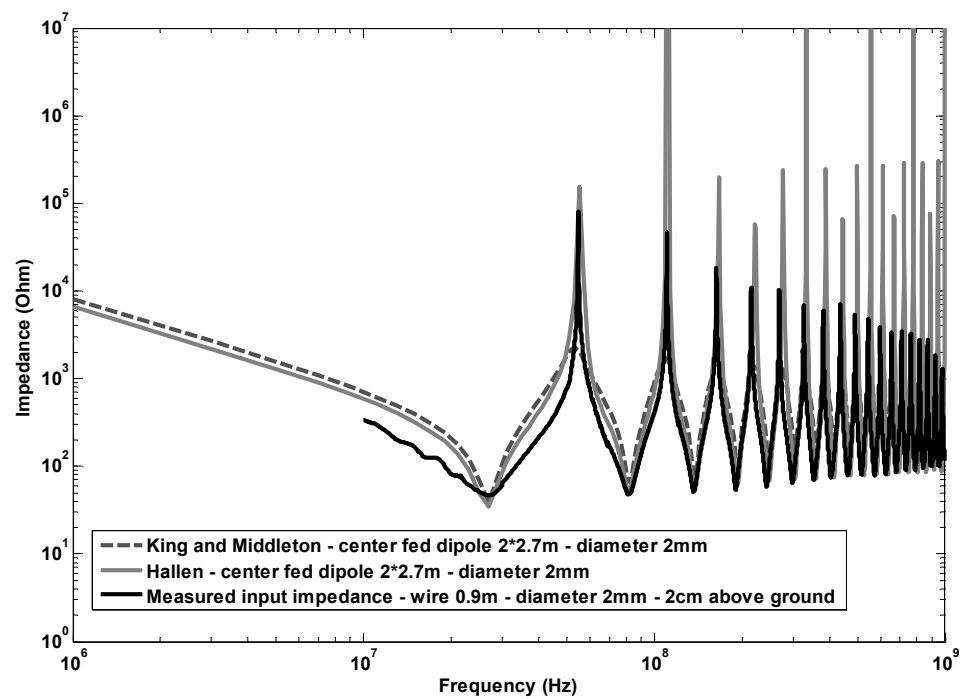

Figure 141: Comparison of the absolute value of the measured input impedance with both Hallén and King models for a wire $2.7 \mathrm{~m}$ long, placed $2 \mathrm{~cm}$ - open ended - above a ground plane. 


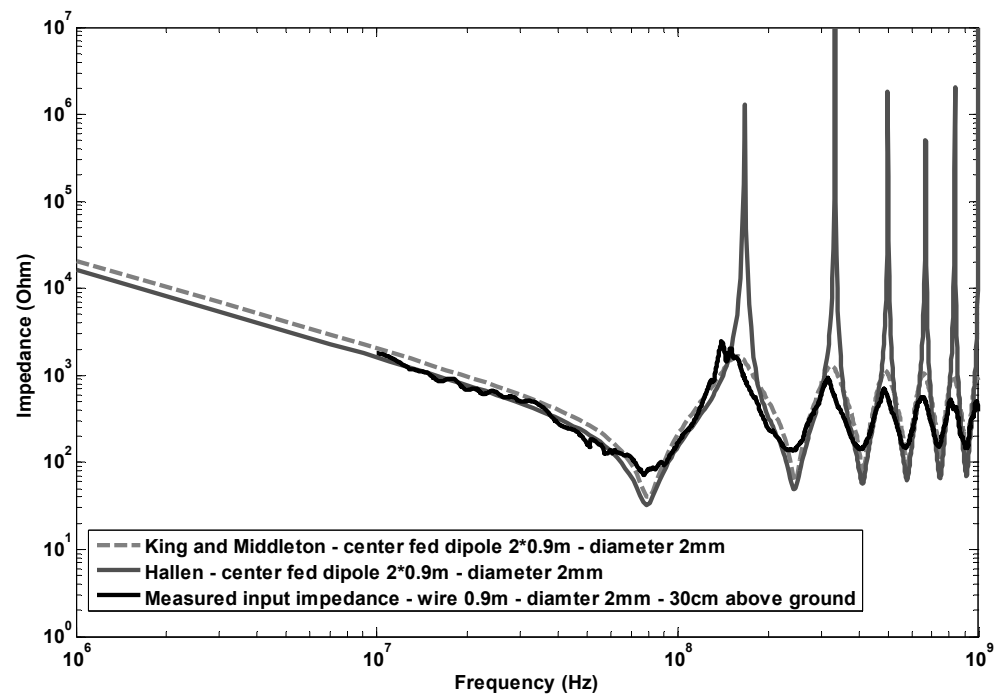

Figure 142: Comparison of the absolute value of the measured input impedance with both Hallén and King models for a wire $0.9 \mathrm{~m}$ long, placed $30 \mathrm{~cm}$ - open ended - above a ground plane.

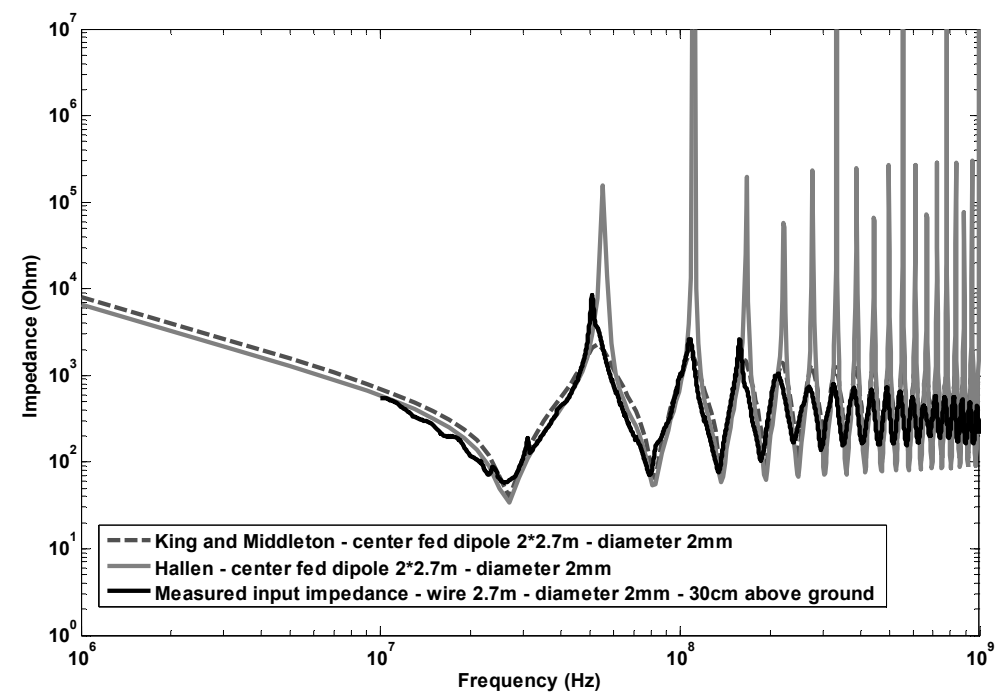

Figure 143: Comparison of the absolute value of the measured input impedance with both Hallén and King models for a wire $2.7 \mathrm{~m}$ long, placed $30 \mathrm{~cm}$ - open ended - above a ground plane. 


\subsection{Minima of input impedance calculations}

Ultimately the designer is not really interested at first in the exact frequencies of maxima and minima of the input impedance, because these are determined by the actual layout. He/she is interested in the asymptotic behaviour of the minima of input impedance, i.e. when the maximum common mode current is driven by the load. It has been shown in the last section that a good modelling of the input impedance of a wire above a ground plane is possible. A direct way to assess to a worst case scenario in term of EMI in the motor drive would be to be able to model the curve of lower values of input common mode impedance. The maximum values of input current in the cable as well as the maximum radiated field around it can be subsequently predicted.

This line of impedance can afterwards be refined in areas of frequencies 'at risk' once the length of the cable is identified and the anti-resonances frequencies are known.

\section{7.a. Input impedance of a vertical impedance, determined by the EMF method}

The antenna can be represented by a complex terminating impedance, where the real part of the impedance is associated with an average power flow away from the antenna (radiation), and the reactive part is associated with the non-radiative "near" fields of the antenna. The field description can be given a mechanical interpretation by considering the motion of electrons on the antenna. When the electrons are accelerated by an applied field (from the generator), they will radiate and hence lose energy. This change in energy is equivalent to a force acting against the motion of the electrons. This force, called the "induced EMF" or "radiation reaction", is attributed to the radiated fields acting back on the current.

In this section a sinusoidal distribution of the current is assumed on the monopole, although a sinusoidal distribution of current is not possible, even for an infinitely thin antenna. More details on the validity of this assumption are available in [63] and [65]. This approximation is fair for a sufficiently thin electrically and not too long monopole.

The input impedance formula is here obtained by integrating the normal component of the Poynting vector over a cylindrical envelope of radius $a$ and length $b$ that completely encloses the antenna. 
Input impedance of an electrically thin monopole with no ground plane - EMF method

The details of the derivation are available in [62]. The input impedance is determined by the induced EMF method. The general equation is:

$$
\begin{aligned}
& R_{\text {in }} \\
& =\frac{\eta}{4 * \pi * \sin ^{2}(k * h)} \\
& *\left(\begin{array}{c}
\operatorname{Cin}\left(x_{1}\right)+\operatorname{Cin}\left(x_{2}\right)-2 * \operatorname{Cin}\left(x_{3}\right)+\frac{\sin (2 * k * h)}{2} \\
*\left[\frac{\left(x_{1}+x_{2}\right) *\left(\cos \left(x_{1}\right)-\cos \left(x_{2}\right)\right)}{x_{1}^{2}+x_{2}^{2}+2 * x_{3}^{2}}\right] \\
+\sin ^{2}(k * h) *\left[\frac{\left(x_{1}+x_{2}\right) *\left(\sin \left(x_{1}\right)+\sin \left(x_{2}\right)\right)}{x_{1}^{2}+x_{2}^{2}+2 * x_{3}^{2}}-\frac{\sin \left(x_{3}\right)}{x_{3}}\right]
\end{array}\right) \\
& X_{\text {in }} \\
& =\frac{\eta}{4 * \pi * \sin ^{2}(k * h)} \\
& *\left(\begin{array}{c}
\operatorname{Si}\left(x_{1}\right)+\operatorname{Si}\left(x_{2}\right)-2 * \operatorname{Si}\left(x_{3}\right)-\frac{\sin (2 * k * h)}{2} \\
*\left[\frac{\left(x_{1}+x_{2}\right) *\left(\sin \left(x_{1}\right)-\sin \left(x_{2}\right)\right)}{x_{1}^{2}+x_{2}^{2}+2 * x_{3}^{2}}\right] \\
+\sin ^{2}(k * h) *\left[\frac{\left(x_{1}+x_{2}\right) *\left(\cos \left(x_{1}\right)+\cos \left(x_{2}\right)\right)}{x_{1}^{2}+x_{2}^{2}+2 * x_{3}^{2}}-\frac{\cos \left(x_{3}\right)}{x_{3}}\right]
\end{array}\right)
\end{aligned}
$$

Where:

$$
\begin{aligned}
& x_{1}=k *\left[\sqrt{\left(a^{2}+h^{2}\right)}+h\right] \\
& x_{2}=k *\left[\sqrt{\left(a^{2}+h^{2}\right)}-h\right] \\
& x_{3}=k * a \\
& \eta=376.73 \mathrm{Ohm} \\
& \mathrm{k}=\frac{2 * \pi}{\lambda} \text { is the wave number in } \mathrm{m}^{-1}
\end{aligned}
$$

For $a=0$, the input impedance equation can be reduced to: 


$$
\begin{array}{ll}
R_{\text {in }}=\frac{\eta}{4 * \pi * \sin ^{2}(k * h)} *\left(\operatorname{Cin}(2 * k * h)-\sin ^{2}(k * h)\right) & \mathrm{a}=0 \\
X_{\text {in }}=\frac{\eta}{4 * \pi * \sin ^{2}(k * h)} *\left(\operatorname{Si}(2 * k * h)-\frac{\sin ^{2}(k * h)}{k * a}\right) & \mathrm{a} \rightarrow 0
\end{array}
$$

The input reactance is sensitive to the element radius $a$. For $\mathrm{a}=0$, the input reactance is given by

$X_{\text {in }}=\left\{\begin{array}{l}-\infty \text { for } k * h \neq n * \pi \\ +\infty \text { for } k * h=n * \pi\end{array}\right.$ where $n \in \mathbb{N}^{*}$ and $a=0$

The resonances occur for $X_{\text {in }}=0$ :

$(\mathrm{k} * \mathrm{~h})_{\text {resonance }} \approx \frac{\eta}{4 * \pi} *\left[\frac{\operatorname{Cin}(2 * \mathrm{n} * \pi)}{\mathrm{k} * \mathrm{~h} * \operatorname{Si}(2 * \mathrm{n} * \pi)}-1\right]$

So the minima of input impedance occurs for

$(k * h)_{\text {minima }} \approx\left(N+\frac{1}{2}\right) * \pi$ for $N \in \mathbb{N}^{*}$

The input resistance at these minima can then be approximate by

$\left(R_{\text {in }}(f)\right)_{\text {minima }} \approx \frac{\eta}{4 * \pi} *(\gamma-1+\ln (f))$

Where $\gamma=$ Euler's constant $=0.57721$. The radiation resistance of an electrically thin monopole with no ground plane is approximately one half that of a monopole with a ground plane of large extent.

Figure 144, Figure 145 and Figure 146 compare the curve of minimum with the measured impedance of a wire of $0.9 \mathrm{~m}, 1.5 \mathrm{~m}$ and $2.7 \mathrm{~m}$ respectively. There is a good agreement between the curve of minimum and the actual anti-resonance points of the impedances. For the wire placed at placed at $2 \mathrm{~cm}$ from the ground the comparison is made with a centre fed dipole and for the one at $30 \mathrm{~cm}$ from the ground the comparison is made with a monopole.

A simple formula, independent of any designable parameters, can therefore be used to quickly provide information about the worst case scenario in term of conducted and radiated electromagnetic noise in the motor drive. (the curve of minima is only valid after the first minima of impedance). 


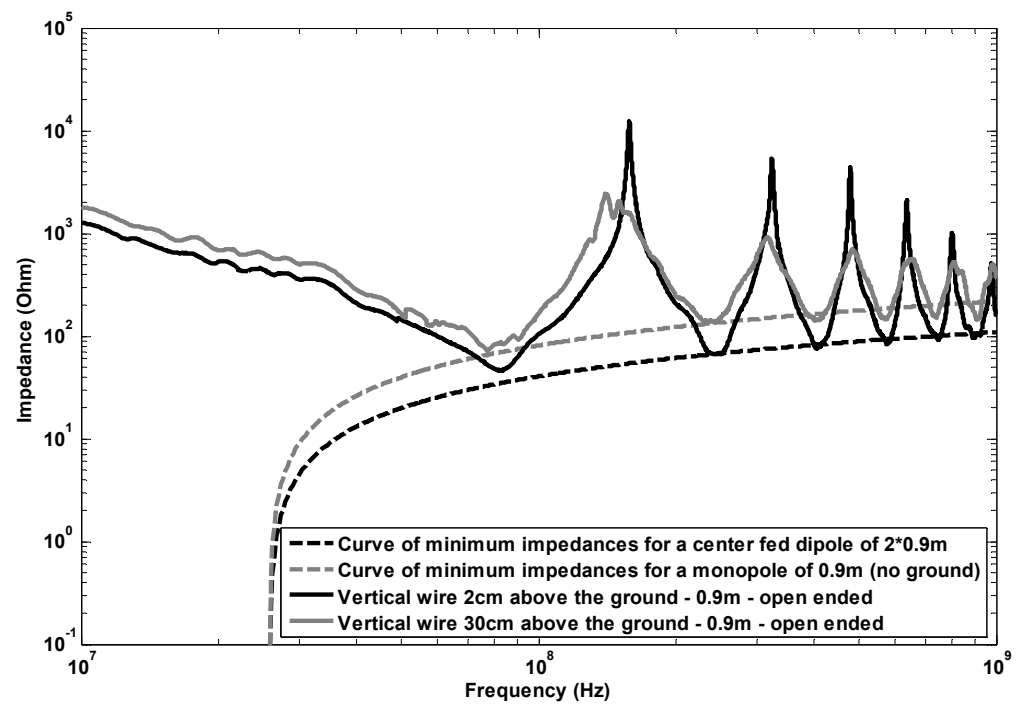

Figure 144: Comparison of the curve of minimum impedances with those measured for a wire $-0.9 \mathrm{~m}-$ open ended - placed $2 \mathrm{~cm}$ and $30 \mathrm{~cm}$ above a ground plane.

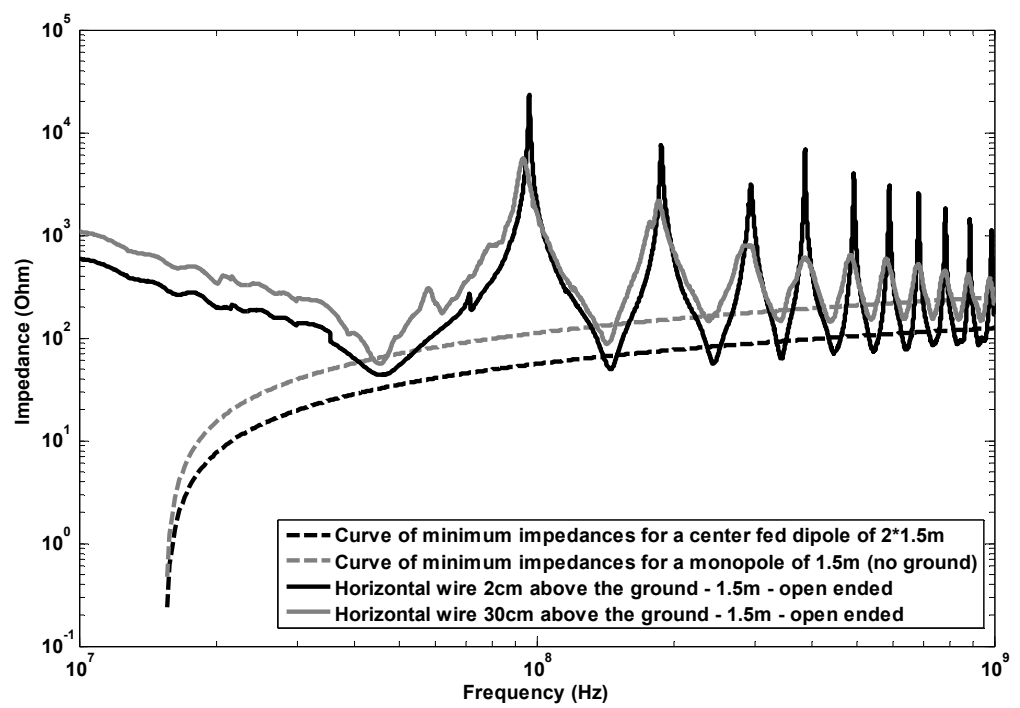

Figure 145: Comparison of the curve of minimum impedances with those measured for a wire $-1.5 \mathrm{~m}$ - open ended - placed $2 \mathrm{~cm}$ and $30 \mathrm{~cm}$ above a ground plane. 


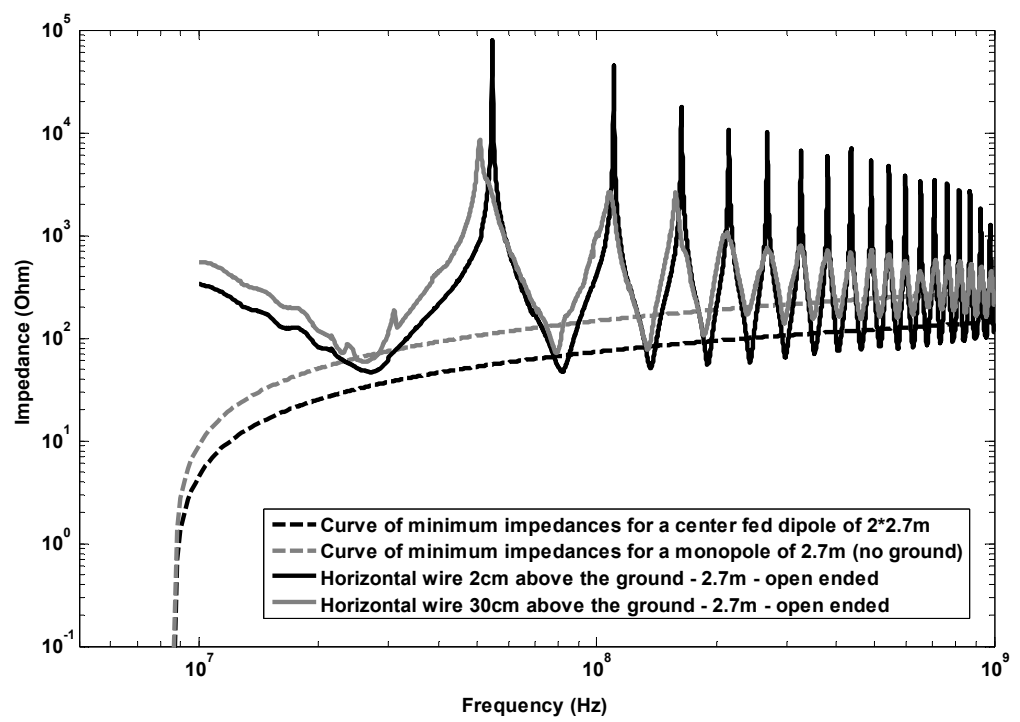

Figure 146: Comparison of the curve of minimum impedances with those measured for a wire $-2.7 \mathrm{~mm}-$ open ended - placed $2 \mathrm{~cm}$ and $30 \mathrm{~cm}$ above a ground plane.

\subsection{Equivalence between the input impedances}

Models of the input impedance of a wire above a ground plane have been previously introduced. The purpose is now to show the equivalence between the input impedance of a cable and its motor with the one of the wire above a ground plane.

\section{8.a. Measurements test set-up}

Measurements have been performed in a full anechoic room. The test set-up (placed on a table of $80 \mathrm{~cm}$ height) is presented in Figure 147.

\section{Details of the test set-up}

- Motor: It is an induction motor, delta connected, rated for $380-400 \mathrm{~V}$ and $5.1 \mathrm{~A}$ $(2.2 \mathrm{~kW})$. Its rotation frequency is set at $26 \mathrm{~Hz}$ during the conducted and radiated measurements.

- Frequency converter: the Danfoss VLT5000 is used. It rectifies AC voltage from mains into DC voltage (diodes rectifier), after which this DC voltage is converted into $\mathrm{AC}$ current with a variable amplitude and frequency.

- Cable: it is a three phases cable without shielding. 


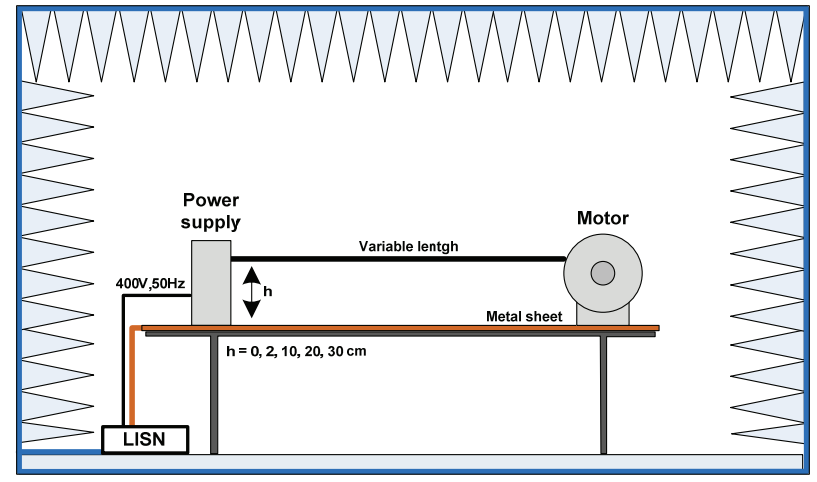

Figure 147: Test set-up.

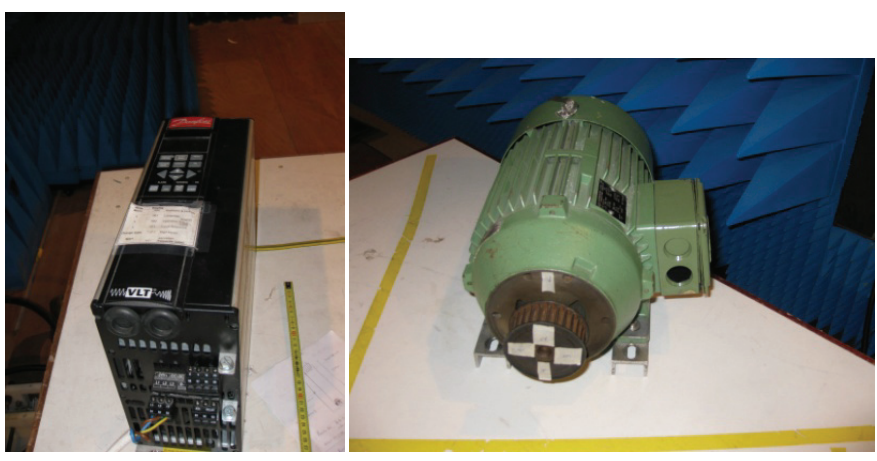

Figure 148: Picture of the VLT5000 and the motor.

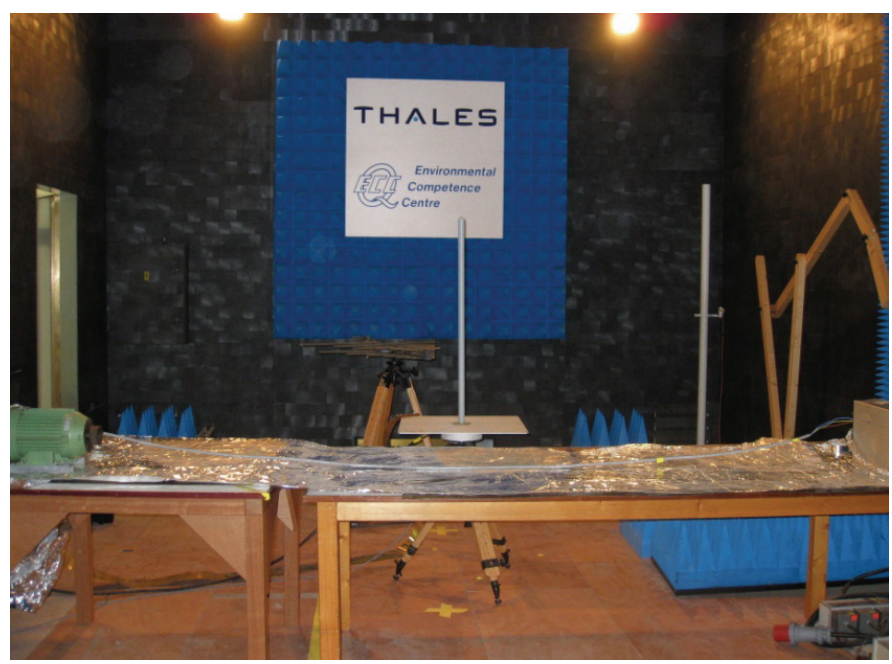

Figure 149: Picture of the test set-up. 


\section{8.b. Type of Measurements performed}

Three types of measurements are carried out with this motor drive: radiated emission levels, conducted emissions and impedance measurements.

For all measurements, the following designable parameters have been considered:

- Length of the cable.

- Height to the cable above the ground plane.

\section{Radiated emission level measurements}

The antenna is placed as presented in Figure 150.

Measurements have been performed between $9 \mathrm{kHz}$ and $1 \mathrm{GHz} .3$ antennas have been used:

- $9 \mathrm{kHz}$ to $30 \mathrm{MHz}$ : Rod antenna for the vertical polarization, manufactured by Rhode \& Schwarz (HFH2-Z6).

- $30 \mathrm{MHz}$ to $150 \mathrm{MHz}:$ Bi-conical antenna, manufactured by EMCO (cat: 3109).

- $150 \mathrm{MHz}$ to $1 \mathrm{GHz}$ : Log-periodic antenna, manufactured by Amplifier Research (AT1000).

\section{Conducted emission measurements}

The conducted emission measurements have been performed with 2 current probes:

- $\quad 20 \mathrm{kHz}-10 \mathrm{MHz}$ : probe from Rhode \& Schwarz (EZ-17).

- $10 \mathrm{MHz}-1 \mathrm{GHz}$ : probe from Fisher Custom Communication (FCC).

\section{Impedance measurements}

Impedance measurements have been performed using the same current probes used in the conducted emission part and the tracking generator $(20 \mathrm{kHz}$ to $1 \mathrm{GHz})$. The same test set-up used in section 6.5.a (Figure 127) to measure the input impedance of a wire above a ground plane has been used. Figure 151 presents the common mode impedance measurements of the common mode impedance of the motor and the cable terminated being performed. 


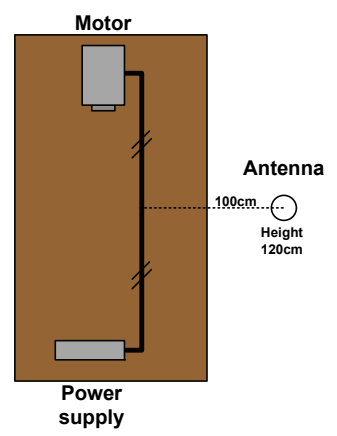

Figure 150: Antenna placement.

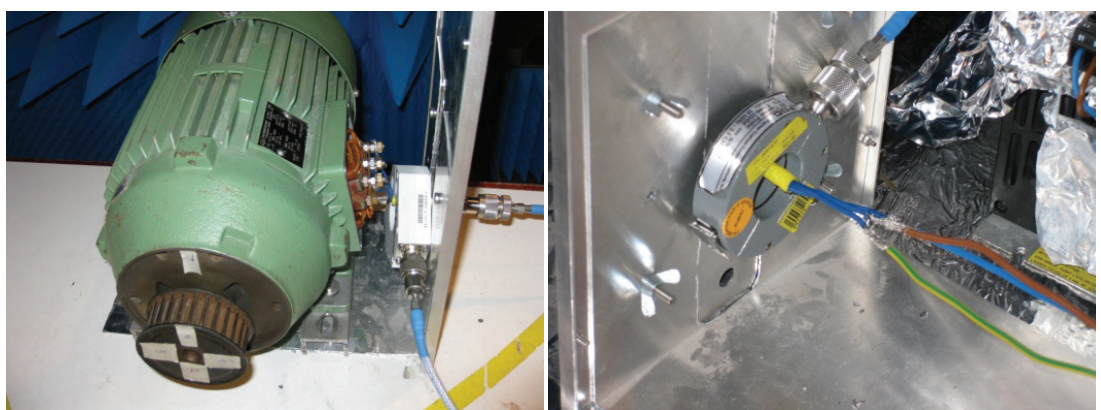

Figure 151 : Measurements of the common-mode impedance of the motor and of the system 'cable and motor'.

6.8.c. Impedance measurements results and equivalence with the one of a wire above a ground plane

The common mode impedance of the motor is pictured in Figure 152 and Figure 153. The impedance is independent of the position of the rotor of the motor. In the low frequency range (up to $2 \mathrm{MHz}$ ) the motor shows a capacitive behaviour with respect to the ground, in the higher frequency range the common mode impedance is inductive with a resonance at $170 \mathrm{MHz}$.

The common mode impedance of the motor together with its cable is presented in Figure 152 where the cable is placed at different heights with respect to the ground.

In the low frequency range (up to $2 \mathrm{MHz}$ ) the impedance of the motor dominates the overall impedance. In this frequency range impedances of both the cable and the motor are capacitive. At higher frequencies, standing waves are setup in the cable and the cable impedance dominates over from the one of the motor. There is clear shift of the resonance frequencies as the height of the cable increases. This shift was 
also noticed in the test set-up with the wire but in a more distinct manner. The dielectric around the cable virtually increases the height to the ground compared to the one of a single bare copper wire as presented in the section 6.5.b and the higher radiation losses make the cable looking significantly shorter to the current. The insulation adds an extra impedance along the wire.

Figure 153 compares the input impedance of the cable and its motor for two different lengths $(3 \mathrm{~m}$ and $6 \mathrm{~m})$. The same principles apply independently of the length of the cable.

The common mode impedance of the motor together with its cable is presented in Figure 154 for different lengths. The impedance is expressed in terms of of the unit length of the cable. A good stability of the resonant frequencies is observed with respect to the length of the cable. The same was noticed for the impedance of the single wire above its ground plane in section 6.5.b.

Figure 155 presents a surface plot of the input impedance of a cable and its motor with respect to the height and the frequency. The cable is above a ground plane and has a length of $3 \mathrm{~m}$. The lower graph presents a bottom view of the top graph. The lines of lowest points of impedances are then more visible. Figure 155 presents very similar surfaces to the ones shown in Figure 136).

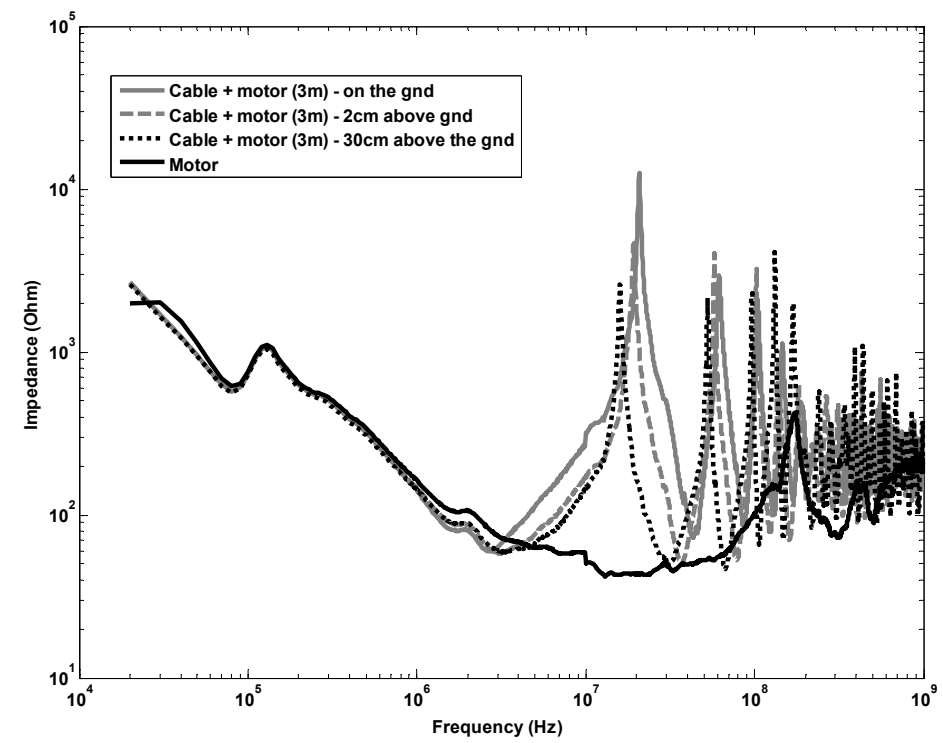

Figure 152: Input common mode impedance of the motor and that of the system 'motor and cable' for different height above the ground versus frequency. 


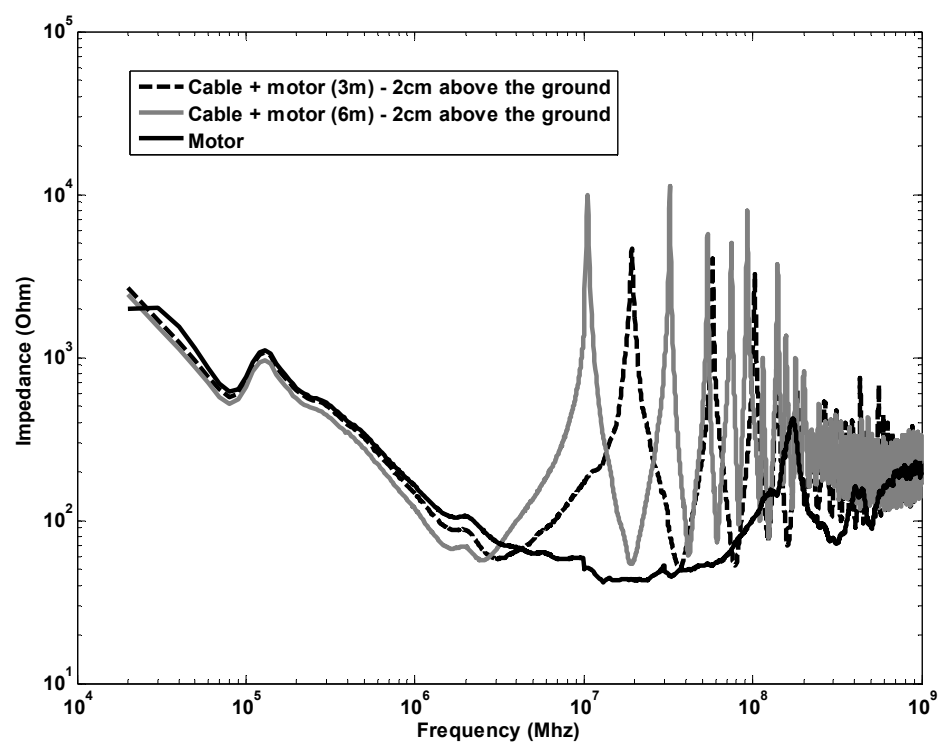

Figure 153: Input common mode impedance of the motor and that of the system 'motor and cable' for different length versus frequency.

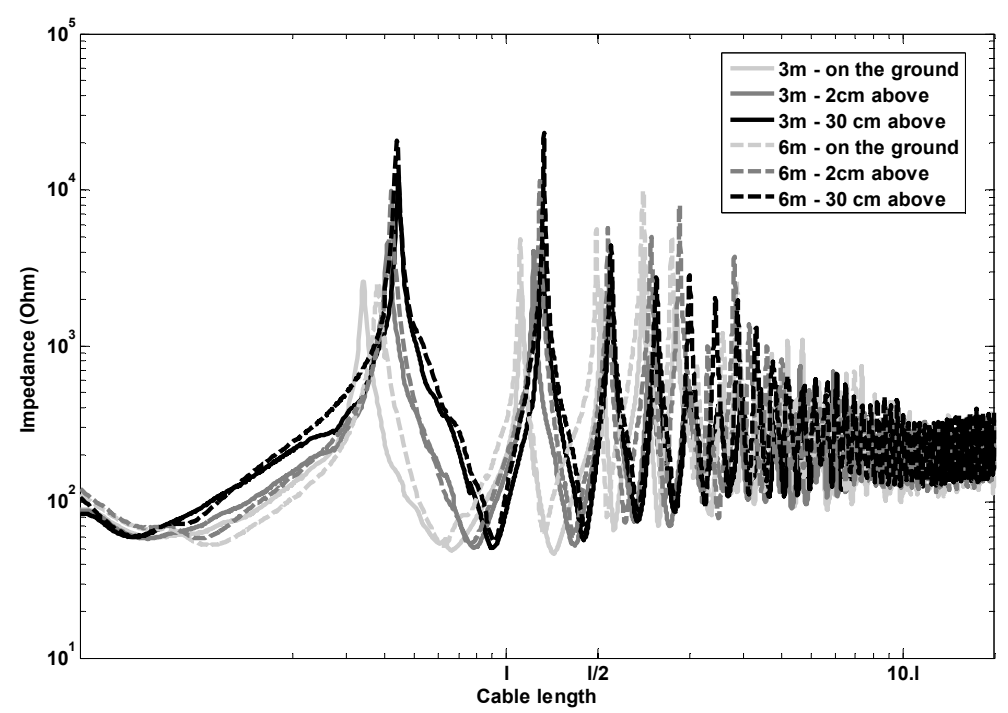

Figure 154: Input common mode impedance of the motor and that of the system 'motor and cable' for different length and different height per unit length. 
Figure 156 and Figure 157 compare the input impedances of the system 'cable + motor' with that of a same length wire placed at the same height above the ground. In Figure 156 the wire is placed at $2 \mathrm{~cm}$ above the ground with a termination of $2.2 \mathrm{nF}$. In Figure 157 the wire is placed at $30 \mathrm{~cm}$ above the ground with a termination of $2.2 \mathrm{nF}$. There is an excellent agreement between the two curves in both figures. The two systems 'cable + motor' and 'single wire + load' placed above a ground plane present an input impedance which is equivalent to each other.
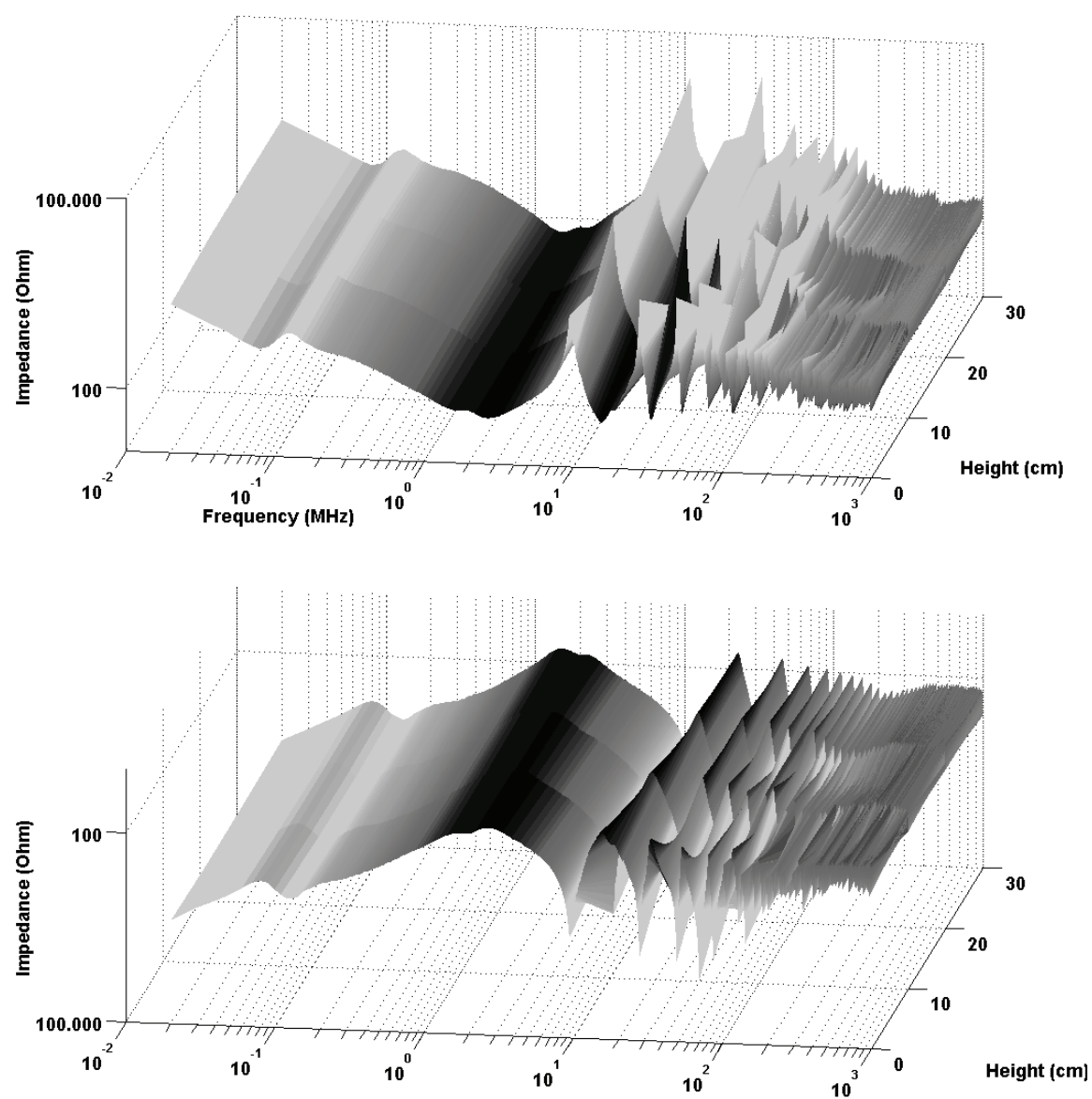

Figure 155: Input common mode impedances of the system 'motor and the cable' Effect of the height (view form top and bottom). 


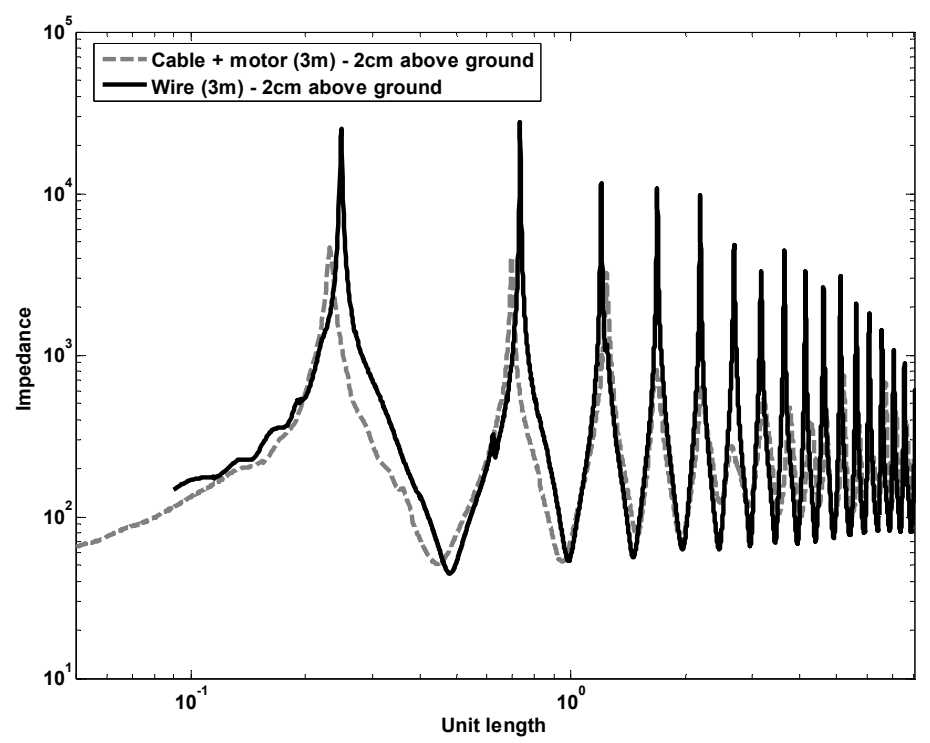

Figure 156: Comparison of the input impedance of the system 'cable + motor' with that of a same length wire at the same height above the ground $(2 \mathrm{~cm}-2.2 \mathrm{nF}$ termination).

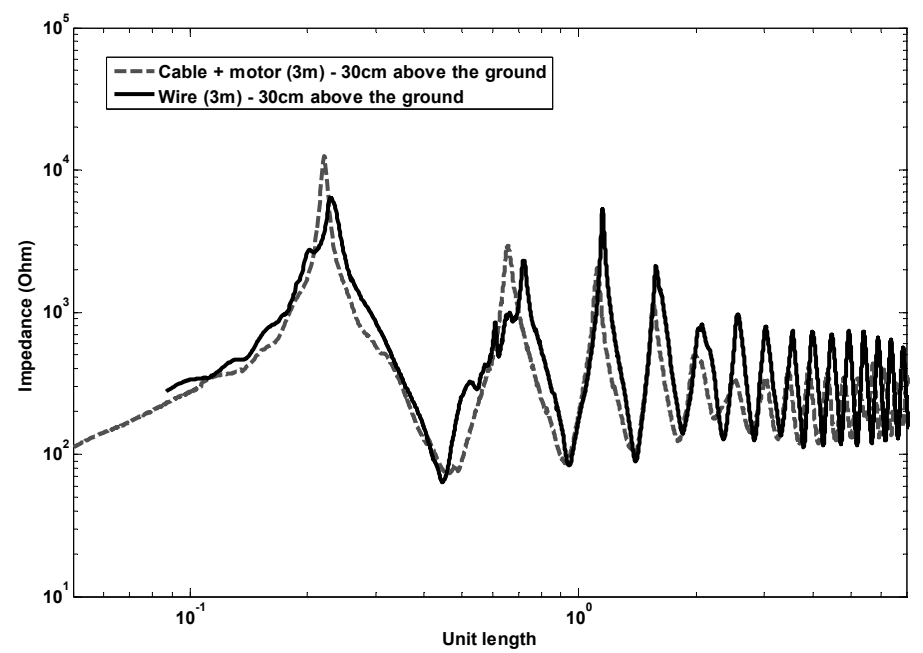

Figure 157: Comparison of the input impedance of the system 'cable + motor' with that of a same length wire at the same height above the ground $(30 \mathrm{~cm}-2.2 \mathrm{nF}$ termination). 


\section{8.d. Current measurements}

Figure 158 compares the measured electric field strength ( $\mathrm{V}$ polarization), the input common mode impedance of the cable and its motor and the corresponding input common mode current for a $3 \mathrm{~m}$ cable placed $2 \mathrm{~cm}$ above the ground. For frequencies above $2 \mathrm{MHz}$, where the antenna behaviour of the cable takes over, there is a clear frequency match between the lowest values of impedances and the highest values of the common mode current. There is also a match between the values of electric field strength and the values of current between $2 \mathrm{MHz}$ and $70 \mathrm{MHz}$.
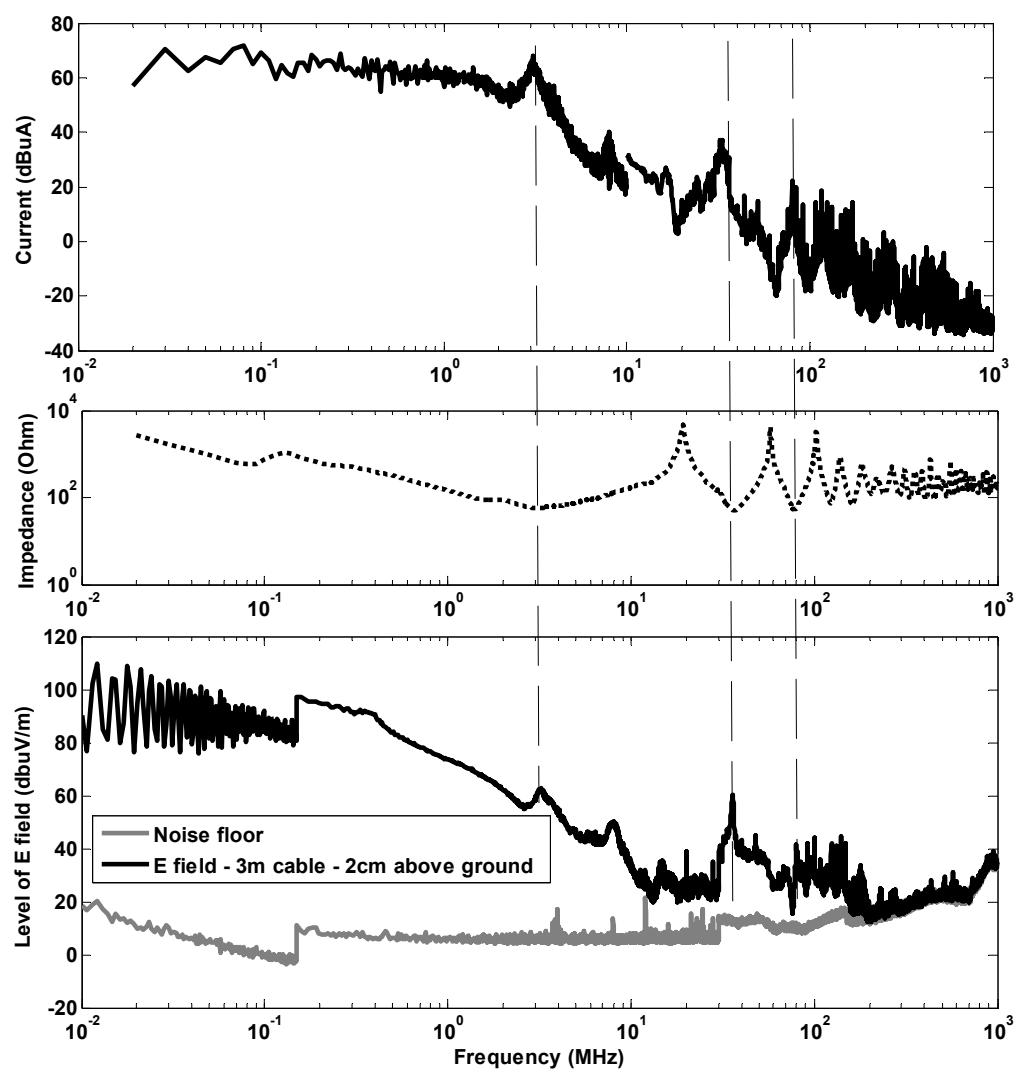

Figure 158: Comparison between the electric field strength (V polarization) measured, the corresponding input common mode impedance of the cable and its motor and the corresponding input common mode current $-3 \mathrm{~m}$ cable placed at $2 \mathrm{~cm}$ above the ground. 
Figure 159 compares the measured electric field strength (V polarization), the input common mode impedance of the cable and its motor and the corresponding input common mode current for a $3 \mathrm{~m}$ cable placed $30 \mathrm{~cm}$ above the ground. The values measured for the cable at $2 \mathrm{~cm}$ above the ground (Figure 158) have been depicted in grey. The match between the values of electric field strength and the values of current between $2 \mathrm{MHz}$ and $70 \mathrm{MHz}$ is even clearer: the frequency shift in the position of maxima in both current and field strength confirms it is due to the height change. The EM environment of cable and its motor is indeed driven by the antenna behaviour of the cable above $2 \mathrm{MHz}$.
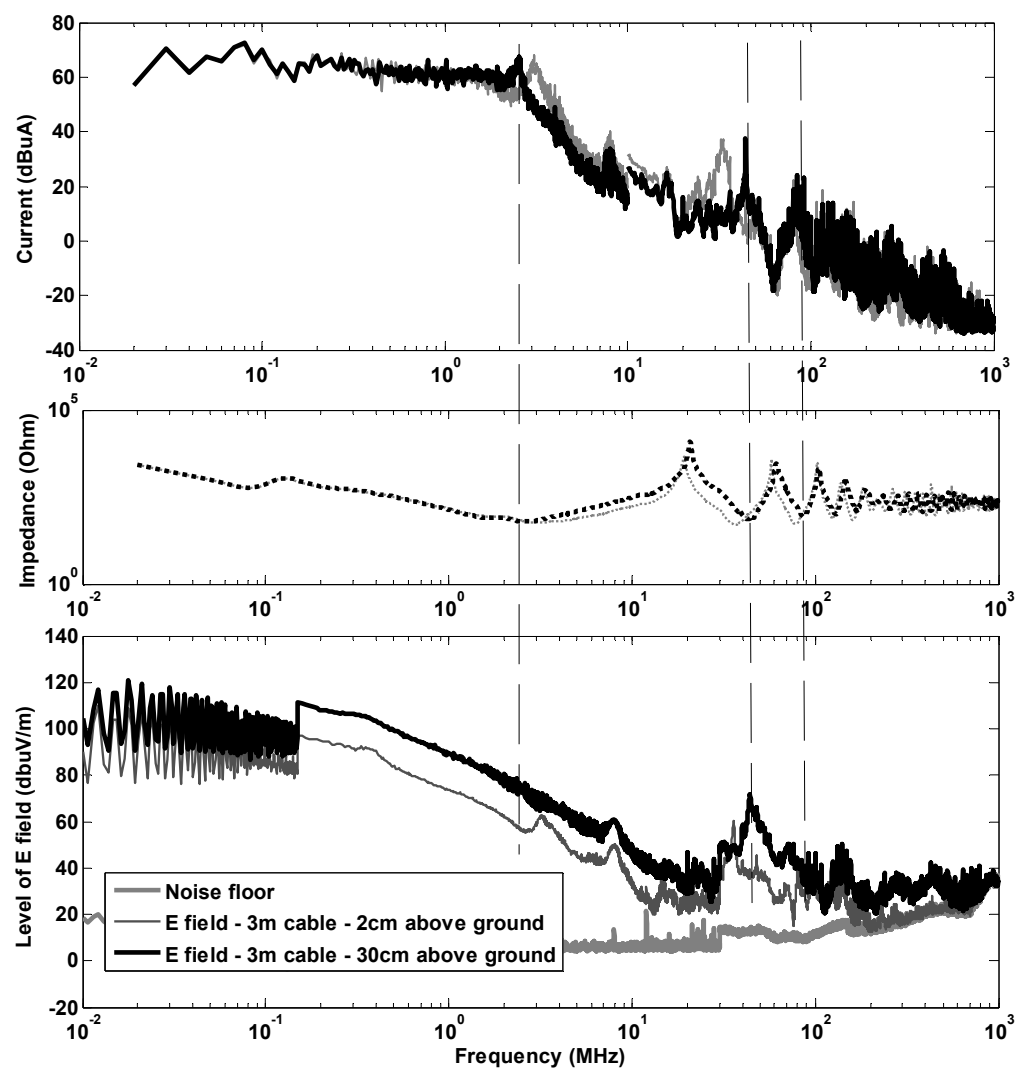

Figure 159: Comparison between the electric field strength (V polarization) measured, the corresponding input common mode impedance of the cable and its motor and the corresponding input common mode current $-3 \mathrm{~m}$ cable placed at $30 \mathrm{~cm}$ above the ground - (in grey the results for the cable at $2 \mathrm{~cm}$ height). 
Figure 160 compares the measured electric field strength ( $V$ polarization), the input common mode impedance of the cable and its motor and the corresponding input common mode current for a $6 \mathrm{~m}$ cable placed $30 \mathrm{~cm}$ above the ground. The cable is longer and the first resonance appears at a lower frequency $(10 \mathrm{MHz})$ than the one for the cable of $3 \mathrm{~m}$ length $(20 \mathrm{MHz})$. There are more resonances visible in the electric field strength.
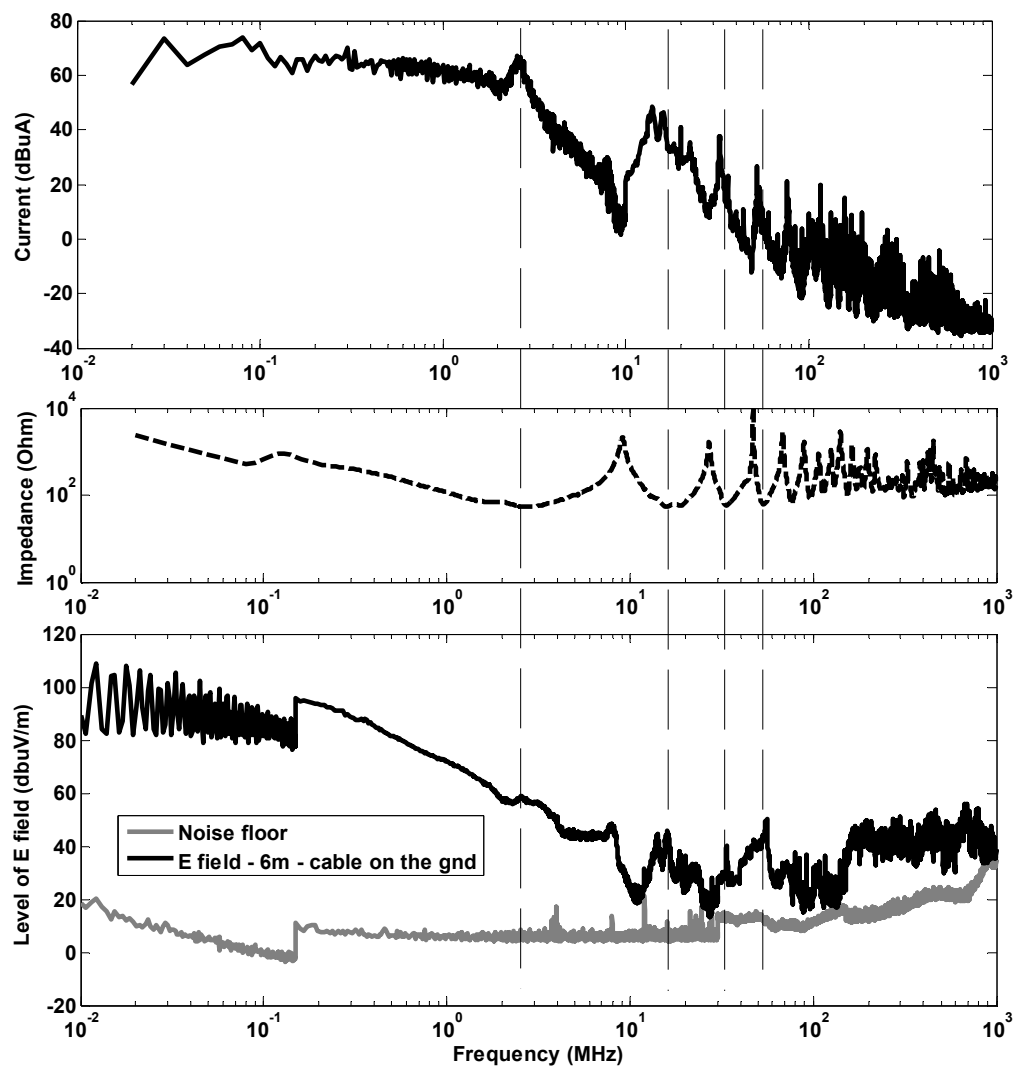

Figure 160: Comparison between the electric field strength ( $\mathrm{V}$ polarization) measured, the corresponding input common mode impedance of the cable and its motor and the corresponding input common mode current $-6 \mathrm{~m}$ cable placed at $2 \mathrm{~cm}$ above the ground. 
Figure 161 compares the measured electric field strength (V polarization), the input common mode impedance of the cable and its motor and the corresponding input common mode current for a $6 \mathrm{~m}$ cable placed $30 \mathrm{~cm}$ above the ground. The values measured for the cable at $2 \mathrm{~cm}$ above the ground (Figure 160) have been depicted in grey.
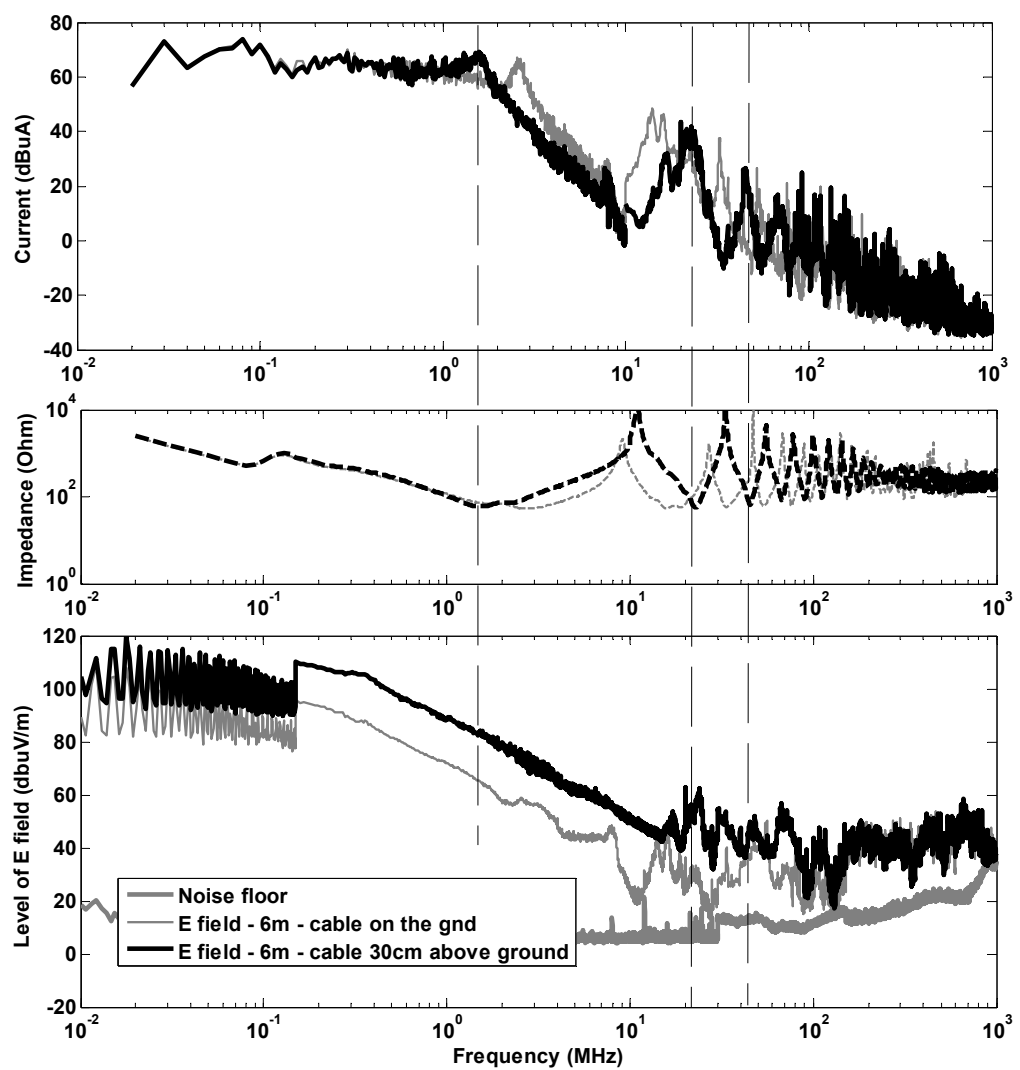

Figure 161: Comparison between the electric field strength (V polarization) measured, the corresponding input common mode impedance of the cable and its motor and the corresponding input common mode current $-6 \mathrm{~m}$ cable placed at

$30 \mathrm{~cm}$ above the ground - (in grey the results for the cable at $2 \mathrm{~cm}$ height).

\subsection{Summary}

It is crucial for the designer to be able to evaluate beforehand the level of conducted and radiated emissions to be expected in a motor drive system. This knowledge allows the management of the EMI to be potentially improved and support a first time right design of the motor drive in term of EMC. The goal of this chapter is to 
provide the designer with a behavioural model linking the designable parameters of the load and its cable to the level of currents and electromagnetic fields to be expected in the motor drive.

After a preliminary investigation of the current distribution along the cable, the input impedance of a wire placed horizontally above a ground plane have been investigated. The method of moment with the use of the software NEC as well as two analytical methods have been described (Hallén's and King and Middleton's methods). The input impedance of copper wires with different length and placed at different heights from the ground have been measured afterwards. The measurements have been compared with the methods described previously. There is a good agreement between them, especially with the analytical method of King and Middleton. It also appeared during both measurements and simulations that the minima of impedances, where a maximum current at the input of the cable is to be expected, remains on a same line. The equation of this line is simple and independent of the designable parameters of a motor drive. It is a simple rule which can be used by the designer to model a worst case scenario of the level of radiated field in their motor drive under design. The equivalence of the input impedance of a wire above a ground plane with the one of a cable and its motor has been shown in the last section of this chapter. 


\section{Chapter 7. Conclusion}

\subsection{Main results of the thesis}

In order to enable industry to design faster and with lower risk, filtering techniques in motor drives, a global behavioural model of the EMI filter has been developed. It requires the modelling of the complete motor drive from a common mode point of view. This model is complex and has been developed step by step starting from a component perspective towards a global approach combining functional parameters together with the EMI ones.

The structure of a typical inverter has been first described in Chapter 2 along with an overview of the noise source generation mechanisms. Chapter 3 has started with the description of the two main components of the EMI filter: the Y-capacitor and the common mode choke. This last component is complex: one first decision faced by the engineer is the choice of the material of the core. An optimized common mode choke presents a high permeability and a high enough level of saturation to the common mode current over the relevant frequency range. The choice of the material is a trade-off between volume, cost and saturation level. A new equivalent circuit for the common mode choke has been developed and validated in which the designable parameters of the common mode choke are linked to its impedances. It has also been demonstrated that for a choke used away from its saturation level, the dynamic behaviour of the permeability in transient conditions can be approximated by the permeability in sinusoidal conditions. The main result of this new equivalent circuit for common mode choke is that the impedances related to the differential 
mode currents and to the common mode currents are different. Both contributions can be decoupled. Therefore the common mode choke presents only its common mode impedance to the common mode current. An overview of the new equivalent circuit developed for the engineer is presented in Figure 162.

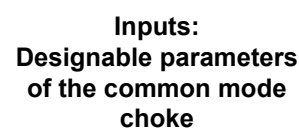

Outputs:

Equivalent circuits for

Common Mode and

Differential Mode

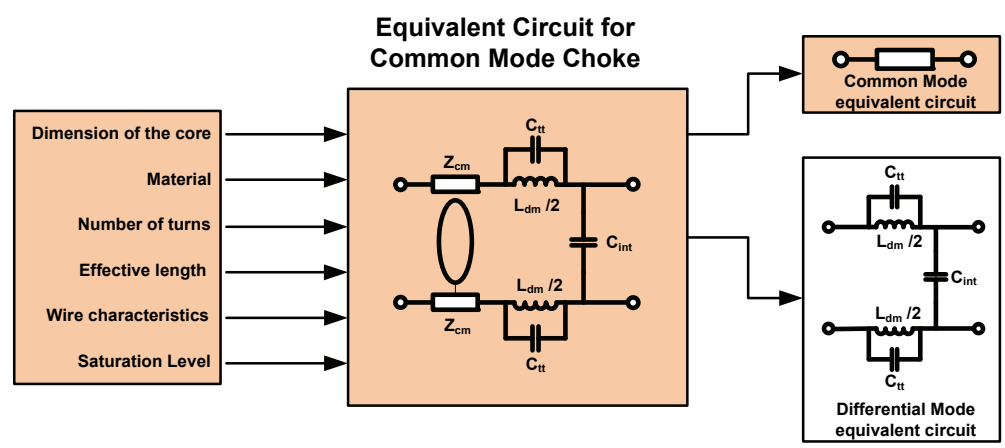

Figure 162: Overview of the black box model developed for the designer in Chapter 3 - Equivalent circuit for Common Mode Choke (CMC).

Chapter 4 has aimed at integrating the new equivalent circuit for common mode chokes into a behavioural one, where the in-situ performance for the choke can be evaluated. As a starting point a modification factor has been introduced. It is the ratio between the common mode current flowing before and after the introduction of the common mode choke in the motor drive. It shows the in-situ performances of the component. This modification factor is the main output of the behavioural model. It will require as inputs data such as the value of current flowing initially in the circuit or the upstream common mode impedance of the filter. The model is validated via both current and impedance measurements. Local sensitivities have been introduced to analyse the stability of the performances of the common mode choke when one of its parameters is slightly modified. The deviation has been used to evaluate the consequences of an error and/or an uncertainty in the model. Finally the influence of each designable parameter on the final performance is analysed: effect of the material, effect of the dimension of the core, effect of the number of turns, effect of the wiring system. An overview of the new behavioural model developed in Chapter 4 is presented in Figure 163. 
Inputs: Designable parameters
Outputs:

In-situ performances

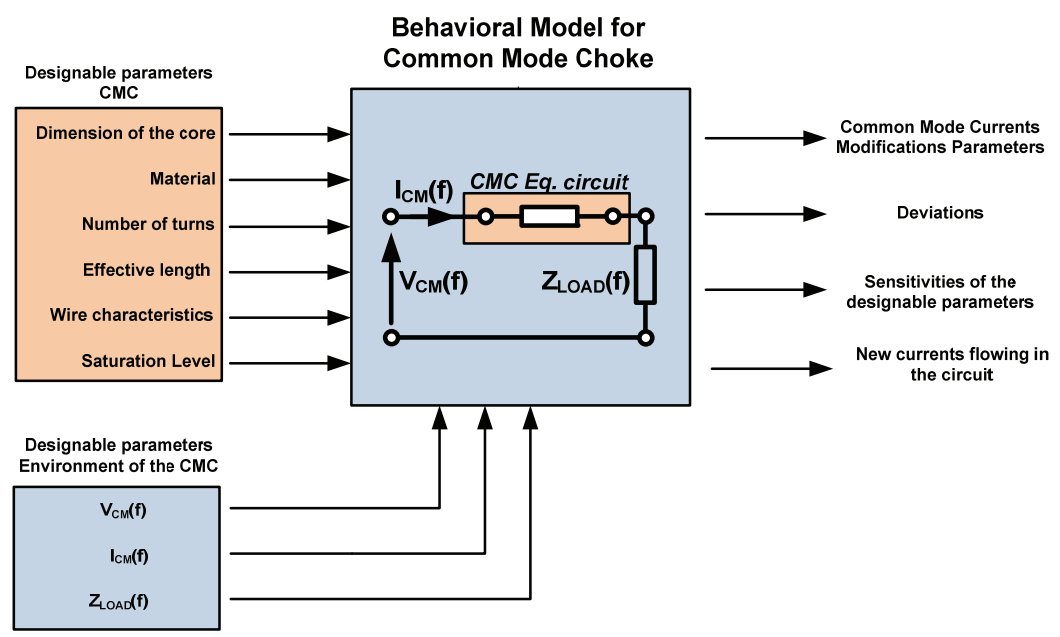

Figure 163: Overview of the black box model developed for the designer in Chapter 4 - Behavioural Model for Common Mode Choke (CMC).

The dynamic behaviour of the common noise source of the motor drive is modelled in Chapter 5 with a Thévenin type of structure. It is an essential knowledge to a proper characterization of the EMI filter in the motor drive. The behaviour of the noise source is described for each of its configurations. The goal of this chapter is indeed to provide the engineer with a global model of the EMI filter where the performances of all configurations can be tested. Each configuration of the EMI filter has been modelled via an equivalent circuit using the model of the noise source and the behavioural model of the common mode choke introduced in Chapter 4. Each modelled configuration has been validated via current and impedances measurements as well as each respective modification factors. Ultimately common design strategies of the EMI filter have been investigated against the new equivalent circuits developed in this chapter. Their strengths and their limitations have been highlighted. A simplified modification factor has been provided for each structure. An overview of the new equivalent circuit developed for the engineer is presented in Figure 164. In Chapter 6 the upstream common mode impedance was measured. 


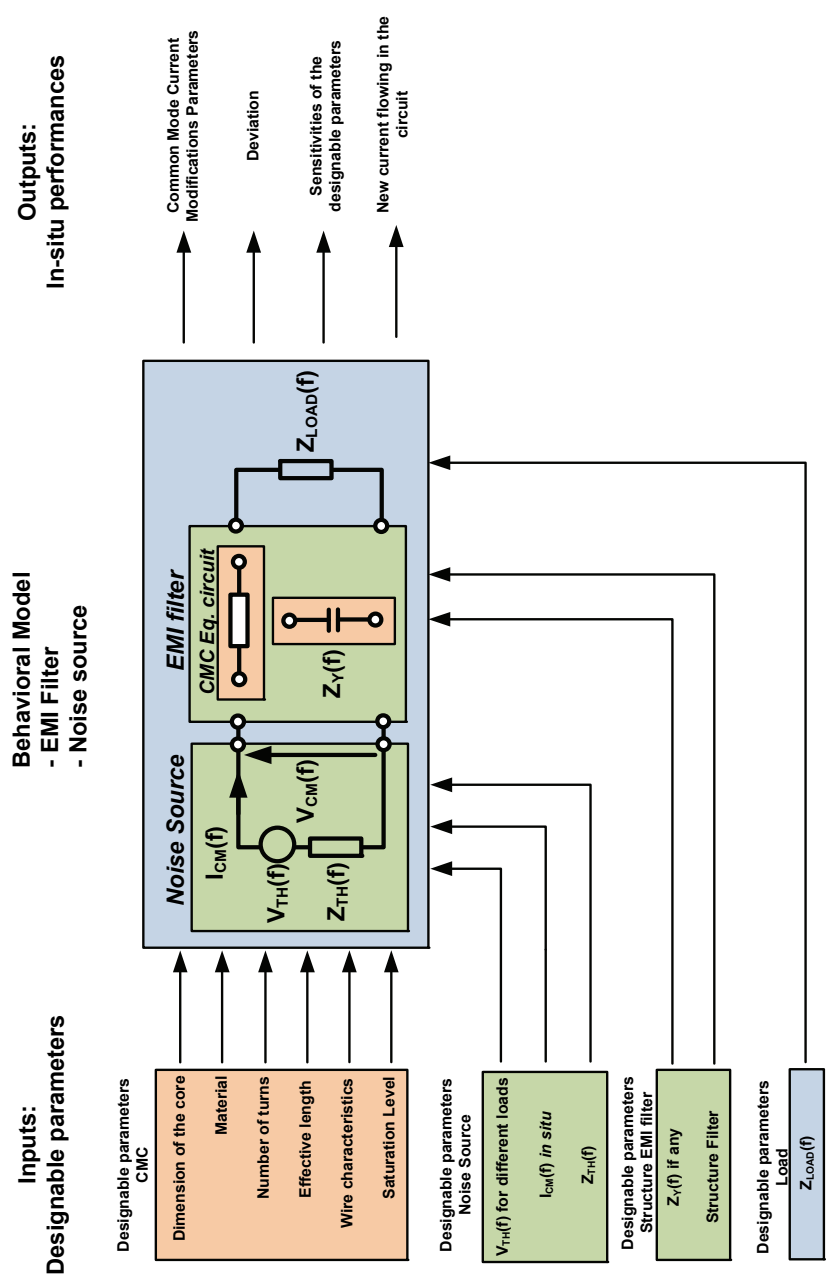

Figure 164: Overview of the black box model developed for the designer in Chapter 5 - Behavioural Model for the EMI filter .

In a motor drive kind of structure, this load would typically be composed of a cable and its motor and this is where most of the radiated interference can be expected. However, beforehand the designer has very little information on the level of electromagnetic field to be expected and the model for high frequencies of such a load is not widely addressed in the literature. 
In Chapter 6 the cable and its motor have been first approximated as a single copper wire. The distribution of the current along this copper wire placed above a ground plane has been investigated. Its input impedance has been modelled using the Method of Moment and two analytical methods. The input impedance of the wire with respect to the ground has also been measured for varying length and height. The measured impedances matched well with the modelled ones. The points of lower impedances, or points of anti-resonances, remain on a logarithmic line as a function of the frequency from around $50 \mathrm{Ohms}$ at $10 \mathrm{Mhz}$ to about $120 \mathrm{Ohms}$ at $1 \mathrm{GHz}$. At these points the input current in the wire can be expected to be maximum and so would be the level of electromagnetic field around it. The equation of the minima of input impedances is extracted. It is independent from any designable parameters besides the length of the cable and can be universally used for any motor drive by the designer for a fast evaluation of a worst case scenario in terms of EMI. The equivalence of the input impedance of a wire with the one of a cable and its motor has been demonstrated with the aid of measurements performed on a real motor drive. The link between input common mode current, input common mode impedance and level of electric field around the cable has been shown by measurements. An overview of the global model developed in this thesis is presented in Figure 165.

This thesis is providing a global behavioural model of the motor drive linking the designable parameters of the in-situ performances of the filter to be inserted in the system. As listed in the introduction all challenges are met:

- The characteristics of the noise source and the load as well as their interactions are included.

- The designer is guided in choosing the right structure for the EMI filter. All topologies of the common mode EMI filter are modelled.

- The designer is also supported in choosing an optimized common mode choke for its application.

Suggestions of further work related to the developed model presented in this thesis are made in the section 7.3. A proposal of design process for EMI filter is presented in Appendix 2. 


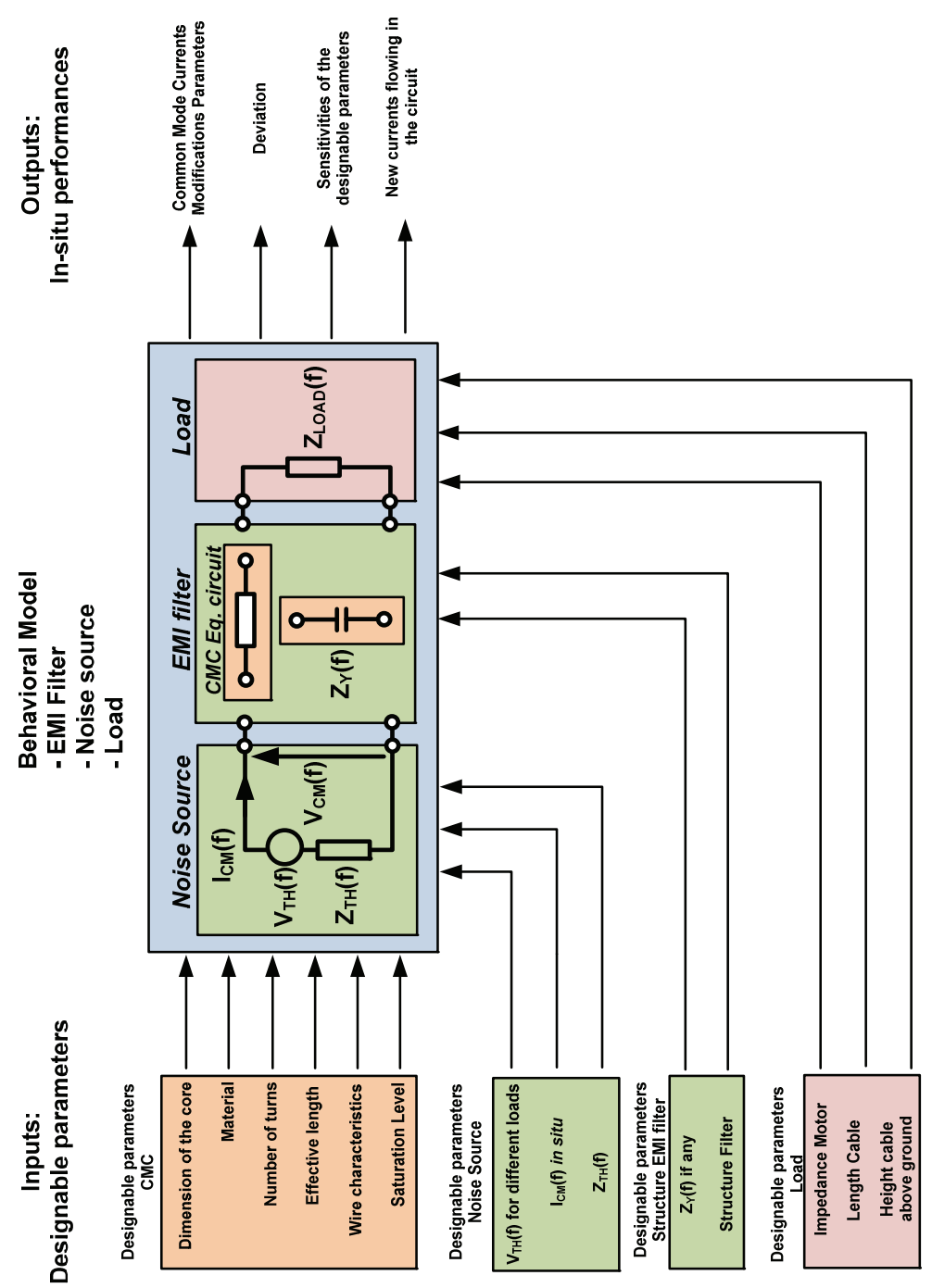

Figure 165: Overview of the black box model developed for the designer in Chapter 6 - Behavioural Model for the Cable and its Load. 


\subsection{Impact on society}

Constant technology milestones in the semiconductor and material industries have led to faster, more dense and more complex electronic devices and systems with increasing risk of Electromagnetic Interference (EMI). These devices present a reduced level of immunity and face an increasingly harsh electromagnetic environment: either in urban areas, with an increased Man-Made-Noise [67], or in complex industrial designs, with more integrated functions in the same location. Electromagnetic Compatibility (EMC) is more than ever a cornerstone in term of robustness and reliability of electronic designs. The philosophy of 'EMC-designedin' has shown to be the most effective way towards electromagnetic robustness and reliability with a reduced cost and time of (re-)design compared to a 'fire-fighting' approach [68], [69], [70], [71], [72] and [73]. This is especially the case for a complex system with many sub-systems. Less EMI solutions are available at later stages of designs and their implementation costs are significantly higher with a risk of serious and costly delays. There are no cook-book methods to implement EMC measures during the design stage [69]: it requires cultural changes and a full integration of the best practices during the development process.

The integration of these best practices is only possible if the relevant knowledge is made available to the electrical engineer in its design specialty. EMC is often only one of its constraints, answers need to come fast and choices in design need to be adequate. A solution is the development of an 'expert system' relating the relevant EMC knowledge to the right designer with the support of behavioural models for which, inputs are its designable parameters. This thesis provides models by relating designable parameters to the performances of the motor drive in term of EMI. It is one of the specific application of this global 'experts system'.

The objectives of behavioural models for the EMI filter are to avoid the construction of several prototypes, and the optimization of (re-)designs thanks to deviation and sensitivity studies. Optimizing an EMI filter is not only meant in terms of increased robustness or reliability but also in term of weight reduction. Selecting a bigger choke than needed, or to choose a more adapted and proportionally smaller material can represent a significant advantage, especially in the transportation industry. In a world where scale and sustainability matters more and more [74] one can imagine how an optimized EMI filter in a product sold in thousands worldwide preserves in some ways the depletion of our energy and raw material sources.

In [75] a wish list is presented in 10 points of urgently needed breakthroughs in technology which often relates to complex systems and design which frequently 
requires better components. For all these 10 points, EMC, and in more specific ways, behavioural models, play a role. There is for instance an increased need to combine large and small effects in computer simulation, given that small causes can have large effects, EMI could be one of them. New fault-tolerant designs are also created and controlled by learning software: behavioural models could teach them to optimise via simulation to counter or diminish the EMI at their sources. We also need faster machines able to measure on a much smaller time scale: more EMI issues can be expected there. All of these points require the need of more efficient techniques to convert energy into movement: with better controlled EMI levels, behavioural models can contribute in reducing energy waste.

These are a few of the examples where behavioural models can be used beneficially. The ones presented in this thesis are only a few contributing stones for building up the edifice.

\subsection{Recommendations for future work}

The behavioural models presented in this thesis could be further optimized. These models are at an early stage of development: the physical phenomena linking performances and parameters in the design is made. But they requires the experience of the engineer for the designable parameters used for the common mode chokes, or even the complete EMI filter. More advanced versions could switch the inputs and the outputs as desired, so that the designable parameters are for instance automatically optimized to fit the environment and its constraints entered as inputs. Full flexibility in the choices of inputs and outputs would be the most efficient structure. The models could be extended to common mode chokes and EMI filter with three or four phases. They could also be extended to higher frequencies in order to take into account the resonances occurring at higher frequencies in the common mode impedance and in the motor drive. EMI filters can be placed in other positions in the motor drive as for instance the DC bus or at the input side of the converter. Dedicated models for those would require further investigations of the modelling of the noise source in the motor drive. A complete statistical modelling of the electromagnetic environment of the motor drive would give more insight to the actual situation than just a worst case scenario which probabilities to occurs could be determined. It allows a better tuning of the design of the EMI filter.

There are no behavioural models linking the noise source characteristics to the designable parameters of the converter. In this thesis it was assumed known or to have been measured. 


\section{References}

[1] OECD report, 2011, "Energy-efficiency policy opportunities for electric motor-driven systems,"

http://www.iea.org/Textbase/npsum/ee_for_electricsystemssum.pdf

[2] Werachet Khan-Ngern, Mr. Vuttipon, Tarateeraseth, "User Manual for EMI toolkit," http://www.kmitl.ac.th/emc/emitoolkit/, 2007.

[3] www.senternovem.nl/iopemvt/algemeen/index/asp, 2012.

[4] Clayton R. Paul, 'Introduction to electromagnetic compatibility,' 1992, ISBN: 978-0471549277.

[5] Mohan, Undeland, Robbins, "Power Electronic: Converters, Applications and Design,” 1995, ISBN: 978-0471584087.

[6] TDK Epcos, "EMC filters guide," www.epcos.com.

[7] Erkuan Zhong; Lipo, "Improvements in EMC performance of inverter-fed motor drives," T.A Industry Applications, IEEE Transactions on, Volume 31, Issue 6, Nov.-Dec. 1995 Page(s):1247-1256.

[8] Chen, S.; Nehl, T.W.; Lai, J.-S.; Huang, X.; Pepa, E.; De Doncker, R.; Voss,I., "Towards EMI prediction of a PM motor drive for automotive applications," Applied Power Electronics Conference and Exposition, 
2003. APEC '03. Eighteenth Annual IEEE, Volume 1, 9-13 Feb. 2003 Page(s):14 - 22 vol.1.

[9] Gokani, S.; Clare, J.; Bradley, K.J.; Christopoulos, C., Ran, L., "Conducted electromagnetic emissions in induction motor drive systems. I. Time domain analysis and identification of dominant modes," Power Electronics, IEEE Transactions on Volume 13, Issue 4, July 1998 Page(s):757 - 767.

[10] Ran, L.; Gokani, S.; Clare, J.; Bradley, K.J.; Christopoulos, C., "Conducted electromagnetic emissions in induction motor drive systems. II Frequency domain models," Power Electronics, IEEE Transactions on Volume 13, Issue 4, July 1998 Page(s):768 - 776.

[11] Chen, S, "Generation and suppression of conducted EMI from inverter-fed motor drives," Industry Applications Conference, 1999. Thirty-Fourth IAS Annual Meeting. Conference Record of the 1999 IEEE Volume 3, 3-7 Oct. 1999 Page(s):1583 - 1589 vol.3.

[12] Skibinski, G.L.; Kerkman, R.J.; Schlegel, D., "EMI emissions of modern PWM AC drives," Industry Applications Magazine, IEEE Volume 5, Issue 6, Nov.-Dec. 1999 Page(s):47 - 80.

[13] Kudyan, H.M., "An empirical model for simulating the system-level radiated emissions behavior of interconnected units and modules Electromagnetic Compatibility," 2004, EMC 2004, 2004 International Symposium on Volume 1, 9-13 Aug. 2004 Page(s):330 - 335 vol.

[14] Moongilan, D., "Method of partial shielding for controlling cable radiated emissions," Electromagnetic Compatibility, 2002 IEEE International Symposium on Volume 1, 19-23 Aug. 2002 Page(s):227 - 232 vol.1.

[15] Eroglu, K., "A practical comparison of cabling effects on radiated emissions," Electromagnetic Compatibility, 1999 IEEE International Symposium on Volume 2, 2-6 Aug. 1999 Page(s):734 - 738 vol.2.

[16] Greenheck Fan Corporation, "Are bearing currents causing your motor failures?," application guide, www.greeenheck.com.

[17] ABB, "Bearing currents in modern AC Drive systems, technical guide number 5," ww.abb.com/automation.

[18] Erdman, J.M.; Kerkman, R.J.; Schlegel, D.W.; Skibinski, G.L., "Effect of $\mathrm{PWM}$ inverters on $\mathrm{AC}$ motor bearing currents and shaft voltages Industry 
Applications," IEEE Transactions on Volume 32, Issue 2, March-April 1996 Page(s):250 - 259.

[19] Don-Han Hwang; Yong-Joo Kim; Sung-Woo Bae; Dong-Hee Kim; Chae-Gyun Ro; In-Woo Lee, "Analysis of voltage stress in stator winding of IGBT PWM inverter-fed induction motor systems Electrical Machines and Systems," 2003. ICEMS 2003. Sixth International Conference on Volume 1, 9-11 Nov. 2003 Page(s):440 - 444 vol.1.

[20] Kempski, A., Smolenski, R.; Kot, E., Fedyczak, Z., "Active and passive series compensation of common mode voltage in adjustable speed drive system," Industry Applications Conference 2004. 39th IAS Annual Meeting. Conference Record of the 2004 IEEE, Volume 4, 3-7 Oct. 2004 pp. $2665-2671$.

[21] A. Roc'h, H. Bergsma, F.B.J. Leferink, D. Zhao, H. Polinder, and J. A. Ferreira, "Design of an EMI Output Filter For Frequency Converters," in Proc. EMC Europe International Symposium on EMC, Barcelona, Spain, 2006.

[22] Frank Leferink, Hans Bergsma, Braham Ferreira, Wim van Etten, "High Performance EMI Filter for Frequency Converters," EMC Europe 2004, Eindhoven.

[23] Clayton R. Paul, 'Introduction to electromagnetic compatibility,' 1992, ISBN: 978-0471549277.

[24] AUNP program, "EMI Self-Learning Toolkit for Switched-Mode Power Supply," 2008, http://www.kmitl.ac.th/emc/emitoolkit.htm.

[25] TDK Epcos, "Film capacitors: EMI suppression capacitors," 2009, www.epcos.com.

[26] Margarita D. Takach, Peter O. Lauritzen: "Survey of Magnetic Core Models," IEEE APEC Record, pp560-566, 1995.

[27] D.C. Jiles, D.L. Atherton, "Theory of ferromagnetic hysteresys, Journal of Magnetism and Magnetic Materials," No 61, pp48-56, 1986.

[28] J. Izydorczyk, "Magnetics," IEEE Transactions on Volume 42, Issue 10, Oct. 2006 Page(s):3132 - 3134.

[29] N.L. Mi, R. Oruganti; S.X. Chen, "Modelling of hysteresys loops of ferrite cores excited by a transient magnetic field," Magnetics, IEEE Transactions on Volume 34, Issue 4, Part 1, July 1998 Page(s):1294 - 1296. 
[30] Jiles, D.C. "Frequency dependence of hysteresis curves in 'non-conducting' magnetic materials," Magnetics, IEEE Transactions on, Volume: 29, Issue: 6, Part 2, On page(s): 3490-3492.

[31] J. Izydorczyk, "Magnetics," IEEE Transactions on Volume 42, Issue 10, Oct. 2006 Page(s):3132 - 3134.

[32] Henglin Chen, Zhaoming Qian, Shaodong Yang;Wolf,C, "Finite-Element Modeling of Saturation Effect Excited by Differential-Mode Current in a Common-Mode Choke," Power Electronics, IEEE Transactions on Volume:24, Issue: 3.

[33] Vacuumschmelze Gmbh\&Co, Technical Information, "Nanocrystalline material in common mode chokes," www.vacuumschmelze.com.

[34] Magnetics, Technical Information, "A Critical Comparison of Ferrites with Other Magnetic Materials," www.mag-inc.com.

[35] K.H.J. Buschow, "Handbook of Magnetic Material," ISBN: 0-444-514597, 2006.

[36] Alex Goldman. "Handbook of modern ferromagnetic material," ISBN: 0412-14661-4, 1999.

[37] Kiyonori Suzuki, "Properties and application of Nanocrystalline alloys form amorphous precursors," ISBN: 978-1402029646, 2005.

[38] Yoshizawa, Y.,Kataoka, S. and Yamauchi, K., New Fe-based soft magnetic alloys composed of ultrafine grain structure, J. Appl. Phys. 64, 6044-6046, 1988

[39] Vacuumschmelze Gmbh\&Co KG, Technical Information, "Making the most of Iron," www.vacuumschmelze.com, 2012.

[40] Wanior, J., "Inductive components and appropriate magnetic materials for filters in SMPS-designs," Industrial Technology, 2003 IEEE International Conference on Volume 2, 10-12 Dec. 2003 Page(s):1178 - 1183 Vol.2.

[41] Fairites, "Technical Information, How to choose Ferrite Components for EMI suppression," www.fair-rite.com, 2008.

[42] Coilcraft Inc., Technical Information, "Common mode filter design," 1997, http://www.coilcraft.com, 2008. 
[43] Weber, M.Schinkel, S.Guttowski, W.John, H.Reichl "Calculating Parasitic Capacitance of Three-Phase Common-Mode Chokes, "PCIM Conference, Nürnberg, 2005.

[44] Stevanovic I., Skibin S., Masti, M., Laitinen, M., "Behavioral Modeling of Chokes for EMI Simulations in Power Electronics,” Power Electronics, IEEE Transactions on Volume :PP, Issue:99, 2012 , Page(s): 1.

[45] S.Weber, M.Schinkel, E.Hoene, S.Guttowski, W.John, H.Reichl, "RadioFrequency Characteristics of High-Power Common-Mode Chokes," EMC Zürich, 2005.

[46] Takanori Tsutaoka, "Frequency dispersion of complex permeability in Mn$\mathrm{Zn}$ and $\mathrm{Ni}-\mathrm{Zn}$ spinel ferrites and their composite materials," Journal of Applied Physics, March, 2003, Volume 93, Issue 5, pp. 2789-2796.

[47] M.J.Nave, Technol Sverdrup, AL Huntsville, "On modelling the common mode inductor Electromagnetic Compatibility," 1991. Symposium Record. IEEE 1991 International Symposium on, 12-16 Aug 1991 on page(s): 452-457.

[48] A.Massarini, M.K.Kazimierczuk, "Self-capacitance of inductors," IEEE Transactions on Power Electronics, Volume 12, Issue 4, July 1997 pp 671 to 676 .

[49] G. Grandii, Kazimiercmk and A. Massarini, "Lumped. Parameter for models for single- and Multiple-layer Inductor," IEEE PESC '96.

[50] Agilent technologies, "Impedance measurement handbook," July 2006, www.agilent.com.

[51] Werachet Khan-ngern, Vuttipon Tarateeraseth, "Self-learning EMC Toolkit for Electronic and Electrical Engineers," The 2nd International Conference on Electromagnetic Compatibility, ICEMC 2005, 27-29 July 2005.

[52] Billings, Keith, H., "Switched mode power supply handbook," ISBN 0-07005330-8, 1999.

[53] Austin Hughes, “Electric Motors and Drives,” ISBN: 978-0-7506-4718-2, 1993. 
[54] Saltelli, Tarantola, Campolongo, Ratto, "Sensitivity Analysis in Practice_A Guide to Assessing Scientific Models,” ISBN-13: 978-0470870938, 2004.

[55] Vlach, Singhal, "Computer methods for circuit analysis and design", ISBN13: 978-0442011949, 1993.

[56] Richard Lee Ozenbaugh, "EMI filter design," ISBN 0-2847-8924-5, 2000.

[57] Dorin O.Neacsu, "Power Switching Converters, Medium and High Power," ISBN 0-8247-2625-1, 2006.

[58] S.J. Orfanidis, "Electromagnetic Waves and Antennas," www.ece.rutgers.edu/ orfanidi/ewa, Chapter 21, 2012.

[59] R.F. Harrigton, "Filed Computation by Moment Methods," The MacMillan Company, 1968.

[60] Burke G.J., Miller E.K., Poggio, A.J., "The Numerical Electromagnetics Code (NEC) - a brief history," Antennas and Propagation Society International Symposium 2004, IEEEVolume:3, Year: 2004, Page(s): 2871 - 2874 Vol.3.

[61] King and Harrison, “Antenna and waves,” 1969, SBN 26211033.

[62] Melvin M. Weiner, "Monopole Antenna," 2003, ISBN 0-8247-0496-7.

[63] King, "Theory of linear antenna," 1956, Harvard University Press.

[64] Frank Leferink, "Reduction of Radiated Electromagnetic Fields by Creation of Geometrical Asymmetry," PhD Dissertation, 2001, ISBN 90365-1689-7.

[65] Elliot, “Antenna Theory and Design,” 1981, ISBN: 0130383562.

[66] Constantine A. Balanis, "Antenna: Analysis and Design," 1982, ISBN: 978-0471667827.

[67] Leferink, F. and Silva, F. and Catrysse, J. and Batterman, S. and Beauvois, V. and Roc'h, A., "Man-made noise in our living environments," Radio Science Bulletin (334). pp. 49-57. ISSN 1024-4530, 2010. 
[68] M.W.C. Chu, R.H.W. Ho, "EMC management methodology and lifecycle adopted by the West Rail project in Hong Kong," IEEE Int. Symposium on EMC, 2002, pp. $791-794$.

[69] G.K Deb, "EMC management for an electronic system design," Proceedings of the International Conference on Electromagnetic Interference and Compatibility, 1999, pp. $17-20$.

[70] R. Sin, D.J. Majewski, "EMC management: an integral part of a company's quality program,” IEEE Int. Symposium on EMC, 2000, pp. 285 - 288.

[71] K. Armstrong, "Opportunities in the Risk Management of EMC," IEEE Int. Symposium on EMC, 2011, pp. 988 - 993.

[72] G. Moore, "Development, implementation and management of a system level EMC design mitigation plan," IEEE Int. Symposium on EMC, 2003, pp. $173-176$.

[73] Frank Leferink, Saverio Lerose, Michel Sauvageot, W.C. van Etten, "The four key elements of EMC implementation in large organizations," Euro EMC 2002, Int. Symposium on EMC, Sorrento, 2002, pp. 619-624.

[74] TEDx Brainport 2012, Arne Hendriks, "The Incredible Shrinking Man," http://www.youtube.com/watch?v=KSNx1Ly0Jok.

[75] Rutger van Santen, Djan Khoe and Bram Vermeer; "The Thinking Pill, and other technology that will change our lives," 2010, ISBN 978-90-4680358-5. 


\section{Appendix 1: EMI toolkit overview - Short description of the $\mathrm{AC} / \mathrm{DC}$ converter used in this thesis}

The aim of electromagnetic interference toolkit is to study electromagnetic interference (EMI) on power electronics. This EMI Toolkit is suitable for learning basic operation mode of power electronic circuit, the conducted EMI generated and their filtering. The details of the design of this toolkit are available in [51]. (The author warmly thanks the designers of this toolkit).

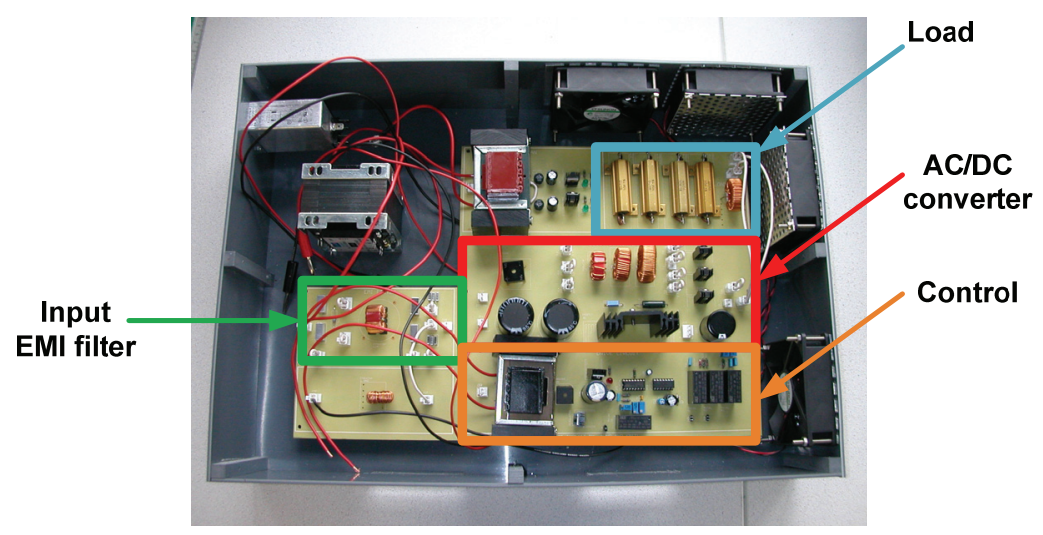

Figure 166: Photo of the EMI toolkit used for measurements in this thesis. 
The block diagram of EMI Toolkit is shown in Figure 167. The details of each block are as follows:

- EMI Filter is fully configurable to observe the effect of each component on the level of conducted EMI. It is optional. In the test set-up used in this thesis it is only placed at the output of the boost converter.

- A low frequency transformer is used to reduce the input voltage from $220 \mathrm{~V}_{\text {rms }}$ to $21 \mathrm{~V}_{\text {rms. }}$

- Bridge rectifier with bulk capacitor is an AC/DC converter, used to convert alternating current to direct current.

- Boost converter is a DC/DC converter with gate drive circuit.

- Load can be selected as a resistive load or resistive-inductive load.

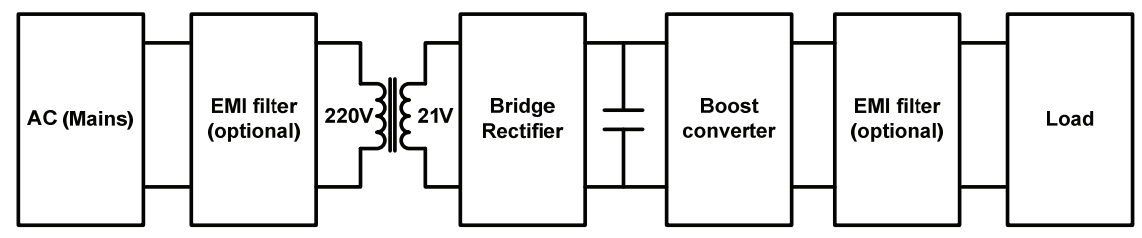

Figure 167: The block diagram of EMI Toolkit. 


\section{Appendix 2: Proposal of design process for an optimized EMI filter}

Figure 168 describes a proposal of a design process for an optimized EMI filter. This design process is organised in four steps. In step 1, the design engineer provides the characteristics of the environment of the motor drive. These parameters can be either modelled or measured. In step 2, the design engineer provides the limits of common mode currents allowed as well as the limits of radiated emission level. The filtering performances are evaluated based on these inputs. In step 3, several topologies of EMI filter are tested using the behavioural models described in this thesis. The results of steps 1 and 2 are linked with several sets of designable parameters describing the $\mathrm{CMC}$ and the $\mathrm{Y}$-capacitor(s). Each set is tested using the simplified modification factors defined in Chapter 5. The modelled in-situ performances are finally compared and the one matching with the filtering objectives are kept for the following step. In step 4 the performances of the pre-selected EMI filter structure from step 3 are re-evaluated using advanced modification factors. An optimization is performed with sensitivities and deviation studies. The final results allow the design engineer to make the choice of the most optimized filter for his/her application. 


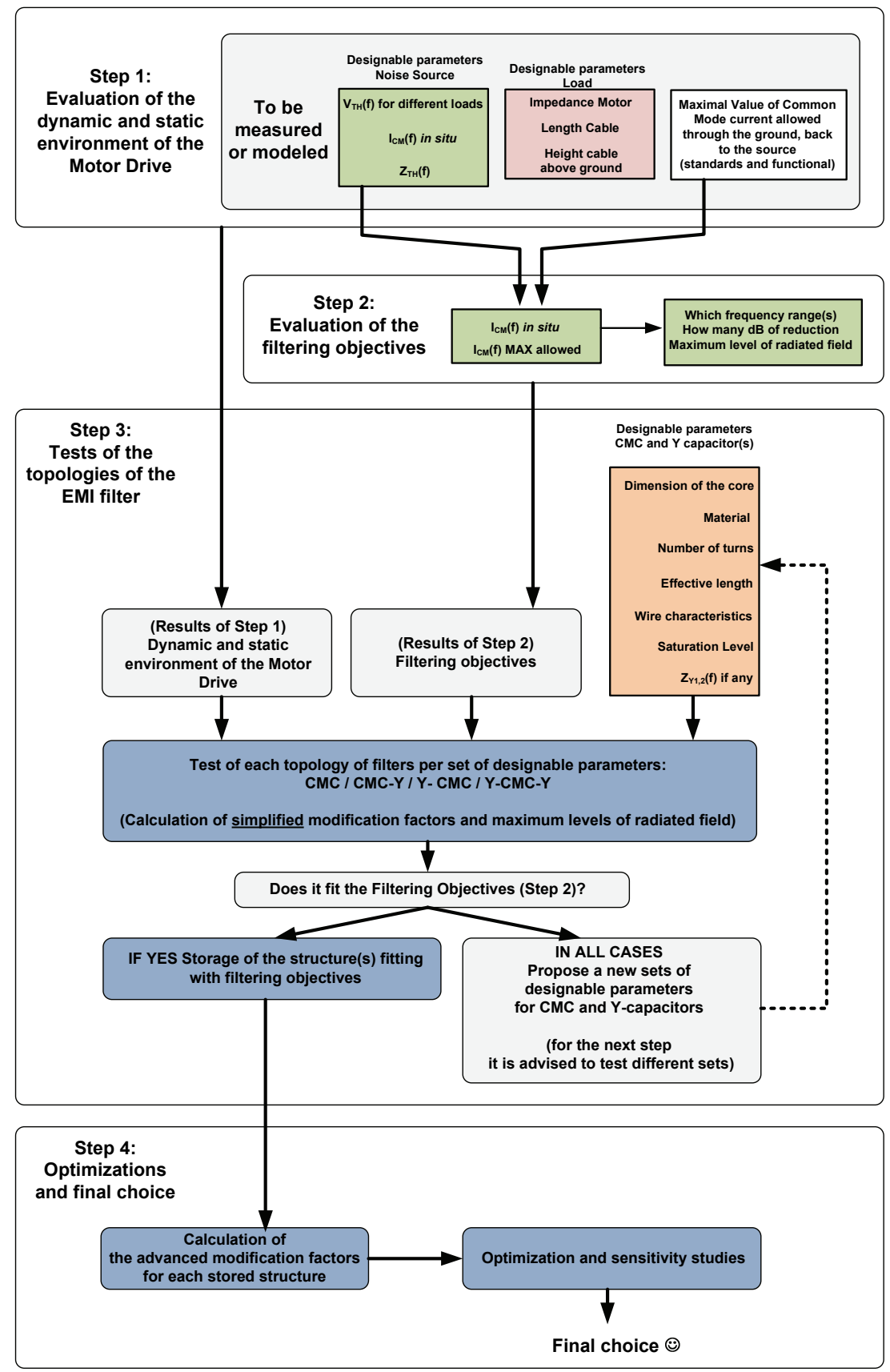

Figure 168: Proposal of a design process for an optimized EMI filter. 


\section{Publications}

\section{Book chapter}

- $\quad$ Roc'h, Anne and Leferink, Frank (2011) Analysis of common mode inductors and optimization aspects. In: Power Electronics and Power Systems. Electromagnetic Interference Issues . Bentham Science Publishers, Australia, pp. 3-37. ISBN 9781608052400

This book is co-authored by Vuttipon Tarateeraseth, Kye Yak See, Flavio G. Canavero, Gordana Klaric Felic, Jaroslaw Luszcz, R. B. Rodrigues, V. M.F. Mendes, and J. P.S. Catalao. The editor is Firuz Zare.

\section{Articles}

- Roc'h, Anne and Leferink, Frank (2012) Nanocrystalline core material for bigh-performance common mode inductors. IEEE Transactions on Electromagnetic Compatibility, PP (99). pp. 1-7. ISSN 0018-9375

- Leferink, F. and Silva, F. and Catrysse, J. and Batterman, S. and Beauvois, V. and Roc'h, A. (2010) Man-made noise in our living environments. Radio Science Bulletin (334). pp. 49-57. ISSN 1024-4530

This paper resulted from Joint Technical Action 3, within COST 286, which is supported by the European Science Foundation - European Union. I was a guest at KHBO in Oostende in June 2006 for a Short Term Scientific Mission dedicated to the "EM ambient site survey of industrial environment". 
- Zhao, D. and Ferreira, J.A. and Roc'h, A. and Leferink, F.B.J. (2009) Common mode dc bus filter design for variable speed drive system via transfer ratio measurements. IEEE on Transactions on Power Electronics, 24 (2). pp. 518-524. ISSN 0885-8993

\section{Conference proceedings as main author}

2012

- Roc'h, Anne and Leferink, Frank (2012) An audit tool for the EMC implementation in large companies. In: EMC Europe 2012, 17-21 September 2012, Rome, Italy.

This paper is related to my work in the company ASML, in the Netherlands.

2011

- Roc'h, Anne and Leferink, Frank (2011) Towards a first time right design of the common mode choke. In: XXXth URSI General Assembly and Scientific Symposium, 2011, 13-20 Aug 2011, Istanbul, Turkey.

- Roc'h, Anne and Leferink, Frank (2011) In situ performances of common mode chokes. In: 10th International Symposium on Electromagnetic Compatibility, EMC Europe 2011, September 26-30, 2011, York, UK.

2009

- Roc'h, A. and Iannarelli, R. and Leferink, F.B.J. (2009) New materials for Inductors. In: EMC Europe 2009, 11-12 June 2009, Athens, Greece.

- Roc'h, A. and Zhao, D. and Ferreira, B. and Leferink, F.B.J. (2009) Scale and weight consideration of EMI filters. In: ESA Workshop on Aerospace EMC, 30 Mar - 01 Apr 2009, Florence, Italy.

2008

- Roc'h, A. and Bergsma, H. and Zhao, D. and Ferreira, B. and Leferink, F.B.J. (2008) Comparison of evaluated and measured performances of common mode chokes. In: EMC Europe 2008, 8-12 Sept 2008, Hamburg, Germany.

- Roc'h, A. and Bergsma, H. and Leferink, F.B.J. (2008) Behavioural model for common mode filter and performance optimization aspects. In: URSI General Assembly, 7-16 Aug 2008, Chicago, U.S.A.

A Young Scientist Award has been received by the author to join this General Assembly of URSI. 
- Roc'h, A. and Bergsma, H. and Zhao, D. and Ferreira, B. and Leferink, F.B.J. (2008) Performance optimization aspects of common mode chokes. In: Proceedings of 2008 Asia-Pacific Symposium on Electromagnetic Compatibility \& 19th International Zurich Symposium on Electromagnetic Compatibility, 19-22 May 2008, Singapore.

This paper received the Best Student Paper Award.

2007

- Roc'h, A. and Bergsma, H. and Zhao, D. and Ferreira, B. and Leferink, F.B.J. (2007) A new behavioural model for performance evaluation of common mode chokes. In: 18th International Zurich Symposium on Electromagnetic Compatibility, 2007. EMC Zurich 2007, 24-28 Sep 2007, Zurich, Swiss.

This paper received the third Best Student Paper Award.

- Roc'h, Anne and Zhao, Dongsheng and Leferink, Frank and Polinder, Henk and Ferreira, Braham (2007) Investigation of the Coupling Paths of a Galvanically Isolated AC/AC Converter. In: IEEE International Symposium on Electromagnetic Compatibility, EMC 2007, 9-13 July 2007, Honolulu, HI, USA.

This work has been performed in collaboration with the company Exendis B.V. and the Technical University of Delft, both in the Netherlands. Dongsheng and myself were guests in the company from September to November 2006.

2006

- Roc'h, A. and Bergsma, H. and Leferink, F.B.J. and Zhao, D. and Polinder, H. and Ferreira, B. (2006) Design of an emi output filter for frequency converters. In: Proceedings of EMC Europe 2006, 04 - 08 sept 2006, Barcelona, Spain.

This work has been performed in collaboration with the company Thales Nederland and the Technical University of Delft, both in the Netherlands.

- Roc'h, A. and Leferink, F.B.J. (2006) EMI concerns in power electronic. In: Proceedings of the URSI Benelux Meeting 2006, 12 May 2006, Eindhoven, Netherlands. 


\section{Conference proceedings as co-author}

2010

- Zhao, D and Roc'h, Anne and Ferreira, Braham and Leferink, Frank (2010) Hierarchical approach used to analyze the EMC performance of a ZVS converter. In: 9th International Symposium on EMC and 20th International Wroclaw Symposium on Electromagnetic Compatibility, 1317 Sept 2010, Wroclaw, Poland.

2008

- Leferink, F.B.J. and Knijff, I. and Roc'h, A. (2008) Experiments for educating electromagnetic effects. In: International Symposium on EMC, 812 Sept 2008, Hamburg, Germany.

This paper is related to my contribution to the educational activities of the University of Twente, in the Netherlands.

- Zhao, D. and Ferreira, B. and Roc'h, A. and Leferink, F.B.J. (2008) New common mode EMI filter for motor drive using a fourth leg in the inverter. In: International Symposium on EMC, 8-12 Sept 2008, Hamburg, Germany.

- Zhao, D. and Ferreira, B. and Roc'h, A. and Leferink, F.B.J. (2008) Hierarchical EMC analysis approach for power electronics applications. In: 39th IEEE Power Electronics Specialist Conference, 15-19 Jun 2008, Rhodos, Greece.

2007

- Zhao, D. and Ferreira, J.A. and Polinder, H. and Roc'h, A. and Leferink, F.B.J. (2007) Noise propagation path identification of variable speed drive in time domain via common mode test mode. In: European Conference on Power Electronics and Applications, 2-5 Sept. 2007, Aalborg, Denmark.

2006

- Zhao, D. and Ferreira, B. and Polinder, H. and Roc'h, A. and Leferink, F.B.J. (2006) Using transfer ratio to evaluate EMC design of adjustable speed drive systems. In: International Symposium on Electromagnetic Compatibility, EMC Europe 2006, 4-8 September 2006, Barcelona, Spain.

- Zhao, D. and Ferreira, J.A. and Polinder, H. and Roc'h, A. and Leferink, F.B.J. (2006) Investigation of EMI noise transfer characteristic of variable speed drive system. In: Proceedings of International Symposium on Power 
Electronics, Electrical Drives, Automation and Motion (SPEEDAM) 2006, 23-26 Mat 2006, Taormina (Sicily), Italy. 


\section{Acknowledgements}

First of all I am indebted to my promoter Frank Leferink, who gave me the opportunity to perform this $\mathrm{PhD}$ research. Frank, thank you for offering me this position. It was a life changing decision for me and one which I cherish. Thanks for your kind and constant support, your very valuable guidance during my $\mathrm{PhD}$ work and also in my professional life. Thanks to have given me an opportunity to travel the world $(\dot{)}$.

I am grateful to Bram Ferreira, my co-promoter. Your support and reviews out of the "EMC box" have been very constructive.

I would like to thank the other members of my graduation committee, Prof. Mouthaan, Prof. Canavero, Prof. Tijhuis, Prof. Antal, Prof. Slump, Dr. Marliani and Dr. Bentum for agreeing to be in the committee and for reading the final draft of my thesis.

This work was carried out within the framework of IOP, EMVT. I would like to acknowledge the funding from the Dutch Ministry of Economic Affair and I thank the project partners for their useful discussions during the IOP project meetings.

Dongsheng Zhao, we have been on the same boat for a while, cooperating in the same $\mathrm{PhD}$ project. I enjoyed working with you. Thanks! I wish you all the best.

I would like to thank my former colleagues as well as my students from the TE group of the University of Twente. To the 'AIOs' : you really did make my PhD days memorable (:). To Lilian, Annemiek and Eduard: thanks for your kindness, your help (even for personal matters) and thanks to have taken away the 
administrative burden out of my hands. I am grateful to Frits Buesink to have coached me during my final assignment in Thales Nederland and to have written the Samenvatting of this present thesis. (You have closed the loop ()). I am also grateful to the members of the ECC group in Thales for their kindness and to have supported me during measurements.

I would like to take this occasion to also thank all the people who have supported me after I left the University of Twente. Especially Prof. Anton Tijhuis, Prof. Wim Coene and Dr. Martijn van Beurden for offering me a Kenniswerkersregeling (KWR) within ASML. Martijn, thanks to have guided me and shared your experience on EM modelling, it has been a pleasure working with you.

I am also grateful to Frank van den Nouweland and Theo Bergman who have offered me my current position in ASML, supported my research ideas and my cooperation with the university. Anton, many thanks (again (-)) to have welcomed me as a guest researcher in the EM group of the Technical University of Eindhoven.

I thank all the members of the EM group to make the place a cheerful one. I also have sweet memories from my times in the Research Group of ASML in 'Building 21'. My new location in ASML is also a warm place to be in. I would like to thank my present colleagues from the SEL group, as well as my 'EMC team' for that. We have exciting times in front of us!

My friends have always been there for me. I have had great times with them and they have supported for me during the rough patches. I would like to thank each one of them personally. Merci à tous.

Carine, Audrey, you both are coming from far away to be my 'paranymfen'. It means a lot to me. Merci!

Merci à toutes ma famille, merci pour votre soutien, vos sacrifices et vos encouragements durant toutes mes longues années d'études. Je ne serais pas là sans vous. Merci. I would also like to thank my family all over the world - India, Dubai and Germany, for their support and their kindness through the years.

Rajeev, thanks for everything $\odot$. Without you, I would not be where I am today. I hope life will give us many more years together. 


\section{About the Author}

Anne Roc'h was born on January $5^{\text {th }} 1981$ in Strasbourg, France. She completed her secondary school in 1999 and her Classes Préparatoires aux Grandes Ecoles in the specialties of Physics and Chemistry in 2002, in Strasbourg. She graduated with an Ingénieur diploma in 2005 from the school ENSIL (Ecole National Supérieure d'Ingénieurs de Limoges) in Electronics, Telecommunication and Instrumentation As a part of her study, from May to September 2004, she performed an internship in the research institute XLIM in Brive-La-Gaillarde on the characterization of an Ultra Wide Band antenna network for radar applications. Her final international assignment was performed in Thales Nederland, Hengelo, the Netherlands from April to September 2005 on aperture effects modelling for Electromagnetic Compatibility.

She joined the University of Twente in Enschede, the Netherlands in November 2005 to start her PhD work in the Telecommunication Engineering (TE) group. The topic of her $\mathrm{PhD}$ project was Multi-domain Optimization of Power Electronics. For the experimental part, she cooperated with the Environment Competence Centre (ECC) of Thales Nederland in Hengelo, the Netherlands. The main results of her $\mathrm{PhD}$ research are presented in this thesis. Her papers have been awarded the Third Best Student Paper Award and the Best Student Paper Award, in the EMC Zurich conference in 2007 and the EMC Asia-Pacific conference in 2008 respectively. She received a personal Young Scientist Award to join the General Assembly of URSI in 2008. 
In June 2010 she joined the Electromagnetics group (EM) in the Technical University of Eindhoven, in the Netherlands, for a research project in collaboration with ASML, Veldhoven, the Netherlands. Her research was focused on Maxwell solvers for computational lithography.

In March 2011 she joined ASML, Veldhoven, the Netherlands as an EMC Engineer in the System Electrical Layout (SEL) group. Her work focuses on design supports and R\&D activities for ASML, in collaboration with the Electromagnetics group in the University of Eindhoven where she is a guest researcher. Her research activities have been so far focused on the development of dedicated test tools and EMC management to organise the implementation of EMC in the early stage of the design process of products. 
C'est juste une flamme, qui brûle sur la montagne, J'espère que tu la vois, j'espère que tu l'aimeras, Juste un signal.

(It is just a flame, burning on top of the mountain, I hope you can see it, I hope you will like it, Just a signal.)

(Atomic Shy, album Nuit Intimes, Indochine, 1999) 

